\title{
Fire Resistance Quantification of Non-Loadbearing Masonry Walls - Numerical Study
}

\author{
by
}

Hannah Keelson

A thesis submitted to the Faculty of Graduate and Postdoctoral Affairs in partial fulfillment of the requirements for the degree of

\author{
Master of Applied Science \\ in \\ Civil Engineering \\ Department of Civil and Environmental Engineering \\ Carleton University \\ Ottawa, Ontario \\ (C) 2018 \\ Hannah Keelson
}




\begin{abstract}
The fire behaviour of masonry elements has promoted a great deal of interest in building construction. Non-loadbearing masonry walls for instance, have a considerable capacity, from the fire perspective, to isolate part of the building's interior from flames, heat and the effect of smoke.

This research focuses on quantifying the fire resistance of non-loadbearing masonry walls subjected to elevated temperatures. Masonry walls constructed with different joint profiles, material properties as well as geometries have been considered. The fire resistance of the walls under each category has been analyzed using a finite element model and compared with full-scale experimental fire resistance tests, which has been conducted in an earlier project by another author.

The numerical model for validation of the results correlates with the tests results from the experimental work. Under the joint profiles, raked and concave joints had similar fire resistance behaviour. In terms of concrete masonry material properties, novel lightweight concrete masonry made of $45 \%$ recycled glass and $10 \%$ metakaolin produced the highest fire resistance of 172 minutes, which was approximately 27 and 50 minutes greater than conventional lightweight and normal weight concrete masonry respectively. Rock wool, an insulating material used as an insert in conventional normal weight concrete masonry walls produced the highest fire resistance of 185 minutes.
\end{abstract}




\section{Acknowledgements}

I am grateful to God for the grace, courage and wisdom in seeing me through this Master's program. I thank my family back home in Ghana, without whom this thesis would not have been started or completed! Your encouragement and support has never faltered; thank you. I am indebted to my supervisor Prof. Ehab Zalok whose guidance, advice and patience has been immeasurable. Thank you for your support throughout my program.

My profound gratitude goes to the Canadian Masonry Design Centre (CMDC) and Canadian Concrete Masonry Producers Association (CCMPA) for their financial and inkind support. I would specially extend my gratitude to David Stubbs and Bennett Banting (CMDC) for their personal involvement in various ways during the entire research. Also, grateful to the National Science and Engineering Research of Canada (NSERC) for the funding support.

I would like to also thank Prof. Heng-Aik Khoo for his guidance with the finite element modelling and analysis software.

Special thanks to Aaron Akotuah and Josh Woods for their assistance with ABAQUS.

Many thanks to the members of my research group in Carleton University, especially Hamish Pope for his guidance in all the experimental work he performed, and all friends for their support, encouragement. Without their participation, this research would not have been possible. 


\section{Table of Contents}

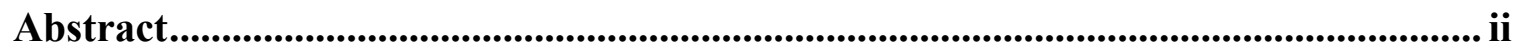

Acknowledgements ............................................................................................................................. iii

Table of Contents ........................................................................................................ iv

List of Tables ............................................................................................................................... ix

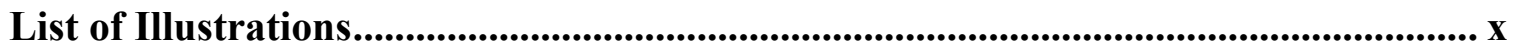

List of Abbreviations ............................................................................................................ Xv

1 Chapter: Introduction ........................................................................................................... 1

$1.1 \quad$ Background ................................................................................................

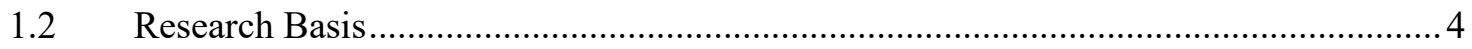

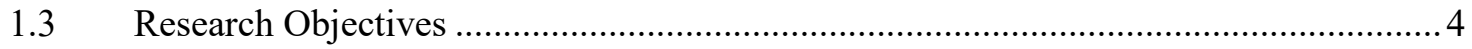

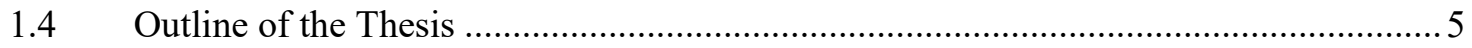

2 Chapter: Literature Review..................................................................................... 8

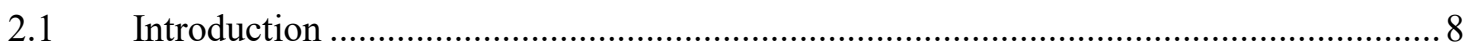

2.2 Fire Resistance - Definition and Goals ................................................................. 8

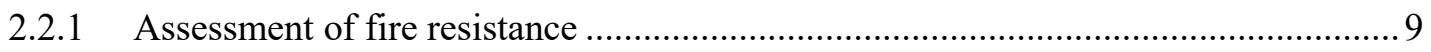

2.3 Masonry Walls.......................................................................................... 12

2.3.1 Unreinforced masonry wall construction .............................................................. 15

2.4 Types of Concrete Masonry used for Masonry Wall Construction ................................ 15

2.5 Mechanical Properties of Concrete Masonry at Elevated Temperatures....................... 16

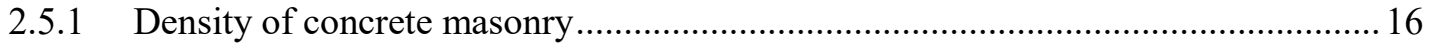

2.5.2 Strength of concrete masonry.............................................................................. 17

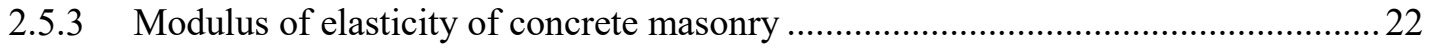

2.6 Thermal Properties of Concrete Masonry at Elevated Temperatures............................23 


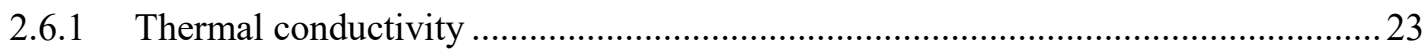

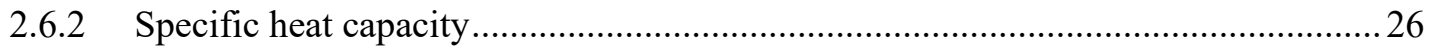

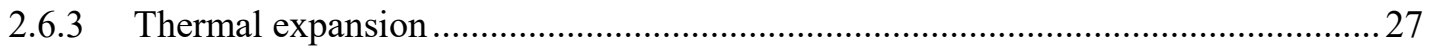

2.7 Types of Mortar used in Masonry Wall Construction .............................................29

2.7.1 Types of mortar joints and joint profiles used for masonry wall construction..........31

2.8 Thermal Properties of Mortar at Elevated Temperatures …..................................... 34

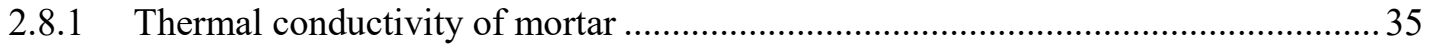

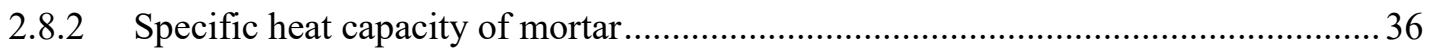

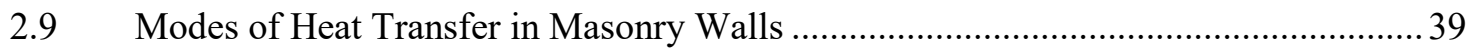

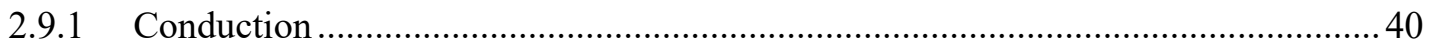

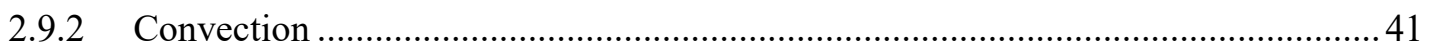

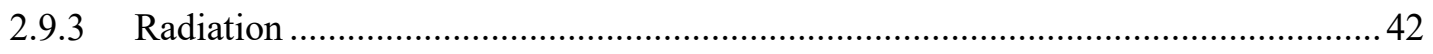

2.9.4 Methods of improving heat flow in masonry walls............................................ 43

2.10 Mechanical Behaviour of Masonry Walls at Ambient Temperatures ......................... 44

2.11 Thermal Behaviour of Masonry Walls at Elevated Temperatures .............................. 45

2.12 Problems Associated with Masonry Walls exposed to Elevated Temperatures ........... 46

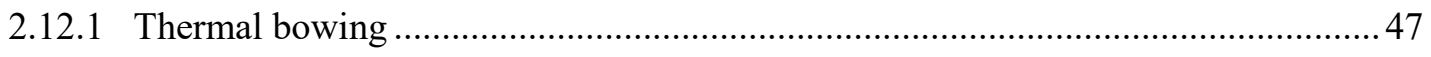

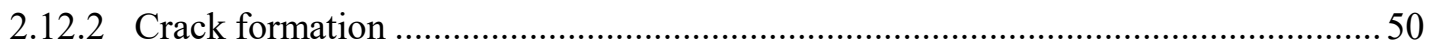

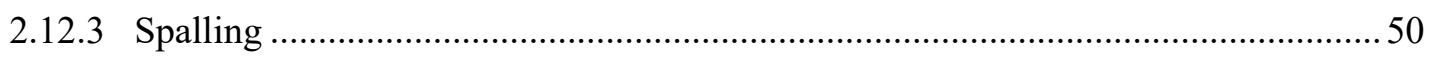

2.13 Methods of improving the fire resistance of concrete masonry - Mix Designs............53

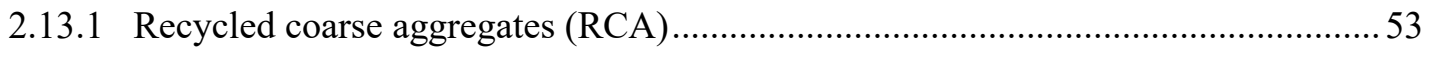

2.13.2 Modified lightweight aggregate concrete (LWAC) …..........................................58

2.13.2.1 LWC made from sintered lightweight aggregates .........................................58

2.13.2.2 LWC made from expanded lightweight aggregate and mineral admixtures ...59

2.13.2.3 LWC made from metakaolin and recycled glass ..........................................62 62

2.13.2.4 LWC made from foamed concrete .............................................................6 69 
2.14 Methods of Improving the Fire Resistance of Concrete Masonry - Insulating Materials 74

2.14.1 Categorization of insulating materials based on their chemical composition .......... 75

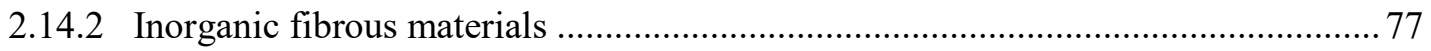

2.14.3 Physical and thermal properties of mineral wool products .................................... 77

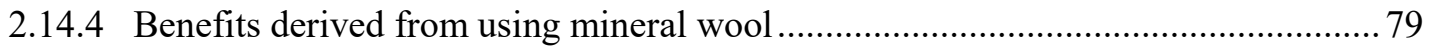

2.15 Numerical Modelling of Non-Loadbearing Masonry Walls ..................................... 80

2.15.1 Analytical approach for simple hand calculated design methods .......................... 80

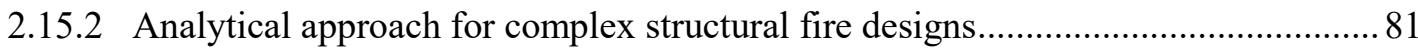

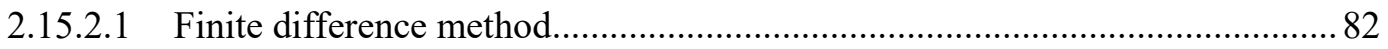

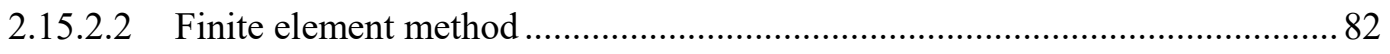

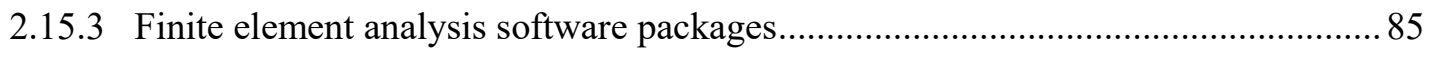

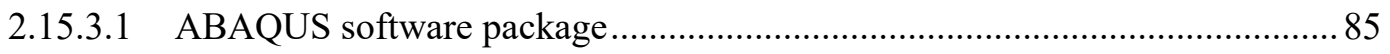

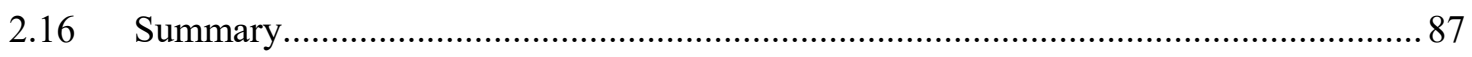

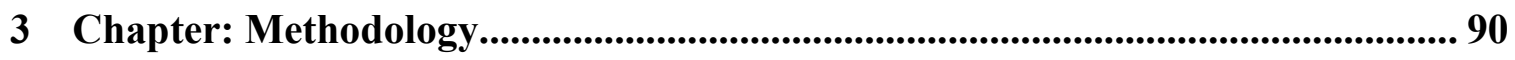

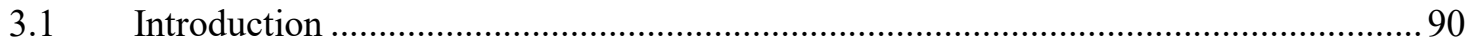

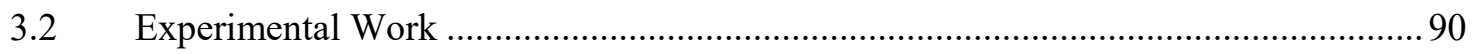

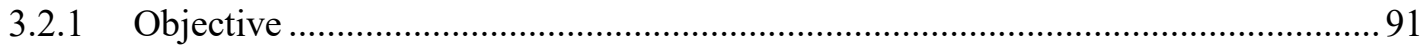

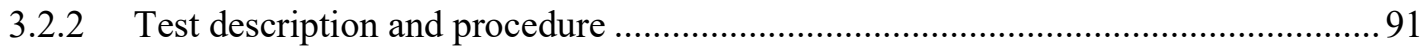

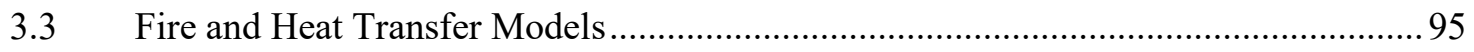

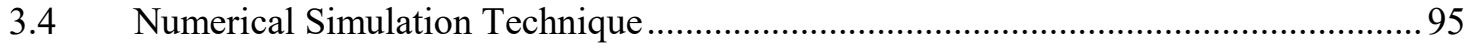

3.4.1 Finite element discretization and meshing ..................................................... 95

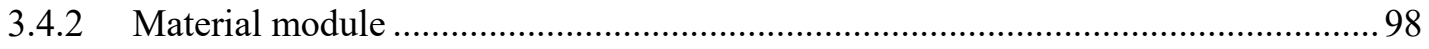

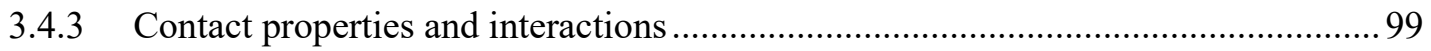

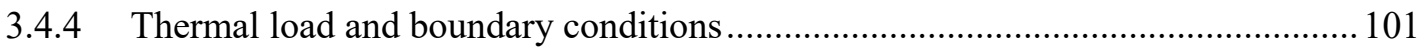

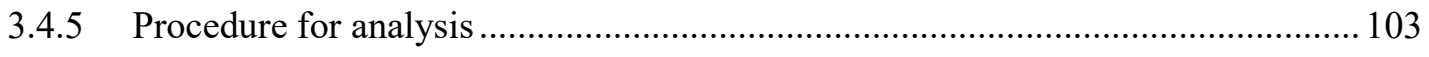




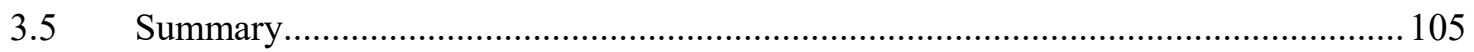

4 Chapter: Results and Discussion .............................................................................. 106

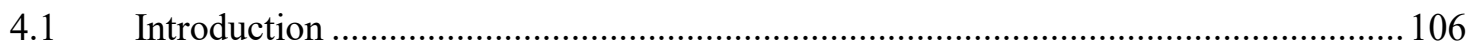

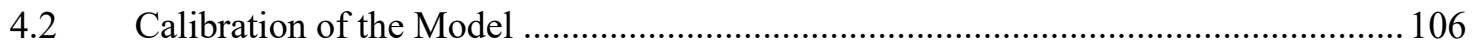

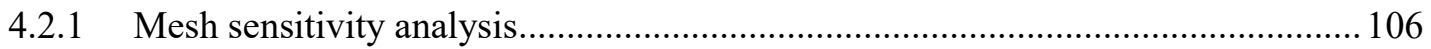

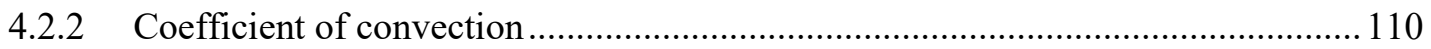

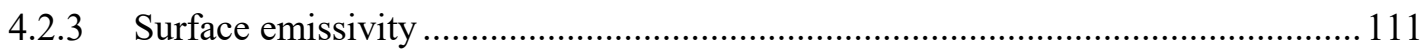

4.3 Validation of the Finite Element Model ................................................................... 113

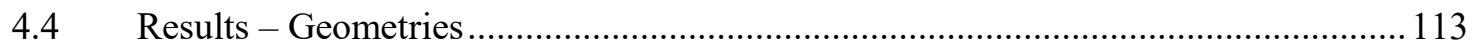

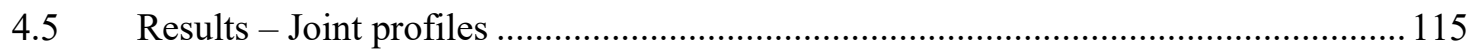

4.5.1 Control wall and raked wall (Numerical analysis -Full Wall) .............................. 117

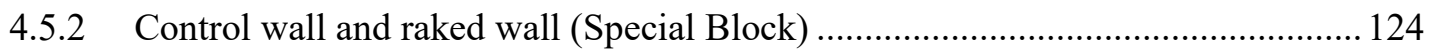

4.5.3 The use of cavity radiation and surface radiation ............................................. 127

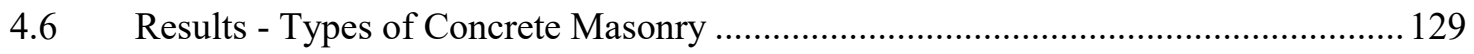

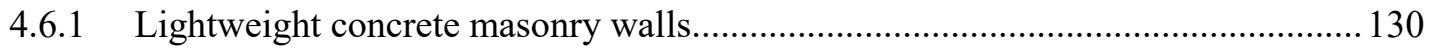

4.6.2 Recycled aggregates - Normal weight aggregates............................................ 132

4.6.3 Novel lightweight concrete (NLWC) masonry walls .......................................... 136

4.6.4 Lightweight foamed concrete masonry walls.................................................... 139

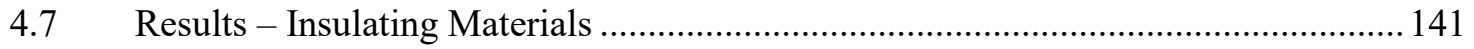

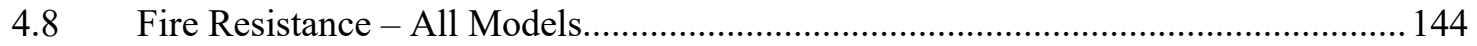

5 Chapter: Summary, Conclusions and Recommendations ................................... 147

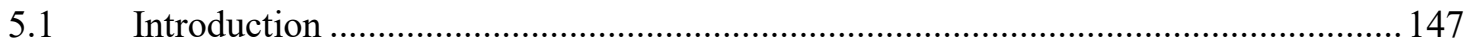

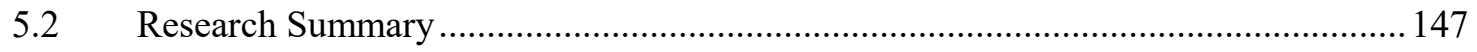

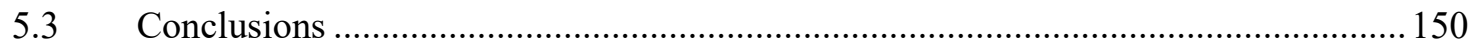

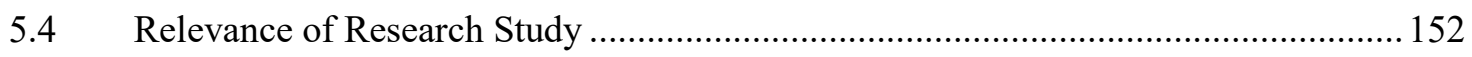

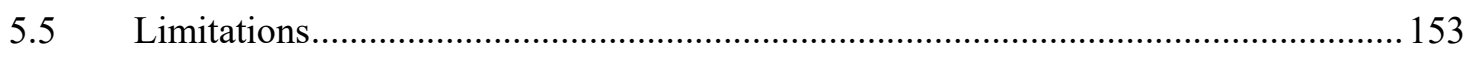




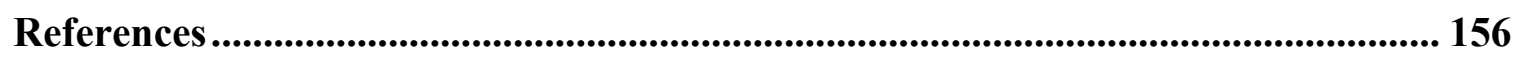

Appendices....................................................................................................................... 170

Appendix A : Thermal Properties of Materials for Model Input .......................................... 170

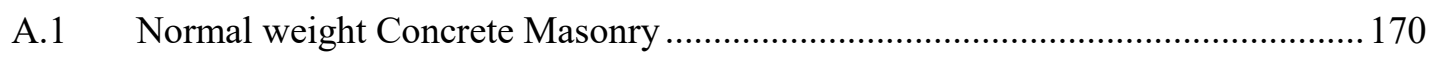

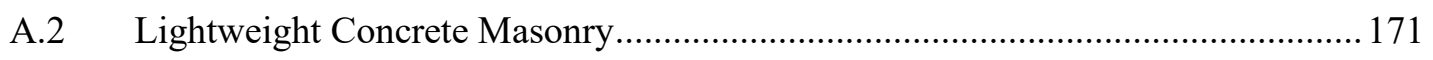

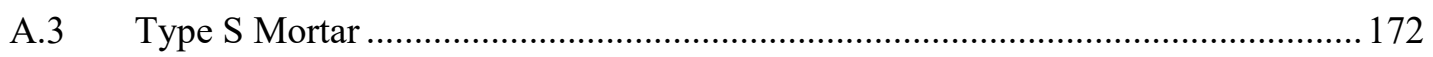

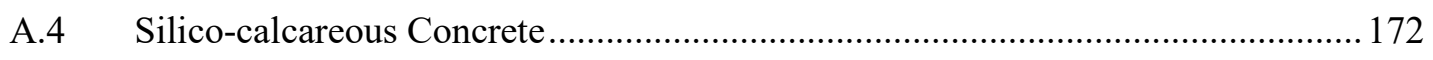

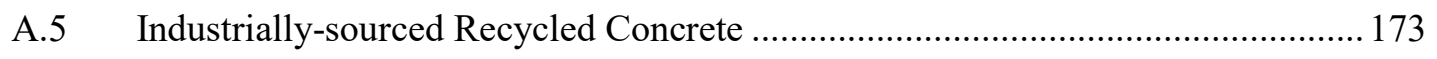

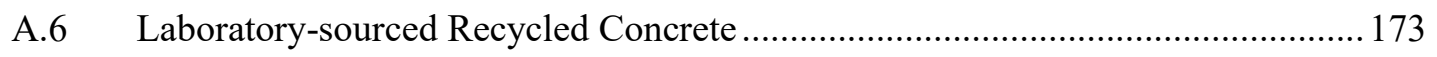

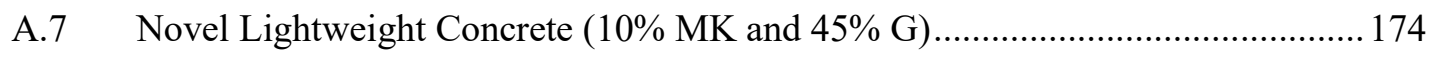

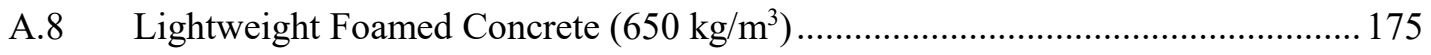

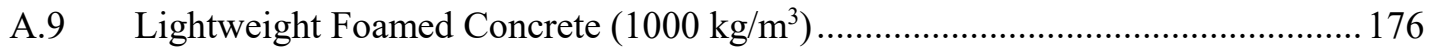

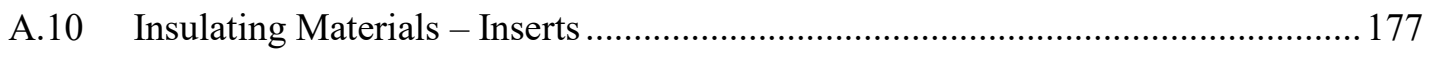

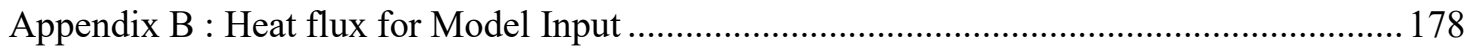

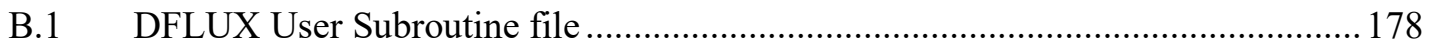

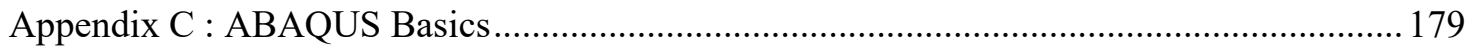

C.1 How to Use ABAQUS on the Carleton Cygwin Terminal ................................... 179

C.2 How to Transfer Files from the User's System to the School's System directly ... 182

C.3 How to Run an Input File (Job) on the Cygwin 64 Terminal................................. 184

C.4 Heat Transfer Problem - Heat flow through a concrete masonry wall .................. 186 


\section{List of Tables}

Table 2-1: Thermal conductivity values of $L W C$ and NWC mixtures as recorded by (Peng,

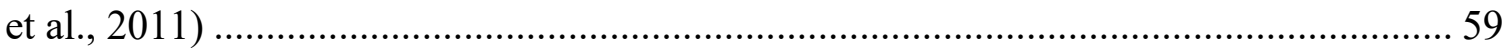

Table 2-2: Concrete mixes, modified from (Demirboga \& Gul, 2003)............................. 59

Table 2-3: Summary of concrete mixtures, (Al-Sibahy \& Edwards, 2012) ....................... 65

Table 2-4: Physical properties of mineral wools, modified from (Mueller, et al., 2009)

and (Kothandaraman \& Subramanyan, 2004) .............................................................. 78

Table 3-1: Role of thermocouple locations within special block ................................... 92

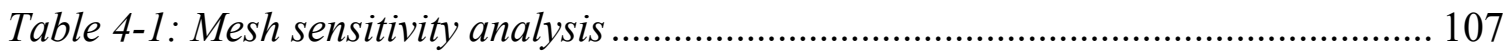

Table 4-2: Data used in the numerical simulation for validation of the model .............. 113

Table 4-3: Different size codes of concrete masonry hollow blocks as modelled in

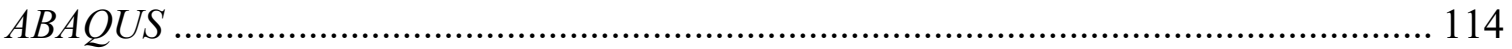

Table 4-4: Wall description- Joint profiles ................................................................ 116

Table 4-5: Wall description - Lightweight concrete masonry ....................................... 129

Table 4-6: Wall description - Normal weight concrete masonry ................................... 129

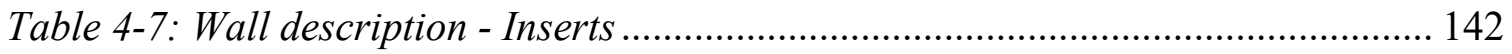




\section{List of Illustrations}

Figure 2-1: Common standard fire temperature curves (Buchanan, 2006) .................... 10

Figure 2-2: Design values for reduction of compressive strength with temperature

(Buchanan, 2006)

Figure 2-3: Design values for modulus of elasticity with temperature (Buchanan, 2006)23

Figure 2-4: Thermal conductivity of concrete (Reproduced from (EC2, 1993) (Buchanan, 2006) 25

Figure 2-5: Specific heat of concrete (Reproduced from EC2, 1993) (Buchanan, 2006) 26

Figure 2-6: Types of Joint Profiles used in Masonry Wall Construction (Sisson, 2017). 32

Figure 2-7: Thermal conductivity of mortar at high temperatures, (Cerny, et al., 2003) 36

Figure 2-8: Specific heat capacity of mortar at high temperatures (Cerny, 2008) .......... 37

Figure 2-9: Additional specific heat for evaporation of free water, (Ang \& Wang, 2004)

Figure 2-10: The effect of mortar joint thickness on the compressive strength of a masonry wall using brick units with a strength of 55.7 MPa, (Drysdale \& Hamid, 2005)

Figure 2-11: Thermal bowing through a section of a wall.

Figure 2-12: a) Masonry spalling (exposed surface), b) Close view of masonry spalling (Pope \& Zalok, 2017)

Figure 2-13: Thermal conductivity evolution of (a) normal concretes, and (b) high strength concretes, along with the temperature, during heating at $150^{\circ} \mathrm{C}, 250^{\circ} \mathrm{C}$ and $300^{\circ} \mathrm{C}$ and after cooling (residual) (Laneyrie, et al., 2016)

Figure 2-14: Specific heat capacity evolution of a) normal concretes b) high strength 
concretes along with the temperature, during heating at $150^{\circ} \mathrm{C}, 250^{\circ} \mathrm{C}$ and $300^{\circ} \mathrm{C}$ and after cooling (residual) (Laneyrie, et al., 2016)

Figure 2-15: Relationship between admixtures and thermal conductivity of concrete mixtures A, B, C, D, E and F; (Fig 2-14 a-f) respectively (Demirboga \& Gul, 2003) ..... 61 Figure 2-16: Relationship between EPA ratio and thermal conductivity, (Demirboga \& Gul, 2003) 62

Figure 2-17: Thermal conductivity of different concrete mixes at ambient and elevated temperatures a) Concrete mixtures containing 5\% MK with varying glass contents. b) Concrete mixtures containing 10\% MK with varying glass contents, (Al-Sibahy \& Edwards, 2012)

Figure 2-18: Specific heat of different concrete mixes at ambient and elevated temperatures a) concrete mixes containing $5 \%$ MK with varying glass contents. $b$ ) concrete mixes containing $10 \% \mathrm{MK}$ with varying glass contents. c) concrete mixes containing $45 \%$ glass content with different percentages of MK. (Al-Sibahy \& Edwards, 2012) 68

Figure 2-19: Temperature difference between exposed and unexposed surfaces temperatures a) concrete mixes containing $5 \% \mathrm{MK}$ with varying glass contents. b) concrete mixes containing $10 \% \mathrm{MK}$ with varying glass contents. 69 Figure 2-20: Specific heat of LFC samples $\left(650 \mathrm{~kg} / \mathrm{m}^{3}\right.$ and $\left.1000 \mathrm{~kg} / \mathrm{m}^{3}\right)$ at elevated temperatures, (Othuman \& Wang, 2011) 72

Figure 2-21: Temperature distributions in $650 \mathrm{~kg} / \mathrm{m}^{3}$ density samples (Othuman \& Wang, 2011) 73

Figure 2-22: Temperature distributions in $1000 \mathrm{~kg} / \mathrm{m}^{3}$ density samples (Othuman \& 
Wang, 2011).

Figure 2-23: Pore sizes for $650 \mathrm{~kg} / \mathrm{m}^{3}$ (a) and $1000 \mathrm{~kg} / \mathrm{m}^{3}$ (b) densities (Othuman \&

Wang, 2011)

Figure 2-24: Thermal conductivity of LFC samples $\left(650 \mathrm{~kg} / \mathrm{m}^{3}\right.$ and $\left.1000 \mathrm{~kg} / \mathrm{m}^{3}\right)$ at

elevated temperatures, (Othuman \& Wang, 2011)

Figure 2-25: Classification of insulating materials based on their chemical structure

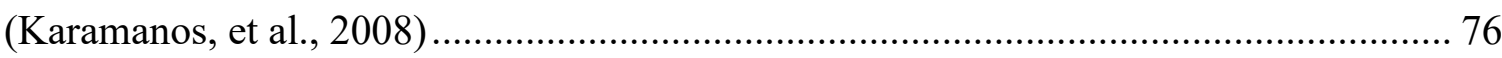

Figure 2-26: The Finite Element Analysis Procedure (Bathe, 1996) ............................ 83

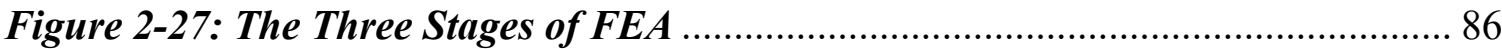

Figure 3-1: Thermocouple locations within the special block .................................... 92

Figure 3-2: Illustration of test setup with dimensions ............................................... 93

Figure 3-3: 3D illustration of experimental test setup .............................................. 93

Figure 3-4: Modes of heat transfer within experimental test setup ............................... 94

Figure 3-5: Thermocouple locations on unexposed side of the test wall ........................ 94

Figure 3-6: Creation of Parts for the Assembly of the Wall ......................................... 96

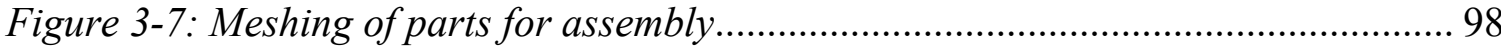

Figure 3-8: Contact interactions assigned to the different components in the assembly module

Figure 3-9: Thermal Load and Boundary Condition on Modelled Assembly ................ 104

Figure 4-1: Mesh sensitivity analysis for all mesh sizes......................................... 109

Figure 4-2: The effect of emissivity value on the simulation results of the exposed surface

Figure 4-3: Temperature profile recorded on the unexposed side of walls with different 
geometries

Figure 4-4: Modelled concave and raked joints.....

Figure 4-5: Temperature profile of control wall and raked wall at positions 1, 5 and 9

(Exp. only).

Figure 4-6: Different frames observed during numerical simulation

Figure 4-7: Nodal temperatures on raked wall and concave wall

Figure 4-8: Masonry wall after complete numerical simulation, showing areas of full

heat penetration through the wall (top view).....

Figure 4-9: Temperature profile on control wall at positions 1 and 9 (Exp. and Num.) 123

Figure 4-10: Temperature profile on raked wall at positions 1 and 9 (Exp. and Num.) 123

Figure 4-11: Temperature profile on control wall at solid, mortar and hollow sections

(Exp. and Num.)

Figure 4-12: Temperature profile on control wall at solid, mortar and hollow sections (Exp. and Num) 126

Figure 4-13: Nodal temperatures on sample model (cavity radiation and surface radiation) 128

Figure 4-14: Temperature profile on masonry wall made from LWC (Num.) at locations

1,5 and 9

Figure 4-15: Temperature profile on masonry walls made from LWC (Num.) and NWC

(Exp.) at locations 1 and 9

Figure 4-16: Temperature profile on masonry wall made from SCCA (Num.) at locations

1,5 and 9

Figure 4-17: Temperature profile on masonry wall made from LRCA (Num.) at locations 
1,5 and 9

Figure 4-18: Temperature profile on masonry wall made from LRCA (Num.) at locations

1,5 and 9 135

Figure 4-19: Temperature profile on masonry walls made from LRCA and IRCA (Num.)

at location 9 135

Figure 4-20: Temperature profile on masonry wall made from NLWC (Num.) at locations

1, 5 and 9.

138

Figure 4-21: Average temperature profile on masonry walls made from NLWC and LWC (Num.) 138

Figure 4-22: Temperature profile on masonry wall made from $\mathrm{LFC}_{1}$ (Num.) at locations

1,5 and 9 140

Figure 4-23: Temperature profile on masonry wall made from $\mathrm{LFC}_{2}$ (Num.) at locations

1,5 and 9

Figure 4-24: Section of modelled masonry wall with inserts

Figure 4-25: Comparison of temperature profile on masonry wall with inserts (Num.) and without inserts (Exp) at locations 9 144

Figure 4-26: Fire resistance of all tested models 146 


\section{List of Abbreviations}

\begin{tabular}{ll} 
ASTM & American Society for Testing and Materials \\
CAN/ULC & Underwriters Laboratories of Canada \\
CSA & Canadian Standards Association \\
CW & Concave wall \\
EC & Eurocode \\
FDM & Finite difference method \\
FEM & Finite element method \\
GW & Glass wool \\
IRC & Industrially-sourced recycled concrete \\
IRCA & Industrially-sourced recycled coarse aggregates \\
ISO & International Organization for Standardization \\
ITZ & Interfacial transition zone \\
LFC & Lightweight foamed concrete \\
LFC 1 & Lightweight foamed concrete $\left(650 \mathrm{~kg} / \mathrm{m}^{3}\right)$ \\
LFC & Lightweight foamed concrete $\left(1000 \mathrm{~kg} / \mathrm{m}^{3}\right)$ \\
LRC & Laboratory-sourced recycled concrete \\
LRCA & Laboratory-sourced recycled coarse aggregates \\
LWAC & Lightweight aggregate concrete \\
LWC & Lightweight concrete \\
NBCC & National Building Code of Canada \\
\hline
\end{tabular}




$\begin{array}{ll}\text { NFPA } & \text { National Fire Protection Association } \\ \text { NLWC } & \text { Novel lightweight concrete } \\ \text { NWC } & \text { Normal weight concrete } \\ \text { OCBA } & \text { Ontario Concrete Block Association } \\ \text { RC } & \text { Recycled concrete } \\ \text { RCA } & \text { Recycled coarse aggregates } \\ \text { ROW } & \text { Rock wool } \\ \text { RW } & \text { Raked wall } \\ \text { SCC } & \text { Silico-calcareous concrete } \\ \text { SCCA } & \text { Silico-calcareous coarse aggregates } \\ \text { SW } & \text { Slag wool } \\ \text { URM } & \text { Unreinforced masonry }\end{array}$




\section{Chapter: Introduction}

\subsection{Background}

Canada is a comparatively young nation and masonry heritage goes back only to when explorers and settlers brought their building skills with them. Nevertheless, the inherent sense of permanence, security and quality associated with masonry construction has made it part of their culture as is the case everywhere in the world (Drysdale \& Hamid, 2005). Masonry construction can be dated back to eight thousand years ago, during the initial stages of urban civilization when building materials mostly comprised of wood, straw and other locally available materials were used for simple masonry building designs. These have been gradually replaced by more advanced technologies, enabling the construction of stronger, longer lasting structures (Como, 2013). The development of masonry structures has been constrained by the availability of materials, construction skills, techniques and abilities as well as cost. The basic importance factors of every construction has been hinged on safety and cost, where cost has been the greatest constraint on the form of every masonry structure built in present day (Drysdale \& Hamid, 2005). For instance, the technological advances in masonry walls construction reduce the construction execution times; improve thermal insulation, sound insulation, fire protection and reduction of coating thickness (Li \& Lam, 2008). For these reasons, the fire behaviour of masonry materials and structural elements have promoted a great deal of interest in building construction ever since the need for fire protection in buildings became apparent (Malhotra, 1982; Andreini \& Sassu, 2011). Building materials such as concrete/clay blocks/bricks, mortar, grout and reinforcement bars serve as the basic components for constructing masonry walls. The choice of these listed materials in constructing masonry walls is dependent on the function of the wall. In 
terms of their function, masonry walls are either loadbearing or non-loadbearing. A loadbearing wall is part of the supporting structure of the building; it holds the building up. A non-loadbearing wall can serve as a partition that divides the various rooms of the building or as a finish. From a fire perspective, non-loadbearing masonry walls have considerable capacity to isolate parts of the building's interior from fire flames, heat, and the effect of smoke. It is known that ungrouted and unreinforced masonry, for instance non-loadbearing walls have less thermal mass and potential lines of weakness at the mortar joints. Although this remains a fact, these walls have demonstrated excellent fire resistance if the foundations and the supporting structures can keep the wall in place during the anticipated duration of fire (Buchanan, 2006).

Non-loadbearing masonry walls are composed of hollow concrete masonry blocks mortared together. The walls are anisotropic in material property, geometry and moisture content. The fire behaviour of the hollow concrete masonry block at its face shell, web and hollow cells, when subjected to elevated temperature, depicts this anisotropy in the overall thermal behaviour of the whole unit. Moisture content variations between the block and that of the mortar also creates a variation in the thermal behaviour when the whole unit is subjected to elevated temperatures. Current experimental work at the Carleton University Fire Lab, affirms this thermal behaviour variation based on the material property, geometry and moisture content.

In addition, in terms of the geometry, the National Building Code of Canada (NBCC) sets forth minimum required equivalent thicknesses for the face shells, which accounts for different fire resistance rating for masonry assemblies made from different types of concrete, which has been documented in (ACI/TMS, 2002). As the thickness of a material 
increases, so does its thermal resistance. The concept of equivalent thickness of a masonry unit is a measure of its solid content. The thermal resistance of masonry unit increase as the equivalent thickness increases, in effect; this increases the fire resistance rating (Sturgeon, 2013). The type of concrete used for the manufacture of the concrete masonry unit has a significant effect on the fire resistance rating. NBCC describes the type of concrete based on the type of aggregate and their relative volumes used in the material to manufacture the concrete masonry. The type of aggregate used determines the fire resistance rating due to its mineralogical nature, thermal and physical characteristics.

Building regulations are set by fire safety codes, which could either be Prescriptive or Performance based. Prescriptive codes set forth minimum requirements for protection and are generic by occupancy. They prescribe sets of measures to reach the fire safety in enclosures. However, these types of codes do not explain how to reach the fire safety objectives/performance, since they do not provide clear guidance on how to develop and assure a safe fire design (Tavares, 2008). Over the years, prescriptive fire codes have been used to allow simple designs, but they come with many restrictions. On the other hand, performance codes attempt to provide clearer guidance than prescriptive codes taking into consideration all possible functional objectives that will affect the fire safety of a building member, assembly or structure. They are usually guided by set objectives and accordingly met by the fire safety engineer, who has the freedom to define the criteria and methodology to achieve them (Tavares, 2008). In the event of a fire, performance based codes require that an element, assembly or a structure should perform regarding integrity, thermal insulation and load bearing capacity. Integrity and insulation are concerned with the ability 
of the element, assembly or structure to provide an adequate barrier to fire while the load bearing capacity concerns its structural stability.

\subsection{Research Basis}

A full-scale fire test is usually required in the quest to provide these defined criteria for guidance in the use of performance based codes as per the requirements in the CAN/ULCS101 (CAN/ULC-S101, 2007). The fire resistance is determined by subjecting elements, members or assemblies to standard fire test conditions and measuring the time elapsed before each of these design criteria (integrity, insulation and load bearing capacity) becomes violated (EN 1363-1, 2000; ISO 834-1, 1999). However, a full-scale fire test is not always a practical solution as it is very expensive, time consuming, and requires the use of a fire lab with an appropriate fire capability. In evaluating the fire resistance of masonry walls for instance, within a single test, there are varying parameters such as moisture contents, concrete masonry mix designs, mortar joints profiles, types of masonry units, etc. which could greatly affect the final experimental results. This in effect, creates varying cases within the single test and therefore requires much detailing to conduct based on expertise and the resources available. A numerical simulation serves as an alternate option, for researchers to account for the effect of heat transfer on an element, assembly or a structure. Therefore, the use of a finite element modelling software to analyze these typical scenarios offers a more affordable, yet practical solution.

\subsection{Research Objectives}

The first part of the research program involved full-scale fire resistance tests, which were 
conducted as part of an ongoing project at Carleton University fire lab. Walls composing of different types of concrete masonry, joint profiles and geometries were investigated for their fire performance. Hamish Pope of Carleton University performed the experimental work, which was the first part of the research, detailed results will be presented in his future publications. The second part of the research, which is presented in this thesis by this author, is a numerical investigation of the tested control wall, tested joint profiles and the use of other forms of concrete masonry and insulating materials from existing literature with the following objectives:

- To develop a reliable finite element model for simulating the thermal behaviour of concrete masonry non-loadbearing walls

- To validate this model using the experimental test results of the control wall

- To evaluate the fire resistance of the different forms of concrete masonry; lightweight and normal weight, used in the construction of non-loadbearing masonry walls

- To evaluate the fire resistance of masonry walls mortared with two different forms of joint profiles; raked and concave

- To evaluate the fire resistance of masonry walls made from different geometries

- To evaluate the fire resistance of insulating materials used as inserts in normal weight concrete masonry blocks

\subsection{Outline of the Thesis}

This thesis is divided into five chapters.

Chapter 1 provides the introductory part of the research. A summary on the research 
program as well as the basis of the research has been discussed.

Chapter 2 provides a review of the literature relevant to the research presented within this thesis. Specifically, there is a review of the standards adopted in assessing the fire resistance of any structural component or member or material. The mechanical and thermal behaviour of masonry walls at ambient temperatures have been addressed. Furthermore, the effects of elevated temperature on the mechanical and thermal properties of the various constituents; concrete masonry blocks and mortar used in constructing masonry walls have also been reviewed. Problems associated with masonry walls due to the generation of heat through different modes of heat transfer has also been investigated. In addition, methods of improving the fire resistance using different concrete masonry mix designs has been investigated. This focused on evaluating the thermal properties of novel forms of concrete masonry from existing research work. The concept of finite difference and element method for analyzing the fire resistance of complex structures has also been reviewed.

Chapter 3 focuses on the methodology of this work. The experimental work done by the ongoing project is reviewed in this chapter. The fire and heat transfer analysis is also discussed. Furthermore, the development of a reliable finite element model to simulate the thermal behaviour of masonry walls subjected to elevated temperatures is presented in this chapter. The choice of element types, material model, mesh sizes, discretization modes, interaction module and application of loads are discussed in this chapter.

Chapter 4 presents the results and further discusses the experimental results from normal weight concrete masonry walls and walls constructed as either raked or concave. In addition, it discusses the validation of the numerical model with experimental data available from previous fieldwork as well as a comparison of the ABAQUS results. A 
parametric study is performed to calibrate the model based on parameters such as meshing techniques, coefficient of convection and surface emissivity. Following the validation and calibration of the model, different concrete masonry types, insulating materials, joint profiles and geometries are numerically analyzed.

Chapter 5 focuses on the main conclusions, which emerge throughout this study. The limitations and conditions of this research and proposes suggestions for future studies based on the findings reported in this thesis. 


\section{Chapter: Literature Review}

\subsection{Introduction}

Preliminary studies on the behaviour of masonry walls in fire are summarized in this part of the thesis. The fire performance of concrete masonry in terms of what is known as "fire resistance" in Fire Engineering Science is also quantified. Masonry walls are constructed with masonry blocks made from concrete and the use of mortar for the joints. Depending on the type of concrete and mortar design mixes, this would affect the performance of the composite material under ambient and elevated temperatures. Therefore, this review presents a comprehensive study on the mechanical and thermal properties of both materials under elevated temperatures. The mechanical properties discussed include the density, compressive strength, and modulus of elasticity. The thermal conductivity, specific heat capacity and the thermal expansion are the thermal properties discussed. Modes of heat transfer as well as the problems associated with masonry walls is also discussed. A review on existing literature on the thermal properties of concrete masonry and insulating materials subjected to elevated temperature is also addressed. This chapter finally closes with a discussion of the potential methods of modelling masonry walls for a numerical solution.

\subsection{Fire Resistance - Definition and Goals}

The primary goal of fire protection is to limit, to acceptable levels, the probability of death, injury and property loss in an unwanted fire event. These fire safety objectives are met by providing a protection system (Buchanan, 2006). Fire resistance serves as the most important component in this regard. Fire resistance is defined as the measure of the ability 
of a building element to resist fire; spread of fire and structural collapse in fire (Buchanan, 2006). Under exposure to standard fires, building elements are normally tested and rated based on their ability to perform intended functions and this is commonly referred to as "fire resistance rating". The objectives of fire resistance include the prevention of internal spread of fire, reduction in the probability of fire spread to other buildings, prevention of structural collapse and the prevention of collapse, which eventually affect people or property (Buchanan, 2006). Fire resistance is usually quantified as time for an element or assembly to meet the above stated objectives.

\subsubsection{Assessment of fire resistance}

Fire is one of the major causes of loss of life and property. All buildings should be designed and assessed regarding fire safety (Drysdale \& Hamid, 2005). Fire resistance is a design parameter that is specific to building elements and assemblies such as columns, beams, walls, composite floors and ceilings. Masonry walls are non-combustible, not subject to flame spread, and do not provide smoke or toxic gases in the presence of fire. The main fire resistance aspects of the design of non-loadbearing masonry walls is its ability to maintain sufficient strength to avoid collapse during and after specified durations of fire. The wall needs to stay in place so as not develop cracks, fissures to further cause smoke and flame spread during the duration of the anticipated fire. Simply, the wall must possess thermal characteristics that prevent temperature rise that could possibly cause new ignitions (Drysdale \& Hamid, 2005).

Fire resistance ratings of an element is determined by conducting full-scale fire resistance tests. Standards for fire resistance such as the International Organization for 
Standardization (ISO) 834 (ISO 834-1, 1975) and American Society for Testing and Materials (ASTM) E119 (ASTM E119, 1988) are used by most countries in Europe and North America respectively. In Canada, standards include the (CAN/ULC-S101, 2007), which is based on (ASTM E1 19, 1988) and the British standards BS 476 (British Standards, 1987), Parts $20-23$. Figure 2-1 below shows the time-temperature curve used by some standard fire tests. As per the CAN/ULC -S101 (CAN/ULC-S101, 2007) standards, the fire test of any structural element, member or assembly requires eighteen thermocouples to be placed on the unexposed and exposed side of the specimen to measure the temperature rise (nine on each side).

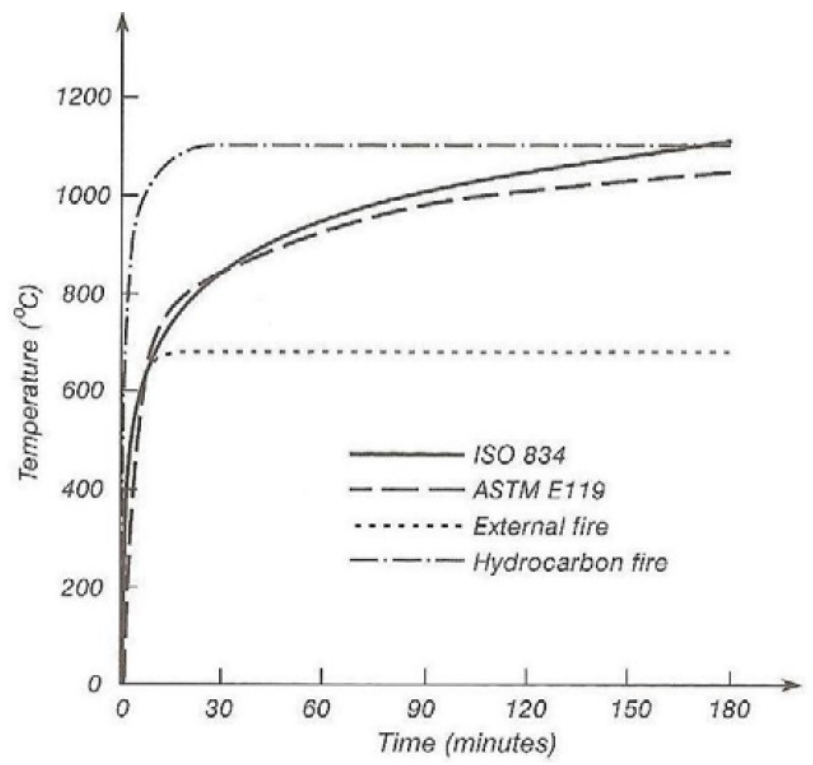

Figure 2-1: Common standard fire temperature curves (Buchanan, 2006)

Depending on the type of element in question, design standards specify the procedure, geometry, loads, support conditions and fire severity required to determine its fire resistance rating. The fire resistance determined through these tests and the required ratings in the standards provide a platform for meeting the fire design needs. An adequate fire design of a building element is one, which satisfies a specified failure criterion for fire resistance. 
The three failure criteria for fire resistance testing are stability, integrity and insulation (Buchanan, 2006). The stability criterion deals with the ability of load bearing elements such as columns, beams, floors and some walls to withstand applied loads up to a certain design level in the event of fire. Integrity ensures that mostly non-structural elements, such as partitions, doors and glazing do not develop cracks or fissures. This criterion hinders the transmission of hot gases and flames to adjacent rooms for fire spread. The insulation criterion, just like the integrity is to ensure the containment of room fires. This is achieved by providing an adequate level of insulation on room boundaries such that the heat transferred to the adjacent rooms do not initiate fire. The failure of a wall as a fire barrier; non-loadbearing walls, occurs if during the test period there is a temperature rise of $180^{\circ} \mathrm{C}$ at any one of nine points on the unexposed side of the wall or an average temperature rise of over $140^{\circ} \mathrm{C}$. Partial collapse of the wall or fire penetration through the wall is also deemed to signify failure of integrity. Therefore, the fire resistance of a non-loadbearing wall is determined by the time to reach any of the following: fire penetration through the wall temperature rise on the unexposed side, collapse or termination of the test. The fire resistance rating is the fire resistance rounded down to the nearest whole hour (Drysdale \& Hamid, 2005).

An analytical method of determining the fire resistance of building elements involves a fire model, a heat transfer model and a structural response model (Buchanan, 2006). The fire model is obtained from standard fires as prescribed in various building codes and is needed as a basic input in such analysis. This leads to the transfer of heat from the fire to the element boundaries and within. The resulting thermal gradients, if conducted successfully, can be enough to determine the fire resistance of such building elements with respect to 
the integrity and insulation criteria. For the stability criterion of fire resistance rating, the thermal gradients are used as input to the structural response model. The analytical approach eventually lends itself to computer-based modelling due to complexities of transient non-uniform temperature distribution, thermal expansion of materials, temperature-dependent properties of materials and the combination of different materials in an assembly.

\subsection{Masonry Walls}

Masonry walls include bricks and blocks made of either clay or concrete masonry covering a wide variety of shapes and densities mortared together (Malhotra, 1982). Although, clay bricks have numerous benefits; high strength, durability, high resistance to fire and abrasion, its construction is time consuming, which serves as one of its major drawbacks. Other drawbacks include its high rate of fuel consumption during production and high susceptibility to lime blowing and efflorescence (Houben \& Guillaud, 1994). Lime blowing is caused when clay bricks contain small amounts of lime. When these bricks are fired, the lime is converted to calcium oxide (quicklime). During an exposure to moisture; rain, snowfalls etc. these bricks get wet thereby causing a reaction to form allowing the calcium oxide to slake off. The process of slaking is vigorous and can cause an eruption on the face of the brick. This describes the process of lime blowing. Efflorescence on the other hand, is a surface defect on masonry units, which has more aesthetic rather than structural consequences. It is a crystalline deposit of salts (carbonates, sulphates, chlorides), usually white, that forms on or near the surface of masonry products (Kompatscher, 2007). In addition, most failure in clay brick walls under elevated temperatures have been attributed 
to the fact that the construction could not withstand thermal movement because of its large size and lack of provision for stability and expansion (Malhotra, 1982).

Concrete masonry is the most commonly used construction material due to its preferable properties; including its high strength, durability, and constructability. Concrete masonry blocks address the major drawbacks observed in clay bricks. Concrete masonry blocks could be solid, hollow or aerated. The type of block is related to its net area and gross area of the unit. The net area of the block is defined as the ratio of the volume of concrete to the height of the block whereas the gross area is the product of the width of the block by its length (Sturgeon, 2013). A solid block is defined as having the net area being equal to $100 \%$ of the gross area and that of a hollow block's net area is less than $75 \%$ of the gross area. Aerated concrete is formed from cement that has been mixed with other materials (such as an expansion agent) and treated in such a way as to substantially reduce its density without reducing its strength. The mechanical behaviour of solid concrete masonry blocks is similar to that of concrete masonry walls as the material properties are similar, but the presence of mortar joints allows improved capacity to compensate for unequal expansion of the section when one face is exposed to heating. Hollow blocks walls have better insulation but the loss of solid material requires an increase in section thickness to support similar loads; fire and structural. It has been found that both solid and hollow blocks are not susceptible to damage by spalling (Malhotra, 1982). However, recent studies have proven otherwise, hollow blocks are susceptible to spalling (Pope \& Zalok, 2017). Owing to the thermal properties of aerated concrete blocks, provision of good fire resistance as loadbearing and non-loadbearing systems is observed in these blocks. Generally, aerated 
concrete blocks have excellent thermal insulation properties as compared to both solid and hollow concrete blocks (Ali, 2014).

With masonry walls, the possibility of structural failure is minimal, so that research has been concerned with the thermal fire endurance and the factors that affect it, that is, with the thermal properties of concrete masonry (Harmathy \& Allen, 1972). Concrete masonry is well known for its capacity to endure high temperatures due to its low thermal conductivity and high specific heat (Buchanan, 2006). The behaviour of concrete masonry when subjected to elevated temperatures is of prime importance as this leads to loss of insulation, integrity and stability and may eventually lead to undesirable structural failures (Harper, 2004). In striving for a high degree of fire resistance in any concrete masonry structure, the design of the concrete mixture should be keenly examined. High temperature behaviour of concrete masonry is generally affected by the design of the concrete mixture, this is narrowed down to the material properties; such as the properties of the aggregates, the cement pastes and the aggregate paste bond, as well as the thermal compatibility between the aggregate and cement paste (Bahar \& Oguzhan, 2010; Koksal, et al., 2012; Aydin, 2008). The practical classification of aggregates is grouped under siliceous and calcareous aggregates (normal weight) and that of lightweight aggregates (Buchanan, 2006; Kosmatka, et al., 2003; Robert \& Colina, 2009). In addition, the use of appropriate chemical and mineral admixtures significantly influence its behaviour under elevated temperature (Adefemi, et al., 2013). 


\subsubsection{Unreinforced masonry wall construction}

Unreinforced masonry, for instance non-loadbearing walls are usually referred to as "plain" masonry. URM's are commonly used in low-rise and medium rise buildings in areas of low seismic activity (Drysdale \& Hamid, 2005). They are the simplest masonry elements to construct since they contain no reinforcement other than the possible inclusion of light joint reinforcement to control shrinkage cracking and for tying (Drysdale \& Hamid, 2005). The strength of the masonry alone to resist loads is primarily the source of strength for URM. Masonry is strong in compression but weak in tension. Therefore, URM has a great resistance to compressive loads, but has a limited resistance to tensile stresses. In designing the tensile stresses of these walls, it must be less than the strength of masonry; otherwise, the masonry section is assumed to crack (Drysdale \& Hamid, 2005).

\subsection{Types of Concrete Masonry used for Masonry Wall Construction}

Based on the Ontario Concrete Block Association (OCBA), there are two main types of concrete mix for block production; lightweight concrete (LWC) and normal weight concrete (NWC) ((CCMPA), 2004). LWC refers to any concrete masonry produced with density of less than $2000 \mathrm{~kg} / \mathrm{m}^{3}$ per the classification given by (Harper, 2004), while, the density of normal weight concrete (NWC) is between 2000 and $2600 \mathrm{~kg} / \mathrm{m}^{3}$ (Harper, 2004). LWC can be classified into three groups based on their use and physical properties; structural use, both structural/insulating purposes, and insulating uses (Laurent, 2014) . LWC for structural purposes is defined as concrete with density range of $1600-2000 \mathrm{~kg} / \mathrm{m}^{3}$ and strength grade not less than $15 \mathrm{MPa}$. LWC used for insulation purposes may provide strength as low as $0.5 \mathrm{MPa}$ and a density of less than $1450 \mathrm{~kg} / \mathrm{m}^{3}$ (Abdel-Reheem, et al., 
2003). Generally, LWC reduces the dead load of structure, construction saving, provides high thermal insulation for buildings and it enhances the inherent fire resistance of buildings. The only major drawback associated with LWC, is its mechanical strength. However, based on its thermal behaviour when subjected to elevated temperatures, the use of LWC is more beneficial than NWC (Abdel-Reheem, et al., 2003). These mechanical and thermal properties have been discussed in sections 2.5 and 2.6.

\subsection{Mechanical Properties of Concrete Masonry at Elevated Temperatures}

Density, compressive strength, modulus of elasticity and Poisson's ratio are the mechanical properties of concrete masonry, which could be significantly affected when subjected to elevated temperatures. The Canadian Standards Association (CSA) 165.1 (CSA A165.1, 2004) contains a set of minimum requirements for concrete block masonry units suitable for both loadbearing and non-loadbearing applications. It also identifies four properties such as the solid content, specific compressive strength, concrete type (density and absorption), and moisture content of concrete block masonry units.

\subsubsection{Density of concrete masonry}

Concrete masonry is composed of different materials such as Portland cement and water combined with aggregates. The type of aggregates and mix design affects the density of concrete masonry. It is economical to use as much aggregates into concrete design mix as possible while not relinquishing other properties. However, economy is not the only reason for using aggregates, it also confers greater volume stability and better durability than the cement paste used alone. Furthermore, the use of aggregates influences the dimensional 
stability, elastic modulus, durability, workability and cost of the concrete. The easiest way to alter the density of the concrete mix is using aggregates. NWC mixes have high densities because they are produced from aggregates with a high density. NWC mixes usually have a density of $2300 \mathrm{~kg} / \mathrm{m}^{3}$ (Buchanan, 2006). In the same vein, LWC mixes are mostly produced from porous aggregates, which reduce this density to about half or two thirds the value (Buchanan, 2006).

When concrete is exposed to elevated temperatures, it loses moisture at approximately $100^{\circ} \mathrm{C}$; which is the temperature moisture evaporates, this in effect reduces the density of concrete by about $100 \mathrm{~kg} / \mathrm{m}^{3}$ (Buchanan, 2006). However, this has no major effect on thermal response. Other than moisture changes, the density of concrete is not affected considerably at elevated temperatures. On the other hand, calcareous aggregates decompose at a temperature of $800^{\circ} \mathrm{C}$, which significantly decreases its density (Buchanan, 2006).

\subsubsection{Strength of concrete masonry}

Concrete masonry is known to be strong in compression and very weak in tension (Arthur H, et al., 2010); hence, its compressive strength becomes a significant property when subjected to elevated temperatures. This is because a loss in the compressive strength may result in many undesirable structural failures (Ali, et al., 2004; Cioni, et al., 2001; Janotka \& Nurnbergerova, 2005; Georgali \& Tsakiridis, 2005). Under elevated temperatures, specific chemical reactions and processes take place thereby influencing the hydration of the cementitious materials which ultimately affect the thermal and physical structure of the 
concrete (Tatro, 2006). The loss of strength could be attributed to the loss of moisture and the degree of moisture depends on the duration of the fire (Reinhardt \& Stegmaier, 2006). When concrete is exposed to high temperatures, its first endothermic peak occurs just about $110^{\circ} \mathrm{C}$ where dehydration such as the release of chemically bound water from calcium silicate hydrate (CSH) occurs (Yoon, et al., 2015; Khoury, et al., 2002). CSH compound is the main product of the hydration of Portland cement and is primarily responsible for the strength in cement-based materials. This dehydration creates thermal expansion of the aggregates thereby increasing the internal stresses (Arioz, 2007). This follows up with its first exothermic peak at about $300^{\circ} \mathrm{C}$, which indicates probable gas release thereby inducing micro-cracks through the material (Yoon, et al., 2015; Arioz, 2007). Just around $530^{\circ} \mathrm{C}$, the cement paste experiences its second endothermic peak where one of its most important compounds; Calcium Hydroxide $\left[\mathrm{Ca}(\mathrm{OH})_{2}\right]$ dissociates resulting in the shrinkage of concrete (Arioz, 2007; Janotka \& Nurnbergerova, 2005; Georgali \& Tsakiridis, 2005). (Equation 2-1). $\mathrm{Ca}(\mathrm{OH})_{2}$ reacts with either a siliceous or siliceousaluminous material in finely divided form and in the presence of water at ordinary temperatures, compounds possessing cementitious materials are formed. Ultimately, the overall strength of the concrete is enhanced and this makes it one of the most important compounds. This reaction process is known as the pozzolanic action.

$$
\mathrm{Ca}(\mathrm{OH})_{2}+\mathrm{H}_{4} \mathrm{SiO}_{4} \rightarrow \mathrm{CaH}_{2} \mathrm{SiO}_{4} \cdot 2 \mathrm{H}_{2} \mathrm{O}
$$

Equation 2-1

The use of aggregates and admixtures that have high silica contents (such as fly ash, silica fume) ultimately provides good pozzolanic action and improves the strength of the concrete mix. Generally, the higher the proportion of silica content the higher the strength (Adefemi, et al., 2013; Poon, et al., 2001). This is because silica can easily combine with $\mathrm{Ca}(\mathrm{OH})_{2}$ in 
the presence of water to form stable compounds such as calcium silicates (CSH) which exhibit cementitious properties thereby enhancing long term durability and strength (Equation 2-1). Previous studies (Aydin, 2008; Serdar Aydin, 2007) have proven that the use of these admixtures significantly increased the strength of the concrete samples when subjected to elevated temperatures.

The changes produced by elevated temperatures are more apparent when the temperature exceeds $500^{\circ} \mathrm{C}$. Most of these changes experienced by concrete at this temperature level are considered irreversible (Luccioni, et al., 2003). CSH gel, which is the strength-giving compound of cement paste, decomposes further above $600^{\circ} \mathrm{C}$. At $800^{\circ} \mathrm{C}$, concrete is usually crumbled and above $1150^{\circ} \mathrm{C}$ feldspar melts and the other minerals of the cement paste turn into a glass phase (Hertz, 2005). Thus, severe microstructural changes are induced and concrete loses its strength and durability (Arioz, 2007).

The decomposition of aggregates eventually reduces the compressive strength of the concrete. The thermal properties of the aggregates play a vital role in assessing the compressive strength of concrete mixtures when exposed to elevated temperatures. Low thermal conductivities of concrete mixtures record less probabilities of spalling occurring in concrete members (Won, et al., 2010). Spalling is a structural failure that may occur once the compressive strength of concrete is reduced drastically or completely lost. The rate of thermal conductivity of aggregates can be related to evaluating the compressive strength of concrete members when exposed to elevated temperatures (Won, et al., 2010). At about $600^{\circ} \mathrm{C}, \mathrm{LWC}$ loses its compressive strength linearly till about $1000^{\circ} \mathrm{C}$ while NWC would start losing its strength at $400^{\circ} \mathrm{C}$ and finally loses this completely at about $900^{\circ} \mathrm{C}$ (Buchanan, 2006) (Figure 2-2). This behavioral difference could be attributed to the 
difference in thermal conductivities of the aggregates used. LWC is generally produced from aggregates that possess low thermal conductivities as compared to those made for NWC. Although, the density of LWC is relatively low as compared to NWC, and therefore possesses a relatively low mechanical strength. It is observed that under subjection to elevated temperatures, the rate of loss in compressive strength is lesser in LWC as compared to NWC (Bahar \& Oguzhan, 2010).

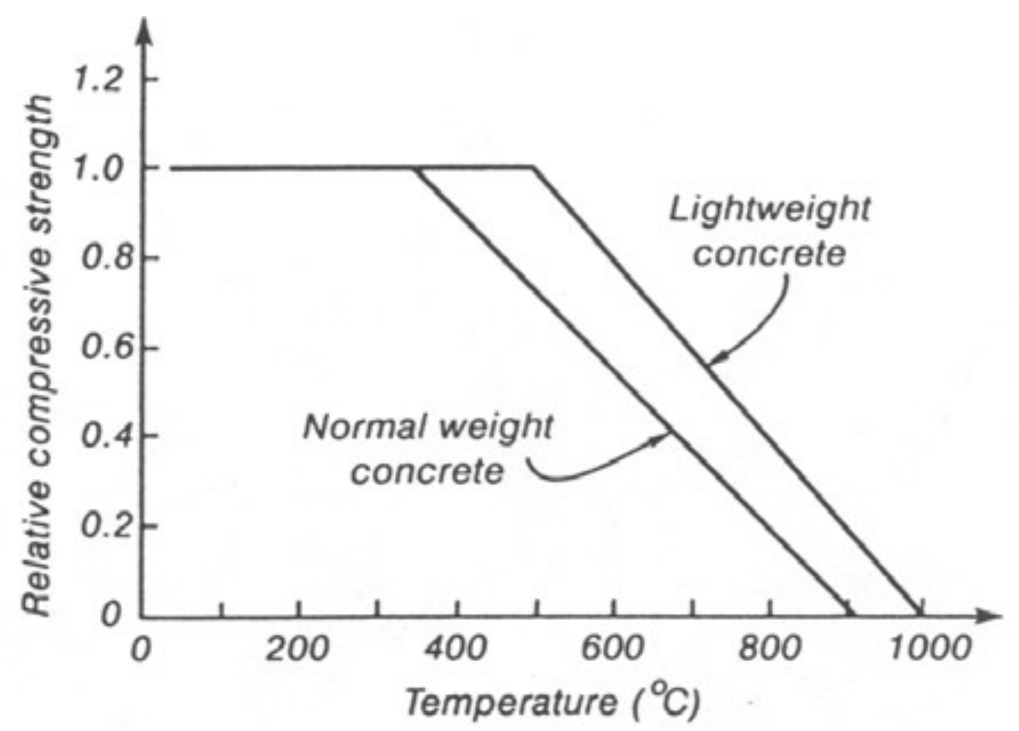

Figure 2-2: Design values for reduction of compressive strength with temperature (Buchanan, 2006)

A study conducted by (Bingol \& Gul, 2004) affirms this trend in the thermal behaviour of LWC and NWC. The study focused on investigating the compressive strength of lightweight aggregate concrete exposed to elevated temperatures using increasing proportions of pumice aggregates (PA) to replace natural normal weight aggregates (NA). Pumice aggregate is a natural sponge-like material of volcanic origin composed principally of silica produced from molten lava, which rapidly cools thereby trapping millions of air bubbles in it. It is a lightweight aggregate. Pumice has a very low thermal conductivity of 
about $0.58 \mathrm{~W} / \mathrm{mK}$ at a density of $1600 \mathrm{~kg} / \mathrm{m}^{3}$ (ACI Committee 122, 2002) as compared to calcareous aggregates; NA which has a high thermal conductivity of $1.8 \mathrm{~W} / \mathrm{mK}$ at a density of $2300 \mathrm{~kg} / \mathrm{m}^{3}$. Due to its sharp-cornered polyhedral form with a coarse surface, it achieves a good bond with cement and mortar. Furthermore, its porous structure and total absence of crystalline substance affords good thermal and acoustic insulation (higher than other inorganic materials). However, its major drawback is its inability to exhibit excellent mechanical characteristics (Cavaleri, et al., 2003). Comparing the chemical and mechanical composition of PA to NA in Bingol and Gul's study (Bingol \& Gul, 2004); it was found out that the silica contents were higher in PA than that of NA. In addition, PA samples had lower thermal conductivities as compared to NA samples. Samples were prepared as cylinders having dimensions $100 \times 200 \mathrm{~mm}$. All samples were subjected to a temperature range of $23^{\circ} \mathrm{C}$ to $750^{\circ} \mathrm{C}$. Samples were cooled to room temperature in air under laboratory conditions after heating. Compressive strength tests were conducted using cylinders capped with a Sulphur compound and then tested in accordance with ASTM C 192 (ASTM C192 M-95 , 1998). After tests were conducted, it was found that there was a decrease in the loss of compressive strength for all samples irrespective of the amount of PA content in the sample. However, it was observed that the loss in compressive strength for all samples decreased with an increase in PA content. For instance, at its peak temperature of $750^{\circ} \mathrm{C}$, all samples containing $100 \%$ NA lost about $80 \%$ of its compressive strength while samples containing $100 \%$ PA samples lost only $55 \%$ of this strength (Bingol \& Gul, 2004). Previous researchers (Bahar \& Oguzhan, 2010) have identified this excellent property of pumice aggregates at not losing its compressive strength significantly until about $600^{\circ} \mathrm{C}$. Also, (Turker, et al., 2001) reported that pumice aggregate mortar subjected to high 
temperatures did not show significant loss in strength when exposed to a temperature of up to $500^{\circ} \mathrm{C}$ and is more resistant to high temperatures.

\subsubsection{Modulus of elasticity of concrete masonry}

The modulus of elasticity is defined as the tendency of a material to deform along an axis when opposing forces are applied along that axis (Hibbeler, 2010). When a material has a high modulus of elasticity, it means that the material is stiffer. A low modulus of elasticity would imply the material is quite flexible. Elevated temperature can be a source of an opposing force on a concrete structure or member. The modulus of elasticity of concrete masonry decreases with increasing temperature and regardless of the type of concrete, the behaviour in trend is the same (Buchanan, 2006) (Figure 2-3). Since there is a reduction in the modulus of elasticity under elevated temperatures, it means the concrete loses its ability to deform elastically. The modulus of elasticity is related to flexural strength of concrete. Comparing, Figure 2-2 and Figure 2-3, the modulus of elasticity of concrete decreases faster than that of the compressive strength, which implies that the flexural strength will be more critical at elevated temperatures. 


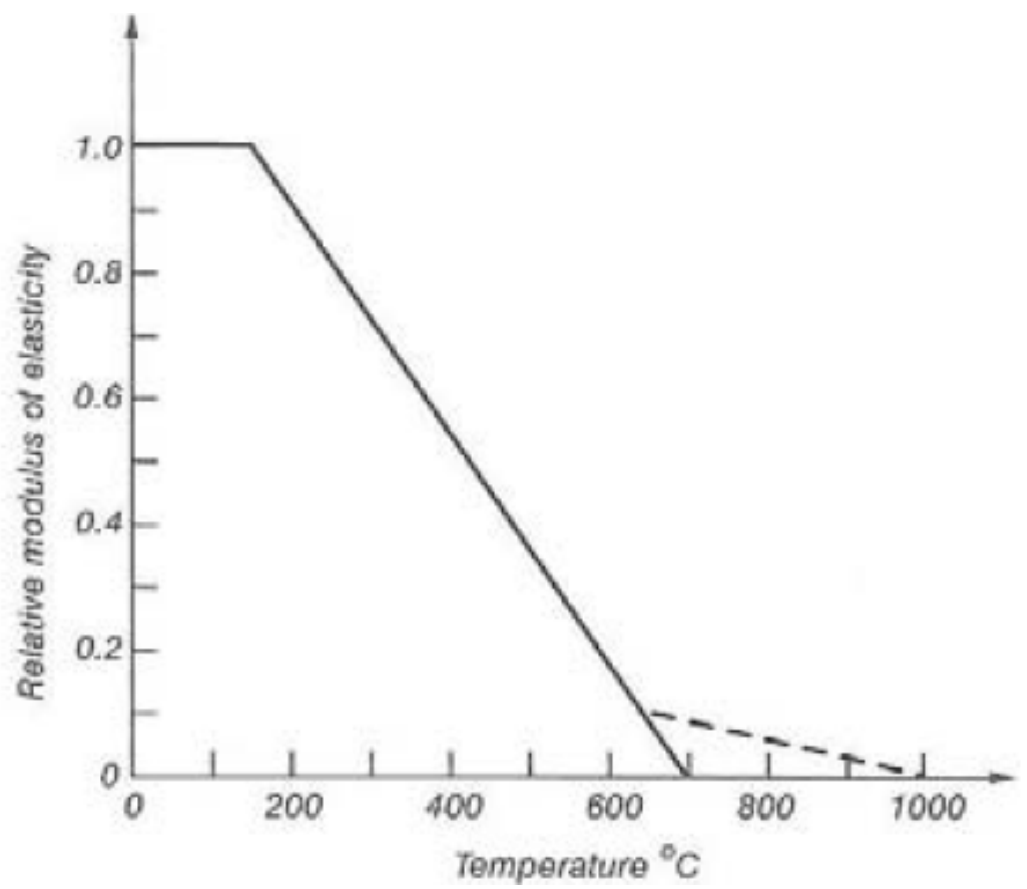

Figure 2-3: Design values for modulus of elasticity with temperature (Buchanan, 2006)

\subsection{Thermal Properties of Concrete Masonry at Elevated Temperatures}

The thermal conductivity, specific heat capacity and thermal deformation of concrete masonry are discussed below.

\subsubsection{Thermal conductivity}

The thermal conductivity of a material is basically the rate at which heat passes through the material, therefore this gives an idea of how much a material can retain/reduce thermal energy; thermal insulation. This heat transfer occurs at a lower rate across materials of low thermal conductivity than that of high thermal conductivity. The lower a material's thermal conductivity, the higher its thermal insulation property.

The thermal behaviour of concrete masonry depends on the conductivity of the concrete material as well as the thermal characteristics of the mass of the concrete. The thermal conductivity of concrete masonry is temperature dependent, and varies in a broad range, 
depending on the type of aggregate, the porosity of the concrete and, until dry, on the moisture content (Buchanan, 2006; Malhotra, 1982). The mineralogical character of the aggregate largely determines the thermal conductivity for NWC, while with LWC air voids and moisture content mask the effect of aggregate type (Tatro, 2006). It is well known that the thermal behaviour of concrete is related to its density. By lowering the density of concrete, a lower thermal conductivity can be achieved (Al-Jabri, et al., 2005). Generally, NWC has a higher density as compared to LWC (Harper, 2004), therefore, it is expected that LWC will have a lower thermal conductivity as compared to NWC. This could also be attributed to the low thermal conductivity of air, which occupies a considerable mass within lightweight concrete (Neville, 2002).

LWC can be easily produced using lightweight aggregates. Research work reported by Buchanan (Buchanan, 2006) recorded that concrete made from lightweight aggregates exhibit the lowest thermal conductivity of about $0.8 \mathrm{~W} / \mathrm{mK}$ as compared to calcareous aggregate concrete which record approximate values of about $1.3 \mathrm{~W} / \mathrm{mK}$ and that of siliceous (normal weight aggregates) being $1.6 \mathrm{~W} / \mathrm{mK}$. This implies that using lightweight aggregates would reduce the thermal conductivity of normal weight concrete by half the original value. As stated previously, the thermal conductivity is temperature dependent and as can be observed from Figure 2-4 (values obtained from EC2, 1993), an increase in temperature causes a decrease in the thermal conductivity. At temperature range of $800^{\circ} \mathrm{C}$ to $1200^{\circ} \mathrm{C}$, no significant change in the thermal conductivities is observed. 


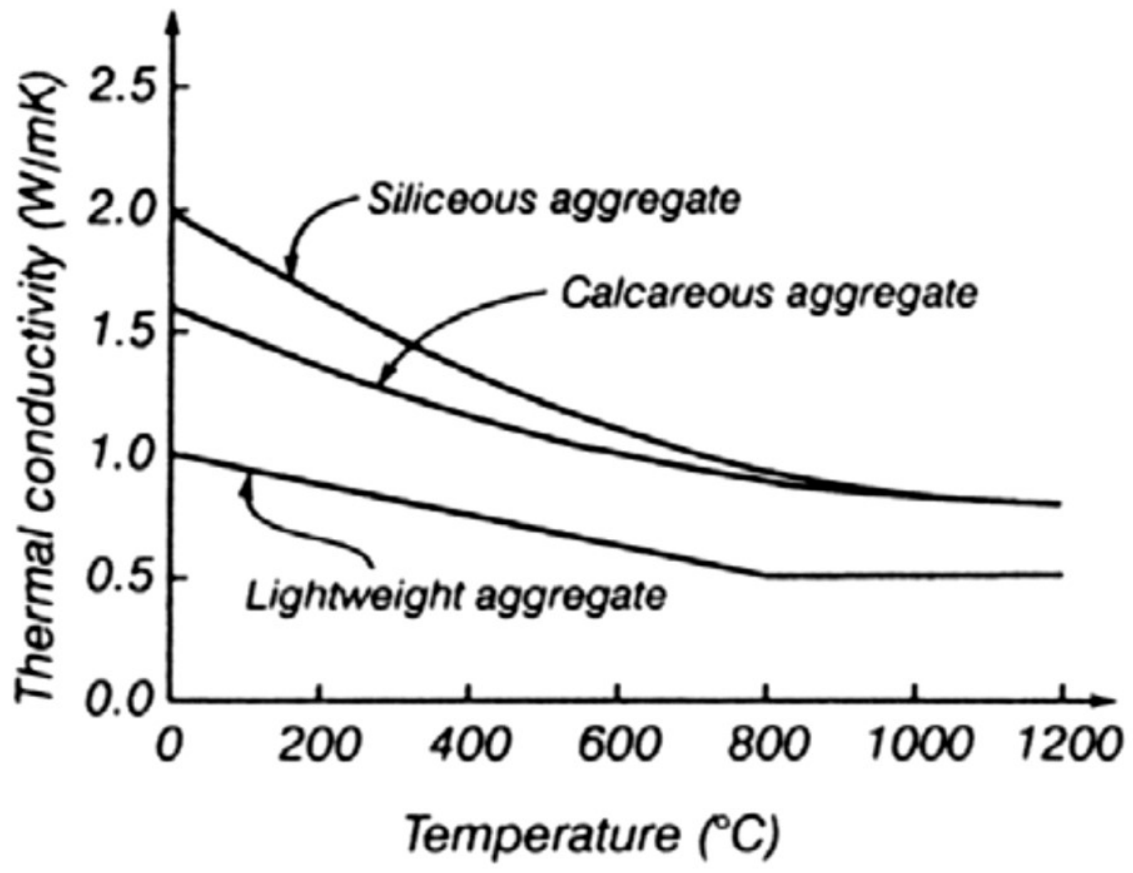

Figure 2-4: Thermal conductivity of concrete (Reproduced from (EC2, 1993) (Buchanan, 2006)

Based on this, it would be observed that at higher temperatures, LWC would record lesser thermal conductivity values. This becomes more advantageous in its usage since the thermal conductivity is related to the thermal insulation property of the concrete as well. Low thermal conductivity is equivalent to high thermal insulation. High thermal insulation of a building would further infer a drastic reduction in heat transfer between objects in thermal contact or through radiative influence.

Therefore, adopting the use of lightweight concrete to produce masonry blocks for nonload bearing walls will enhance the overall thermal insulation when exposed to elevated temperatures. 


\subsubsection{Specific heat capacity}

The thermal properties of concrete masonry influence the rate of heat transfer into it, which under the transient heating conditions experienced in fires and in standard furnace tests, depends not only on the thermal conductivity but also on the specific heat capacity of the material (Malhotra, 1982). This is related to concrete's ability to retain heat and the rate at which it will heat up or cool. The specific heat capacity of concrete masonry varies in a broad range, depending on the moisture content primarily. The mineralogical differences among aggregates have little effect on the specific heat of concrete. From Figure 2-5, it is observed that concrete made from both siliceous and calcareous aggregate record approximate design values of $1000 \mathrm{~J} / \mathrm{kgK}$ (Buchanan, 2006). For concrete made with lightweight aggregate, a low specific heat capacity of $840 \mathrm{~J} / \mathrm{kgK}$ is obtained (Buchanan, 2006). Generally, there is no change in specific heat capacity for concrete made from lightweight aggregates across all temperature ranges; however, for both siliceous and calcareous aggregate concrete there is an increase with increase in temperature.

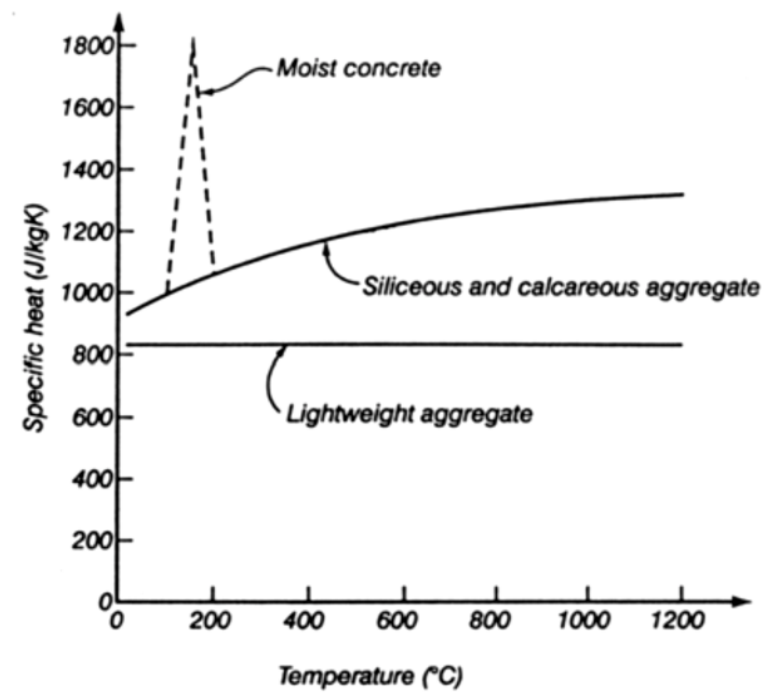

Figure 2-5: Specific heat of concrete (Reproduced from EC2, 1993) (Buchanan, 2006) 
Depending on the moisture content within the concrete masonry mixture, evaporation of the moisture is seen to occur during a temperature range of $80^{\circ} \mathrm{C}$ to $150^{\circ} \mathrm{C}$ (Figure 2-5). This effectively increases the specific heat capacity of the concrete masonry mixture during that duration and this ultimately requires the need of a higher energy to drive out all this moisture, which serves as a positive effect in increasing the fire resistance of the unit. The higher the specific heat capacity of the material, the higher the amount of energy required to heat up the material and in effect a slower rate to cool the material. Therefore, it is essential that concrete structures have high specific capacity rates so that when exposed to elevated temperatures, the heating up period of the structure will be relatively long. It is advantageous in the sense that it gives occupants enough time to escape before undesirable structural failures may occur.

\subsubsection{Thermal expansion}

Thermal expansion is the tendency of a material to change in shape, area, and volume in response to a change in temperature, through heat transfer. Thermal expansion of any material is related to the coefficient of thermal expansion. A coefficient of thermal expansion can be high or low depending on the type of material in question and the mode in which that material reacts when exposed to different temperature ranges. A material with a high coefficient of thermal expansion is one that increases its size significantly with an increase in temperature while a material with a low thermal coefficient decreases its size with an increase in temperature. (Bergman, et al., 2011). The main problem associated with thermal expansion is the induction of thermal stresses due to possible unequal thermal expansion. 
Masonry walls are built around a frame of reinforced concrete members, once heated up, the wall is put into compression due to the forces being exerted on the surface. This could further cause unfavourable conditions if the compressive forces generated are uneven. However, since masonry walls are composed of different materials, which have different magnitudes in terms of their coefficient of thermal expansion, these differences cause unequal expansions to occur. For instance, the mortar does not expand as much as the block units it holds together. This behaviour, coupled with shrinkage from loss of moisture caused by vaporization during its exposure to elevated temperatures, can cause cracks to form at the mortar to block interface. These cracks reduce the bonding between blocks and can greatly reduce the strength of the entire wall.

Furthermore, since aggregates are the main components of any concrete masonry unit and mortar; approximately $80 \%$ of the constituents' structure, they play a vital role in affecting the structural and thermal response of the concrete masonry. For instance, taking the thermal expansion of several concretes formulated from different aggregates into perspective, it showed that the coefficient of thermal expansion for concrete mainly depends on the type of aggregate (Piasta, et al., 1984). The chemical composition and physical structure of concrete will be altered significantly under elevated temperatures. This is because, concrete consist of different materials which have different thermal expansion coefficients and therefore when the temperature of concrete is increased, not only cement hydration products are decomposed but crack occurs within the concrete due to different volume change of component materials, thus reducing its durability (Yoon, et al., 2015). Furthermore, the mineralogy of the aggregates plays a significant role in determining the magnitude of the coefficient of expansion and its subsequent effects on the 
overall thermal stability. For instance, siliceous aggregates have a higher coefficient of thermal expansion as compared to those of calcareous aggregates. Therefore, concrete masonry walls made from siliceous aggregates will have a lower thermal stability than calcareous aggregates (Xing, et al., 2011). From EC2 (1993), the approximate expressions for the coefficient of thermal expansion $(\Delta L / L)$ of concrete show that LWC possesses the least value $\left(8 \times 10^{-6} \mathrm{Tc}\right)$ as compared to normal weight concrete; calcareous $\left(12 \times 10^{-6} \mathrm{Tc}\right)$ and subsequently siliceous aggregate concrete $\left(18 \times 10^{-6} \mathrm{Tc}\right)$; where Tc represents the concrete temperature (Buchanan, 2006). The reason for the low thermal expansion of lightweight aggregate concrete is that these aggregates have been exposed to high temperatures during their formation and production stages. Due to this, these aggregates have a high resistance to volume expansion and decomposition when subjected to elevated temperatures (Turker, et al., 2001). It is known that concretes with lower thermal coefficient of expansion characteristics retain higher bond strength values, which significantly limit the rate of deformation (Malhotra, 1982).

In summary, it is expected that LWC used for concrete masonry walls will be less susceptible to thermal deformation as compared to those made from NWC subjected to elevated temperatures.

\subsection{Types of Mortar used in Masonry Wall Construction}

Mortar is the main component used to bond concrete masonry units in masonry structures. For walls, it primarily holds it together. The compressive strength of a masonry structure depends not only on the brick being used but also on the type and size of mortar between the blocks (Drysdale \& Hamid, 2005). However, the compressive strength of mortar has 
only a small effect on the strength of the wall; it gives it durability (Drysdale \& Hamid, 2005). The main role of mortar is to bond masonry units into a composite assemblage that will withstand the imposed conditions of loads and weather withstand constant conditions of loads and weather. However, it serves the following functions;

i. Serves to bond joint reinforcement and metal ties so that they can act integrally with the masonry (Drysdale \& Hamid, 2005)

ii. Provides a uniform bearing between masonry units (Drysdale \& Hamid, 2005)

iii. Maintain the thermal characteristics of a masonry wall, for instance, heat gain or loss is dependent on openings, which can be an extent minimized by the presence of well-constructed mortar joints (Patnayaka, 2013)

iv. Maintain the sound insulation of a masonry wall through the reduction of greater pores which serve as transmission routes for the sound (Patnayaka, 2013)

v. Prevent the transmission of moisture from penetrating through the joints in the wall during heavy rains and flooding (Patnayaka, 2013)

vi. Compensates for minor dimensional variations in the masonry units, thereby providing coursing adjustment to meet required dimensions (Patnayaka, 2013)

vii. Contributes to the architectural quality of the masonry assembly both through colour and shadow (Patnayaka, 2013)

There are four types of mortar as classified by the ASTM; M, S, N and O. These four types of mortar can be made with Portland cement, masonry cement, mortar cement or blended cements some of which are combined with hydrated lime (Drysdale \& Hamid, 2005). Each mortar type has basic characteristics; 
i. Type M mortar - High compressive-strength mortar, but not very workable

ii. Type S mortar - General all-purpose mortar with higher flexural bond strength

iii. Type $\mathrm{N}$ mortar - General all-purpose mortar with good bonding capabilities and workability

iv. Type O mortar - Low-strength mortar, used mostly for interior applications and restorations

\subsubsection{Types of mortar joints and joint profiles used for masonry wall construction}

In masonry, a course is a continuous horizontal layer of similarly sized building materials; bricks or blocks. Courses are connected horizontally by a layer of mortar, which are known as the bed joints. Bed joints are created by the placement of mortar above and below the face shells of the concrete masonry blocks. The vertical joint between two masonry units that is perpendicular to the face of the wall is known as the head joint. These two joints are primarily the main types of joints created in a masonry wall. In addition, these joints in blockwork take up a considerable amount of the wall's surface area and therefore have a significant influence on the wall's overall appearance. Some mortar joints profiles accentuate their individual designs, while others merge the blocks and mortar to form a flush, homogeneous surface. Figure 2-6 highlights a few of these joint profiles, which contribute to the architectural quality of the masonry assembly through both colour and shadow. 


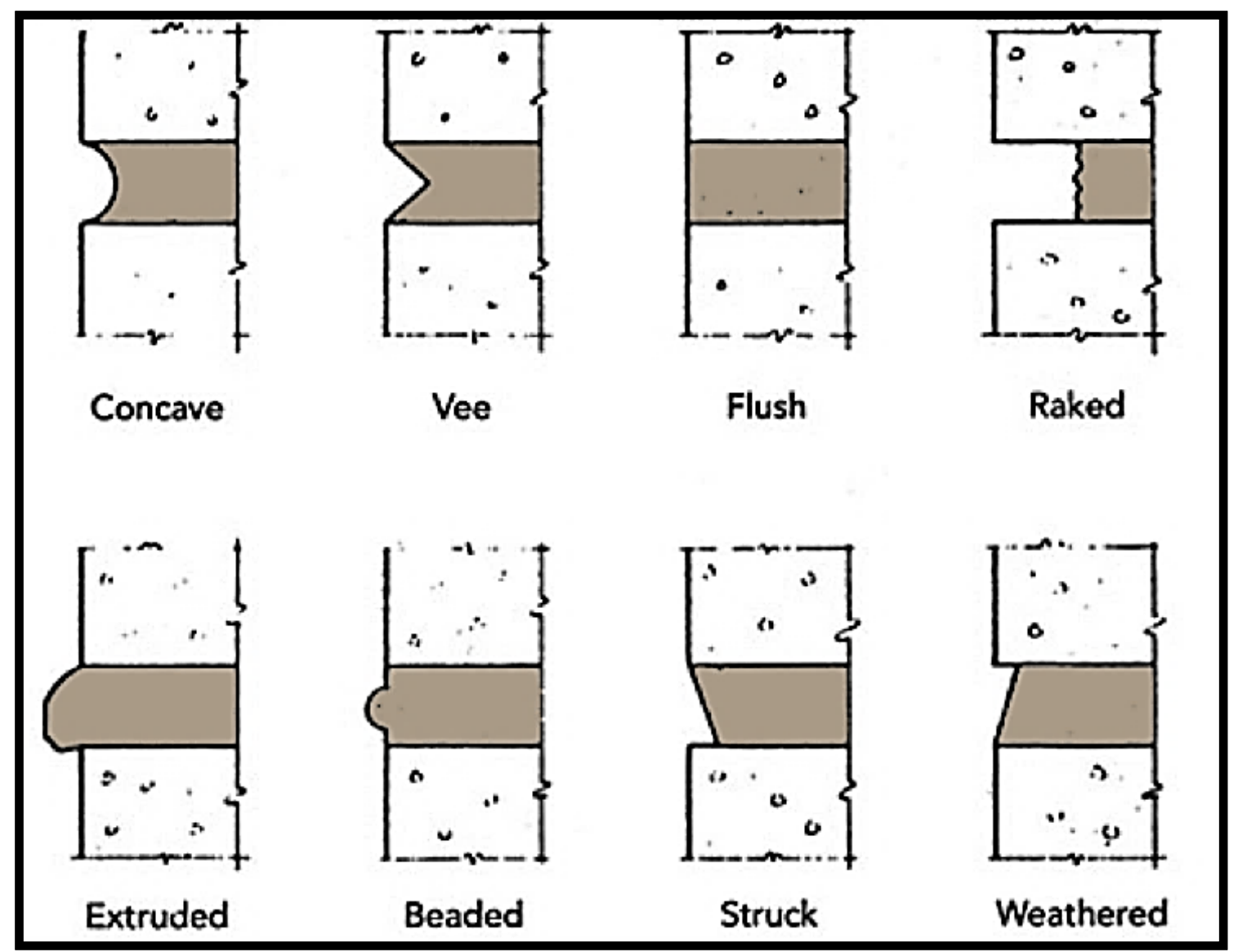

Figure 2-6: Types of Joint Profiles used in Masonry Wall Construction (Sisson, 2017)

1. Concave joint: This common type of joint is formed in mortar with the use of a curved steel jointing tool. Concave joints are very effective at resisting rain penetration due to the recessed profile and tight seal formed by the compacted mortar (Trisco Systems, 2016). Patterns are emphasized on a dense, smooth surface, and small irregularities are hidden (Sisson, 2017). It is recommended for use in walls exposed to wind driven rain.

2. Vee-joint: This type of joint can be made with either a $\mathrm{V}$-shaped jointer or a trowel soon after the masonry blocks are laid. Ornamental and highly visible, the joint conceals small irregularities and is highly attractive. Just as the concave joint, the Vee -joint is water-resistant because its formation compacts the mortar and its shape 
directs water away from the seal (Trisco Systems, 2016).

3. Flush joint: When walls are intended to be plastered or joints are to be hidden under paint, the flush joint is used (Trisco Systems, 2016). However, it is less waterresistant than some of the other mortar joint profiles because the mortar is less compacted. It is recommended for use on walls that are to receive additional finishes (Sisson, 2017).

4. Raked joint: Mortar is scraped out to a consistent depth. Though often left roughened, it can be compacted for better water-resistance. This design highly emphasizes the joint and is sometimes used in modern buildings to match the historic appearance of their locales. Unless it is compressed, it is not as waterresistant as other mortar joints because the design incorporates ledges, which will collect water as it runs down the wall (Sisson, 2017). In addition, when mortar is removed from the joints, it becomes smeared on the surfaces of the brick at the recesses. To remove the mortar, contractors often aggressively clean the walls with pressurized water or acid solutions, which can open additional voids and increase the possibility of water penetration (Trisco Systems, 2016).

Raked joints are commonly used for aesthetic purposes; however, they have been thought to reduce the fire resistance of masonry (Drysdale \& Hamid, 2005). Since mortar is scraped at a consistent depth, it creates potential points of failure and allows for thermal bridging. Thermal bridging of mortar is a phenomenon where the area around the mortar has the possibility of having a significant higher heat transfer than the surrounding materials (concrete block) resulting in an overall reduction of the thermal insulation of the wall (Cash, 1997). 
5. Extruded (squeezed) joint: No tooling and is formed naturally as excess mortar is squeezed out from between the bricks for this joint. The result is a rustic, textured appearance. This design is not recommended for exterior building walls due to the tendency for exposed mortar to break away, degrading the wall's appearance (Trisco Systems, 2016).

6. Beaded joint: This is formed by raising a rounded, bead-shaped segment of the mortar away from the mortar surface, which produces this old-fashioned, formal design. Although beaded joints can create interesting shadows, they are not suitable for exterior use due to their exposed ledges (Trisco Systems, 2016).

7. Weather joint: Mortar is recessed increasingly from the bottom to the top of the joint, with the top end not receding more than $3 / 8$-inch into the wall. The straight, inclined surfaces of the bed (horizontal) joints tend to catch the light and give the brickwork a neat, ordered appearance. This joint is less compacted than the concave and Vee-joints, although it is still suitable for exterior building walls (Trisco Systems, 2016).

8. Struck joint: This joint is formed in a similar way as the weathered joint, except that the bottom edge, instead of the top edge, is recessed. It is a very poor insulator against water, as it will allow water to collect on its bottom ledge (Trisco Systems, 2016).

\subsection{Thermal Properties of Mortar at Elevated Temperatures}

The thermal conductivity and specific heat capacity of mortar when subjected to elevated 
temperatures are discussed in this section.

\subsubsection{Thermal conductivity of mortar}

(Cerny, et al., 2003) investigated the thermal conductivity of cement mortar from specimens subjected to four types of pre-treatment. These pre-treatments included;

i. Specimens at room temperature not exposed to any load (NL)

ii. Specimens exposed to a gradual temperature increase up to $800^{\circ} \mathrm{C}$ for 2 hours and further left for another 2 hours at $800^{\circ} \mathrm{C}$, but without prior mechanical load (TL)

iii. Specimens exposed to a mechanical load of $90 \%$ of compressive strength but without thermal load (ML)

iv. Specimens exposed to a mechanical load of $90 \%$ of compressive strength initially, then to a gradual temperature increase up to $800^{\circ} \mathrm{C}$ over 2 hours and finally left for a further 2 hours at $800^{\circ} \mathrm{C}(\mathrm{MTL})$

Mortar samples were prepared from Portland cement, natural quartz sand and water. Samples were $71 \times 71 \times 71 \mathrm{~mm}$ for the measurement of high-temperature thermal conductivity. The thermal conductivity was determined by applying a mathematical approach; double integration method. The double integration method was used based on the analysis of the temperature field. Full details of this method are discussed in (Cerny, et al., 2000). The primary principle of this method consists of measuring the temperature field in the sample during one sided heating, and of the subsequent solution of the inverse heat conduction problem (Cerny, et al., 2003). This method requires that the density and specific heat of the material as functions of temperature must be known.

Results from the test showed that the thermal conductivity of mortar samples TL, ML and 
MTL were significantly affected due to their pre-treatment methods. TL samples recorded the highest thermal conductivity at $800^{\circ} \mathrm{C}$ as compared to all samples. MTL samples recorded values of $10 \%$ to $30 \%$ lower than the TL samples. ML and NL samples on the other hand, recorded the lowest conductivity values (Figure 2-7).

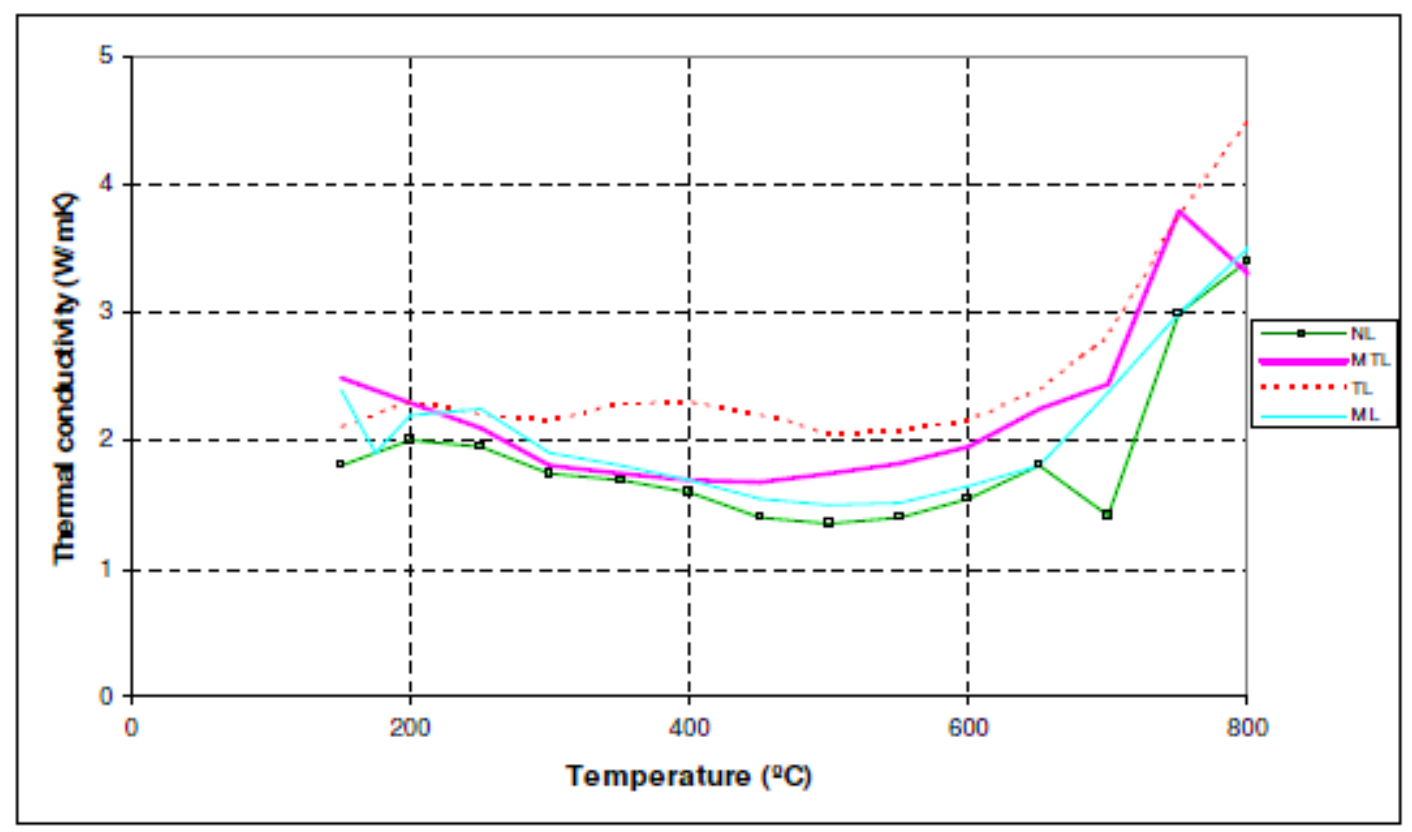

Figure 2-7: Thermal conductivity of mortar at high temperatures, (Cerny, et al., 2003)

\subsubsection{Specific heat capacity of mortar}

The specific capacity of cement mortar was determined in the temperature range of $25^{\circ} \mathrm{C}$ to $800^{\circ} \mathrm{C}$ by (Podebradska, et al., 2003; Toman, et al., 2007; Cerny, 2008). The specific heat capacity was determined through a nonadiabatic process developed by (Toman \& Cerny, 1995). A nonadiabatic process occurs when there is transfer of heat and matter between a system and its surrounding. This process was used because, in measuring hightemperature specific heat capacity of building materials, they require relatively smaller samples as compared to an adiabatic process (Podebradska, et al., 2003). Mortar samples were prepared $71 \times 71 \times 71 \mathrm{~mm}$ and heated to a predetermined temperature of $800^{\circ} \mathrm{C}$, and 
from this step, various heat calculations were performed to obtain the actual specific heat capacity of the mortar samples (Podebradska, et al., 2003). The specific heat had a constant increment in the temperature range of $25^{\circ} \mathrm{C}$ to $600^{\circ} \mathrm{C}$; this could be attributed to the effects of the aggregates properties and/or the amount of moisture content within the mortar samples. The mortar samples, gradually decreased in specific heat capacity after the peak temperature of $600^{\circ} \mathrm{C}$ (Figure 2-8).

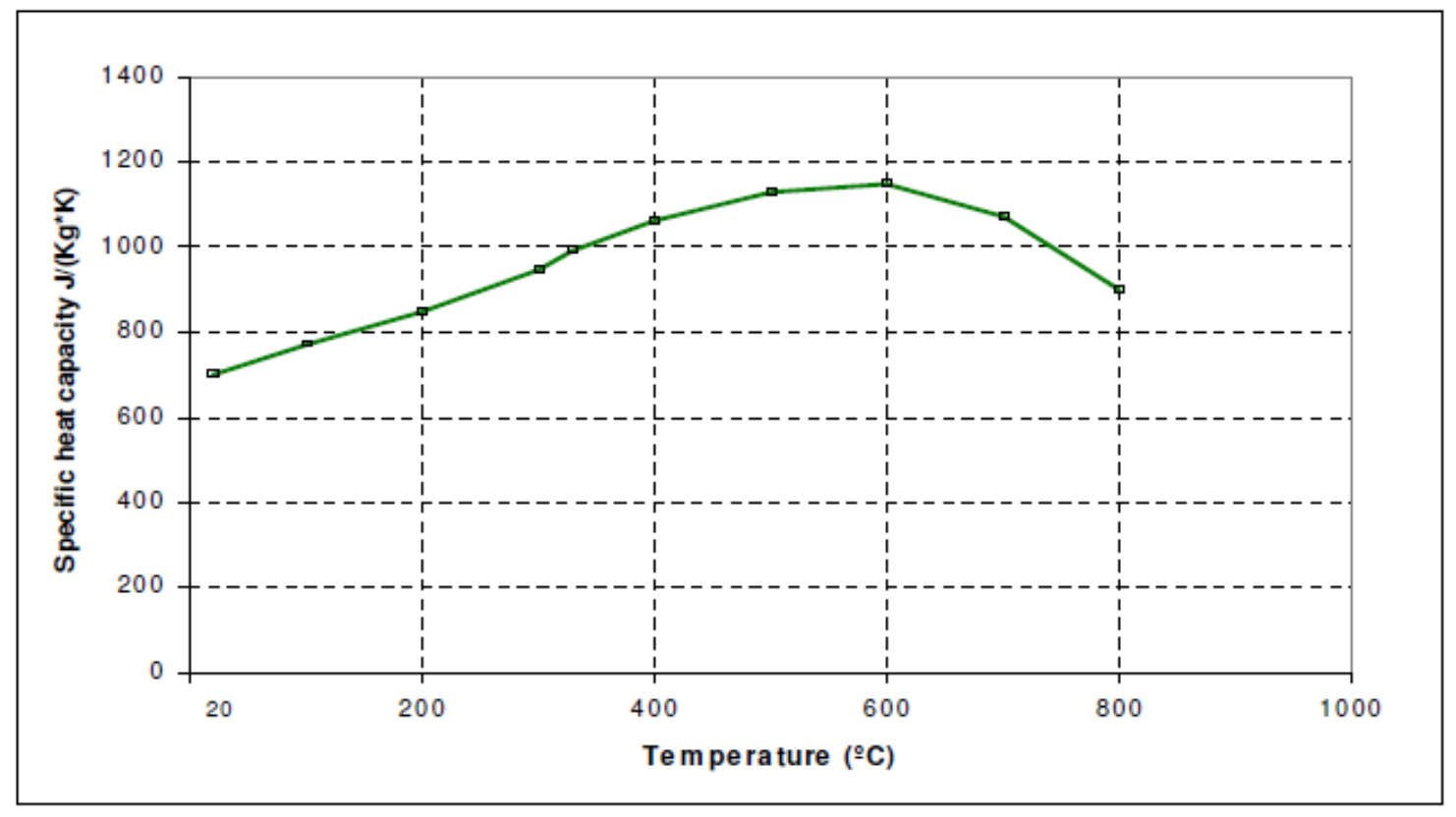

Figure 2-8: Specific heat capacity of mortar at high temperatures (Cerny, 2008)

However, studies conducted by (Wang, 1995) and, (Ang \& Wang, 2004), suggests that the specific heat capacity of mortar and other construction materials with relative high moisture content should be calculated in two parts. The base value corresponding to a mixture of the dry components and the effect of water evaporation. The base value of the dry components may be calculated using the mixture law as seen in Equation 2-2 (Wang, 1995): 


$$
C_{p}=\sum_{i=1}^{n} F_{i} C_{p i}
$$

Where;

$C_{p}=$ overall specific heat capacity, $F_{i}=$ weight fraction of each component, $C_{p i}=$ component specific heat

To calculate the component of effect of water evaporation, this has been illustrated in Figure 2-9 and the use of Equation 2-3.This component was considered because many previous studies (Taylor, 1992; Noumowe, 1995) have assumed that water is simply evaporated at the evaporation temperature range. Consequently, the area within the triangle, Figure 2-9, is the latent heat of evaporation of water.

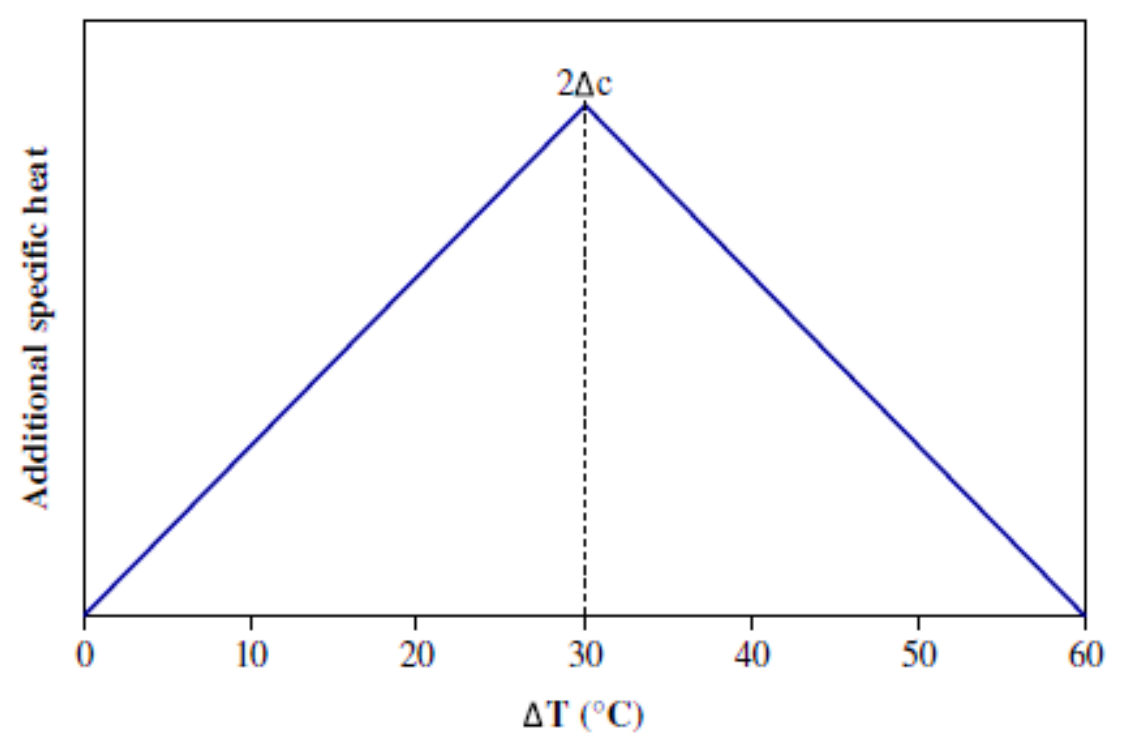

Figure 2-9: Additional specific heat for evaporation of free water, (Ang \& Wang, 2004)

Studies done by Wang (Wang, 1995) suggested that due to water movement, this was insufficient and therefore a higher value of specific heat should be applied. This theory was further confirmed by (Ang \& Wang, 2004) who carried out a combined heat and mass 
analysis. This was computed in (Othuman \& Wang, 2011) as;

$$
\Delta c=\frac{2.26 \times 10^{6}}{\Delta T} \times e \times f\left(J / k^{\circ} \mathrm{C}\right)
$$

Equation 2-3

Where;

$\Delta c=$ average additional specific heat, $\Delta T=$ the magnitude of the temperature interval during which water is evaporated, $e=$ dehydration water content (percentage by total weight), $f$ = modification factor accounting for water movement.

A value of $f=1.4$ was chosen by (Ang \& Wang, 2004) as studies confirmed that this value was found to be relatively insensitive to different values of permeability provided the permeability is high. Mortar mixtures have been found to have quite significant permeability characteristics and therefore this value was adopted in this present research work. In calculating the total value of specific heat, previous literature, including fire resistance design codes for concrete, only considers the first phase of dehydration and this is due to the evaporation of free water. Therefore, this average additional specific heat capacity is added to the specific heat obtained from the first phase of dehydration.

\subsection{Modes of Heat Transfer in Masonry Walls}

Heat is transferred through materials in different mediums, which converts the heat energy from one state to another. A typical fire scenario is a condition where heat transfer is considered to occur between the materials in or not in contact. There are three modes of heat transfer namely; Conduction, Convection and Radiation (Buchanan, 2006). 


\subsubsection{Conduction}

Conduction is a mechanism of heat transfer in solid materials. This is an important factor when considering the ignition of solid surfaces, and in the fire resistance of barriers and structural members. In the case of masonry walls, conduction of heat will occur within the solid sections of the block units; face shell, webs, and the mortar joints. Conduction occurs based on the result of a material's ability to allow molecules to transfer energy across them. The physical properties of the materials determine whether they are good or bad conductors of heat. Generally, good heat conductors transfer heat through materials quickly while bad conductors transfer heat slowly. Concrete masonry is a poor conductor of heat and therefore the transfer of heat energy within concrete masonry members is slow. The governing equation for conduction in a steady-state situation is given in Equation 2-4. (Buchanan, 2006)

$$
\dot{q}^{\prime \prime}=k \frac{d T}{d x}
$$

\section{Equation 2-4}

Where;

$\dot{q}^{\prime \prime}=$ heat flow per unit area $\left(\mathrm{W} / \mathrm{m}^{2}\right), k=$ thermal conductivity $(\mathrm{W} / \mathrm{mK}), T=$ temperature $\left({ }^{\circ} \mathrm{C}\right.$ or $\left.\mathrm{K}\right), x=$ distance in heat flow direction $(\mathrm{m})$.

The Fourier law of conduction within solid materials includes the effects of a cross sectional area normal to the direction of heat flow (A) of the solid materials, Equation 2-5.

$$
\dot{q}^{\prime \prime}=k A \frac{d T}{d x}
$$

Equation 2-5

In transient heat flow when temperatures are changing with time, the amount of heat required to change the temperature of the material must be included (Buchanan, 2006). A typical transient heat flow state is observed when standard fire resistance tests are 
performed. For one dimensional heat transfer by conduction in a material with no internal heat being released, the governing equation is, Equation 2-6 (Buchanan, 2006). In this case, the effects of thermal diffusivity $(\alpha)$ is included, all other parameters have the same definitions as previously noted.

$$
\frac{\delta^{2} T}{\delta x^{2}}=\frac{1}{\alpha} \frac{\delta T}{\delta x}
$$

\section{Equation 2-6}

Although, these equations may be beneficial in performing conductive heat transfer problems, it becomes complex when dealing with a mass heat transfer for instance, masonry wall assemblies.

\subsubsection{Convection}

Convection uses the motion of fluids to transfer heat. In a typical convective heat transfer, a hot surface heats up the surrounding fluid, which is then transmitted away by fluid movement such as the wind. This is in effect replaces the warm fluid by a cooler fluid, which draws more heat energy away from the surface (Buchanan, 2006). The rate of heat transfer is enhanced since the cooler fluid constantly replaces the heated fluid. In concrete masonry, the sources of fluids are the air in the cells of blocks, the hot air generated from the exposed side and that of the ambient air on the unexposed side. The magnitude of the heat being transferred depends on the nature of flow, geometry of the surfaces, and the thickness of the boundary layer (Buchanan, 2006). This is governed by Equation 2-7. Masonry block cells are constructed in different geometries depending on the function of the block unit. Therefore, this becomes an important parameter in evaluating the rate of convection within the cells during a fire standard test. The convection coefficient is the parameter, which significantly affects the magnitude of convection. The convection 
coefficient is the measure of how effectively a fluid transfers heat by convection. There are two types of convection; natural and forced (Bergman, et al., 2011). Natural will occur by variation of densities of the fluids in question. This is because, once temperature increases, the density decreases and this variation in density will eventually force the fluid to move through the volume (Bergman, et al., 2011). Forced convection on the other hand, requires the use of an external means to cause fluid movement (Bergman, et al., 2011). This can be achieved by using a pump or a blower. In the case of fire resistance tests performed on masonry wall assemblies, convection is caused by the effects of forced means. This is because blowers, which have been attached to the experimental set up, cause the temperature rise within the masonry assembly.

$$
\dot{q}^{\prime \prime}=h \Delta T
$$

Equation 2-7

Where;

$\dot{q}^{\prime \prime}=$ heat flow per unit area $\left(\mathrm{W} / \mathrm{m}^{2}\right), h=$ convection coefficient of heat $\left(\mathrm{W} / \mathrm{m}^{2} \mathrm{~K}\right)$, $\Delta T=$ temperature difference between exposed and unexposed surfaces.

\subsubsection{Radiation}

Radiation heat transfer does not require a medium to pass through. It is the form of heat transfer that occurs within a vacuum, a transparent solid or liquid (Buchanan, 2006). However, it occurs most efficiently in a vacuum. Radiation occurs by using electromagnetic waves which travels at the speed of light and the heat energy is emitted when temperature is above $0 \mathrm{~K}\left(-273^{\circ} \mathrm{C}\right)$ (Bergman, et al., 2011). Radiation is extremely important in fires since it is the main mechanism for heat transfer from flames to fuel surfaces, from hot smoke to building objects, and from a burning building to an adjacent 
building (Buchanan, 2006). In masonry walls, radiation occurs within the cells of the blocks, as well as the exposed side to the unexposed side. Radiation is governed by Equation 2-8. It is dependent on a configuration factor; the measure of how much of the emitter is "seen" based on the size and distance by the receiving surface, and the emissivity of the materials (Buchanan, 2006)

$$
\dot{q}^{\prime \prime}=\varphi \varepsilon \sigma\left(T_{e}{ }^{4}-T_{r}{ }^{4}\right)
$$

\section{Equation 2-8}

Where;

$\varphi=$ configuration factor, $\varepsilon=$ emissivity, $\sigma=$ Stefan-Boltzmann constant $\left(5.67 \times 10^{-8}\right.$

$\left.\mathrm{W} / \mathrm{m}^{2} \mathrm{~K}^{4}\right), T_{e}=$ absolute temperature of the emitting surface $(\mathrm{K}), T_{r}=$ absolute temperature of the receiving surface $(\mathrm{K})$

\subsubsection{Methods of improving heat flow in masonry walls}

The main modes of heat transfer through masonry walls when exposed to elevated temperatures is by convection and radiation (Nguyen \& Meftah, 2012; Mariyana, et al., 2015). However, at ambient conditions or low temperatures, conduction is usually the governing factor. At elevated temperatures, these heat effects can be effectively decreased by increasing the thickness of the wall, incorporating insulating materials or additives, changing the mix designs of block units and mortar, changing the geometries of the block units or masonry wall assemblage etc. These are done primarily to achieve better thermal properties of the masonry block or mortar. It could either increase the specific heat capacity or lower the thermal conductivity of these materials. For instance, in increasing the thickness of the wall, more material is available and therefore, when the wall is heated up, it will require more energy to go through the thicker material than a significant thinner 
material. This method though simple, can effectively decrease the rate of heat flow through the wall. This is because it takes the wall a longer time to heat up with conduction and causes a reduction in the radiation of heat through the cells. On the other hand, it is not cost effective since it requires more material to construct as well as takes up more space within the room. Therefore, the choice of an appropriate method will depend on the cost involved and the overall magnitude of heat flow reduction provided in adopting such a method.

\subsection{Mechanical Behaviour of Masonry Walls at Ambient Temperatures}

Masonry walls are composed of composite materials; block units, mortar and in some cases grout and reinforcement. A comprehensive understanding of the behaviour of masonry walls as a unit will depend on the behaviour on the individual components and their interactions with each other (Drysdale \& Hamid, 2005; Hendry, et al., 2004). The mechanical behaviour of the block units and mortar are discussed in section 2.5 .

The overall strength of the wall can be reduced significantly when the effective height (relative to the effective thickness) is increased. The effective height of a masonry wall $\left(h_{e f}\right)$ is defined using Equation 2-9 (Drysdale \& Hamid, 2005) .

$$
h_{e f}=k h
$$

\section{Equation 2-9}

Where;

$k=$ effective height factor, $h=$ height of wall

The effective height factor accounts for end conditions; restrained and/or unrestrained at the top and bottom of the wall. The reduction in strength is attributed to buckling failure, which is known to occur in most cases. Buckling failure is characterized by a sudden sideways failure of a structural member subjected to high compressive stresses. The 
compressive stress at the point of failure is less than the ultimate compressive stress that the material is capable of withstanding (Casandijian, et al., 2013).

In addition, the effects of adopting a type of mortar would increase or decrease the strength of a masonry wall. High strength mortar increases the strength of masonry walls and vice versa (Hendry, et al., 2004). However, when high strength mortars are used, the block units must be of low strength. Furthermore, the thicker the mortar joints, lower strengths are produced in the masonry walls, Figure 2-10, study done by (Drysdale \& Hamid, 2005).

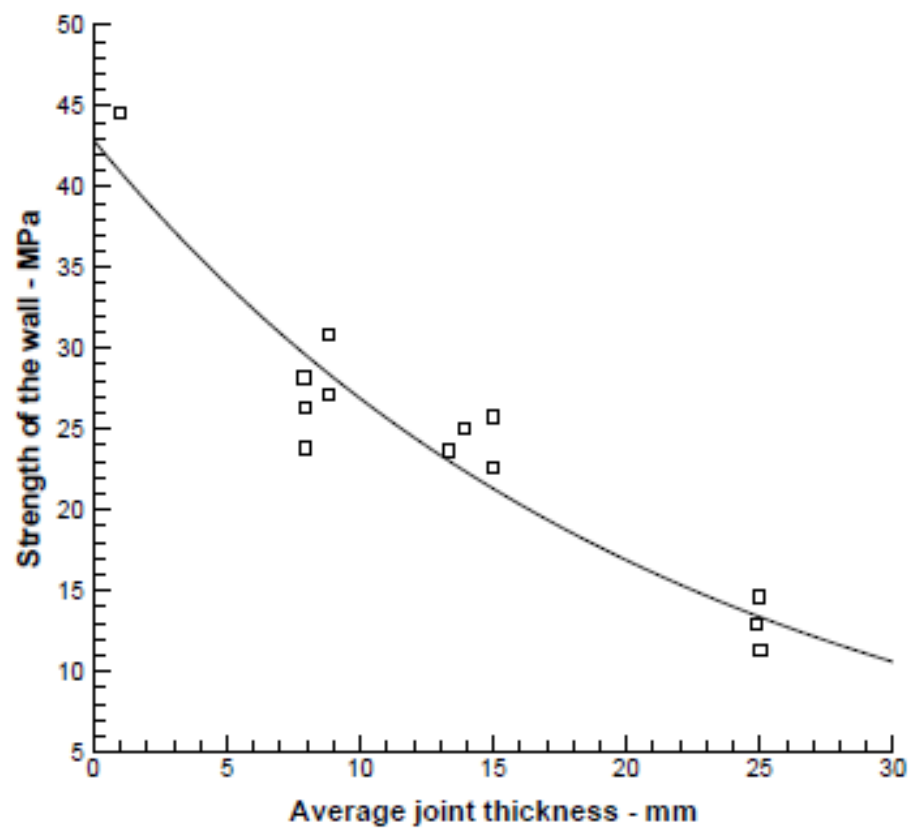

Figure 2-10: The effect of mortar joint thickness on the compressive strength of a masonry wall using brick units with a strength of 55.7 MPa, (Drysdale \& Hamid, 2005)

\subsection{Thermal Behaviour of Masonry Walls at Elevated Temperatures}

When masonry walls are subjected to elevated temperatures, the three criteria as discussed previously in section 2.2.1 is of importance to assess its behaviour. The insulation criterion represents the time elapsed from the beginning of exposure to elevated temperatures during 
which the masonry wall maintains its separation function so that the average temperature at the unexposed surface is not greater than the initial average temperature plus $140^{\circ} \mathrm{C}$. In addition, the developing temperature of the unexposed surface of the masonry wall at any location does not exceed the initial average temperature plus $180^{\circ} \mathrm{C}$. In masonry walls, the integrity criterion refers to the ability of the wall to preserve its separation role without causing ignition of any material through the formation of cracks and fissures to subsequently result in flame spread. The load bearing capacity represents the ability of the masonry wall to withstand applied loads during its exposure to elevated temperatures. It is essential that all criteria be met, otherwise the wall is deemed to have failed. However, concrete masonry walls or partition, which are not part of the main loadbearing structures do not require structural design. The fire resistance requirements can be made for provisions, which meet the insulation criterion.

At elevated temperatures, masonry block units and mortar joints are heated up. The thermal properties of the individual components have a significant effect on its overall behaviour. Density, specific heat and thermal conductivity are the primary thermal properties in a typical heat transfer exposure. These properties have been discussed in detail for both concrete masonry blocks and mortar in sections 2.6 and 2.8. The combined effects generated from these components is the overall thermal behaviour observed within the masonry wall.

\subsection{Problems Associated with Masonry Walls exposed to Elevated Temperatures}

Masonry walls are composed of different units, which are ultimately different in thermal and mechanical properties. Due to these differences, masonry walls are subjected to 
different mechanisms such as thermal bowing, crack formation, and spalling when exposed to elevated temperatures.

\subsubsection{Thermal bowing}

In most fires, walls are subjected to heat on one side, which gives rise to temperature gradient across the thickness of the wall. The thermal gradient thereby causes an uneven expansion inside the wall. This is due to a differential thermal expansion; when exposed surface expands more than the unexposed surface. The exposed surface of the wall also experiences a considerable reduction in the mechanical material properties, which effectively can be represented as a reduction in the thickness of the hot surface (Lawrence

\& Gnankrishnan, n.d.) In the case of concrete masonry, the expansion of the exposed surface results in the bowing towards the heated area relative to the ends of the element unless the element is restrained (Cooke, 1988). The maximum curvature is usually located at the centre of the wall (Figure 2-11). This occurs at a relative fast rate due to the rapid increase in temperature during the exposure. Right after this phase occurs, the shape of the wall recovers because the inner part of the wall increases in temperature, and the Young's modulus decreases at elevated temperatures (Nguyen, et al., 2009). For masonry walls, thermal bowing is particularly important due to its low thermal conductivity thereby producing high thermal gradient across the section of the wall. However, this can be alleviated when design factors such as the provision of a restraint and adopting a material with low coefficient of thermal expansion are considered in the designing the wall (Cooke, 1988). Although adopting materials with low coefficient of thermal expansion can reduce thermal bowing, on the other hand, the walls are susceptible to fail prematurely due to 
integrity failure. Studies conducted show that walls constructed with aggregates possessing low thermal expansion, failed due to integrity (Gnankrishnan \& Lawther, 1990). This is because when the walls are heated up, the mortar is subjected to shrinkage and within this phase the blocks begin to expand laterally, possible cracks are formed which may eventually lead to the failure of the wall (Harmathy \& Allen, 1972; Gnankrishnan \& Lawther, 1990). On the positive side, most non-loadbearing masonry walls are constructed within a frame of reinforced concrete members and therefore act as restraints to prevent the possible failure, which emerges from thermal bowing. This serves as a primary factor, which makes masonry walls less susceptible to fail due to thermal bowing. 


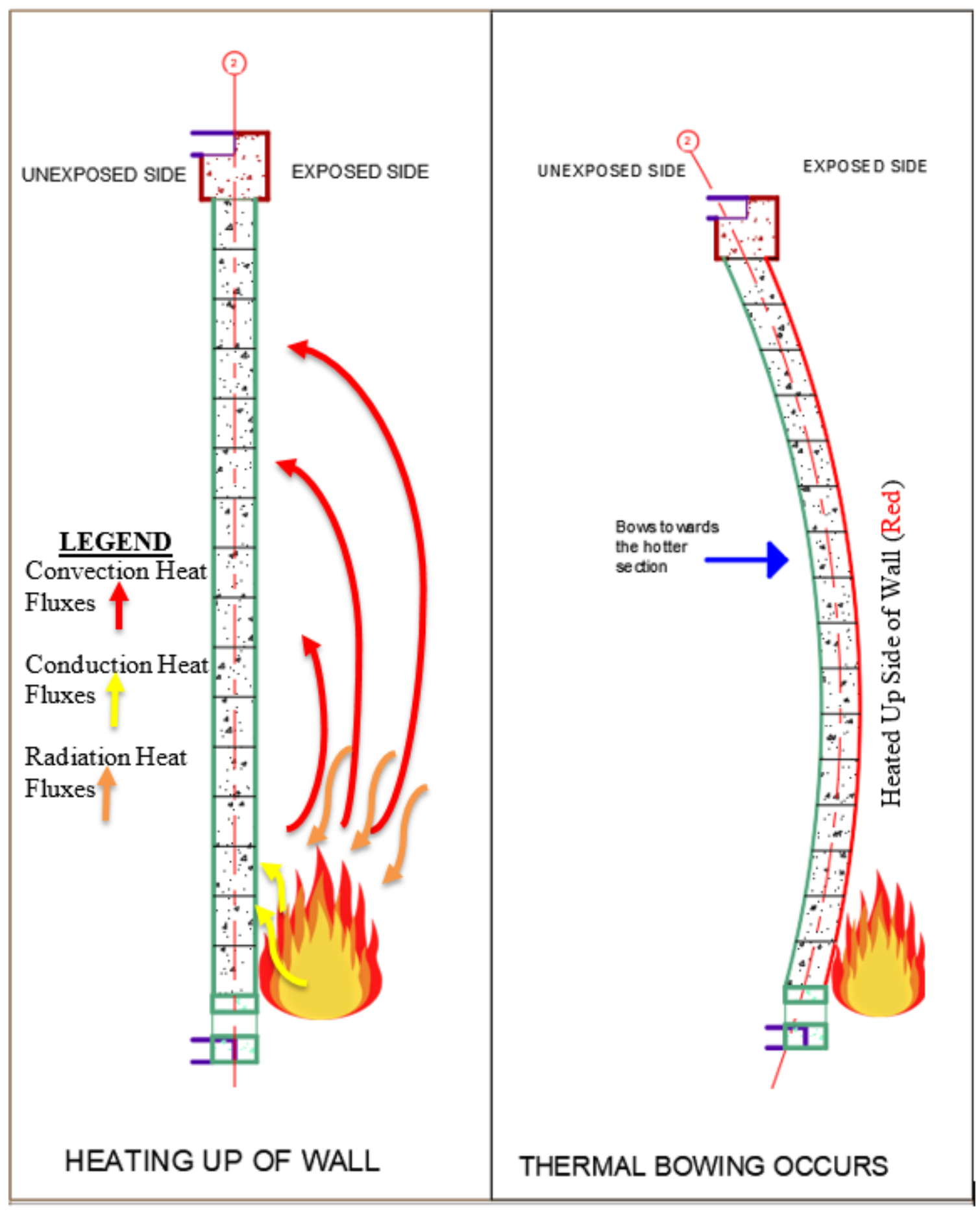

Figure 2-11: Thermal bowing through a section of a wall 


\subsubsection{Crack formation}

Concrete masonry is subjected to crack formation and growth when exposed to elevated temperatures. This is because when masonry walls are heated up, the volatile constituents; moisture and gases within the wall begin to evaporate during the evaporation phase. Depending on the type of concrete mix and its density, the crack formed can be wide enough to cause further detrimental effects. The cracks are formed because of the heated volatile constituent's mode of evaporation to the outer surface. The presence of pores within the concrete masonry creates a pathway for the gases to be evaporated to the outer surface. With a higher density, the pores within the concrete masonry are less in number as compared to block units with a lower density. This eventually results in a complex mode of evaporation as heated gases force their way through the minimal pores to the outer surface. This in turn produces subsequent cracks due to the forcible interactions, which could ultimately grow in width and depth causing further detrimental effects such as spalling. In addition, the amount of moisture within the concrete masonry mix can beneficially delay the temperature rise within the material due to the moisture content requiring a longer duration to evaporate. However, it may lead to more crack formation if the available pores are not efficient in releasing the moisture content to the outer surface due to a pore pressure buildup (Harper, 2004).

\subsubsection{Spalling}

Based on the differences in thermal expansions between the components of masonry walls, the bond strength at the interfacial transition zone (ITZ) at various joints of the wall can be determined. When a weak bond strength forms between the cement paste and aggregates 
due to its exposure to elevated temperatures, thermal deformation of the wall can occur. This could lead to susceptible failure in integrity, which may eventually lead to spalling (Koksal, et al., 2012; Aydin, 2008). Spalling is a rapid physical process of the breakdown of surface layers of concrete, which crumble into small pebble-like pieces in response to high temperatures and/or mechanical pressure. The breakdown of the surface exposes the inner layers of the concrete to high temperatures further, which increases the rate of heat transmission into the inner layers. The physical appearance of spalling may include striated lines, discolouration of the masonry and pitting or rough texture to the concrete. Spalling is caused by heating, mechanical pressure or both (Corbitt-Dipierro, 2016). There are two different types of spalling, Explosive and Slower. Explosive spalling occurs in an initial phase and involves chunks of concrete exploding from the concrete member. Slower spalling, also known as sloughing off occurs after the initial phase as cracks form parallel to the fire exposed surfaces, which causes the separation of the concrete layers and part of the concrete falls off eventually (Ingham, 2009). In Pope's experimental work (Pope \& Zalok, 2017), these two forms of spalling were observed, Figure 2-12 .
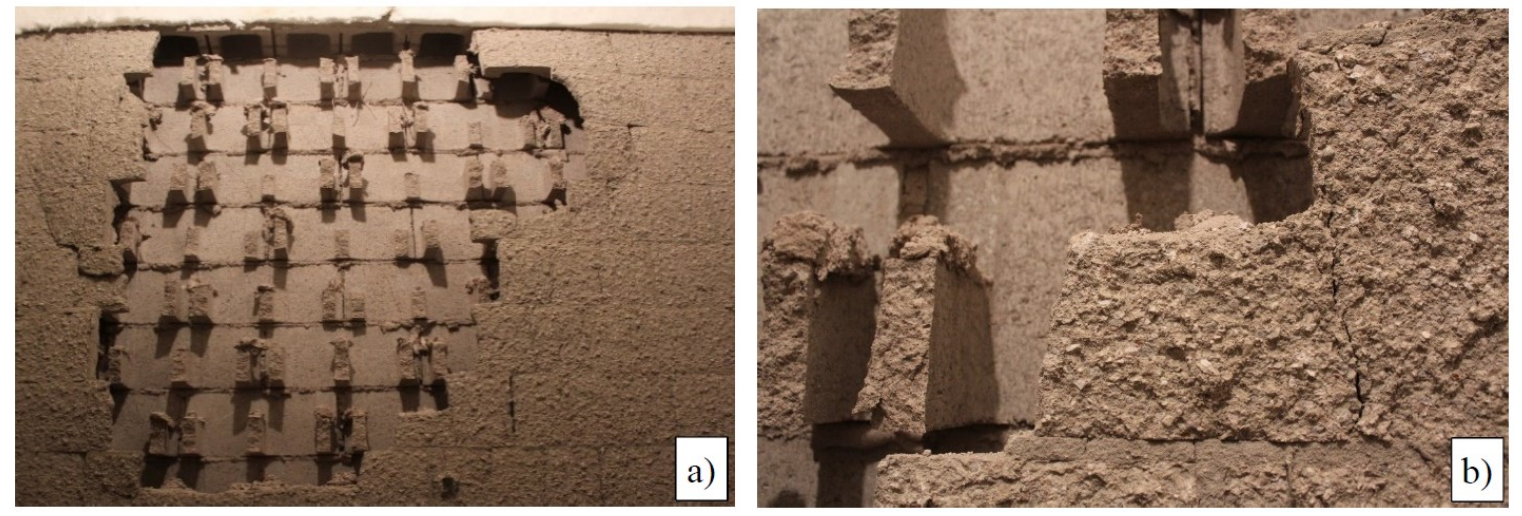

Figure 2-12: a) Masonry spalling (exposed surface), b) Close view of masonry spalling (Pope \& Zalok, 2017)

The likelihood of damage to concrete structures by spalling exists under the transient 
heating condition as steep temperature gradients across the section of the concrete member, which leads to damages in the early stages of fire (Malhotra, 1982). The exact mechanisms of the emerging damage due to spalling remain incompletely understood, with previous research publications indicating contrary results. The current understanding of spalling behaviour includes two mechanisms; a thermo-mechanical and thermal-hygral process (Chen, et al., 2009; Mindeguia, et al., 2010; Khoury \& Anderberg, 2000).

Whether the concrete masonry will spall when heated up is highly variable and depends on the complex interaction of the composition of the concrete material, temperature and temperature change from burning fuel load, configuration of materials, and pressure on the concrete and local conditions (Corbitt-Dipierro, 2016). For instance, based on the composition of the concrete material, it is known that the higher the strength of the concrete, the higher the probability of spalling. This is because high strength concrete possesses a lower porosity and therefore internal vapour pressure built up cannot escape due to the minimal availability of pores (Phan, 2008). In addition, resistance to spalling during a fire is also a main function of the moisture content within the concrete. The higher the moisture content within the concrete mixture, the higher the probability of the concrete been susceptible to spalling. For instance, when concrete is "green" meaning recently poured, it is more likely to spall because its water content is higher than concrete that has cured (Lotfy, et al., 2016). LWC is very porous and therefore will easily allow the evaporation of moisture as compared to NWC, which is denser. However, if LWC possess more water due to saturation of aggregates, the chance of spalling is high.

Fibre reinforcement is an effective and efficient method of reducing the probability of spalling in concrete masonry structures. Conventionally, either polypropylene (PP) or steel 
fibres are used. Studies have proved that PP fibers melt at very low temperatures and therefore create a pathway within the concrete mix, thereby allowing the passage of vapor pressure during its exposure to elevated temperatures. PP fibres cause a significant reduction in the pore pressure, which stops the concrete from spalling (Won, et al., 2010; Kodur \& Phan, 2007). On the other hand, when steel fibres are used, they increase the strength and ductility of the concrete, and causes a reduction in the crack widths. This eventually, reduces the probability of the occurrence of spalling (Kodur \& Phan, 2007).

\subsection{Methods of improving the fire resistance of concrete masonry - Mix Designs}

Many researchers have investigated and examined various methods of improving the fire resistance of concrete through the variation of mix designs. Reduction of commercial and industrial wastes, processing products of naturally occurring materials and energy efficiency during manufacturing; are factors that have driven researchers in their bid to enhance the fire resistance of most concrete mix designs which can be ultimately used to produce concrete masonry blocks.

\subsubsection{Recycled coarse aggregates (RCA)}

Recent studies show that Canadians produce over 35 million tons of waste, or 1,000 kg per person - up eight per cent from 2004. Of the total, 22 million tons came from nonresidential sources and 13 million tons came from residential sources. Twenty-seven million tons of waste (about 77 per cent) was sent to landfills or incinerators. Out of this $77 \%$ of solid waste that was sent to landfills, approximately $25 \%$ of this value composed of solid waste from construction and demolition sources (Federation of Canadian 
Municipalities, 2009). The construction and demolition waste includes wood, scrap metal, drywall, concrete, brick and various packaging materials (Federation of Canadian Municipalities, 2009).

For many years, the construction industry is faced with this dilemma of waste being produced. RCA can be a promising solution for sustainable development. RCA contain mortar and therefore have very different properties than natural aggregates; they are more porous, have a higher water absorption coefficient and they contain hydrates. In addition, they have twice as many ITZ's which can be found between the mortar and original aggregate and the RCA and the new cement paste. The presence of the many ITZ's serve as weak areas and thereby reduce the overall mechanical strength of the concrete. This is a major drawback with using RCA to produce concrete masonry blocks (Laneyrie, et al., 2016) . However, the following have been observed when recycled concrete (RC) was subjected to elevated temperatures (Zega \& Maio, 2006; Sarhat \& Sherwood, 2013; Vieira, et al., 2011; Zega \& Maio, 2009; Xiao \& Zhang, 2007) .

- $\mathrm{RC}$ show a decrease in its overall mechanical behaviour just as natural concrete

- No explosive spalling has been witnessed in all recycled mixes tested

- RC show better residual mechanical properties when compared to referenced natural concretes.

- $\mathrm{RC}$ with low water to cement (w/c) ratios seem to have better mechanical and thermal properties than natural concretes with high w/c ratios

- RCA obtained from calcareous sources have better thermal stability as compared to sources obtained from siliceous sources. This trend is similar to natural concretes made from both sources. 
Cleo et al. (Laneyrie, et al., 2016) investigated the performance of concretes made from RCA, the sources of these aggregates were from real demolition waste and those sourced from concrete made in a laboratory. The research involved subjecting concrete mixes made from natural crushed silico-calcareous coarse aggregate (SCCA); RCA from concrete made in the lab (LRCA) and RCA from concrete made from an industrial source (IRCA). Samples were composed of either 0.3 or $0.6 \mathrm{w} / \mathrm{c}$ ratio. This was to differentiate between the normal and high-performance concretes. All concrete mixes were subjected to a temperature range of $20^{\circ} \mathrm{C}$ to $300^{\circ} \mathrm{C}$ for evaluating the thermal properties. The thermal properties of interest were the thermal conductivity and specific heat. In conducting tests for the thermal conductivity, the Hot -Disk probe TPS 1500 was used. This followed a method that has been developed by researchers in Chalmers University of Technology. After the tests were conducted, it was observed that generally lower thermal conductivity values were recorded for all RCA samples as compared to the SCCA for both normal and high strength concretes. It was reported that this was due to the high porosity of the RCA. In addition, the thermal conductivity for all samples decreased as the temperature increased, Figure 2-13. This was attributed to the bound water departure just when temperatures reach the boiling temperature for water. Furthermore, the thermal conductivity of water $(0.6 \mathrm{~W} / \mathrm{mK})$ is higher than that of air $(0.2 \mathrm{~W} / \mathrm{mK})$ and therefore once this is evaporated during the heating process, it further reduces the thermal conductivity. The decrease of the conductive bonds is linked to the decomposition of the hydrates. In comparing the thermal conductivity of IRCA and LRCA samples, it was reported that the thermal conductivity of IRCA samples were far lower than those of LRCA due to the presence of impurities such as wood, brick, plastic thereby lowering the original magnitude 
of the thermal conductivity. Reason being, these impurities have a far lower thermal conductivity as compared to the constituent material in the concrete samples, Figure 2-13. This therefore proves that using materials that already have a low thermal conductivity could significantly alter the thermal conductivity of the entire concrete sample.
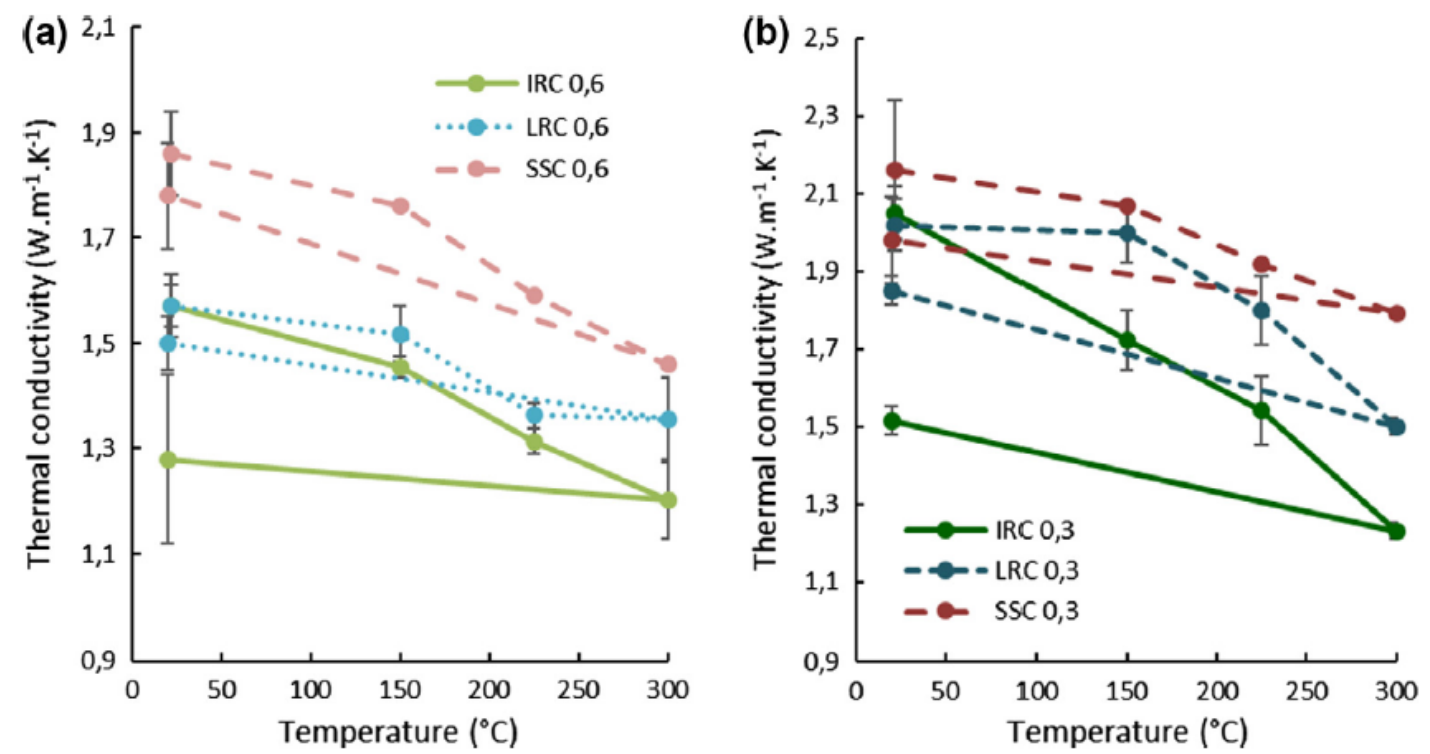

Figure 2-13: Thermal conductivity evolution of (a) normal concretes, and (b) high strength concretes, along with the temperature, during heating at $150^{\circ} \mathrm{C}, 250^{\circ} \mathrm{C}$ and $300^{\circ} \mathrm{C}$ and after cooling (residual) (Laneyrie, et al., 2016)

Specific heat capacity values increased slightly as the temperature was increased, Figure 2-14. This could be linked to the endothermic reactions that occurred during the heating phase as reported in the paper. However, the test procedures require that these be measured after the temperature of the sample has stabilized and therefore all the latent heat of consumption reactions are complete. Preliminary tests reported that RCA samples were high in porosity than SCCA samples, these increases observed in their specific heat could be related to this phenomenon. Furthermore, it was caused by the increases of porosity within the cement paste since the specific heat of air $(1005 \mathrm{~J} / \mathrm{kgK})$ is slightly higher than that of concrete $(880 \mathrm{~J} / \mathrm{kgK})$. For normal strength concretes, the residual values of specific 
heat were approximately the same as those measured for the unheated specimens except for the case of the IRC concrete.

In this case, the higher residual value of average specific heat was likely due to decomposition of the non-cementitious impurities in the IRCA. A similar phenomenon was observed for the high strength IRC as reported in (Laneyrie, et al., 2016).
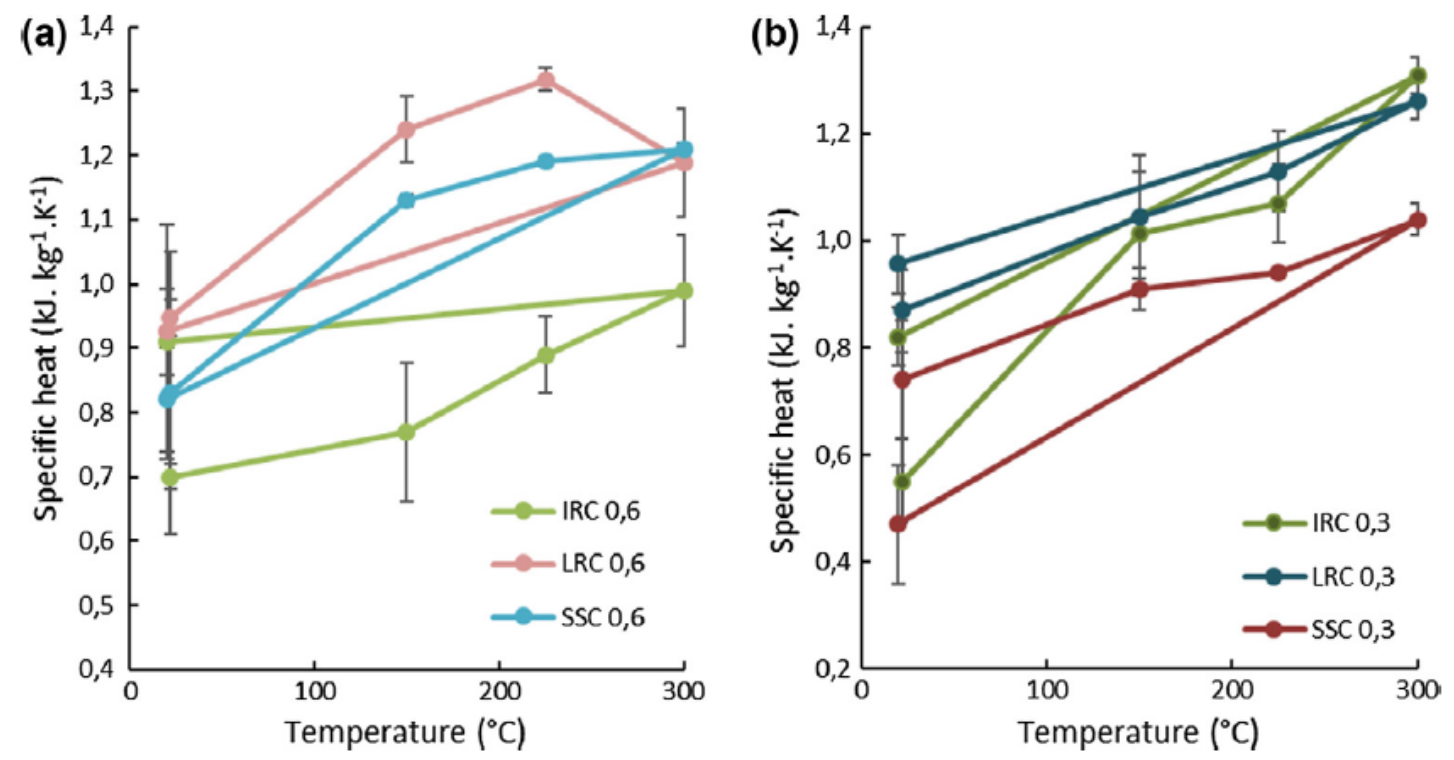

Figure 2-14: Specific heat capacity evolution of a) normal concretes b) high strength concretes along with the temperature, during heating at $150^{\circ} \mathrm{C}, 250^{\circ} \mathrm{C}$ and $300^{\circ} \mathrm{C}$ and after cooling (residual) (Laneyrie, et al., 2016)

As previously mentioned, the thermal conductivity and specific heat capacity of concrete masonry play an integral role in determining the fire resistance of the concrete masonry member, assembly or structure. Low values of thermal conductivity and high specific heat capacity values reduce the probability of these members reaching the failure insulation criterion quickly. This is because, members require more energy to heat up and with a low thermal conductivity, the transfer of this heat energy is at a slower rate as compared to a material with high thermal conductivity. Analyzing these two thermal properties in perspective, the direct outcome is a reduced heating time and eventually buying time for 
occupants to escape, fire fighters to fight fire and therefore reduced or no occurrences of integrity failures.

\subsubsection{Modified lightweight aggregate concrete (LWAC)}

LWC has proven to possess better thermal and mechanical characteristics as compared to NWC when subjected to elevated temperatures. The effective and efficient way of producing LWC is the use of lightweight aggregate. This is because, relevant literature has shown that the overall thermal behaviour of concrete is governed by the thermal properties of its components; cement paste and aggregate. This is because it forms approximately $50 \%$ or more of its volume, and from extensive research, the mineralogical characteristics of the aggregates have been reported to have a greater thermal influence on the thermal properties as compared to the effect of the cement paste (Neville, 2002). Many researchers have therefore extensively investigated the addition of materials, which are usually byproducts of these lightweight aggregates. Others have also included varying admixtures to record the substantial effect these admixtures have on LWC.

\subsubsection{LWC made from sintered lightweight aggregates}

The thermal conductivity of LWC and NWC wall systems and structural members were investigated. (Peng, et al., 2011). Structural members were heated and exposed to the standard heating curve. LWC mixtures were prepared using sintered lightweight aggregates whereas those of NWC were prepared with normal weight aggregates. Both LWC and NWC mixtures were prepared using two concrete strength grades. The thermal conductivity of all concrete members was determined by the ASTM C518 standard. The results from the thermal conductivity tests indicate that LWC show about $53 \%$ reduction 
in thermal conductivity as compared to that of NWC for both strength grades (Table 2-1). This further confirms that LWC has better fire resistance characteristics as compared to NWC. This is highly beneficial to the heat insulation performance of concrete.

Table 2-1: Thermal conductivity values of $L W C$ and NWC mixtures as recorded by (Peng, et al., 2011)

\begin{tabular}{|c|c|c|}
\hline Strength Grade (MPa) & LWC (W/mK) & NWC (W/mK) \\
\hline 20 & 0.805 & 1.547 \\
\hline 40 & 0.872 & 1.657 \\
\hline
\end{tabular}

\subsubsection{LWC made from expanded lightweight aggregate and mineral admixtures}

(Demirboga \& Gul, 2003) investigated the effects of expanded perlite aggregate (EPA), silica fume (SF) and fly ash (FA) on the thermal conductivity of lightweight concrete. The main concrete mixes contained pumice aggregate (PA) and EPA in increasing proportions. Mixtures were prepared by replacing the weight of Portland cement by either SF or FA. All concrete mixes have been summarized in Table 2-2.

Table 2-2: Concrete mixes, modified from (Demirboga \& Gul, 2003)

\begin{tabular}{|c|c|c|c|}
\hline Concrete Mixes & PA (\%) & EPA (\%) & SF or FA (\%) \\
\hline A & 100 & 0 & $0,10,20$, and 30 \\
\hline B & 80 & 20 & $0,10,20$, and 30 \\
\hline C & 60 & 40 & $0,10,20$, and 30 \\
\hline D & 40 & 60 & $0,10,20$, and 30 \\
\hline E & 20 & 80 & $0,10,20$, and 30 \\
\hline F & 0 & 100 & $0,10,20$, and 30 \\
\hline
\end{tabular}


The thermal conductivity for all concrete mixes were measured using the Quick Thermal Conductivity Meter (ATM 500) based on the ASTM C 113-90 Hot Wire Method (ASTM $\mathrm{C} 113-90,2013)$. This method offers a wide temperature range of $100^{\circ} \mathrm{C}$ to $1000^{\circ} \mathrm{C}$. It has been widely used by other applications in determining the thermal conductivity of refractory materials where, instead of measuring heat flow, the temperature variation with time at certain locations is measured. The overall effect is that since it is transient in nature, this method takes only a few minutes in contrast to earlier methods involving steady-state conditions (Demirboga \& Gul, 2003).

All concrete mixtures recorded a reduction of the thermal conductivity by up to $43.5 \%$ and this is mainly due to the relatively low thermal conductivity of these admixtures and EPA, and the consequent low density of LWC. It was observed that the thermal conductivity and dry unit weight of the LWC decreased with increasing SF and FA content. The maximum reduction of thermal conductivity for both SF and FA was observed at 30\% replacement of PC in all the concrete mixes groups. However, FA was more effective than SF in decreasing the thermal conductivity for the overall LWC (Figure 2-15). 


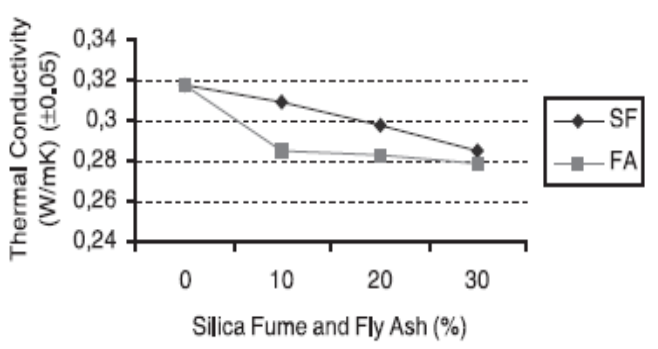

Fig. 2-15a

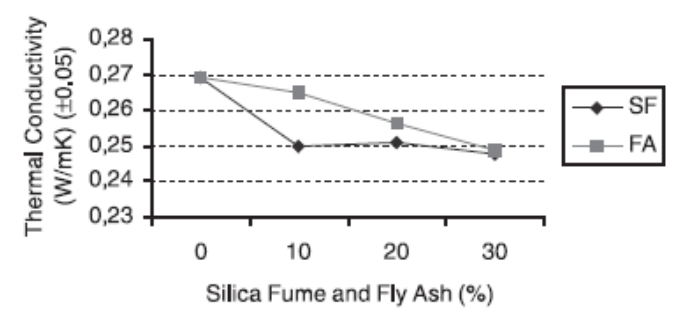

Fig. 2-15c

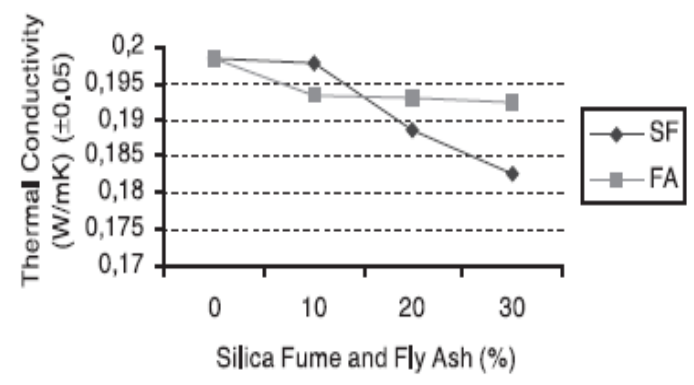

Fig. 2-15e

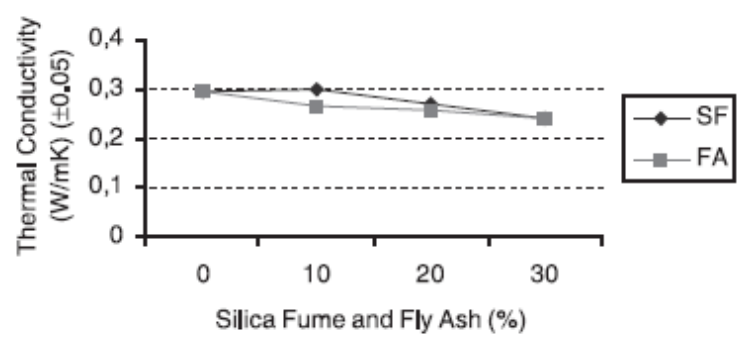

Fig. 2-15b

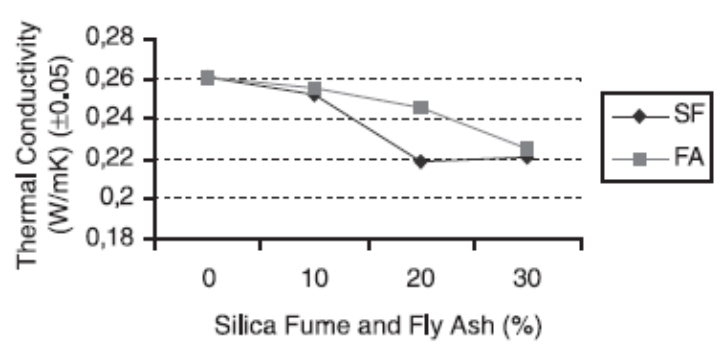

Fig. 2-15d

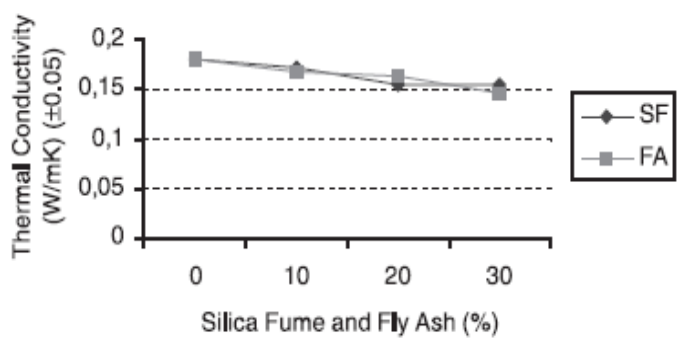

Fig. 2-15f

Figure 2-15: Relationship between admixtures and thermal conductivity of concrete mixtures $\mathrm{A}, \mathrm{B}$, C, D, E and F; (Fig 2-14 a-f) respectively (Demirboga \& Gul, 2003)

Among the different LWC mixes investigated throughout this study, the concrete mix containing $100 \%$ EPA and 30\% FA showed the lowest thermal conductivity at about $0.15 \mathrm{~W} / \mathrm{mK}$ (Figure 2-16). (Demir \& Serhat, 2008) have also produced similar results for the thermal behaviour of EPA. 


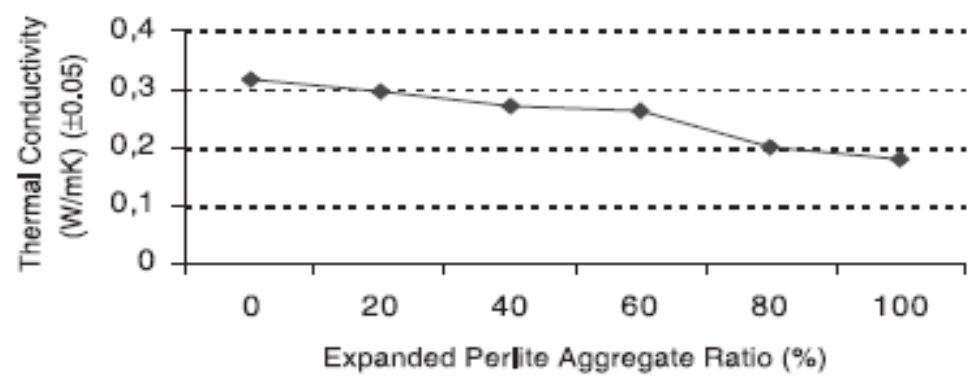

Figure 2-16: Relationship between EPA ratio and thermal conductivity, (Demirboga \& Gul, 2003)

\subsubsection{LWC made from metakaolin and recycled glass}

Al-Sibahy and Edwards (Al-Sibahy \& Edwards, 2012) investigated the thermal behaviour of a new type of LWC at ambient and elevated temperatures. The new type of LWC was composed of metakaolin (MK) and recycled glass (RG) in increasing proportions of a partial replacement of PC and the fine aggregate. This new type of LWC was further investigated for its suitable use as loadbearing concrete masonry unit (Al-Sibahy \& Edwards, 2012). Metakaolin is a pozzolanic material, which is obtained from the calcination of kaolinitic clay at a temperature ranging between $500^{\circ} \mathrm{C}$ and $800^{\circ} \mathrm{C}$ (Siddique \& Klaus, 2009). A pozzolanic material belongs to broad class of siliceous or siliceous and aluminous materials which, in themselves, possess little or no cementitious value but which will, in finely divided form and in the presence of water, react chemically with calcium hydroxide at ordinary temperature to form compounds possessing cementitious properties. Prior to their study (Al-Sibahy \& Edwards, 2012), Poon et al. (Poon, et al., 2003), investigated the performance of metakaolin concrete at elevated temperatures. In that research, MK concrete mixes were compared to the addition of other pozzolanic materials such as SF and FA. Unlike other pozzolans such as SF and FA, MK 
is a primary product, not a secondary or by-product. This is beneficial in the sense that, it allows the manufacturing process to be structured to produce the optimum characteristics for the MK, thereby ensuring the production a consistent product and supply. MK is also white in colour, which results in a lighter colour in the concrete mix (Poon, et al., 2003). Poon et al. (Poon, et al., 2003) centered their study on evaluating the mechanical behaviour of these concrete mixes when exposed to elevated temperatures. Mixtures were heated in an electric furnace up to $200,400,600$ and $800^{\circ} \mathrm{C}$. A heating rate was set at $2.5^{\circ} \mathrm{C}$ per minute to simulate both natural fire and oil/gas industry temperatures. Results showed that MK concrete showed a distinct pattern of strength gain and loss at elevated temperatures. In the initial stages, it gained an increase in the compressive strength at $200^{\circ} \mathrm{C}$ where it maintained higher strengths as compared to corresponding of SF, FA and pure PC concretes. However, there were explosive spalling recorded by MK concretes at a temperature range of $400-800^{\circ} \mathrm{C}$ and possessed lower residual strengths than the other concretes. This could be attributed to the dense micro-structure and lowest porosity structure for the MK concretes at elevated temperatures. However, MK concretes that contained a small percentage of cement replacement (5\%) showed better mechanical performance than corresponding pure $\mathrm{PC}$ and SF concretes.

Based on the study performed by Poon et. al (Poon, et al., 2003), Ali-Sibahy and Rodger (Al-Sibahy \& Edwards, 2012) observed that the probability of the MK concretes having explosive spalling could be attributed to other factors and therefore further investigated the mechanical and thermal behaviour of MK concretes composed of lightweight aggregates and recycled glass. The reason for the choice of RG was based on the huge amounts of waste that are produced worldwide yearly. For instance, in the UK, every household 
disposes 29.1 million tons of waste of which $4.2 \%$ is glass (Al-Sibahy \& Edwards, 2012). The Recycling Council of Ontario stated that recycling one ton of glass saves about nine gallons of fuel oil. In the construction industry, recycling glass makes an important contribution to overall sustainability since there are several options for making use of glass waste and other by-products in concretes. This has become an alternative for the conventional materials of concrete mixes. Glass aggregates are granular particles with a smooth surface texture and very low ability to absorb water. A reduction in the concrete strength and drying shrinkage have been found to be the negative effects based on these characteristics of glass as reported by (Chen, 2006; Seung, 2004; Topcu \& Canbaz, 2004). Further studies have reported that MK serves as a versatile mineral admixture that can be used to ultimately improve both strength and durability of concrete mixes (Poon, et al., 2003; Siddique \& Klaus, 2009).

Therefore, using appropriate proportions of MK and RG can to an extent increase the thermo-mechanical properties of concrete mixes exposed to elevated temperatures. In (AlSibahy \& Edwards, 2012), modified LWC mixtures were produced using ordinary PC, natural sand, expanded clay aggregates, MK and RG. MK and RG were partial replacement of the ordinary PC and natural sand by weight. The reference concrete mix contained no MK or RG. Summary of the concrete mixes can be seen in Table 2-3. 
Table 2-3: Summary of concrete mixtures, (Al-Sibahy \& Edwards, 2012)

\begin{tabular}{|c|c|}
\hline $\begin{array}{c}\text { Concrete Mix } \\
\text { Design Number }\end{array}$ & $\begin{array}{c}\text { Modified concrete mixes } \\
\text { (\% of Glass }(\mathrm{G})+\% \text { of MK) }\end{array}$ \\
\hline 1 & $15 \mathrm{G}+5 \mathrm{MK}$ \\
\hline 2 & $30 \mathrm{G}+5 \mathrm{MK}$ \\
\hline 3 & $45 \mathrm{G}+5 \mathrm{MK}$ \\
\hline 4 & $15 \mathrm{G}+10 \mathrm{MK}$ \\
\hline 5 & $30 \mathrm{G}+10 \mathrm{MK}$ \\
\hline 6 & $45 \mathrm{G}+10 \mathrm{MK}$ \\
\hline
\end{tabular}

The thermal conductivity test was conducted by using the hot wire method as described in (BS EN $993-15,2005$ ). It was conducted at a temperature range of $20^{\circ} \mathrm{C}$ and $800^{\circ} \mathrm{C}$. A heat flow test was also conducted to evaluate the temperature difference between the exposed and unexposed surfaces of the modified concrete mixtures. In this test, concrete specimens were subjected to a unidirectional heat flow test where a digitally- controlled furnace was used with a constant heating rate of $300^{\circ} \mathrm{C} / \mathrm{h}$ to produce the thermal action. The furnace was heated up to a temperature of $800^{\circ} \mathrm{C}$. Three type $\mathrm{K}$ thermocouples were attached to measure the temperature rise in the furnace and on the exposed and unexposed surfaces of the concrete sample. The specific heat capacity was computed based on the results of the density and thermal conductivity tests using the following equation, Equation 2-10 (BS EN 993-15, 2005). 


$$
\begin{aligned}
& C_{p}=\frac{\lambda}{p \cdot a} \\
& a=c \times r^{2} \times \exp \left[\frac{4 \times \pi \times \Delta T \times \lambda}{Q}\right] /(4 \times t)
\end{aligned}
$$

Where;

$C_{p}=$ specific heat capacity $(\mathrm{J} / \mathrm{kgK}), \lambda=$ thermal conductivity $(\mathrm{W} / \mathrm{mK}), p=$ density $\left(\mathrm{kg} / \mathrm{m}^{3}\right), a=$ thermal diffusivity $\left(\mathrm{m}^{2} / \mathrm{s}\right), c=$ Euler's constant $(1.781), \Delta T=$ temperature difference $(\mathrm{K}), Q=$ power per unit length $(\mathrm{W} / \mathrm{m}), t=$ time (s)

The thermal conductivity results reported showed that all modified concrete mixes showed superior thermal behaviour, with their measured thermal conductivity values up to $42 \%$ lower than the reference concrete mix (Figure 2-17). This could be attributed to the low thermal conductivity values exhibited by glass and metakaolin as compared to the natural sand and Portland cement that they partially replaced. One important variation observed was between the concrete mix containing $30 \%$ glass and $15 \%$ glass; the thermal conductivity of the preceding was lesser than that of the latter. Therefore, it was found out that another factor influenced the magnitude of the thermal conductivity. It was reported that this could be attributed to the distribution of air voids within the entire concrete sample. Modified concrete mixes Nos. 1 to 3, showed 37\%, 32\% and 16.5\% decrease in thermal conductivity whereas those with Nos. $4-6$, showed $31 \%, 30 \%$ and $42 \%$ decrease in reference concrete (Figure 2-17 $a$ and $b$ ). In addition, the thermal conductivity of all the concrete mixes was higher at $100^{\circ} \mathrm{C}$ than at ambient temperature due to the evaporation of free water with associated loss of latent heat of vaporization. Once the free water was completely removed, the thermal conductivity decreased with an increase in temperature. From all the modified concrete mixes, concrete mixture containing $10 \% \mathrm{MK}$ and $45 \% \mathrm{G}$ 
showed the best reduction in thermal conductivity.
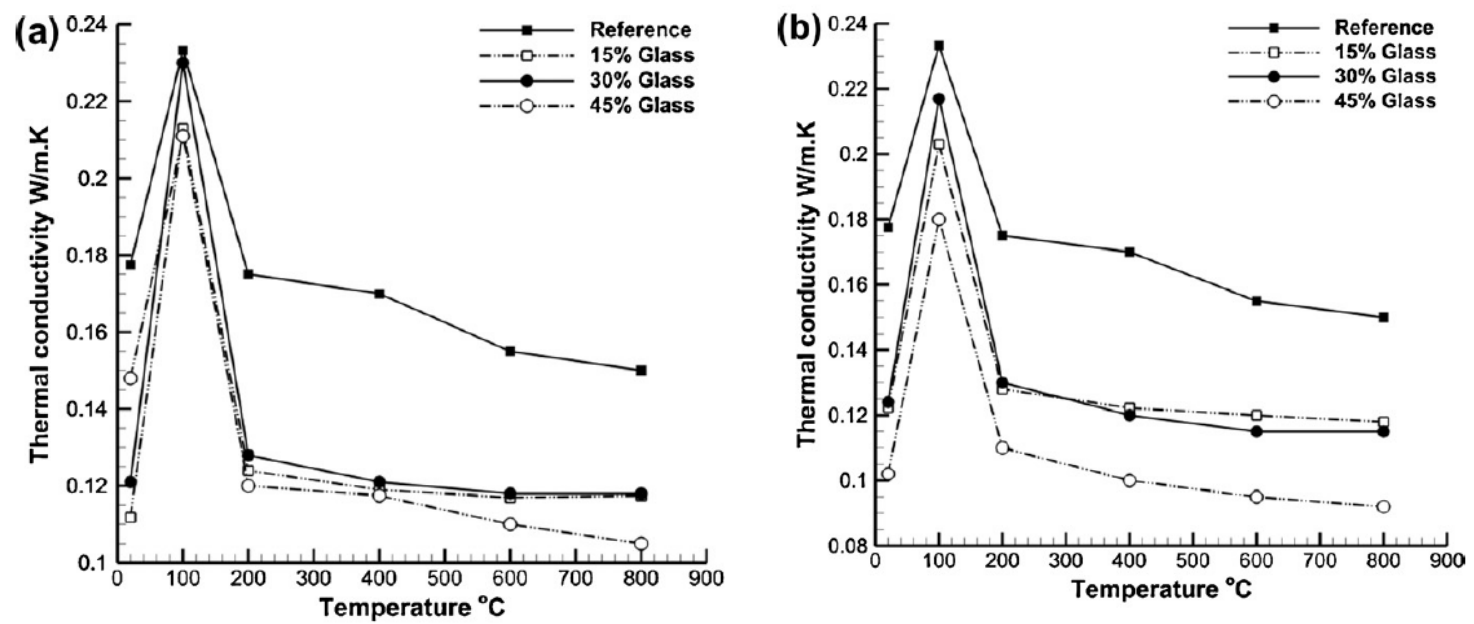

Figure 2-17: Thermal conductivity of different concrete mixes at ambient and elevated temperatures a) Concrete mixtures containing $5 \%$ MK with varying glass contents. b) Concrete mixtures containing $10 \%$ MK with varying glass contents, (Al-Sibahy \& Edwards, 2012)

The calculated values of specific heat for the modified concrete mixes were lower than those of the reference samples except for values recorded at $100^{\circ} \mathrm{C}$ (Figure 2-18). This was reported to be related to the lower thermal conductivity of these mixes. The reason for the exception at $100^{\circ} \mathrm{C}$ was due to the modified concrete mixes holding excessive amounts of water in the interior pores, which caused an increase in the specific heat at this temperature. In contrast, a smaller increase was recorded for the reference samples at this temperature. As stated earlier, MK is made from kaolinitic clay and clay is known to hold large amounts of water due to the substantial greater volume of open spaces as compared to sand; high porosity. To further examine into this characteristic of $\mathrm{MK}$, varying percentages of $\mathrm{MK}$ and a constant percentage of glass was investigated. This phenomenon was observed significantly for concrete mixtures containing 10\% MK and 45\% Glass (Figure 2-18c). 

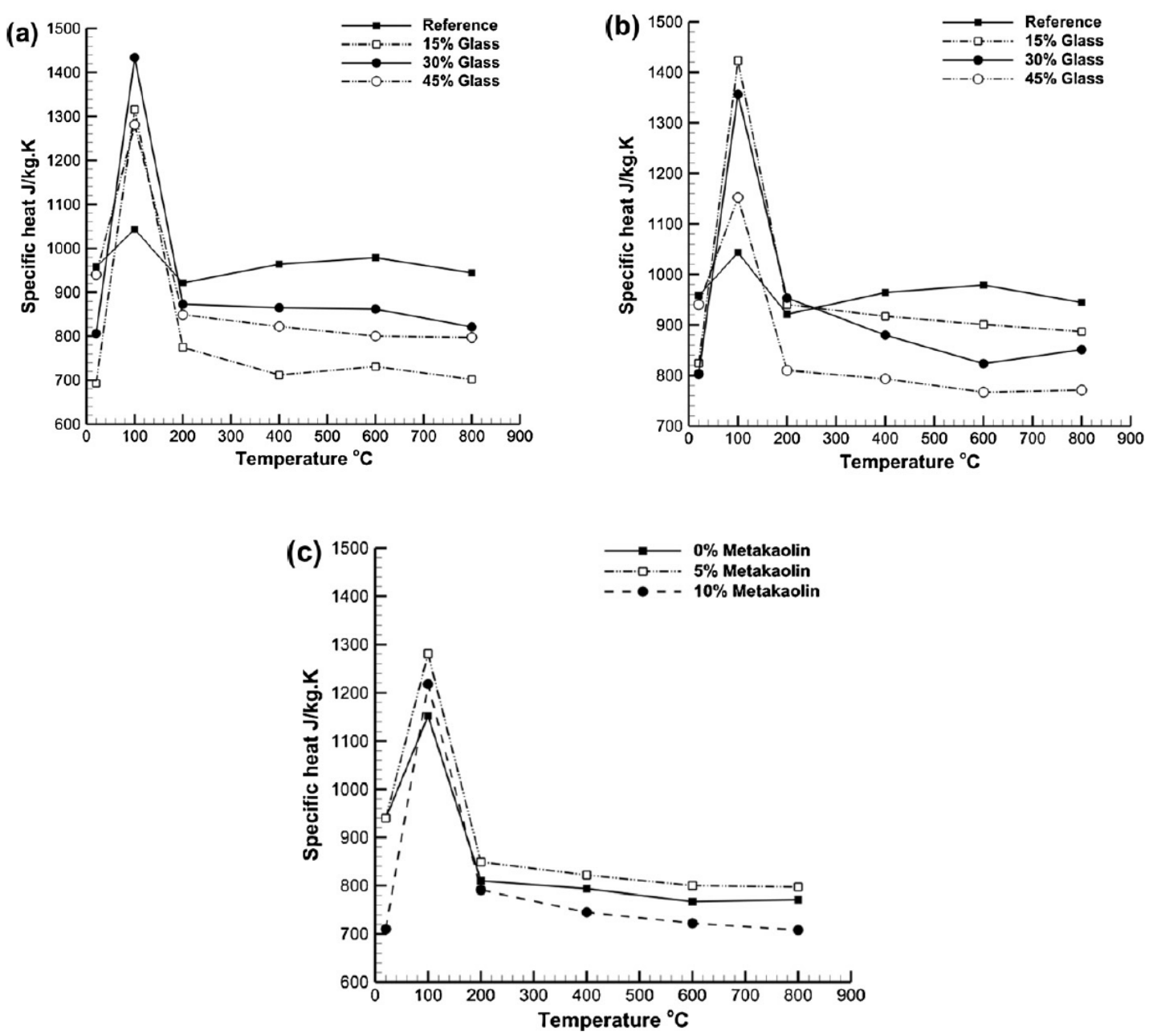

Figure 2-18: Specific heat of different concrete mixes at ambient and elevated temperatures a) concrete mixes containing $5 \%$ MK with varying glass contents. b) concrete mixes containing $10 \%$ MK with varying glass contents. c) concrete mixes containing $45 \%$ glass content with different percentages of MK. (Al-Sibahy \& Edwards, 2012)

The results from the heat flow test show that the modified concrete mixes showed better thermal properties (Figure 2-19). This was due to the greater temperature differences recorded for the modified mixes as compared to the reference concrete. This further implied that the heat flow rate was lower in the modified mixes. Increasing the proportion of MK and glass content reduced the amount of heat transfer; this is similar to the trend observed when the thermal conductivity tests were done. Furthermore, to meet the BS EN standards (EN 1363-1, 2000; BS EN 1996-1-2, 2005) based on the requirements for the 
insulation criterion, modified concrete mix $6 ; 45 \% \mathrm{G}$ and $10 \% \mathrm{MK}$ had the longest period of thermal insulation, which was $110.25 \mathrm{~min}$.
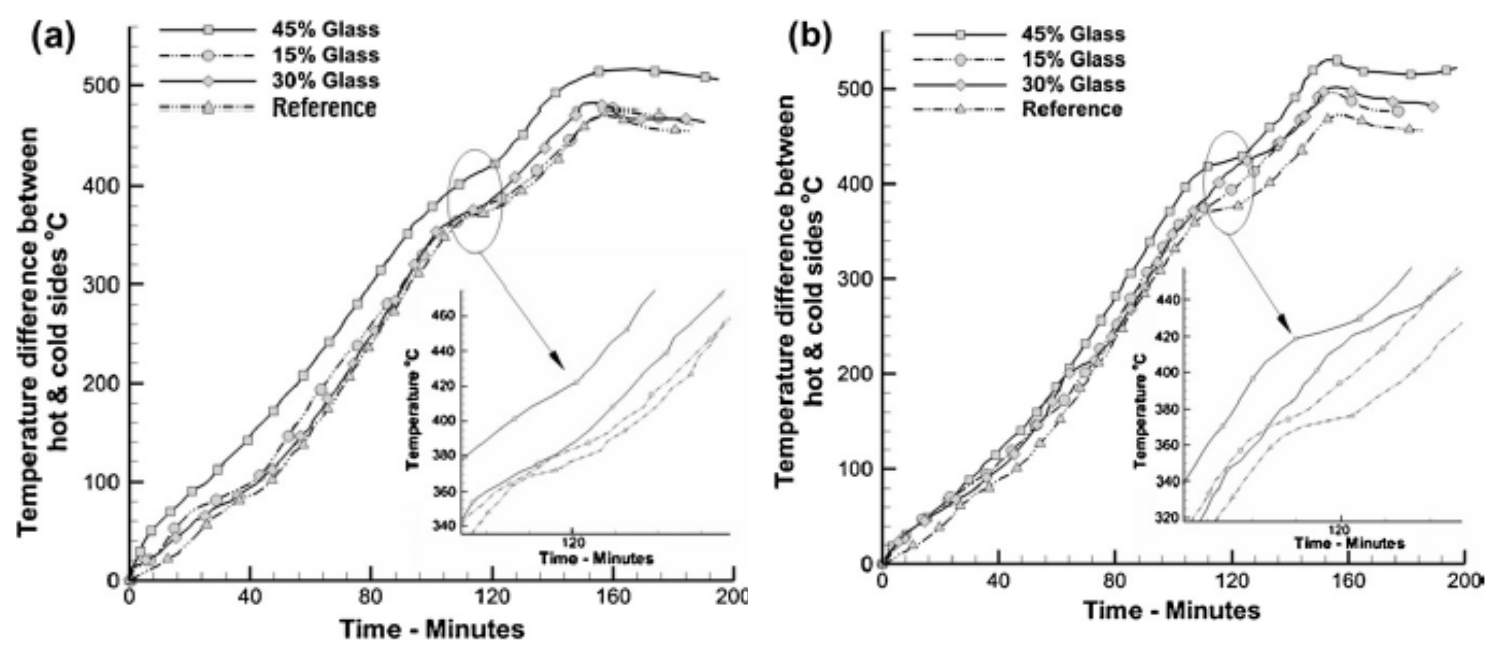

Figure 2-19: Temperature difference between exposed and unexposed surfaces temperatures a) concrete mixes containing $5 \%$ MK with varying glass contents. b) concrete mixes containing $10 \% \mathrm{MK}$ with varying glass contents.

In evaluating all the thermal properties at elevated temperatures, it was found out that concrete mixes containing $45 \% \mathrm{G}$ and $10 \% \mathrm{MK}$ performed best.

\subsubsection{LWC made from foamed concrete}

Lightweight foamed concrete (LFC) is a material consisting of Portland cement paste or cement filler matrix (mortar) with a homogeneous pore structure created by introducing air in the form of small bubbles. Common characteristics associated with LFC are; good thermal and acoustic insulation, self-flowing and it been easy to fabricate (Hamidah, et al., 2005). Most civil engineering works prefer to use this type of concrete as a filler material. However, it has a strong potential as a material in the building construction due to its good thermal and acoustic performance. Although, its mechanical properties are low compared to normal strength concrete and regular lightweight concrete, LFC may be used in 
partitions or light load bearing walls in low-rise residential constructions. LFC is a porous material and therefore its thermal conductivity is significantly affected due to the presence of air pores within the material. This is because within each air pore, heat conduction will dominate at relatively low temperature. At elevated temperatures, radiation will play a more important role because the radiant heat transfer coefficient is related to temperature, which is raised to the power of three from the radiation equation. Based on these two effects, the effective thermal conductivity of LFC at elevated temperature depends not only on the thermal conductivities of the cement paste and the air, but also radiation effect inside the pores (Othuman \& Wang, 2011). The behaviour of LFC when exposed to elevated temperatures is like that of NWC. The free water in the pores and chemically bonded water in the hydrated cement paste are released.

(Othuman \& Wang, 2011), conducted an experimental and analytical study to quantify the thermal properties of LFC at high temperatures. In the study, analytical models of thermal conductivity and specific heat of LFC were proposed, based on an assumed internal structure (porous structure) and constituents (cement, water and air) of LFC. From this phase, thermal properties were obtained and used to evaluate the thermal performance of LFC under different heating conditions. LFC is a non-reactive material and therefore its thermal properties are considered temperature dependent only. All thermal property models of LFC at high temperatures were then validated using a one-dimensional heat transfer analysis program (Rahmanian, 2008).

Several heating tests were also carried out on LFC specimens in which an LFC panel of $150 \mathrm{~mm}$ in thickness was subjected to heating from an electric kiln. The heating tests were carried out for $\mathrm{LFC}$ of densities of $650 \mathrm{~kg} / \mathrm{m}^{3} ; \mathrm{LFC}_{1}$ and $1000 \mathrm{~kg} / \mathrm{m}^{3} ; \mathrm{LFC}_{2}$. The numerical 
prediction results were then compared with the experimental results. Through correlation between the prediction and experimental results, the proposed thermal property models were assessed.

For the heating tests, a transient high temperature tests on LFC slabs in an electric kiln and Hot Guarded Plate (HGP) were conducted. The electric kiln test was performed to provide transient temperature information to validate the thermal property models while the HGP test provided data to correlate with the analytical model. The HGP test followed the ASTM Procedure in (ASTM, 1997). The source of heat to the furnace in the electric kiln test was controlled by BS 476 (Standards, 1987).

The specific heat temperature relationship of concrete has only peak, due to the evaporation of pore water, which corresponds to the first phase of dehydration. This behaviour is confirmed by the experimental results obtained from the tests performed in (Othuman \& Wang, 2011). The temperature plateau between $90^{\circ} \mathrm{C}$ and $170^{\circ} \mathrm{C}$ illustrate this, which reflects the first phase of dehydration. Afterwards, the temperature development is smooth and continuous without any plateau at the other two dehydration phases, Figure 2-20. It can be further observed that $\mathrm{LFC}_{2}$ samples considerably took a longer duration to reach all the temperature ranges as compared to the $\mathrm{LFC}_{1}$ samples. For instance, at a distance of $37.5 \mathrm{~mm}, \mathrm{LFC}_{2}$ took approximately 65 minutes to reach a temperature of $200^{\circ} \mathrm{C}$ as compared to $\mathrm{LFC}_{1}$ samples, which record this temperature at about 50 minutes, Figure 2-21 and Figure 2-22. This could be attributed to higher thermal capacitance value; density times specific heat, which allows more heat to be absorbed and in effect slows down the rate of heating for specimens with higher densities (Othuman \& Wang, 2011), 


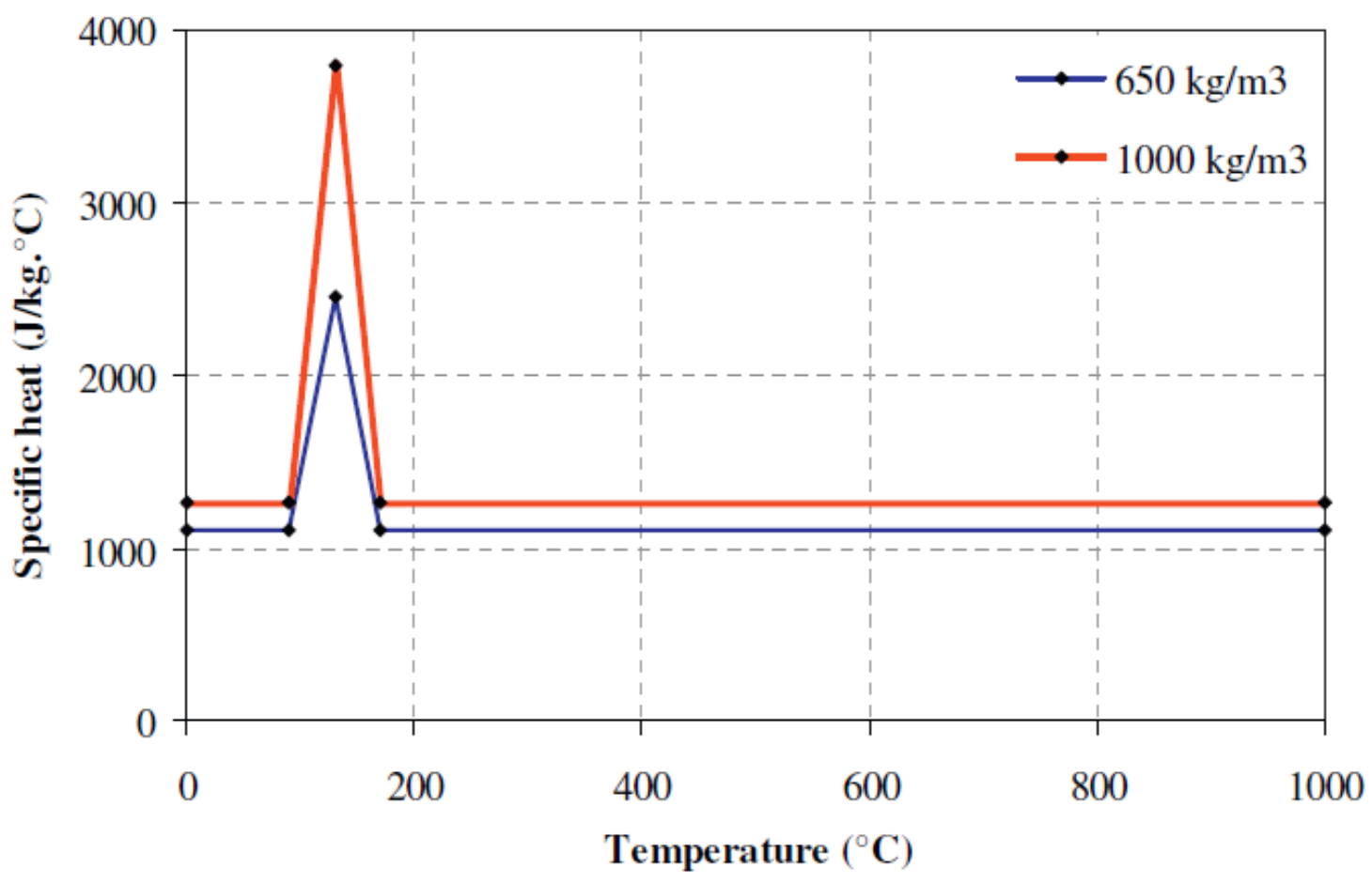

Figure 2-20: Specific heat of LFC samples $\left(650 \mathrm{~kg} / \mathrm{m}^{3}\right.$ and $\left.1000 \mathrm{~kg} / \mathrm{m}^{3}\right)$ at elevated temperatures,

(Othuman \& Wang, 2011)

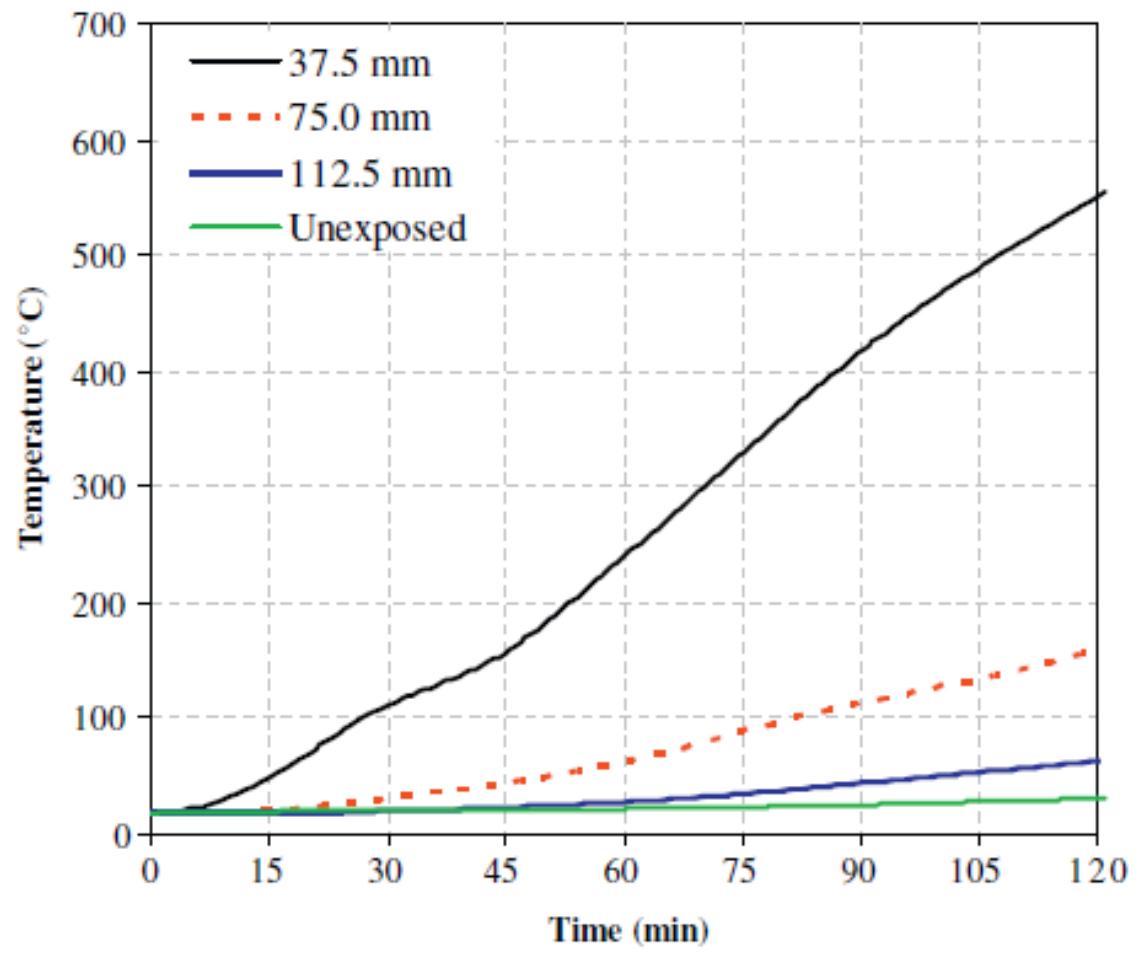


Figure 2-21: Temperature distributions in $650 \mathrm{~kg} / \mathrm{m}^{3}$ density samples (Othuman \& Wang, 2011)

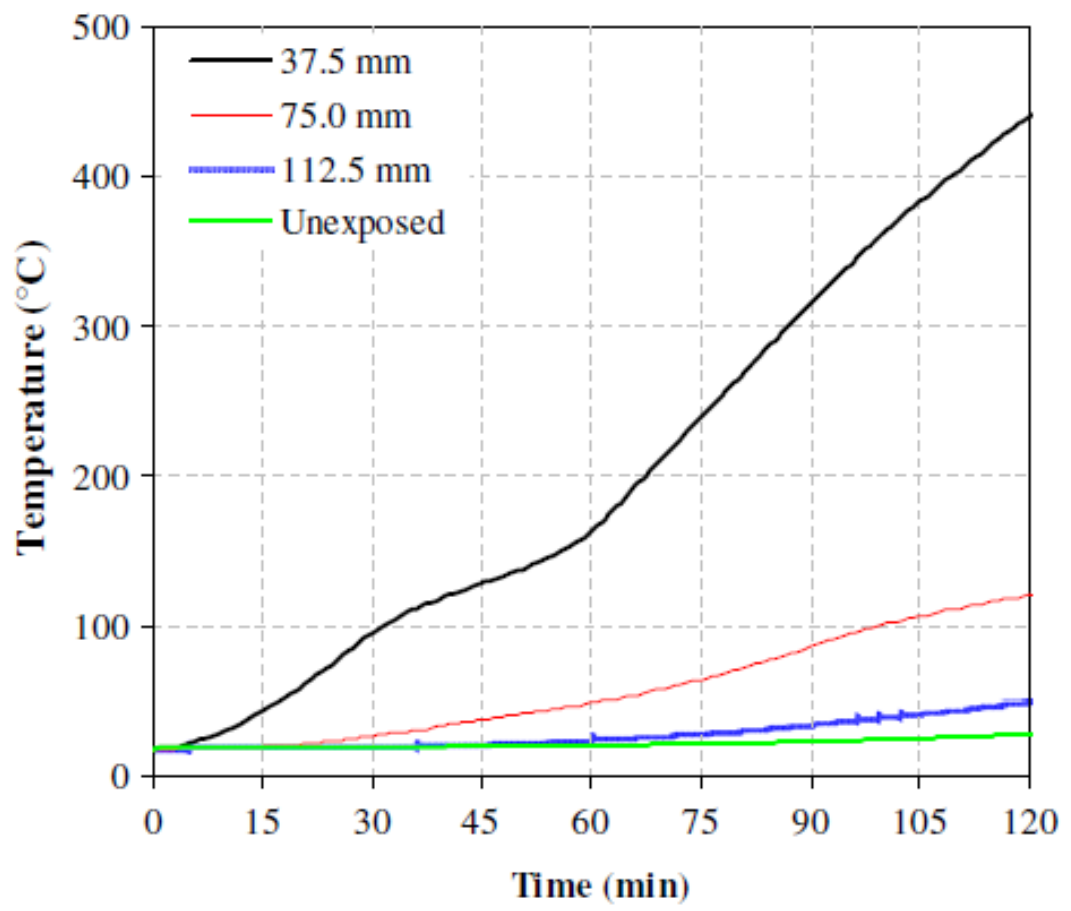

Figure 2-22: Temperature distributions in $1000 \mathrm{~kg} / \mathrm{m}^{3}$ density samples (Othuman \& Wang, 2011)

For the thermal conductivity tests, both the experimental and analytical results produced similar results and therefore validated the use of the analytical model, Figure 2-24. The thermal conductivity for all LFC samples regardless of the density was significantly low as compared to most lightweight aggregate concrete (ACI Committee 122, 2002). However, samples at higher densities record higher thermal conductivity values as compared to the lower densities. This could be attributed to porous nature of the $\mathrm{LFC}_{2}$ samples; they were less porous as compared to LFC $_{1}$ samples, Figure 2-23. Higher porosity increases the rate of thermal conductivity within the sample. In addition, the thermal conductivity of water is very low during the first phase of dehydration and could significantly cause a reduction in thermal conductivity within this phase for all samples, Figure 2-24. 


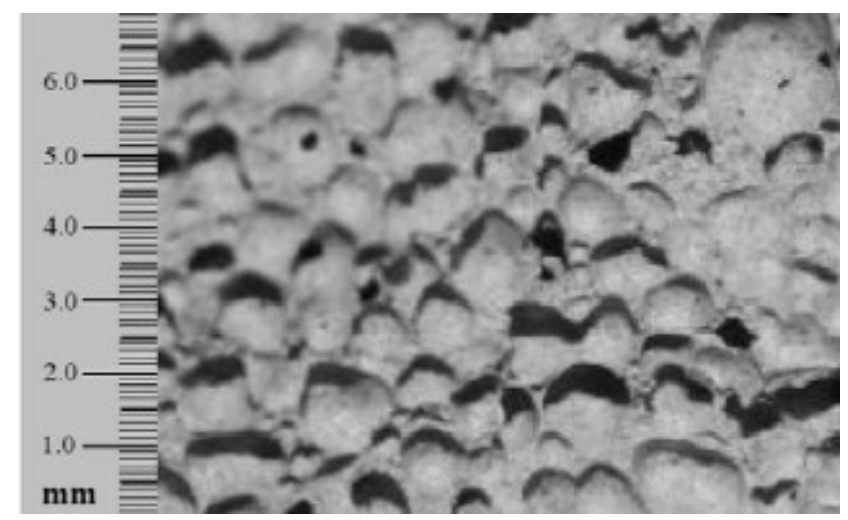

(a)

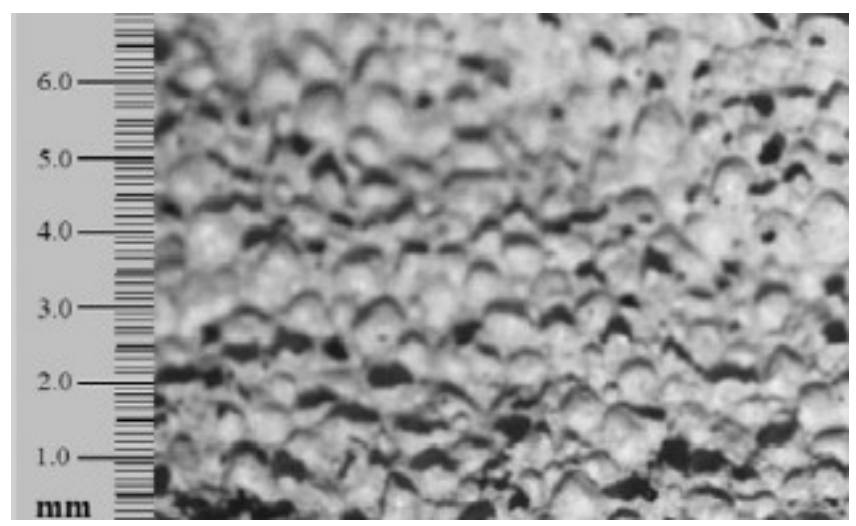

(b)

Figure 2-23: Pore sizes for $650 \mathrm{~kg} / \mathrm{m}^{3}$ (a) and $1000 \mathrm{~kg} / \mathrm{m}^{3}$ (b) densities (Othuman \& Wang, 2011)

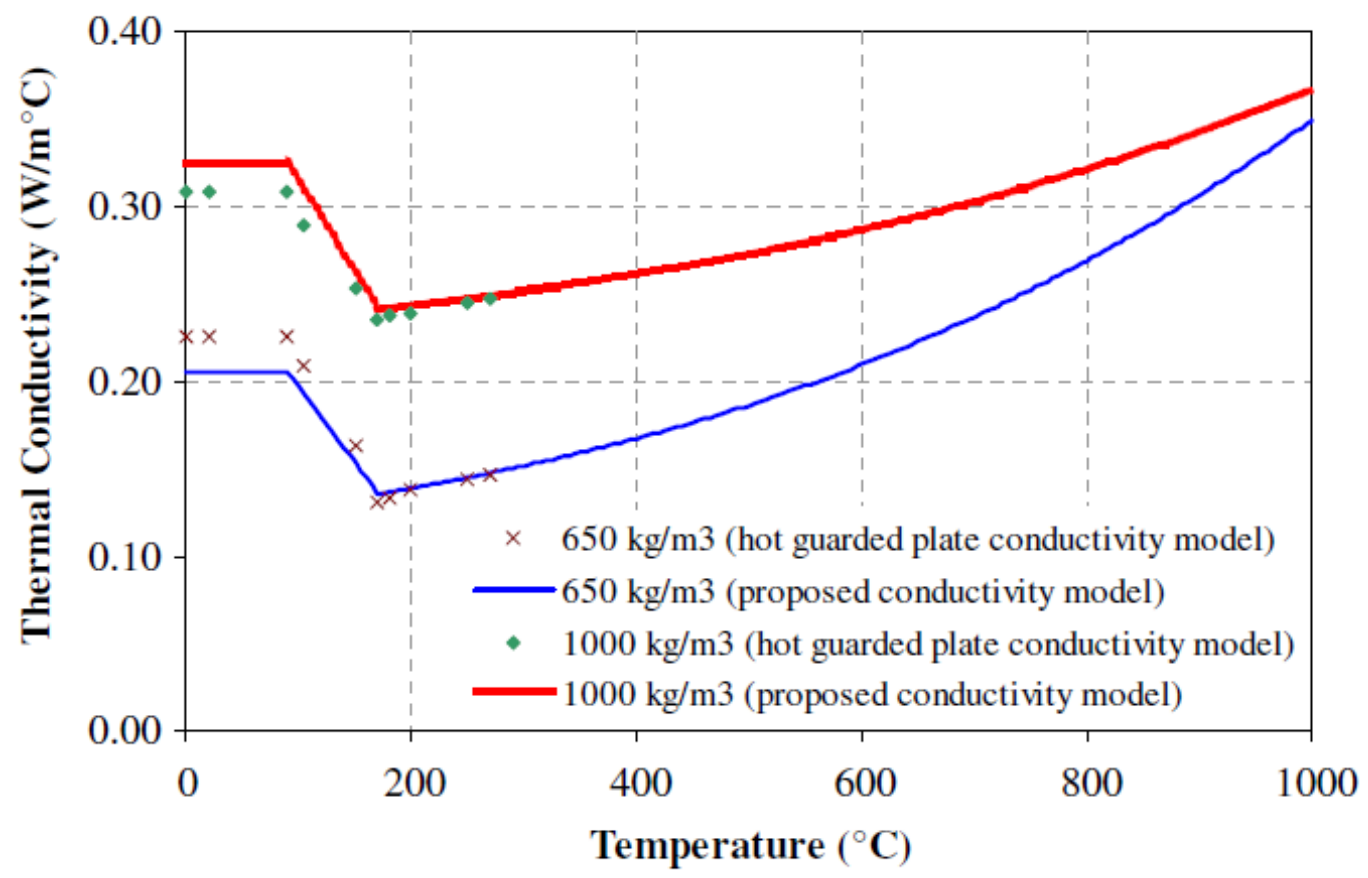

Figure 2-24: Thermal conductivity of LFC samples $\left(650 \mathrm{~kg} / \mathrm{m}^{3}\right.$ and $\left.1000 \mathrm{~kg} / \mathrm{m}^{3}\right)$ at elevated temperatures, (Othuman \& Wang, 2011)

\subsection{Methods of Improving the Fire Resistance of Concrete Masonry - Insulating \\ Materials}

Insulating materials are materials that form the thermal envelope of a building or otherwise 
reduce heat transfer. These materials can be further categorized based on their composition (natural or synthetic), form (batts, blankets, loose-fill, spray foam, and panels), structural contribution (insulating concrete forms, structured panels, and straw bales), functional modes (conductive, radiative, and convective), and resistance to heat transfer, environmental impacts and many more. The factors that affect the type and amount of insulation used include; the thermal conductivity, moisture sensitiveness, compressive strength, ease of installation, durability; that is its resistance to degradation from compression, moisture, decomposition, high temperatures, ease of replacement at end of life, cost effectiveness, toxicity, flammability, environmental impact and sustainability, just to mention a few.

However, the common characteristic all insulating materials have is their low thermal conductivity factor $\lambda$, usually lower than $0.1 \mathrm{~W} / \mathrm{mK}$, because a quantity of gas, usually air, is embodied in the material's mass. Dry and firm air, when not moving and in small quantities, has the lowest thermal conductivity factor over a wide range of temperatures, typically $\lambda=0.024 \mathrm{~W} / \mathrm{mK}$ (Karamanos, et al., 2008).

\subsubsection{Categorization of insulating materials based on their chemical composition}

Figure 2-25 illustrates a description of insulating materials categorized based on their chemical composition. 


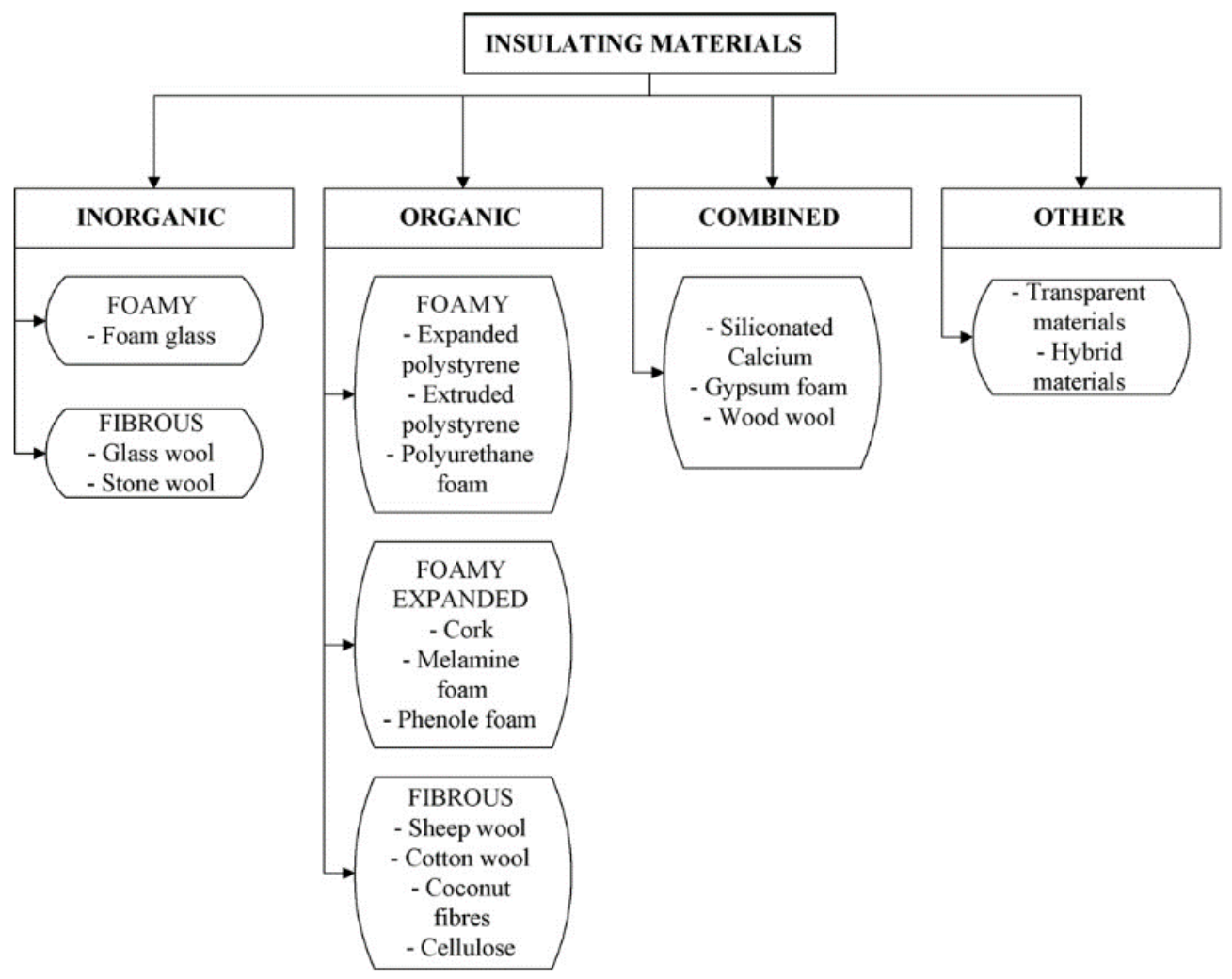

Figure 2-25: Classification of insulating materials based on their chemical structure (Karamanos, et al., 2008)

Based on the availability of materials by marketing industries, the European market of insulating materials is characterized by the domination of two groups of products: inorganic fibrous materials, glass wool and stone/rock wool, which account for $60 \%$ of the market, and, finally, organic foamy materials, expanded and extruded polystyrene and to a lesser extent polyurethane, which account for some 27\% of the market (EURIMA, 2006). In the first group, atmospheric air is "trapped" between the fibres, whilst in the others the air is embodied - in bubble form - in the material's mass (Karamanos, et al., 2008). It can be seen from the above that inorganic fibrous materials are widely used and to further break this category, stone wool accounts for about $35 \%$ of the total of inorganic fibrous produced making it a single most important insulation material for buildings. 


\subsubsection{Inorganic fibrous materials}

Inorganic fibrous materials are generally known as mineral wool materials and from these; different products are manufactured based on the raw materials used. Mineral wool is a generic term used to describe amorphous synthetic fibers produced from mineral raw

materials. This material has been produced naturally for centuries. It covers glass wool, rock wool or slag wool depending on the starting material used. Glass wool is produced from quartz sand, soda and limestone. These raw materials, which are typical of the glass industry, are mixed with recyclable glass in a ratio of between 50:50 and 30:70 and then melted in pot or tank furnaces at temperatures of about $1200^{\circ} \mathrm{C}$ (Mueller, et al., 2009). During volcanic eruptions, when a strong wind passes over a stream of molten lava, the lava is blown into fine silky threads that look like wool. From this natural inspiration, sprang one of the most innovative and versatile insulation products on the market today; rock wool (Crane \& McLaren, 2008). Rock/stone wool is made from volcanic rock such as diabase or basalt together with limestone and /or dolomite production wastes. The starting materials are usually melted in cupola furnaces at temperatures of up to $1500^{\circ} \mathrm{C}$ (Mueller, et al., 2009). Slag wool is made from approximately $70 \%$ blast furnace slag, with the remaining volume of raw materials being natural rock (Crane \& McLaren, 2008).

\subsubsection{Physical and thermal properties of mineral wool products}

The thermal conductivity, specific heat capacity as well as the building material class are very important properties to consider when evaluating the fire resistance of building materials. The physical and thermal properties of mineral wool products have been outlined in Table 2-4. 
Table 2-4: Physical properties of mineral wools, modified from (Mueller, et al., 2009) and

(Kothandaraman \& Subramanyan, 2004)

\begin{tabular}{|l|c|c|c|}
\hline Properties & Glass wool (GW) & Rock wool (ROW) & Slag wool (SW) \\
\hline $\begin{array}{l}\text { Bulk density } \\
\left(\mathrm{kg} / \mathrm{m}^{3}\right)\end{array}$ & $20-153$ & $22-200$ & 250 \\
\hline $\begin{array}{l}\text { Thermal conductivity } \\
(\mathrm{W} / \mathrm{mK})\end{array}$ & $0.035-0.045$ & $0.035-0.045$ & $0.050-0.065$ \\
\hline $\begin{array}{l}\text { Specific heat capacity } \\
(\mathrm{J} / \mathrm{kgK})\end{array}$ & $840-1000$ & 840 & 840 \\
\hline Building material class & A2 & $\begin{array}{c}\text { A1, A2 } \\
\text { Non-combustible }\end{array}$ & $\begin{array}{c}\text { A1, A2 } \\
\text { Non-combustible }\end{array}$ \\
\hline
\end{tabular}

The thermal conductivity of a material is basically the rate at which heat passes through a material, therefore this gives an idea of how much a material can retain/reduce thermal energy; thermal insulation. This heat transfer occurs at a lower rate across materials of low thermal conductivity than that of high thermal conductivity. The lower a material's thermal conductivity, the higher its thermal insulation property. Mineral wool products possess very low thermal conductivity values and based on this it provides excellent insulating properties as discussed above.

Regarding the specific heat, the higher the specific capacity of the material, the higher the amount of energy required to heat up the material and consequently the slower the rate to cool the material. From Table 2-4, mineral wool products have high specific capacities, which further affirms its capability of providing excellent thermal performance when used in buildings. 


\subsubsection{Benefits derived from using mineral wool}

These materials are widely used in building construction due to several benefits it possesses. Due to the exposure of materials to high temperatures during their fabrication, mineral wool materials are known to be fire resistant. This is because they are naturally non-combustible and remain so for the life of the product. These products, with stone wool can resist temperatures more than an $1100^{\circ} \mathrm{C}$ and since they do have high melting temperatures, they are widely used in a broad spectrum of applications that call for these unique properties (Crane \& McLaren, 2008). They are mostly used as insulation materials for passive fire protection in many buildings. In addition, mineral wool products meet the National Fire Protection Association (NFPA) and the American Society for Testing and Materials (ASTM) E136 standards and test methods. Furthermore, these products fall under the Class A products tested per ASTM E84 and NFPA 101 (Crane \& McLaren, 2008). Other benefits include its capability to provide excellent sound absorption properties due to their fibrous structure and high density. Under environmental standards, the use of slag to produce slag wool serves as a means of reducing the amount of waste generated by the steel manufacturers, which would have winded up in landfills thereby curbing the issue on land degradation and pollution. In addition, the fibrous composition of rock and slag wool insulations provides a flexibility and versatility, which is not found in most other insulations. They come in wide variety of forms, shapes and sizes, including board, batt, loose-fill, spray applied, and pipe insulation for many common and specialized applications (Crane \& McLaren, 2008). 


\subsection{Numerical Modelling of Non-Loadbearing Masonry Walls}

\subsubsection{Analytical approach for simple hand calculated design methods}

Non-loadbearing masonry walls have considerable capacity, from a fire perspective, to isolate parts of the building's interior from fire flames, heat, and the effect of smoke. Based on this, the overall performance of the masonry wall as a unit is to ensure that in the event of a fire, this criterion is met. This involves assessing the masonry wall to various forms of tests where the temperature rise within the wall is monitored for each time increase until the insulation criterion is met. Experimental investigation of the fire performance of these test walls is the primary approach where researchers construct these walls and test in the laboratory.

In addition, analytical methods have been developed over time through correlation with test results and computer models with the goal of predicting the fire behaviour of the wall. For instance, Wickström proposed and developed a method of calculating the surface fire temperature of different forms of concrete members exposed to a standard fire (Equation 2-11) (Buchanan, 2006). This equation can also be used in determining the surface temperature when heat is conducted from two directions (Equation 2-12) (Buchanan, 2006). However, in applying Wickström's equation, the thermal properties of the material, assembly or structure are not taken into consideration. It solely depends on the fire temperature of the assembly in question as well as the depths of exposure from the heat source. This does not offer much of a solution for the fire resistance quantification of assemblies or structures, which are anisotropic in terms of their thermal properties, of which masonry walls fall under this category. Once there is a difference in thermal properties, it is expected that these assemblies will behave independently and differently 
when subjected to elevated temperatures.

$$
\begin{aligned}
& T_{c}=\eta_{x} \eta_{w} T_{f} \\
& \eta_{x}=0.18 \operatorname{In}\left(t_{h} / x^{2}\right)-0.81 \\
& \eta_{w}=1-0.0616 t_{h}^{-0.88}
\end{aligned}
$$

Where;

$T_{c}=$ temperature at any depth into the member/assembly/structure $\left({ }^{\circ} \mathrm{C}\right), T_{f}=$ surface temperature of the member/assembly/structure $\left({ }^{\circ} \mathrm{C}\right), x=$ depth into the member/assembly/structure along the x-axis, $t_{h}=$ time (hours),

$$
T_{c}=\left[\eta_{w}\left(\eta_{x}+\eta_{y}-2 \eta_{x} \eta_{y}\right)+\eta_{x} \eta_{y}\right] T_{f}
$$

Equation 2-12

In addition to the Wickström approach, there are good published temperature curves available for determining the temperature within concrete members (Buchanan, 2006). Although this availability of information makes it much easier to design for standard fire exposure, it is mainly applied for simple hand calculated design methods.

\subsubsection{Analytical approach for complex structural fire designs}

Most structural fire designs are complex in nature and therefore an analytical approach, finite element or finite difference, serves as an alternate option for such complex analysis. This approach is used to compute the temperature rise developed within assemblies and to provide much more accurate results by incorporating the thermal properties and other required parameters such as heat transfer coefficients, mode of heat transfer, heat flux and boundary conditions (failure criteria).

(Reddy, 1993), stated that to effectively analyze any science or engineering challenge using numerical simulation approach, there are two major tasks involved: 
1. Mathematical formulation of the physical problem

2. Numerical analysis of the mathematical model

Under the mathematical formulation, the problem is broken down into a system of differential equations, followed by applying appropriate numerical methods to solve the given problem through iterative numerical simulations. The two most common methods of solving these problems can be done either by finite element method (FEM) or a finite difference method (FDM).

\subsubsection{Finite difference method}

The FDM is the oldest and is based upon the application of a local Taylor expansion to approximate the differential equations. The FDM uses a topologically square network of lines to construct the discretization of the partial differential equations (PDE). This is a potential bottleneck of the method when handling complex geometries in multiple dimensions (Ablowitz \& Clarkson, 1991). However, this issue motivated the use of an integral form of the PDE and subsequently the development of the FEM technique.

\subsubsection{Finite element method}

A finite element method (FEM) discretization is based upon a piecewise representation of the solution in terms of specified basis functions. The computational domain is divided up into smaller domains (finite elements) and the solution in each element is constructed from

the basic functions (Bathe, 1996). The actual equations that are solved are typically obtained by restating the conservation equation in weak form: the field variables are written in terms of the basic functions; the equation is multiplied by appropriate test functions, and then integrated over an element. The general finite element analysis (FEA) procedure has 
been described by Bathe (Bathe, 1996), and illustrated in Figure 2-26. This procedure comprises the application of mathematical equations to the finite elements. An approximate value of the solution variable is obtained at nodal points on the element and inter-element continuity functions can be used to further obtain equilibrium at the local level of these nodal forces (Bathe, 1996).

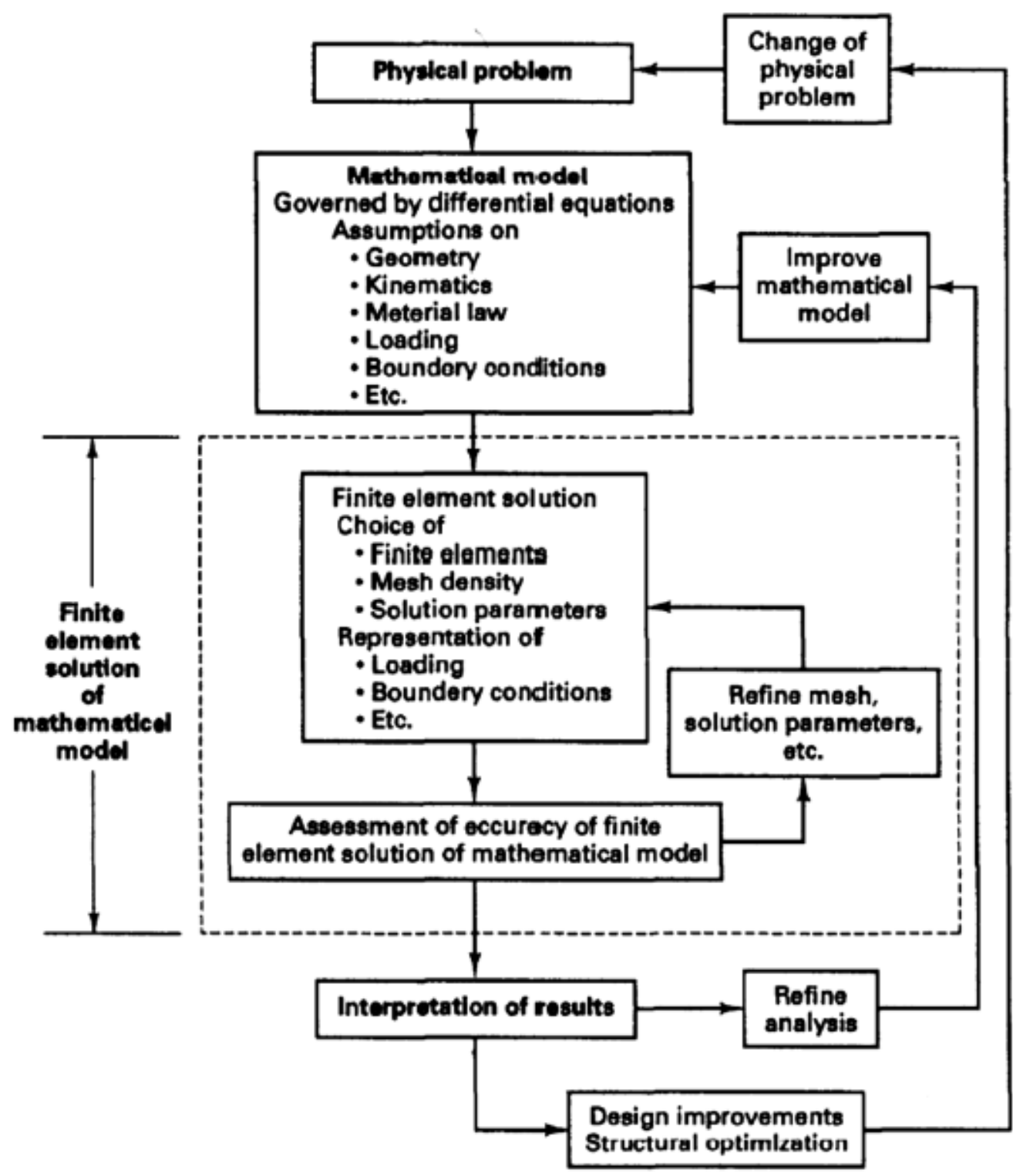

Figure 2-26: The Finite Element Analysis Procedure (Bathe, 1996)

Engineering and mathematical physics problems can be solved using the finite element 
method. Typical problems of interest that are solvable by using the finite element method include structural analysis, heat transfer, fluid flow, mass transport and electromagnetic potential (Logan, 2007).

For instance, a physical problem such as heat transfer through a hollow concrete masonry block can be solved using the analysis procedure as defined by Bathe, (Bathe, 1996). This problem focuses on the heat flow through the block and as such considers all the modes of heat transfer; conduction, convection and radiation. In this case, the mathematical model is governed by the differential heat equation which takes into assumption the geometry (dimensions), the material properties (density, specific heat and thermal conductivity), loadings (structural and/or thermal), boundary conditions (failure criteria; stability, integrity and/or insulation) of the block. Once these have been defined in the mathematical model, the process of achieving the finite element solution is defined. Under this section, the choice of finite elements, mesh parameters, solution parameters and the representation of the loading, boundary conditions, and predefined fields are also defined in the model. The model is then set into a run stage where iterative analysis takes place based on all the defined parameters. This could take a second, an hour, several hours, days etc. based on the choice of meshes as well as the type of analysis/solvers, which have been set for the model. Once results are obtained, there is an assessment of the accuracy of the finite element solution of the mathematical model. For instance, if nodal temperatures were the output results, did these temperatures meet the failure criterion temperatures? Such questions are used for these assessment and comparison of the mathematical model to the finite element model. Refinement of mesh and solution parameters are performed until there is a convergence of results between the mathematical model and the finite element 
model. These could be done iteratively and once the results make a good interpretation, either the analysis could be refined, which will improve the mathematical model or a design improvement, which aims at changing the physical problem. In the latter case, for example, the physical problem could be changed from a fully thermal analysis to a thermomechanical analysis.

\subsubsection{Finite element analysis software packages}

FEA has been packaged in many commercial computer programs such as ABAQUS (Dassault Systemes Simulia Corp., 2013), ANSYS (ANSYS Inc., 2013), LS-DYNA (Livermore Software Technology Corporation, 2007), and many others. The availability of different element types, analysis procedures, material models, interfaces, load types and platform usage are the basic standard capabilities of these programs. The choice of the FEA software for any analysis is an important factor in determining the quality and scope of analysis that can be performed.

\subsubsection{ABAQUS software package}

ABAQUS is a high fidelity general-purpose finite element code. It was first developed in the 1970's with an implicit finite element solver with only four elements, beam, gap, truss and SPHEX. However, over the years, it has been improved significantly to be effectively used in various fields of engineering (Prior, 2012). 


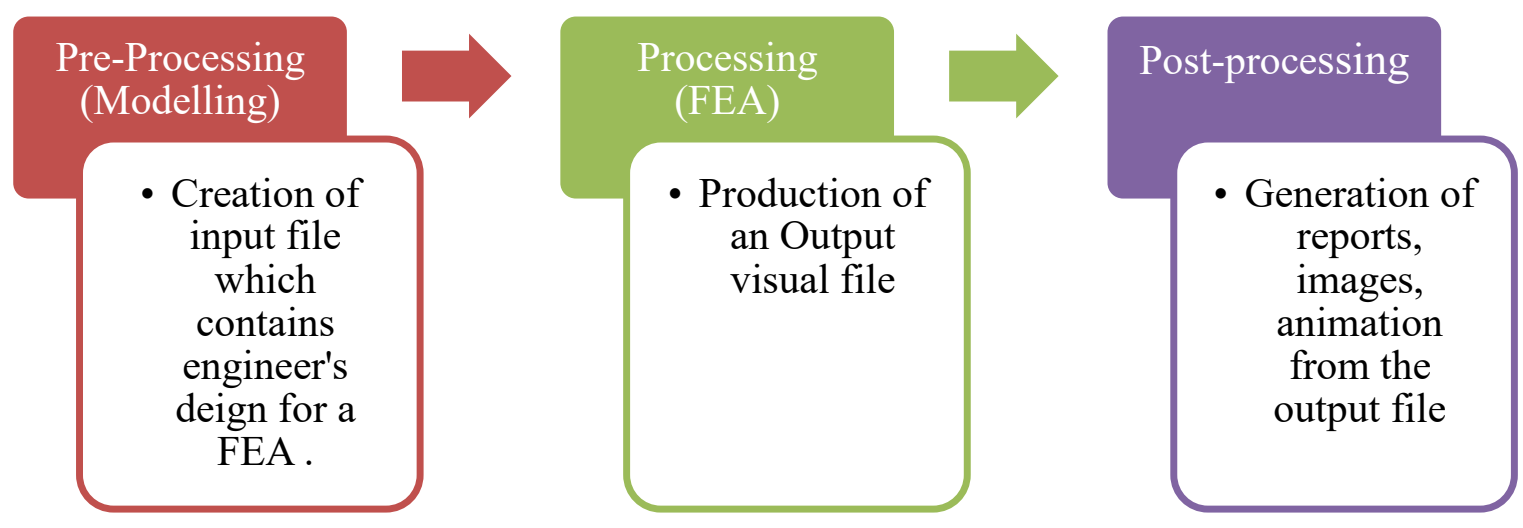

Figure 2-27: The Three Stages of FEA

Every complete FEA consists of three (3) separate stages (Figure 2-27). The ABAQUS/CAE (computer-aided engineering) can perform all three stages efficiently, in addition, the first stage can also be done with other compatible computer-aided design (CAD) software, or a text editor which makes the program very resourceful to use. ABAQUS is command-line accessible and therefore supports scripting functionality (Gardner, et al., 2005). ABAQUS offers a user-friendly interface and therefore allows the user to easily adapt to the tools in modelling and analyzing complex three-dimensional problems. It is an equation based FEA software that has two main solvers; Standard and Explicit and has the capability to run a variety of simulations. Such Multiphysics simulations include coupled acoustic-structural, piezoelectric, and structuralpore capabilities, making it attractive for production-level simulations where multiple fields need to be coupled. ABAQUS has no modules or packages for machining simulations and therefore the user can perform very thorough analysis right from the start without using any pre-set controls and assumptions. This provides the user with control over the entire simulation process. Joints, connections and other discontinuities can be also modelled into the program. It was initially designed to address non-linear physical behaviour, thus, the package has an extensive range of material models such as elastomeric 
material capabilities. Though ABAQUS has no support for any specific materials, it gives the user the ability to configure the materials using a variety of parameters, due to this it is popularly used by the non-academic and research institutions in engineering since it can be customized. In addition, it has a very fine and precise control over the meshing in the model (Gardner, et al., 2005). Meshing in any FEA is very important as this determines the computational time and accuracy of the output. The accuracy of the FEA results measured on the exact solution of the mathematical model, highly depends on the use of an appropriate mesh, and this holds true when coarse meshes need be used to reduce the computational time employed for complex analyses. Hence, effective mesh generation procedures are most important (Bathe, 1996). For instance, in refining a mesh, the user is provided with a wide variety of options; seeding, partitioning and virtual topology. The user can optimize the mesh chosen and verify the mesh concerning the quality of the elements used in the mesh (Dassault Systemes Simulia Corp., 2013)

\subsection{Summary}

Masonry walls could be either reinforced or unreinforced. Unreinforced masonry walls, for instance non-loadbearing walls from a fire perspective, have considerable capacity to isolate parts of the building's interior from fire flames, heat, and the effect of smoke. This in a way lessens the rate of occurrence of structural problems; spalling, cracking, and thermal bowing, which could be associated with such walls. Conduction, convection and radiation are the modes of heat transfer that occur when these walls are subjected to elevated temperatures. Convection and radiation have been observed to be the dominant modes of heat transfer within non-loadbearing masonry walls.

Fire resistance of non-loadbearing masonry walls can be determined based on the 
insulation criterion. This criterion ensures the containment of room fires to avoid spread of smoke, gases and flames to adjacent rooms. The failure of such walls, occurs if during the fire test period, there is a temperature rise of $180^{\circ} \mathrm{C}$ at any one of the nine points on the unexposed side of the wall or an average temperature rise of $140^{\circ} \mathrm{C}$. For any heat transfer problem, there are thermal properties, which could either increase or decrease the rate of heat transfer through the member, assembly or structural element. The heat transfer within these structures in turn determines the overall fire resistance of the member. These thermal properties include density, thermal conductivity and specific heat capacity of materials under study. The literature review focused on assessing the thermal properties of two main types of concrete masonry mix designs, LWC and NWC, after exposure to elevated temperatures. Under the NWC, other forms of concrete masonry, which can be found in this category, include SCC, IRC, and LRC. LFC and NLWC fall under the LWC category. From both categories, it could be observed that the LFC and NLWC showed the best thermal behaviour when subjected to elevated temperatures.

Insulation materials that would be used as inserts in the hollow sections of the concrete masonry blocks were also investigated. Two forms of materials were reviewed; inorganic and organic fibres. However, only inorganic fibres, slag wool, rock wool and glass wool were further assessed for their thermal properties. These materials proved to have the lowest thermal conductivity when compared with the all the other forms of concrete masonry mix designs.

Based on these materials, non-loadbearing masonry walls would be constructed and analyzed for their fire resistance accordingly. These walls fall under the complex structural fire design section and as such, the finite element method would be adopted for all the 
analyses. The finite element method unlike the finite difference method focuses on a piecewise representation of the solution in terms of specified basis functions. Analysis of such problems can be achieved by using a finite element software program. This research adopts the ABAQUS 6.13/Cae Standard software package to model, analyze and provide results for all the walls. Input files would be generated after models have been created and further analysis would be performed on the Carleton University Cygwin 64 Terminal where output files will be generated after complete analysis. 


\section{Chapter: Methodology}

\subsection{Introduction}

The scope of this Chapter is to describe the numerical simulations, which were conducted to determine the fire performance of the studied masonry walls. It further investigates and predicts the fire performance of other masonry walls constructed from concrete masonry based on the literature review. A robust and reliable three-dimensional finite element model was developed to simulate the fire resistance tests, which has been conducted earlier, as part of an ongoing fire-masonry research at Carleton University. The numerical simulations were performed using the ABAQUS/Standard V 6.13 (Dassault Systemes Simulia Corp., 2013), a commercial finite element software. A pure heat transfer analysis was further employed to simulate the thermal behaviour of the modelled assembly in fire conditions since this is a pure thermal analysis. Calibration of the modelled assembly was done by evaluating different parameters; coefficient of convection, surface emissivity and mesh sizes in several iterative procedures on a sample model. The experimental results were used to validate the fully developed model.

\subsection{Experimental Work}

To examine the fire performance of the masonry walls, several fire resistance tests have been conducted at the Fire Research Facility of Carleton University, located in Almonte, Ontario. The research examined the fire performance of four different masonry walls used in the masonry industry by conducting fire resistance tests.

The scope of the current numerical study is in two parts. The first part focuses on developing a model that simulates the fire performance of one of the studied walls where 
the results from this model are validated using the experimental results obtained from Carleton's research. The second part focuses on using the validated model to analyze other forms of novel concrete masonry in a parametric study based on the thermal properties.

\subsubsection{Objective}

The main objective is to evaluate the key parameters, which govern the fire performance of the different forms of concrete masonry used in the construction of masonry walls, and to suggest the best form of concrete masonry used for this construction.

\subsubsection{Test description and procedure}

The test setup comprised walls which were $2.8 \mathrm{~m}$ wide and $3.2 \mathrm{~m}$ tall (7 blocks wide and 16 courses high), Figure 3-2. Each of the walls were built within a frame of reinforced concrete masonry columns and beams comprised of $20 \mathrm{~cm} \mathrm{NWC} \mathrm{hollow} \mathrm{block} \mathrm{mortared}$ with Type S mortar, Figure 3-3. Type S mortar is suitable for general and below-grade uses and particularly when high lateral strength is required (Drysdale \& Hamid, 2005). The strength of the masonry block was $15 \mathrm{MPa}$. Masonry blocks used were hollow and therefore since grout and reinforcement bars were not used in the construction of the walls, the cells of the block were left hollow. The walls were subjected to a standard fire temperature curve as prescribed in the CAN/ULC S-101 (CAN/ULC-S101, 2007). The modes of heat transfer on the masonry wall were through convection, radiation and

conduction. Figure 3-4. Eighteen (18) thermocouples were used to measure the temperature of the exposed and unexposed sides of the wall (nine on each side) (Figure $3-5)$.

Masonry walls are anisotropic in geometry and moisture content, therefore three different unique locations for placing thermocouples were used; Solid Section (S), Hollow Section 
(H) and Mortar Section (M), Table 3-1. A special block, which was located on the $9^{\text {th }}$ thermocouple, was chosen and an additional eleven (11) thermocouples were used to evaluate the effect of temperature rise within the three unique locations. These include M1M3, S1-S3 and H1-H5 (Figure 3-1).

Table 3-1: Role of thermocouple locations within special block

\begin{tabular}{|c|c|}
\hline $\begin{array}{l}\text { Thermocouple } \\
\text { location (TL) }\end{array}$ & Role \\
\hline M1 & $\begin{array}{l}\text { Temperature measurement of mortar at right end web on the exposed } \\
\text { side }\end{array}$ \\
\hline M2 & Temperature measurement of mortar within the right frog \\
\hline M3 & $\begin{array}{l}\text { Temperature measurement of mortar at right end web on the unexposed } \\
\text { side }\end{array}$ \\
\hline S1 & $\begin{array}{l}\text { Temperature measurement of the solid section at the top end of the } \\
\text { central flange on the exposed side }\end{array}$ \\
\hline S2 & $\begin{array}{l}\text { Temperature measurement of the solid section at the middle part of the } \\
\text { central flange }\end{array}$ \\
\hline S3 & $\begin{array}{l}\text { Temperature measurement of the solid section at the bottom end of the } \\
\text { central flange on the unexposed side }\end{array}$ \\
\hline H1 & $\begin{array}{l}\text { Temperature measurement of the hollow section end web on the } \\
\text { exposed side }\end{array}$ \\
\hline $\mathrm{H} 2$ & $\begin{array}{l}\text { Temperature measurement of the hollow section at the top end web } \\
\text { (towards the exposed side) }\end{array}$ \\
\hline $\mathrm{H} 3$ & Temperature measurement of the hollow section within the cell \\
\hline $\mathrm{H} 4$ & $\begin{array}{l}\text { Temperature measurement of the hollow section at the bottom end web } \\
\text { (towards the unexposed side) }\end{array}$ \\
\hline $\mathrm{H} 5$ & $\begin{array}{l}\text { Temperature measurement of the hollow section end web on the } \\
\text { unexposed side }\end{array}$ \\
\hline
\end{tabular}

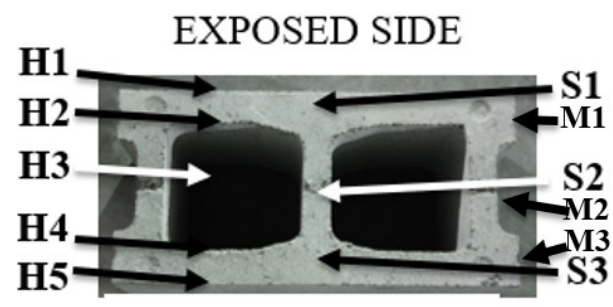

UNEXPOSED SIDE

Figure 3-1: Thermocouple locations within the special block 


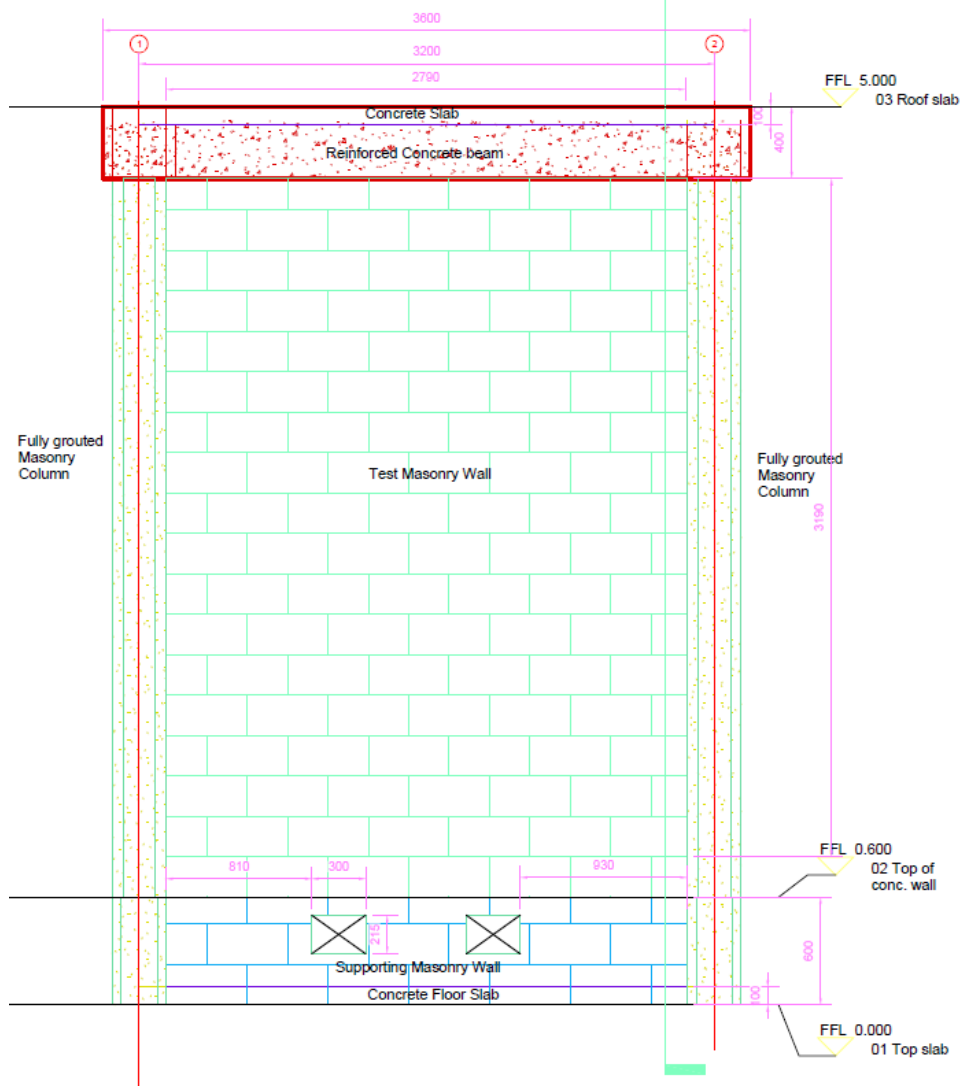

Figure 3-2: Illustration of test setup with dimensions

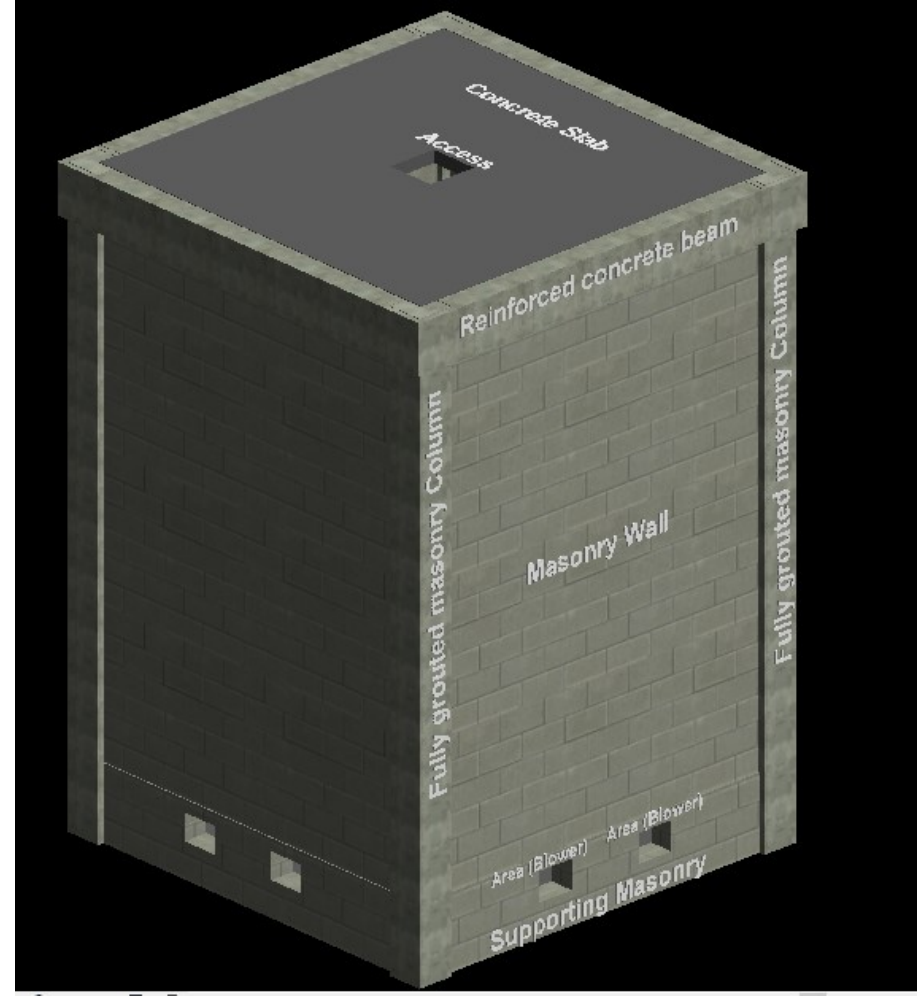

Figure 3-3: 3D illustration of experimental test setup 


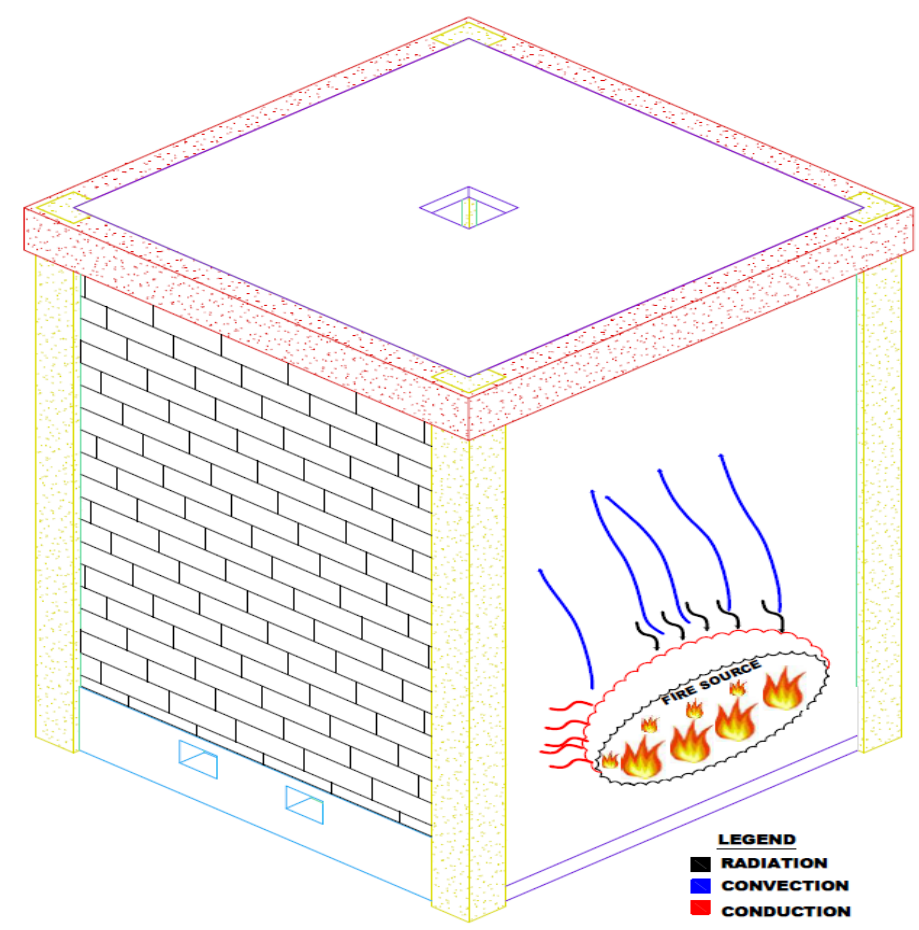

Figure 3-4: Modes of heat transfer within experimental test setup

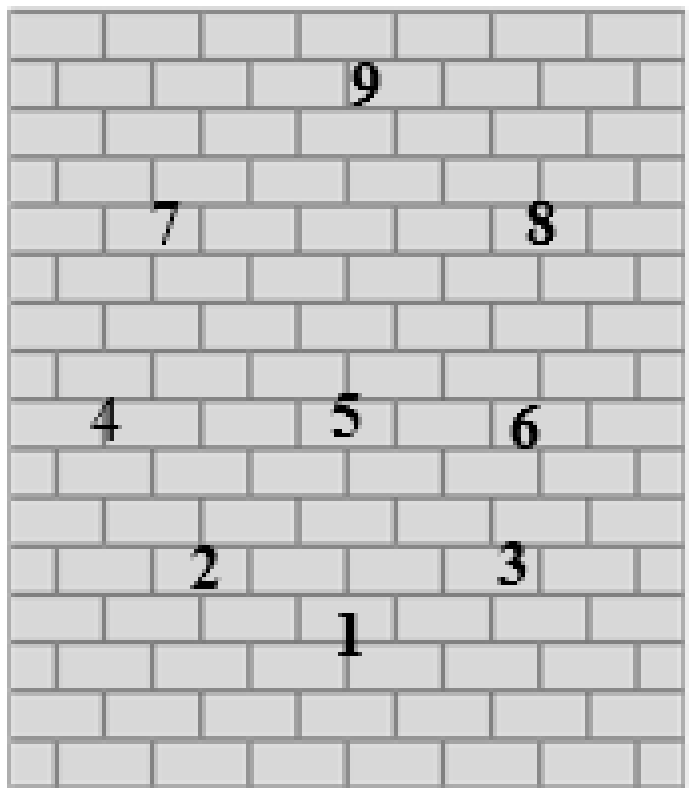

1- Mortar Joint (M)

2- Hollow Section $(\mathrm{H})$

3- Solid Section (S)

4- Mortar Joint (M)

5- Hollow Section $(\mathrm{H})$

6- Solid Section (S)

7- Hollow Section $(\mathrm{H})$

8- Solid Section (S)

9- Special Block (SB)

Figure 3-5: Thermocouple locations on unexposed side of the test wall 


\subsection{Fire and Heat Transfer Models}

The finite element method would be used to simulate the fire resistance tests. This is a pure thermal analysis, which is a form of analysis which focuses on evaluating the temperature profile within a given material, member or assembly. Therefore, only the fire and heat transfer model would be developed. The fire model is essentially an input, which can be selected from a set of time-temperature curves including; the standard fire, measured real fire or a parametric fire curve (Buchanan, 2006). In this research, the CAN/ULC S-101 fire curve (CAN/ULC-S101, 2007) is adopted for the input in the analysis for the fire model. The heat transfer model is essential in calculating the fire resistance because the insulation criterion, which is the most common failure mechanism for partition walls, depends on the internal temperature. The temperature of any material is known to increase as heat is conducted from the heat-exposed surface to the unexposed surface. The computation of this model requires knowledge of the geometry of the element, thermal properties of the material and the heat transfer coefficients at the boundaries (Buchanan, 2006).

\subsection{Numerical Simulation Technique}

In a pure thermal analysis, the main components of the finite element model are the finite element discretization and meshing, material model, contact properties and interactions, thermal load and boundary conditions, and procedure for analysis. All these components are discussed in the context of their place within the ABAQUS (Dassault Systemes Simulia Corp., 2013) finite element package in the following sections.

\subsubsection{Finite element discretization and meshing}

All parts of the assembly were first created and then assembled under the assembly module.

Figure 3-6 illustrates all the parts that were modelled and assembled. These parts include 
the standard $20 \mathrm{~cm}$ masonry blocks (corner and middle block), half block, head and bed joints. Extrusion and cut features were employed to model all components of the assembly. Mortar was modelled in ABAQUS as a uniform rectangular shape as compared to the experimental mortar joint to accommodate the effective interaction module, which was generated. From the ABAQUS element library, an eight-node linear interpolation diffusion heat transfer brick (DC3D8) element was selected to simulate the heat flow through the concrete masonry block and the mortar units. This solid segment three-dimensional element has the capability to formulate the geometry of the concrete masonry block and mortar joints. The degree of freedom associated with adopting the use of this element is a scalar temperature denoted as NT11. To simulate the non-linear behaviour of the full assembly solid homogenous sections are assigned to all the parts within the assembly.

\section{CREATION OF PARTS FOR ASSEMBLY OF MASONRY WALL}

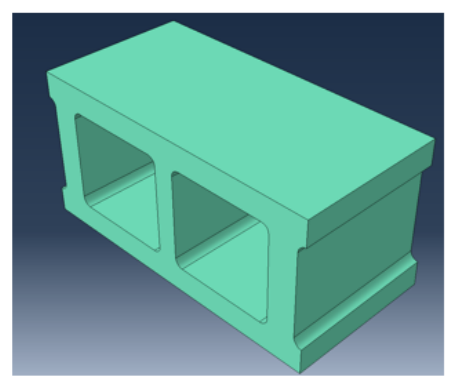

Standard $20 \mathrm{~cm}$ Masonry Block (Middle Block)

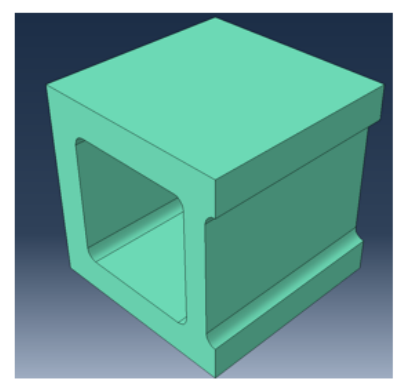

Half Block

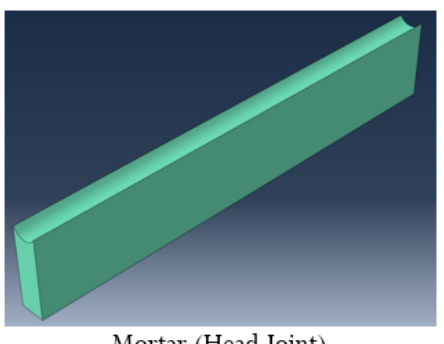

Mortar (Head Joint)

Figure 3-6: Creation of Parts for the Assembly of the Wall

A finite element analysis of any physical problem requires that a mesh of finite elements 
be generated. Generation of finite element meshes is a fundamental step and can require both significant human and computational efforts, as such, procedures have been developed and thus implanted that automatize the mesh generation without necessarily human intervention as much as possible (Bathe, 1996). Basic problems, which involve automatic mesh generation, include the following:

- Given geometries which are complex but however have small features such as holes and chamfers, which are hidden within large geometric sections

- The choice of certain element types which could be much preferable over other types of elements

- Graded meshes are to be used for effective solutions; this implies that finer meshes should be used in regions of critical stress, temperature, etc. concentrations.

Based on these points, meshing of the parts were controlled by the geometry, discontinuities and contact interactions of the assembly. Different mesh sizes were adopted to fit the curvature geometry of each of the components (Figure 3-7). Though automatically generated, the mesh sizes were chosen based on several iterative simulations to ensure the assessment of accuracy of the finite element solution to the mathematical model. The size of the meshes is very important since it determines the computational time as well as the accuracy of the solution. Graded meshes were chosen for areas of critical temperature concentrations such as within the mortar regions and the hollow sections. Therefore, different meshing techniques were adopted for the mortar and block parts. Areas of the hollow sections with the curved areas were meshed along the edges and a finer mesh was used in such sections. This technique was also adopted for the mortar sections. 


\section{ELEMENT TYPE AND DISCRETIZATION}

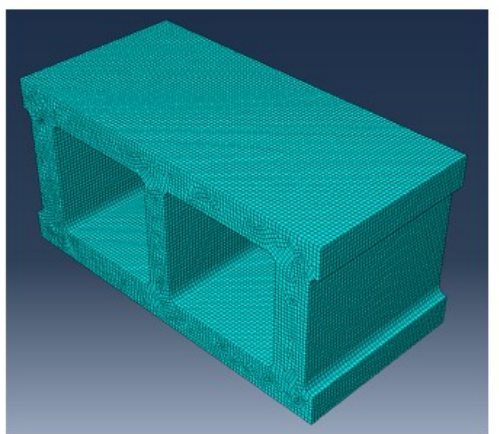

Standard 20cm Masonry Block (Middle Block)

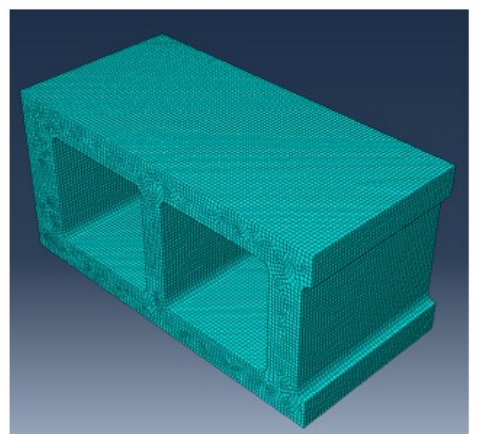

Standard $20 \mathrm{~cm}$ Masonry Block (Corner Block)

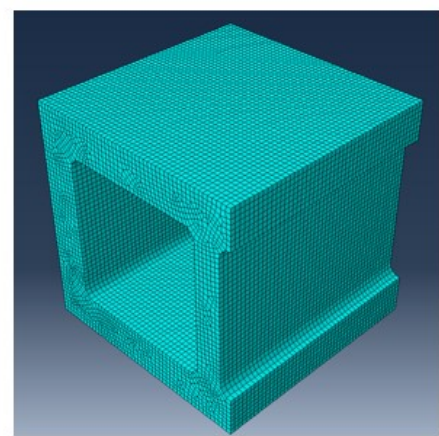

Half Block

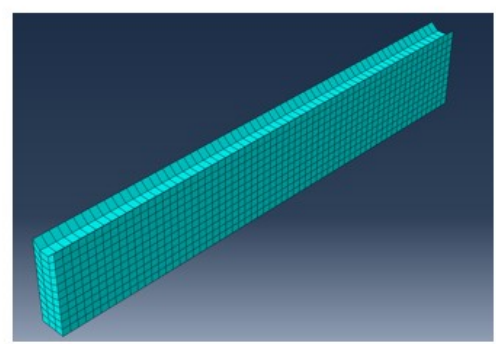

Mortar (Head Joint)

Mortar (Bed Joint)

Figure 3-7: Meshing of parts for assembly

\subsubsection{Material module}

To compute the fire resistance of the assembly, the heat transfer model requires the thermal properties of the material. These thermal properties, which govern the thermal behaviour in a heat transfer analysis, include density $(\rho)$, specific heat capacity $\left(C_{p}\right)$ and thermal conductivity $(k)$. Thermal properties of all concrete masonry units as well as mortar samples vary with change in temperature, making the heat transfer non-linear. To incorporate this into the material model, ABAQUS provides an option to define any temperature-dependent data items. The critical temperature range for most concrete masonry units is within $20^{\circ} \mathrm{C}$ to $800^{\circ} \mathrm{C}$ (Arioz, 2007) and therefore this was the chosen temperature range used for the analysis.

The density of most concrete masonry will be reduced by about $100 \mathrm{~kg} / \mathrm{m}^{3}$ when heated to 
a temperature of about $100^{\circ} \mathrm{C}$ (free water evaporation). However, this has a minor effect on the thermal response. Other than these moisture changes, there is no significant changes in the density at elevated temperatures (Buchanan, 2006). The thermal conductivity represents how easily heat flows within the material and for most concrete materials as the temperature increases, the thermal conductivity reduces (See Sec. 2.6.1 and Figure 2-4). However, for most concrete masonry materials, the specific heat capacity increases with an increase in temperature (See Sec. 2.6.2 and Figure 2-5). Detailed values for the density, specific heat and thermal conductivity for all the different forms of concrete masonry used in the analysis has been tabulated in Appendix A

\subsubsection{Contact properties and interactions}

The ABAQUS model, though assembled needs to be further connected in the interaction module. Generally, a contact can be defined in two scopes; physically, a contact involves interactions between bodies and numerically, contact includes severe nonlinearities. The basic components of a contact model in ABAQUS, involves the following; contact surfaces, contact interactions, surface property assignments, contact property models, contact formulation aspects, and algorithmic contact controls.

In the Assembly module, many contacts occur between the surfaces such as the concrete masonry block and mortar joint interactions. The interaction between these surfaces are sources of discontinuities in the model and therefore become critical during the analysis process. Contact elements and contact algorithms are needed to cater for these discontinuities during the numerical simulation. This is achieved by first defining a contact property in the interaction module. For the developed model, since materials in contact 
were solid bodies transmitting heat energy, thermal conductance property was selected for the entire assembly. The thermal conductance property defines a conductance between the surfaces in contact (Dassault Systemes Simulia Corp., 2013). To define these contact interactions, surfaces in contact must be identified. Surfaces in contact are therefore referred to as "contact pairs"; these can be generated automatically or manually. Once the property has been defined and the surfaces in contact have been identified, a master and slave surface were defined for all surfaces in contact. For each contact pair, the thermal conductance property was defined. The meshing techniques are applied in this module to define which surface is master and which is the slave. Master and slave surfaces are roles, which are assigned to surfaces in the contact interaction formulation of a numerical simulation. The contact interaction formulation in ABAQUS requires that the specific slave surfaces are more finely meshed of the surfaces and it should be a softer underlying material surface (if the mesh sizes are similar). (Dassault Systemes Simulia Corp., 2013). In the current developed model, the concrete masonry block was the master surface while that of the slave surface was assigned to the mortar joint. For this model, a total of 641 interactions were defined between the concrete masonry block and mortar joint. These interactions were applied to the initial step of the analysis in the interaction module. A second form of interaction involving surface radiation was used in the heat transfer step in the interaction module. For this form, a surface emissivity and film coefficients were both defined as interaction properties and then applied to the hollow sections of the assembly Figure 3-8. 


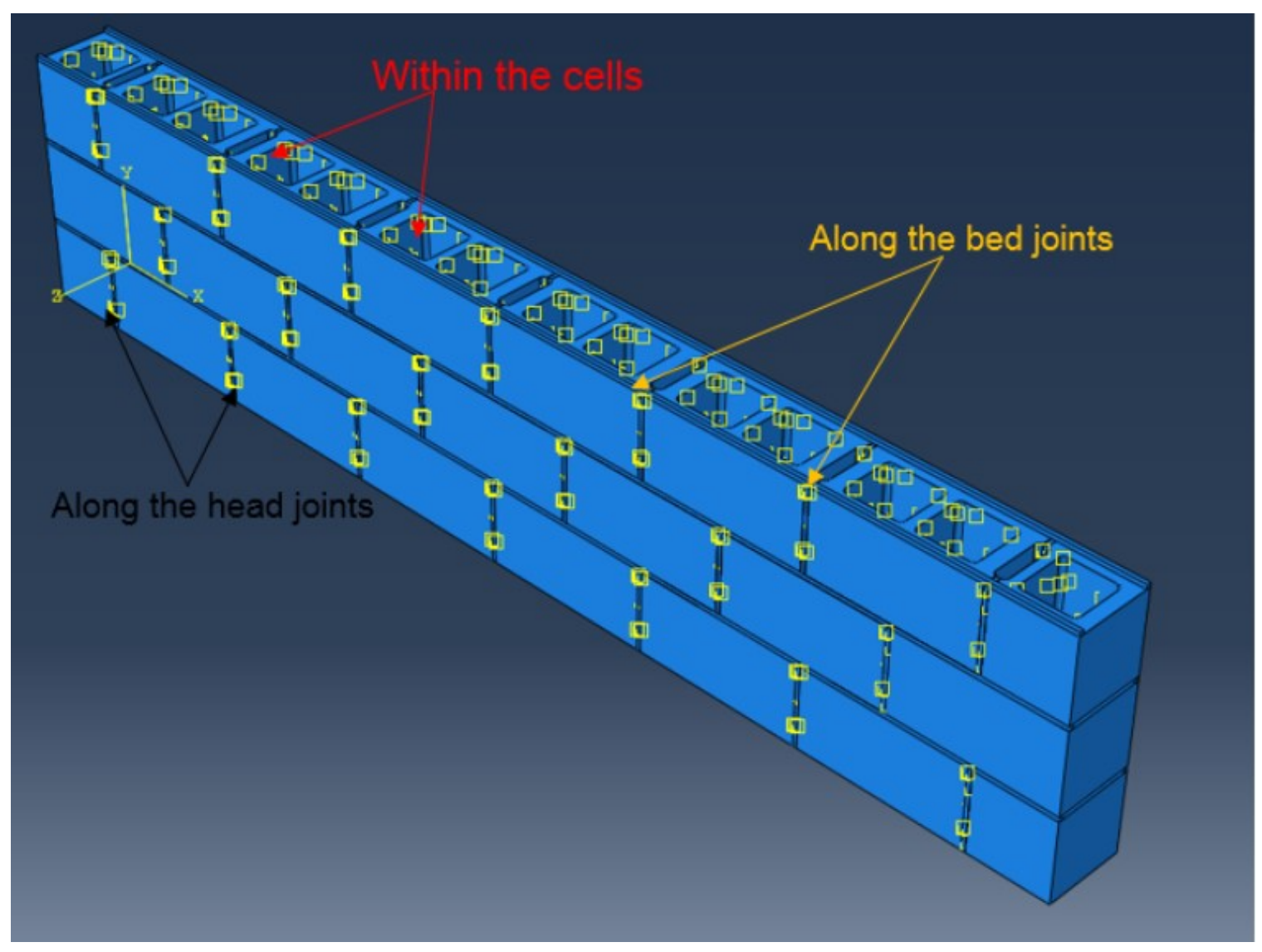

Figure 3-8: Contact interactions assigned to the different components in the assembly module

\subsubsection{Thermal load and boundary conditions}

The thermal load and boundary conditions are required to define the effective modes of heat transfer. A propane burner was used as the heat source during the experimental fire resistance test. The heat generated from the propane burner increases the temperature of the air in the furnace and the furnace boundaries beyond the ambient conditions. Furthermore, the furnace enclosure and its boundaries, which are at elevated temperatures, transmit heat energy to the boundaries of the test assembly through convective and radiative heating. The masonry walls were built within a frame of reinforced concrete columns and beams which clearly depicts a typical wall in a building. The geometry of the 
masonry wall was divided into exposed surface (hot), unexposed surface (cold), and the side surfaces were considered unexposed as they were insulated.

The heat to the exposed surfaces of the assembly was modelled as a uniform heat flux, $\dot{q} "$ $\left(\mathrm{W} / \mathrm{m}^{2}\right)$, Equation 3-1

$$
\dot{q}^{\prime \prime}=h_{c}\left(T_{f}-T_{s}\right)+\emptyset \varepsilon_{f f} \sigma\left(T_{f}^{4}-T_{s}^{4}\right)
$$

Equation 3-1

Where;

$h_{c}=$ coefficient of convection, $T_{f}=$ furnace temperature $(\mathrm{K}), T_{s}=$ surface temperature of assembly $(\mathrm{K}), \varnothing=$ configuration factor, $\varepsilon_{f f}=$ surface emissivity, $\sigma=$ Stefan-Boltzmann constant, $\left(5.67 \times 10^{8} \mathrm{~W} / \mathrm{m}^{2} \mathrm{~K}^{4}\right)$

In the ABAQUS model, this estimated heat flux was incorporated as a boundary condition to the modelled assembly surface through an edited user Distributed Flux (DFLUX) subroutine developed by (Peng, 2010) (See B.1). The DFLUX subroutine is a set of computer programming instructions, which is incorporated in an ABAQUS simulation for applying thermal loads on a modelled assembly. In adopting the use of a DFLUX subroutine, the heat flux to the boundary of a model can be applied as a distributed flux to the exposed surface. The DFLUX subroutine applies heat flux uniformly as a function of position, time, temperature, element number and integration point number of the assembly during the heat transfer analysis (Dassault Systemes Simulia Corp., 2013). To depict the experimental fire scenario, which provides heat non-uniformly within the assembly, the application of radiation and convection coefficients during the heat transfer is performed in ABAQUS.

The transient conduction of heat within the entire assembly is governed by the threedimensional heat transfer equation, Equation 3-2 
$\rho c \frac{\partial T}{\partial t}=\frac{\partial}{\partial x}\left(k \frac{\partial T}{\partial x}\right)+\frac{\partial}{\partial y}\left(k \frac{\partial T}{\partial y}\right)+\frac{\partial}{\partial z}\left(k \frac{\partial T}{\partial z}\right)+S$

Equation 3-2

Where;

$\rho=$ density $\left(\mathrm{kg} / \mathrm{m}^{3}\right), x, y, z=$ distances in the respective axes from heat source, $c=$ specific heat capacity $(\mathrm{J} / \mathrm{kgK}), k=$ thermal conductivity $(\mathrm{W} / \mathrm{mK}), t=$ time $(\mathrm{s}), S=$ Source of heat $\left(\mathrm{W} / \mathrm{m}^{3}\right)$

\subsubsection{Procedure for analysis}

The ABAQUS program requires that steps be created for each analysis stage depending on the number of analyses to be performed. The analysis procedure first commences with an initial step, which is then followed by the user-defined steps. The initial step is a default step, which cannot be modified in ABAQUS but is used to initiate boundary conditions as well as contact interactions before the commencement of the analysis. The user-defined steps are created to analyze the finite element model during simulation of the physical problem. Each step defined within the analysis contains a procedure, which is suitable for solving the problem.

A heat transfer step was created for computing the temperature rise within the masonry wall in this research. Non-linear numerical simulation was considered due to the nonlinearity of the material properties with temperature. To incorporate this into the finite element solution, a pure heat transfer analysis was conducted on the entire assembly. This form of analysis requires primarily inputting an ambient temperature to the entire assembly at the start of the test. A "predefined field" serves as the input for this temperature in ABAQUS. An initial predefined temperature of $5^{\circ} \mathrm{C}$ was applied on the whole assembly. This temperature was chosen because the experimental test took place during the winter and therefore at the time of the test, this was the ambient temperature recorded. Heat flux 
was applied uniformly to the exposed surfaces on the assembly and the heat penetrated the modelled test assembly over a period (Figure 3-9). The full Newton method was adopted for the transient heat analysis. This method is an iterative scheme, which can resolve potential non-linearities during the heat transfer analysis. The sources of these nonlinearities include the non-linear temperature-dependent properties of the materials and radiation heat flux effects (Dassault Systemes Simulia Corp., 2013). A nodal temperaturetime history at all points in the assembly during the duration of the fire exposure was the output obtained from this analysis.

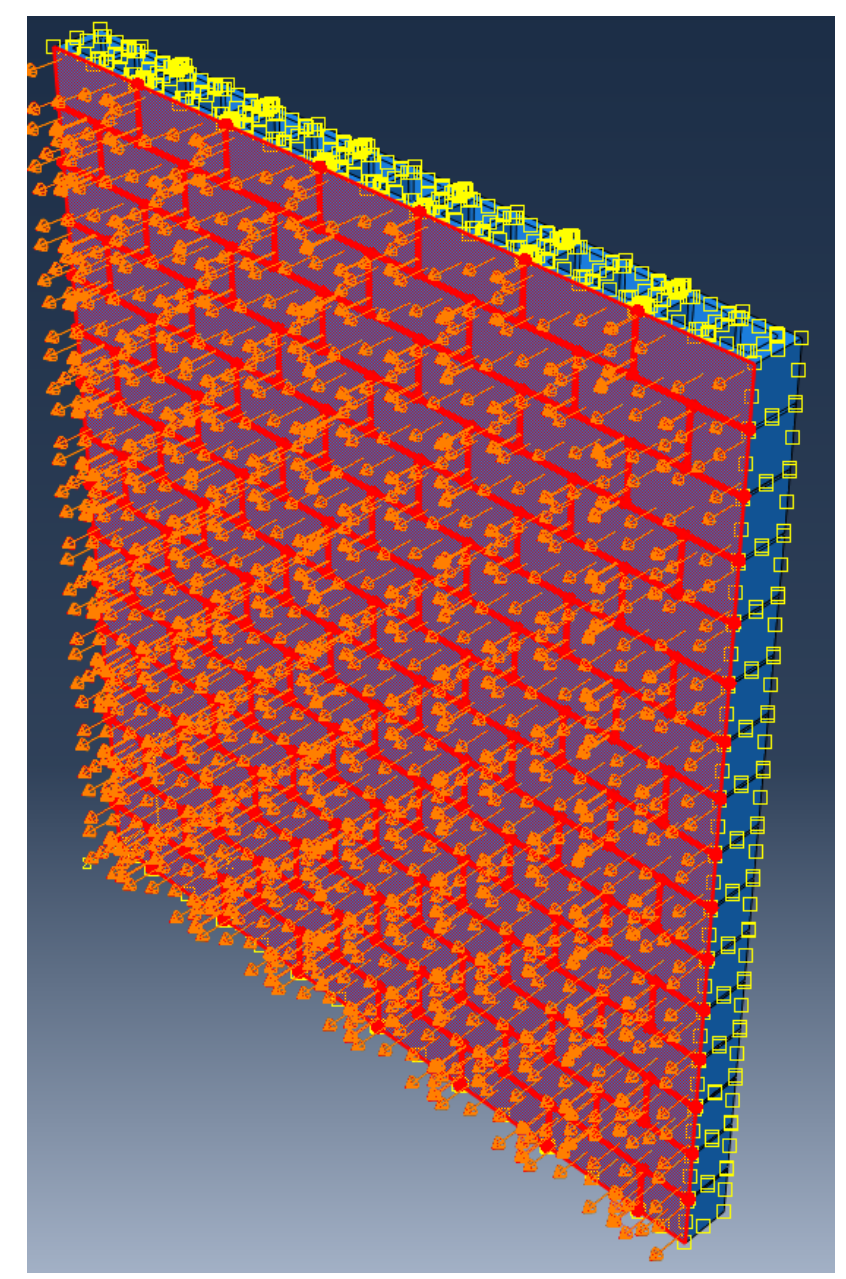

Figure 3-9: Thermal Load and Boundary Condition on Modelled Assembly 


\subsection{Summary}

A finite element model was developed to simulate the temperature rise within masonry walls assemblies. The overall thermal behaviour in a fire resistance test includes the transient heat transfer on the assembly. This has been achieved by incorporating the nonlinear properties caused by temperature variation into the model. Thermal convection and radiation governed the heat transfer between the furnace environment and the exposed surface of the sample. Mode of conduction between the solid sections of the assembly has been incorporated into the interaction module through a surface-to-surface contact property. Mesh sensitivity analysis would be performed to obtain results that converge to the experimental results and thereby calibrate and validate the model. The pure thermal analysis procedure will be used to analyze the model. The fire resistance of the masonry wall assemblies can then be estimated as the time to failure after being exposed to the elevated temperatures of the fire. 


\section{Chapter: Results and Discussion}

\subsection{Introduction}

The developed model as discussed in 3.4 was used to simulate the thermal behaviour of masonry walls constructed with different joint profiles, geometries, mix designs and insulating materials (inserts). Geometries of the block units considered are a $10 \mathrm{~cm}, 15 \mathrm{~cm}$ and $20 \mathrm{~cm}$ standard block units. The joint profiles include the raked and standard concave joints. LWC, SCCA, IRCA, LRCA, NLWC and LFC were the different concrete mix designs examined. The insulating materials include mineral wool, stone wool and slag wool. The model was first validated to ensure its reliability in simulating the actual thermal behaviour obtained from experimental work done on NWC masonry walls. The heat transfer and temperature distribution in the assembly over the duration of fire exposure are discussed and compared with test results. The average temperature on the masonry walls are also examined by comparing the results obtained for the different forms of walls grouped generally under NWC and LWC.

\subsection{Calibration of the Model}

\subsubsection{Mesh sensitivity analysis}

Mesh sensitivity analysis was performed on walls made from normal weight concrete masonry mortared with Type S mortar. The total number of elements that are produced for each mesh choice are presented in Table 4-1. The table highlights the seeding techniques and number of elements used for the different parts of the assembly. This was done in three

modes; a coarse, medium and fine mesh analysis. The finer the mesh, the higher the number of elements used and vice versa. 
Table 4-1: Mesh sensitivity analysis

\begin{tabular}{|c|c|c|c|c|c|c|}
\hline \multicolumn{7}{|c|}{ Mesh Sensitivity Analysis } \\
\hline Mesh & \multicolumn{2}{|c|}{ Coarse } & \multicolumn{2}{|c|}{ Medium } & \multicolumn{2}{|c|}{ Fine } \\
\hline $\begin{array}{c}\text { Size Block } \\
\text { Type }\end{array}$ & $\begin{array}{c}\text { Seed } \\
\text { (Edges) }\end{array}$ & $\begin{array}{c}\text { No. of } \\
\text { Elements }\end{array}$ & $\begin{array}{c}\text { Seed } \\
\text { (Edges) }\end{array}$ & $\begin{array}{c}\text { No. of } \\
\text { Elements }\end{array}$ & $\begin{array}{c}\text { Seed } \\
\text { (Edges) }\end{array}$ & $\begin{array}{c}\text { No. of } \\
\text { Elements }\end{array}$ \\
\hline $\begin{array}{l}\text { Middle } \\
\text { Block }\end{array}$ & 0.018 & 2365 & 0.015 & 3640 & 0.009 & 11907 \\
\hline $\begin{array}{l}\text { Corner } \\
\text { Block }\end{array}$ & 0.018 & 2090 & 0.015 & 3419 & 0.009 & 12159 \\
\hline $\begin{array}{l}\text { Half } \\
\text { Block }\end{array}$ & 0.019 & 770 & 0.015 & 1599 & 0.009 & 6237 \\
\hline Bed joint & 0.06 & 47 & 0.08 & 70 & 0.02 & 140 \\
\hline Head joint & 0.008 & 192 & 0.007 & 270 & 0.003 & 2079 \\
\hline Total & & 5464 & & 8998 & & 32522 \\
\hline
\end{tabular}

The experimental results were compared to the different meshes that were adopted for analysis. A fine, medium and coarse mesh sizes were employed to evaluate the temperature profiles on the exposed (EX) and unexposed (UN) sides of the wall.

The results obtained for the mesh sensitivity analysis are presented in Figure 4-1 similar in all cases. This behaviour may be explained by the uniformity of the heating action upon the exposed surface resulting from the unidirectional mode. This trend has been observed by previous research authors; (Al-Sibahy \& Edwards, 2012) and (Chow \& Y, 1996), who performed numerical analysis on samples, which were subjected to, elevated temperatures from a unidirectional mode. Another influencing parameter is the isotropic behaviour of the thermal conductivity feature, which may to some extent cause uniform heat transfer within the samples. However, in this research study, the assembly composed of two different members having different thermal conductivities and therefore though the temperature profile was similar in all mesh cases, there were certain points within the 
model, which clearly depicted the difference in thermal conductivities of the assembly. This was notably observed in the numerical model when a particular block from the assembly was chosen and nodal temperatures at various sections was taken.

Based on the mesh sensitivity analysis, the difference in temperatures on the exposed and unexposed vary from about $4^{\circ} \mathrm{C}$ for the fine mesh, $9^{\circ} \mathrm{C}$ for the medium mesh while that of the coarse mesh records about $20^{\circ} \mathrm{C}$ difference in temperature. This behaviour may be explained due to the size of the meshes used. The size of the meshes determines the accuracy of the solution as well as the computational time. The prime objective of using a particular mesh size and technique is to as much as possible obtain results that converge to the actual physical problem, in this case; the experimental test. Therefore, though computational time is another factor to be considered, the accuracy of the results is paramount.

In this mesh sensitivity simulation, the difference in temperature recorded on the unexposed side of the wall between the medium and fine mesh is $5^{\circ} \mathrm{C}$. Comparing the number of elements produced using these meshes; the difference is approximately 23524 elements, which is relatively large. On this basis, to reduce the computational intensity of the analysis as well as calibrate the model and to validate its experimental results, the medium mesh size was selected to perform the entire numerical simulation. 


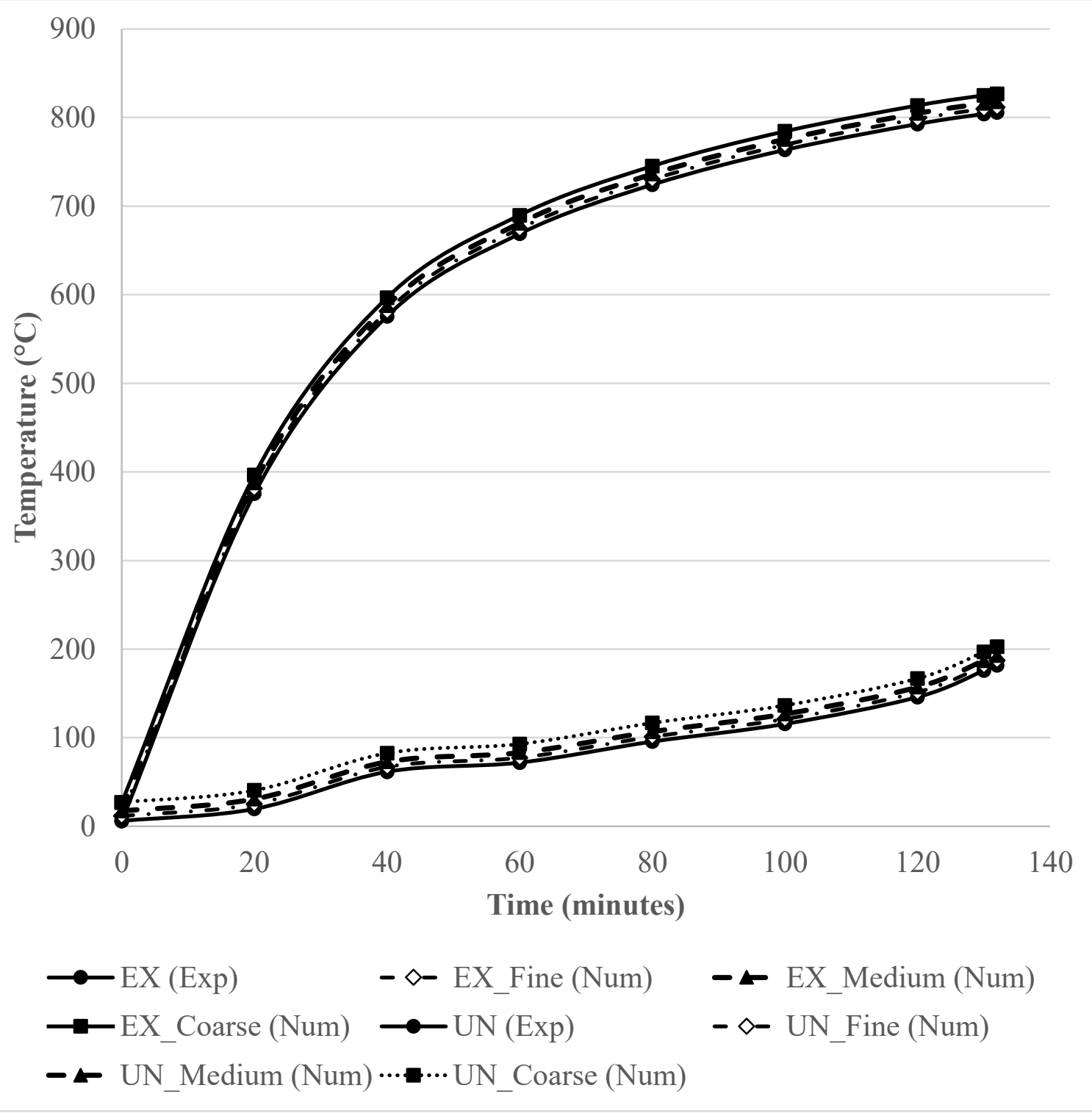

Figure 4-1: Mesh sensitivity analysis for all mesh sizes 


\subsubsection{Coefficient of convection}

The combined effect of convection and radiation serve as the major source of heat transfer from the furnace environment to the exposed surface of the masonry walls and from the unexposed surface to the atmosphere. Chow and Chan (Chow \& Y, 1996) and research work done in the Eurocode (BS EN, 2002) have outlined various ways of applying the convection and radiation actions during exposure to elevate temperatures. There are three cases, which have been summarized below:

1. Case 1: Considering the effects of convection and radiation on both surfaces with values of coefficient of convection (film condition) as $25 \mathrm{~W} / \mathrm{m}^{2} \mathrm{~K}$ and $9 \mathrm{~W} / \mathrm{m}^{2} \mathrm{~K}$ for the exposed and unexposed surfaces respectively (BS EN, 2002).

2. Case 2: Same as Case 1, however with a range of film condition between 7.59.5 W/m $/ \mathrm{m}^{2} \mathrm{~K}$ and $4.5 \mathrm{~W} / \mathrm{m}^{2} \mathrm{~K}$ for the exposed and unexposed surfaces respectively (Chow \& Y, 1996).

3. Case 3: Applying the combined effects of both convection and radiation to the exposed surfaces, while the unexposed surface is only subjected to the convection effect. For this case, the exposed surface has a film convection of $25 \mathrm{~W} / \mathrm{m}^{2} \mathrm{~K}$ while the unexposed is $4 \mathrm{~W} / \mathrm{m}^{2} \mathrm{~K}$

Even though, all these cases are to be considered, the experimental test was performed in a very conservative way. Thermocouples placed on the unexposed side had insulation coverings and as such reduced the effects of convection and radiation to the unexposed side of the wall. This made such losses to the unexposed side almost zero. As such to account for the combined effect of convection and radiation, a coefficient of convection was taken into consideration for only the exposed surface. This parameter was included in 
the (CAN/ULC-S101, 2007) standard fire equation in the DFLUX Subroutine file

\subsubsection{Surface emissivity}

To evaluate the effect of radiation, the surface emissivity of the concrete masonry samples was investigated. The effect of surface radiation was considered within the surfaces of the hollow sections. Three different values forming a practical range of surface emissivity for the various concrete masonry were selected. These were 0.8, 0.85 and 0.9 (ACI Committee 122, 2002).

Temperature results obtained from the experimental work have been compared to the simulated surface emissivity in Figure 4-2. The temperature profile is similar in all cases. For simulated surface emissivity value of 0.80 there is an initial slight reduction in the temperature however, after an hour into the simulation it begins to follow the temperature profile of the experimental test. Surface emissivity of 0.85 and 0.9 follow directly the experimental temperature profile, however, it can be observed that the difference in temperature for surface emissivity value 0.85 is less as compared to that of 0.9 . As a result, the value of 0.85 was selected as an emissivity for the exposed surface, as it represents the mean of the examined values. 


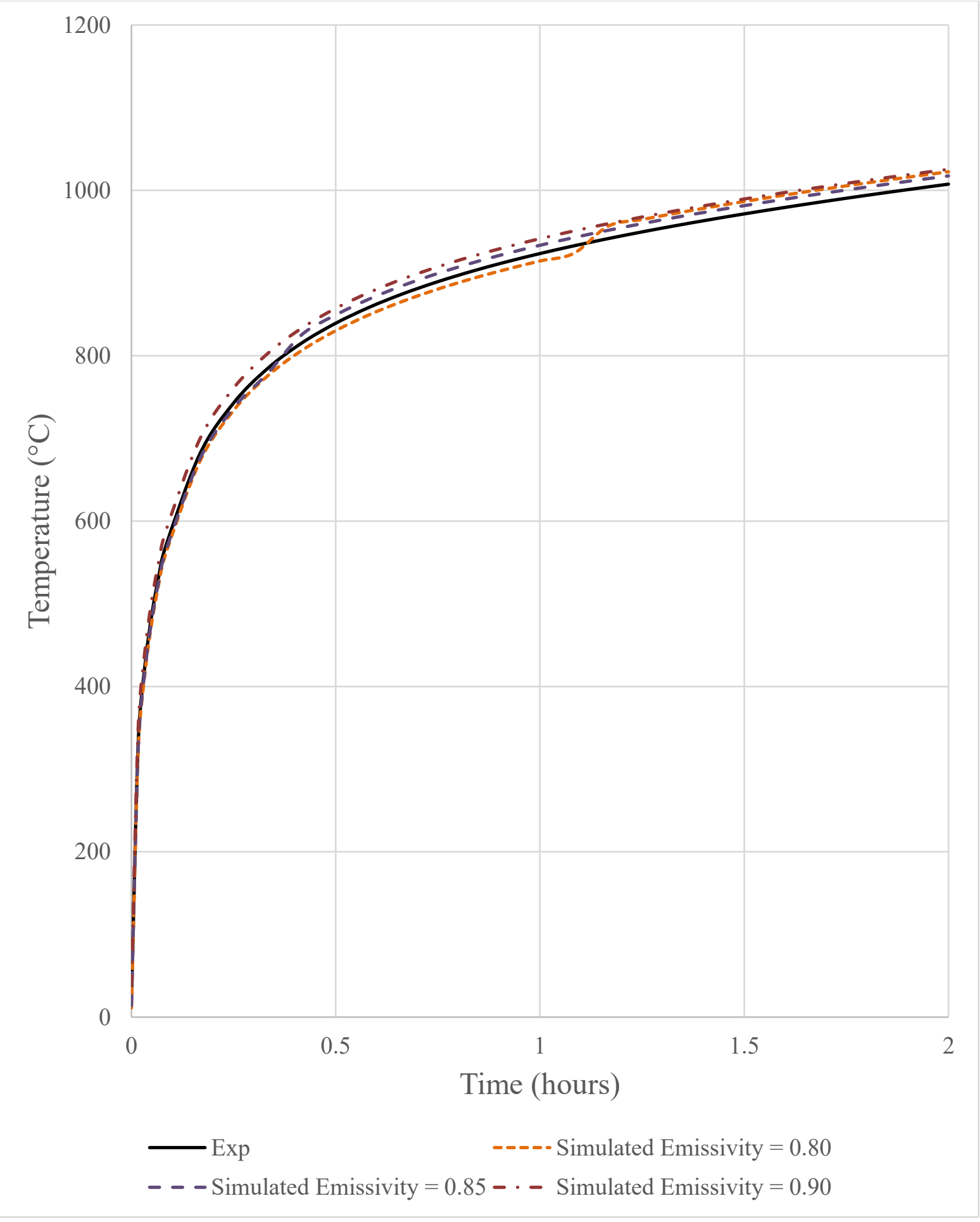

Figure 4-2: The effect of emissivity value on the simulation results of the exposed surface 


\subsection{Validation of the Finite Element Model}

The main parameters that were used in the numerical simulation for the calibration and validation of the model include coefficient of convection, surface emissivity, thermal conductance, density, thermal conductivity and specific heat capacity. The thermal conductance value was obtained from numerical computation from (Cooper, et al., 1969) . Final values have been summarized in Table 4-2.

Table 4-2: Data used in the numerical simulation for validation of the model Property Value

Coefficient of convection $\left(\mathrm{W} / \mathrm{m}^{2} \mathrm{~K}\right)$
Surface emissivity at the exposed surface
Density at exposure to various temperatures
$\left(\mathrm{kg} / \mathrm{m}^{3}\right)$
Specific heat at exposure to various temperatures
$(\mathrm{J} / \mathrm{kgK})$
Thermal conductivity at exposure to various
temperatures $(W / m K)$
25 0.85

See, A.1 and A.3

See, A.1 and A.3

See, A.1 and A.3

\subsection{Results - Geometries}

Three different sizes were considered based on the standards given in ((CCMPA), 2004). The fire resistance for size code 10, 15 and $20 \mathrm{~cm}$ hollow NWC masonry blocks were modelled and evaluated. A total of 3 walls were tested based on this specification. An illustration of the modelled blocks is presented in Table 4-3. 
Table 4-3: Different size codes of concrete masonry hollow blocks as modelled in ABAQUS

\begin{tabular}{|c|c|c|c|}
\hline Block & $10 \mathrm{~cm}$ & $15 \mathrm{~cm}$ & $20 \mathrm{~cm}$ \\
\hline Type/Size & & & \\
\hline Full & & & \\
\hline Half & & & \\
\hline
\end{tabular}

The thermal simulation depicted a true reflection of how the effect of geometry affected the fire resistance of non-loadbearing masonry walls. Masonry walls made of less material and thicknesses were subjected to a faster rate of heat transfer within the assembly. For this numerical simulation, focus was placed on the exact time the unexposed side of the wall reached the average failure temperature based on the insulation criterion. The failure criterion based on the average temperature calls for a rise in temperature of $140^{\circ} \mathrm{C}$ in addition to the predefined field temperature (or $180^{\circ} \mathrm{C}$ at any single point). This brings it to $145^{\circ} \mathrm{C}$ since all walls were subjected to an ambient temperature of $5^{\circ} \mathrm{C}$ (See section 3.4.5). $10 \mathrm{~cm}$ walls attained this average temperature within the first 40 minutes of the simulation, while $15 \mathrm{~cm}$ and $20 \mathrm{~cm}$ blocks recorded this at $50 \mathrm{~min}$ and $90 \mathrm{~min}$ respectively, 
Figure 4-3. Tf refers to the CAN/ULC standard fire temperature curve.

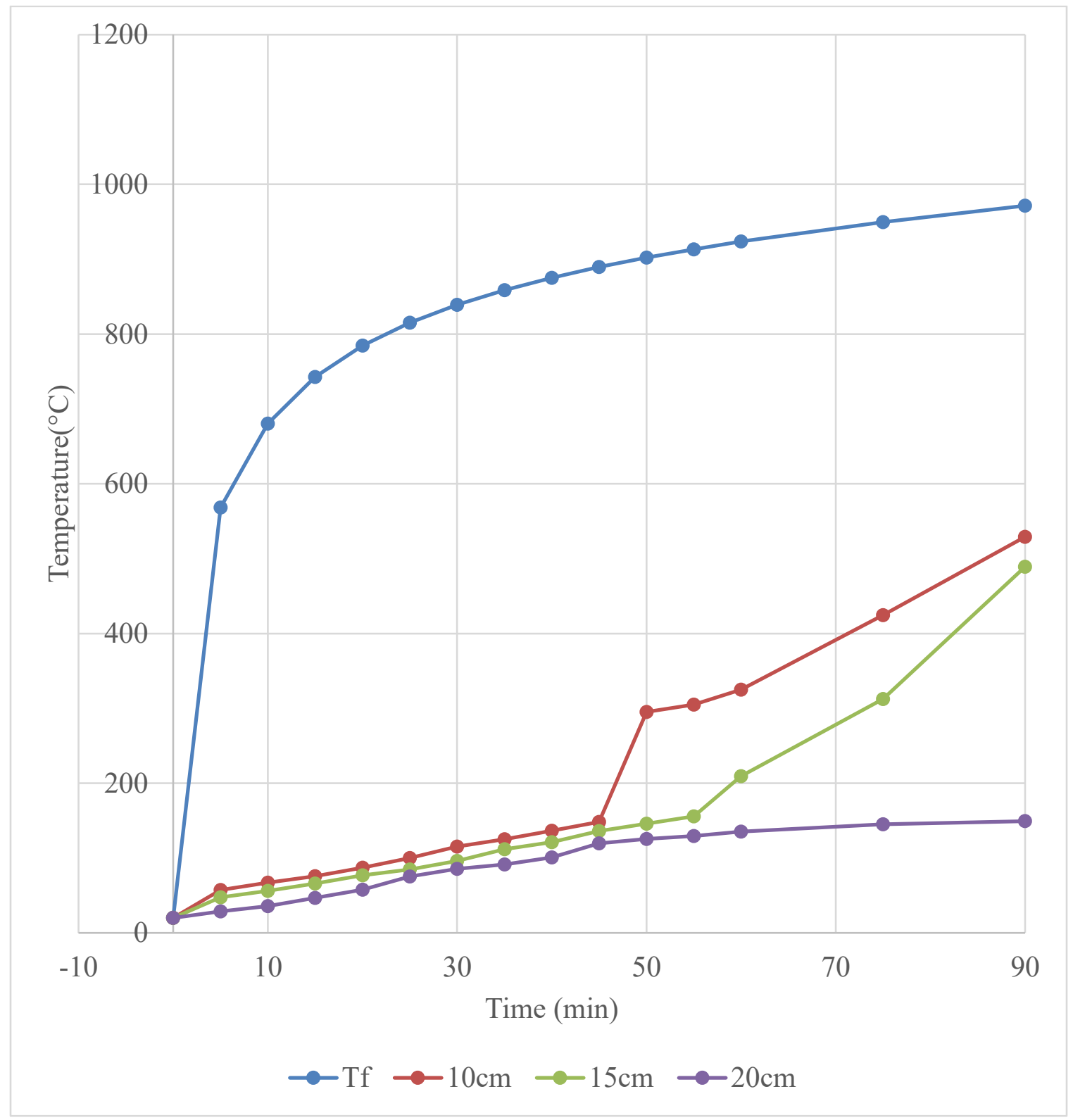

Figure 4-3: Temperature profile recorded on the unexposed side of walls with different geometries

\subsection{Results - Joint profiles}

A numerical study was conducted on walls mortared with the standard concave (control) and raked mortar joints (Table 4-4). This was done to evaluate the fire resistance of raked mortar joints because of the phenomenon of thermal bridging occurring in this type of 
joints. Raked joints modelled were $0.5 \mathrm{~cm}$ on both sides of the wall, similar to the experimentally tested walls, Figure 4-4.

Table 4-4: Wall description- Joint profiles

\begin{tabular}{|c|c|c|c|}
\hline Wall Name. & $\begin{array}{c}\text { Concrete Masonry } \\
\text { Type }\end{array}$ & Joint Profile Type & Mortar Type \\
\hline Concave Wall (CW) & NWC & Concave & $\mathrm{S}$ \\
\hline Raked Wall (RW) & NWC & Raked & $\mathrm{S}$ \\
\hline
\end{tabular}

Concave Joint

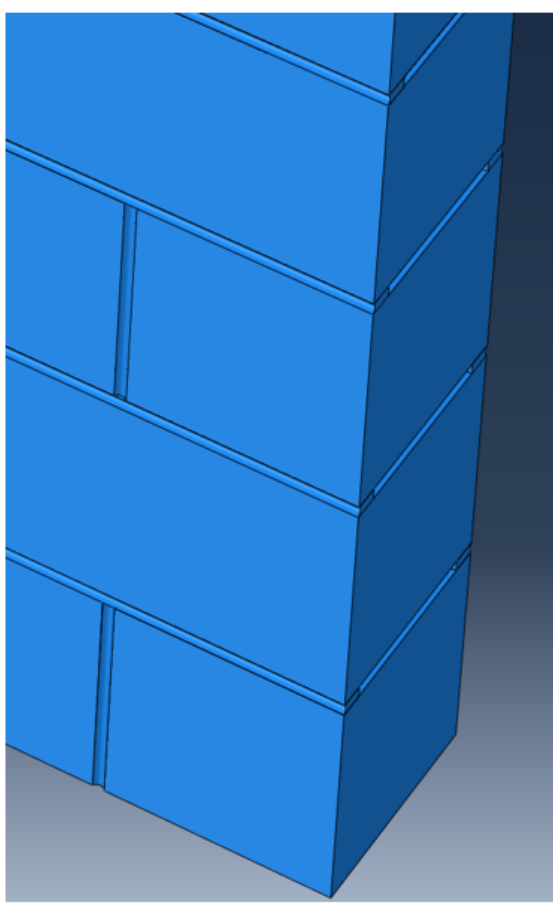

Raked Joint

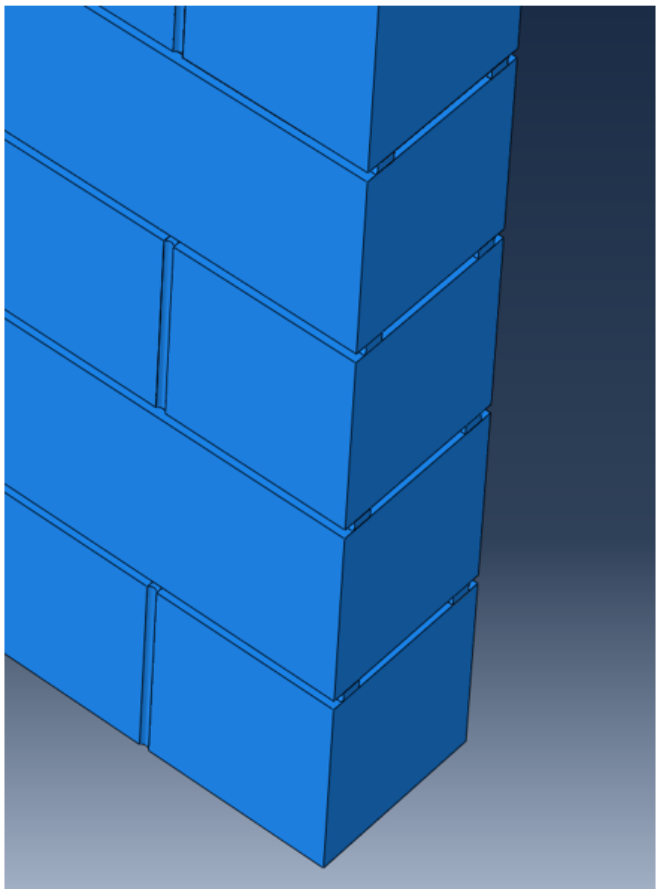

Figure 4-4: Modelled concave and raked joints

To first validate the model, the experimental results from both walls having these types of joints were compared. Thermocouple location (TL) were chosen at points 1,5 and 9 to evaluate the nodal temperatures at these points. This depicted the various levels on the full masonry wall; a low section, mid-section and topmost section; Figure 3-5. The temperature 
profile for both the CW and RW were similar at TL 1, 5 and 9, Figure 4-5. TL 9 recorded highest temperatures on the walls as compared to the lower locations, 5 and 1 respectively. This behaviour is attributed to the fact that the topmost part of the walls gets hotter as compared to the lower locations due to buoyant gases rising steadily to the topmost part. In both cases, this was observed to occur. The temperature difference between the control and raked walls was about 5 to $10^{\circ} \mathrm{C}$ temperature rise, which do not significantly affect the fire resistance of the raked walls when subjected to elevated temperatures. The failure temperature, which is $140^{\circ} \mathrm{C}$ for a single point and an average of $180^{\circ} \mathrm{C}$.

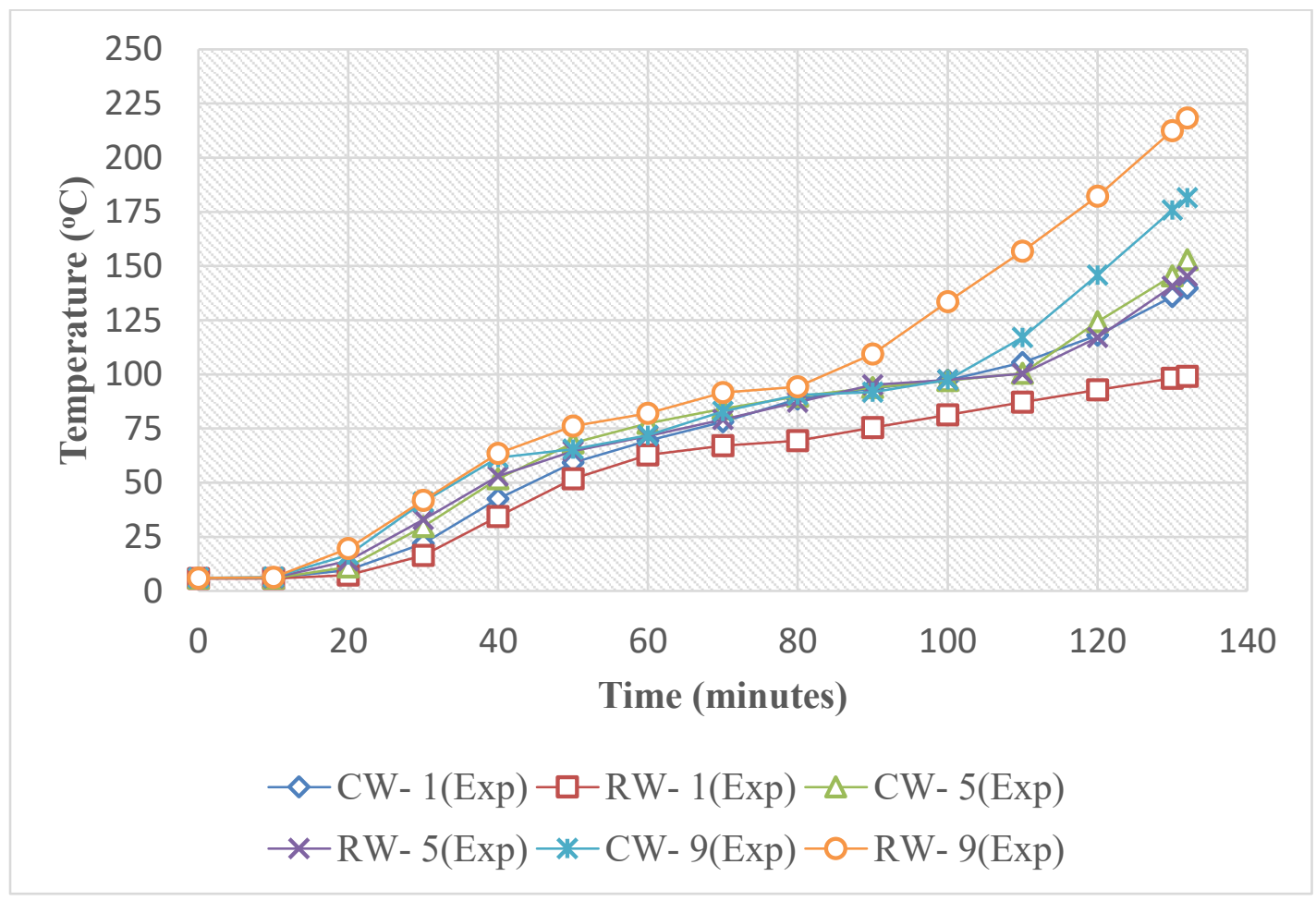

Figure 4-5: Temperature profile of control wall and raked wall at positions 1, 5 and 9 (Exp. only)

\subsubsection{Control wall and raked wall (Numerical analysis -Full Wall)}

The experimental work proved that adopting the use of raked joints does not significantly affect the fire resistance of masonry walls made from these joints. As such, a numerical study to evaluate this was also carried out. The modelled concave and raked joints is 
illustrated in Figure 4-4. These walls were subjected to a DFLUX heat load and from this; nodal temperatures were taken once the analysis was completed.

Once the numerical simulation begins, it can be observed that on the exposed side of the wall, mortar joint sections begin to show various levels of high temperatures as compared to the other sections, solid and hollow. This behaviour is also observed in the experimental test. The numerical model depicts areas of hotter regions by using different contours to show the level of hotness. Numerical models illustrated in Figure 4-6 show the frames obtained from different stages. A frame in ABAQUS uses more of a film analogy in the sense that it depicts each convergence increment where a set of results can be viewed within each stage of the analysis. In this case, it shows either how the nodal temperatures or facet temperatures increase with an increase in heat fluxes computed from the DFLUX subroutine. The first frame shows the beginning of the test, which is when the model is subjected to the predefined field temperature. The second frame shows the step time at which possible evaporation of moisture within the mortar joints is observed. A third frame which depicts the point at which all the possible moisture within the exposed mortar joint has been evaporated shows an increase in high temperatures within the other sections of the masonry wall. In addition, to observe the effect of convection and radiation within the hollow cells, a facet temperature is measured. Frame 4, shows the cut through the wall to show these facet temperatures. 


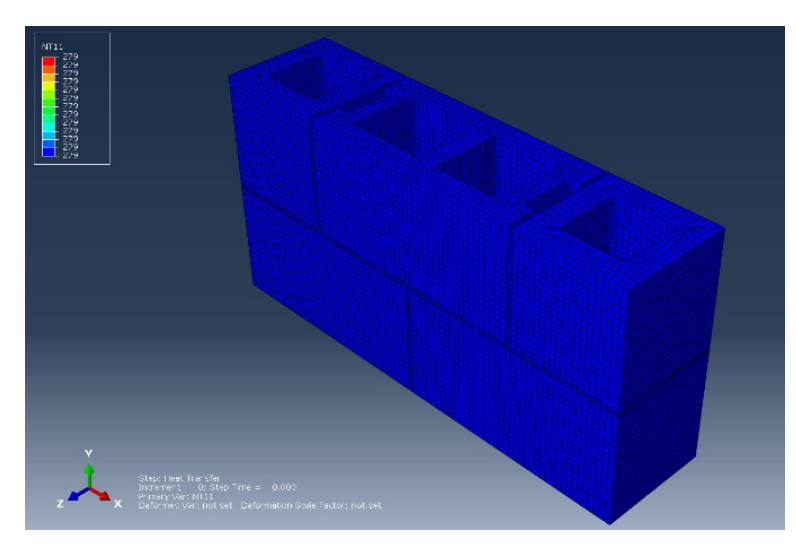

Frame $1\left(5^{\circ} \mathrm{C}\right)$

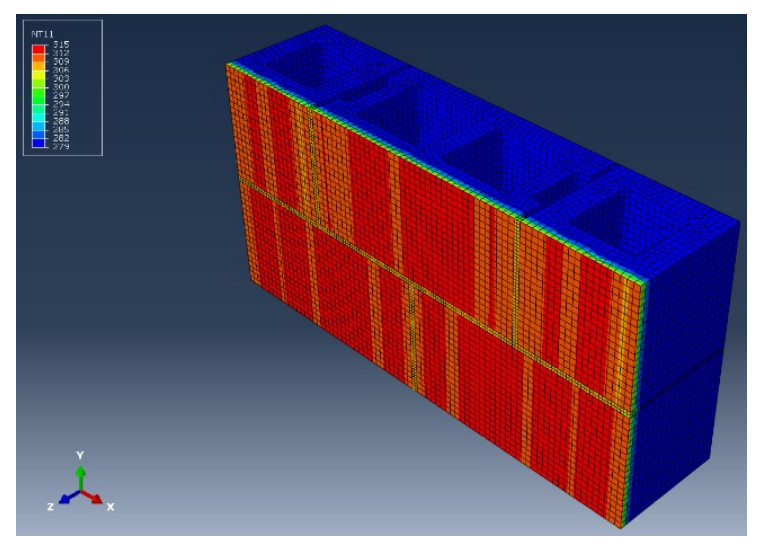

Frame $3\left(140^{\circ} \mathrm{C}\right.$ upwards)

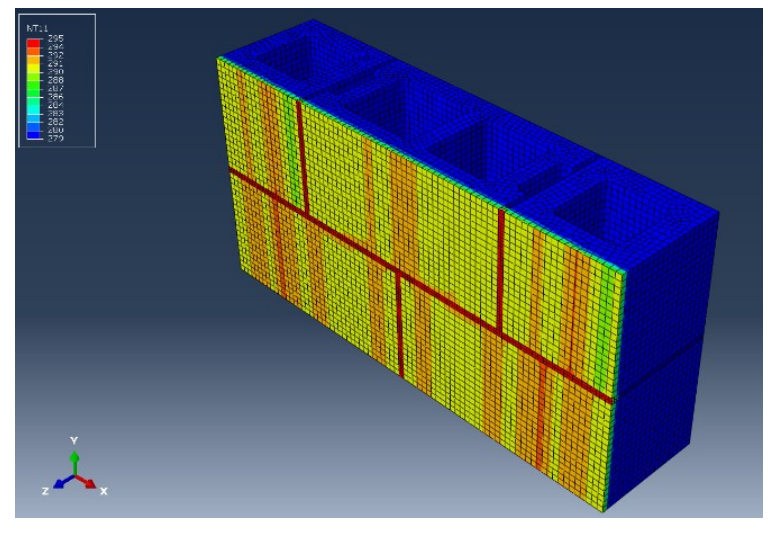

Frame $2\left(\right.$ approximately $80^{\circ} \mathrm{C}-120^{\circ} \mathrm{C}$ )

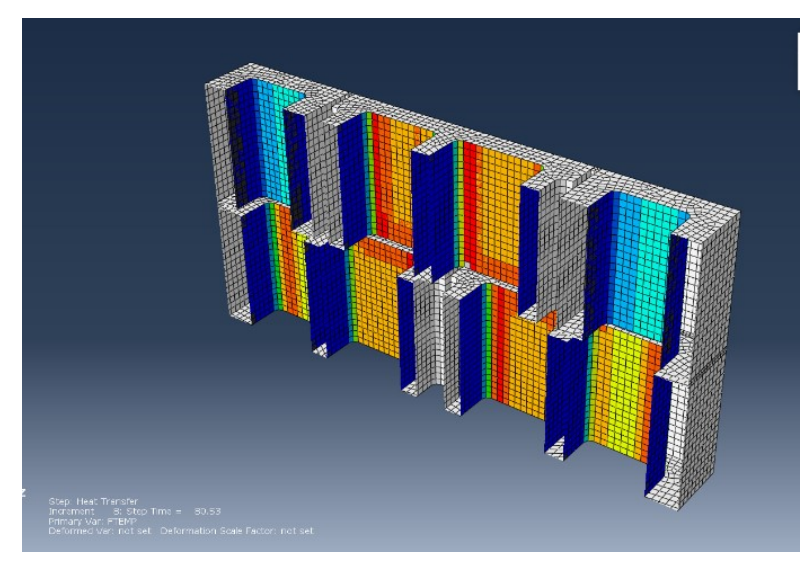

Frame $4\left(140^{\circ} \mathrm{C}\right.$ upwards $)$

Figure 4-6: Different frames observed during numerical simulation 
The ability of the model to demonstrate these frames is dependent on the reliability of the thermal properties as well as the DFLUX subroutine file. The temperature distribution on the control wall and raked wall on both the exposed and unexposed sides from the numerical simulation are illustrated in, Figure 4-7. The nodal temperatures for both cases are also recorded in these figures. The full wall after numerical simulation has been illustrated in Figure 4-8; it depicts the full penetration of heat through all the wall sections. In both numerical (Num) and experimental (Exp) studies, for both cases raked wall (RW) and control wall $(\mathrm{CW})$, top block courses recorded highest temperatures as compared to bottom courses, Figure 4-9 and Figure 4-10. This is independent of whether the position was within the mortar, solid or hollow sections. This could be attributed to the movement of buoyant hot gases, which rise rapidly to the topmost part of the wall during the burning stage thereby making the wall hotter at the top than at the bottom. This was achieved in the numerical study using the DFLUX subroutine and the incorporation of an efficient interaction module in ABAQUS. The interaction module considers the various modes of heat transfer of which surface radiation, convection and conduction were inputted into the model efficiently. 


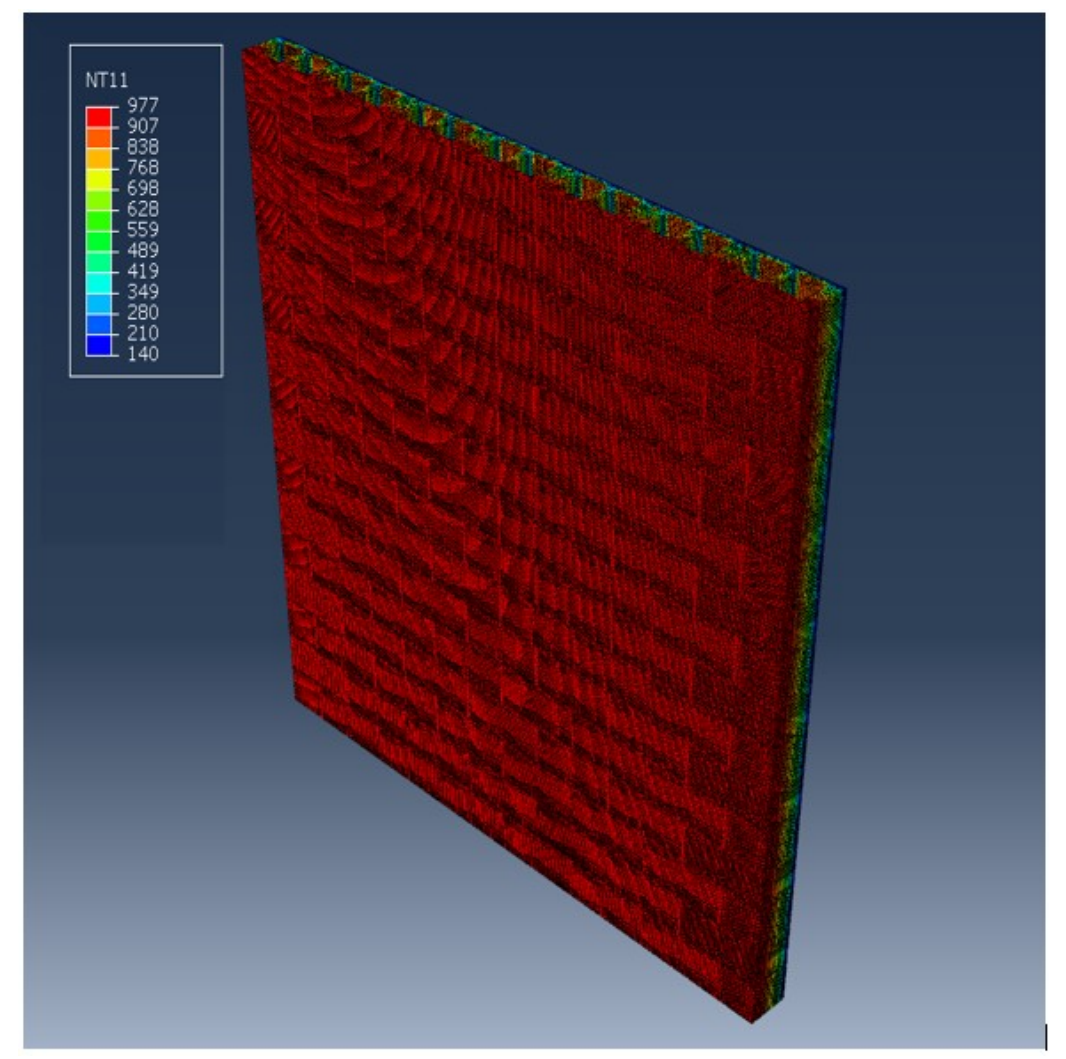

Masonry wall (concave joints)

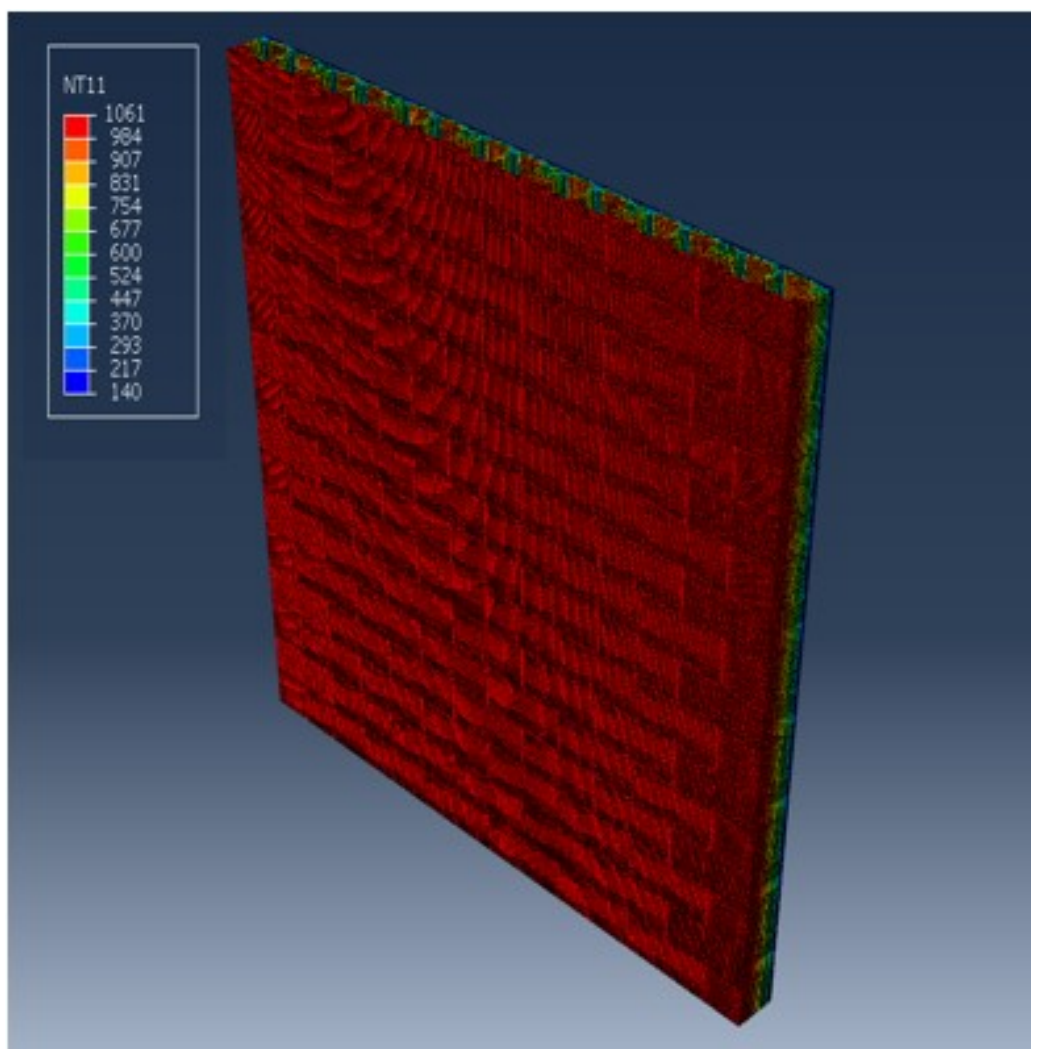

Masonry wall (raked joints)

Figure 4-7: Nodal temperatures on raked wall and concave wall 


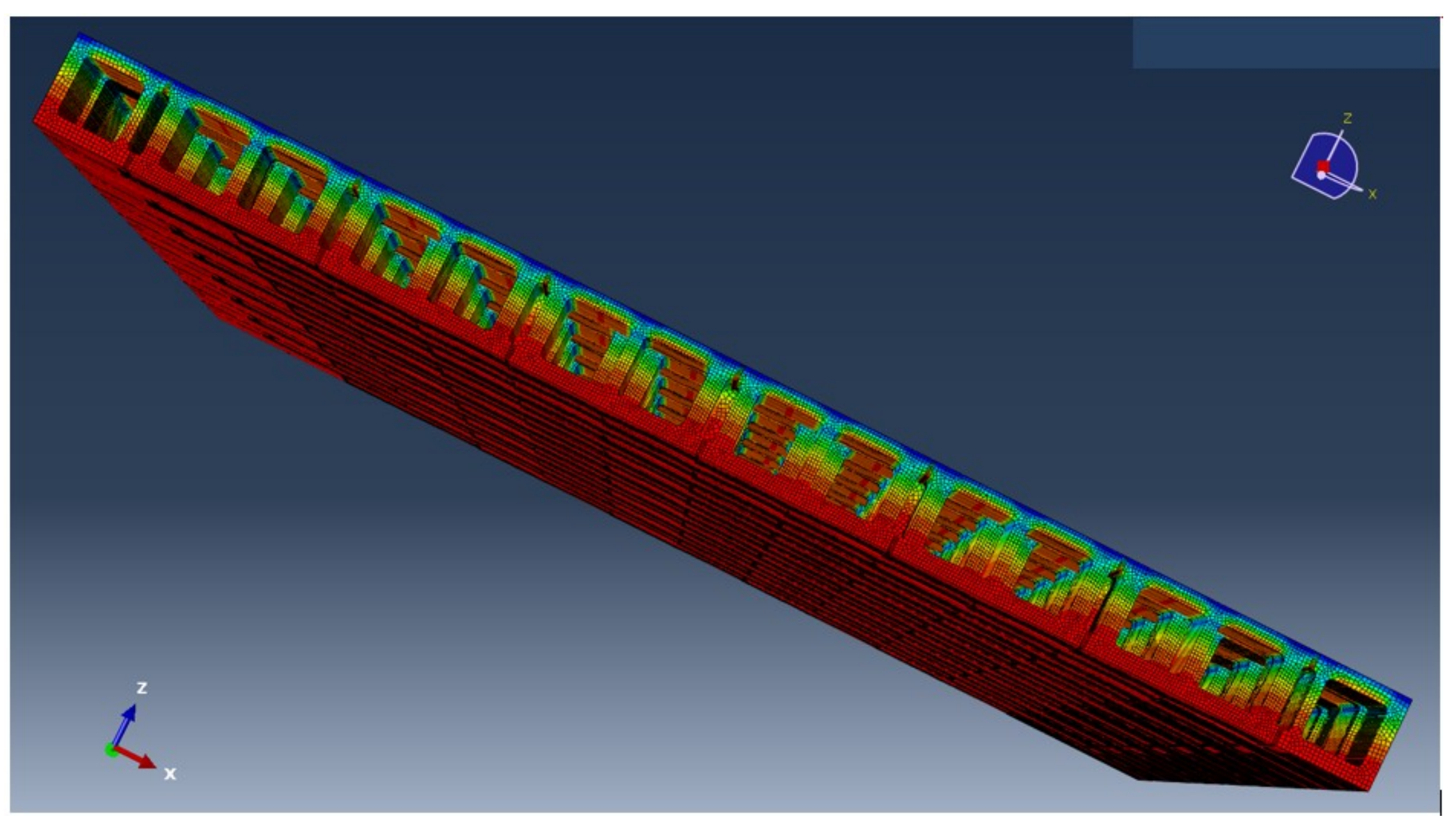

Figure 4-8: Masonry wall after complete numerical simulation, showing areas of full heat penetration through the wall (top view) 


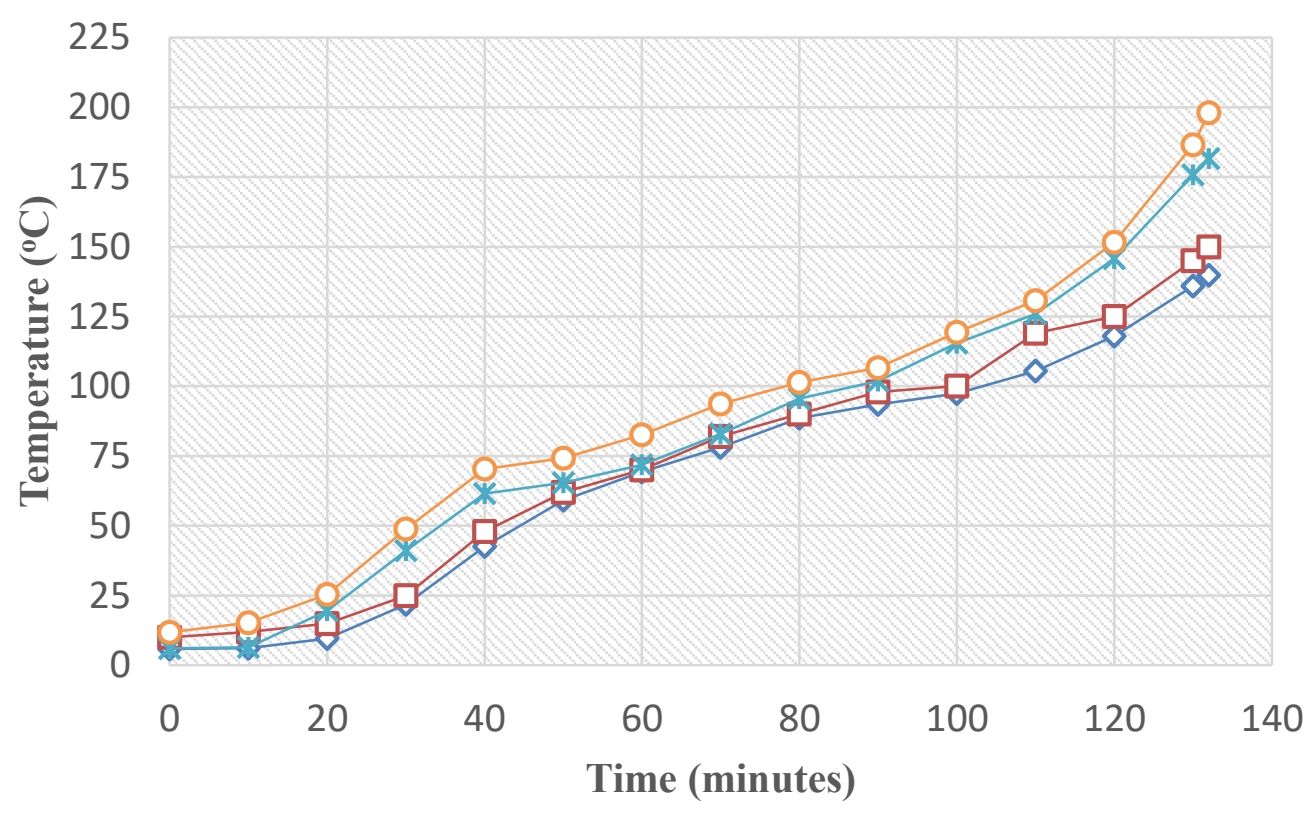

$\diamond-\mathrm{CW}-1($ Exp) $-\square-\mathrm{CW}-1(\mathrm{Num})-*-\mathrm{CW}-9(\operatorname{Exp})-0-\mathrm{CW}-9(\mathrm{Num})$

Figure 4-9: Temperature profile on control wall at positions 1 and 9 (Exp. and Num.)

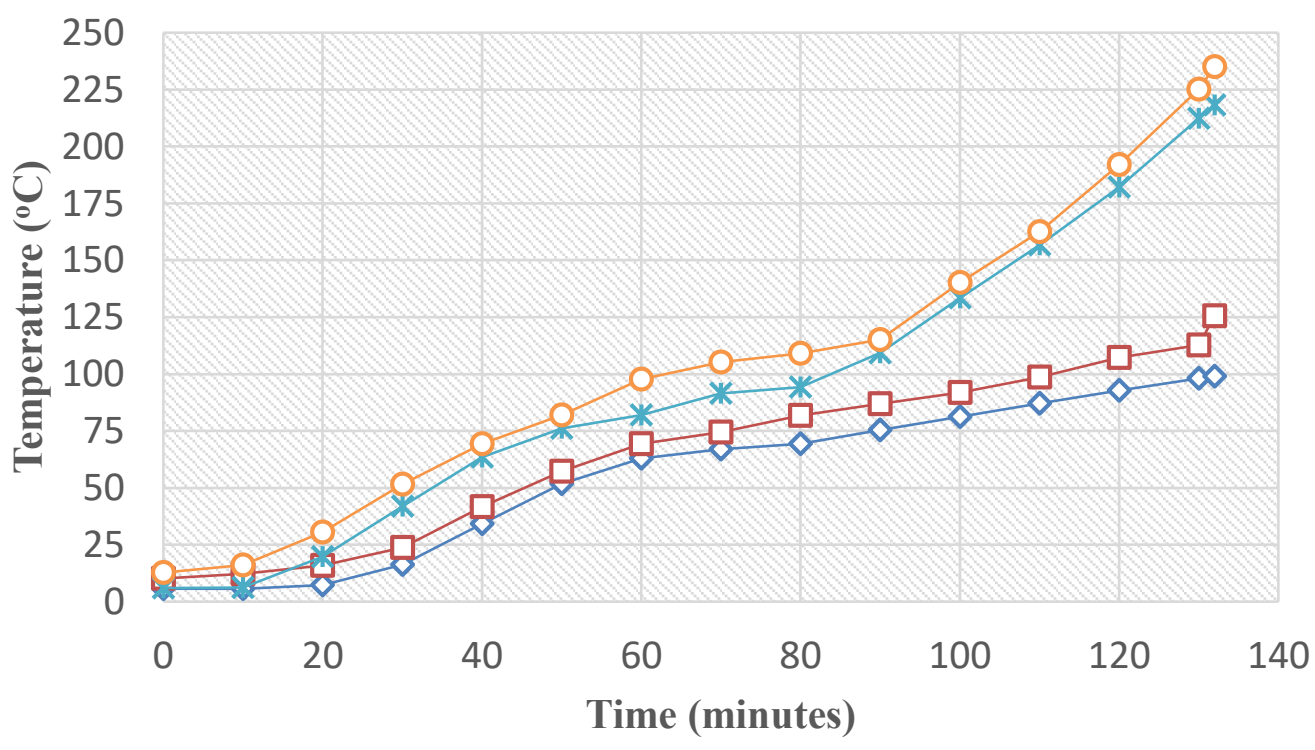

$\diamond-\mathrm{RW}-1(\operatorname{Exp})-\square-\mathrm{RW}-1(\mathrm{Num}) \rightarrow-\mathrm{RW}-9(\operatorname{Exp})-\mathrm{O}-\mathrm{RW}-9(\mathrm{Num})$

Figure 4-10: Temperature profile on raked wall at positions 1 and 9 (Exp. and Num.) 


\subsubsection{Control wall and raked wall (Special Block)}

To predict the thermal behaviour of the different sections, a block was chosen and various nodal temperatures were taken for the M, H and S section (See Figure 3-1), Results from the numerical simulation are in Figure 4-11 and Figure 4-12. In that block, the locations of interest were M3, H5 and S3; these were sections on the unexposed side of the wall. H5 recorded highest temperatures right from the start of the analysis. This could be attributed to the air cavities within this section and the rapid transfer of heat by convection and radiation. S3 records a higher temperature as compared to $\mathrm{M} 3$ as it conducts heat rapidly through the web. Comparatively, the main modes of heat transfer are through convection and radiation and this affirms the higher temperatures recorded by H5. However, just around $90^{\circ} \mathrm{C}, \mathrm{M} 3$ records a much higher temperature as compared to the $\mathrm{H} 5$ and $\mathrm{S} 3$ for both cases. This could be attributed to the moisture content (MC) within M3; M3 contains the highest $\mathrm{MC}$ and therefore would require a higher temperature to evaporate the moisture. This process lags on until the entire MC is evaporated; this explains why it takes a relatively lengthy duration while maintaining the same temperature. The model's ability to demonstrate this similar behaviour is from the effective interaction module as well as the DFLUX subroutine file. Also, the reliable thermal properties of the mortar to capture the temperature at which evaporation takes place is based on computation from Equation 2-2 and Equation 2-3. These equations take into consideration the base value corresponding to a mixture of the dry components of the mortar and the effect of water evaporation. The effect of water evaporation of the mortar considers the magnitude of the temperature interval during which water is evaporated, dehydration water content and a magnification factor accounting for water movement. The results are similar to the test for both walls. 


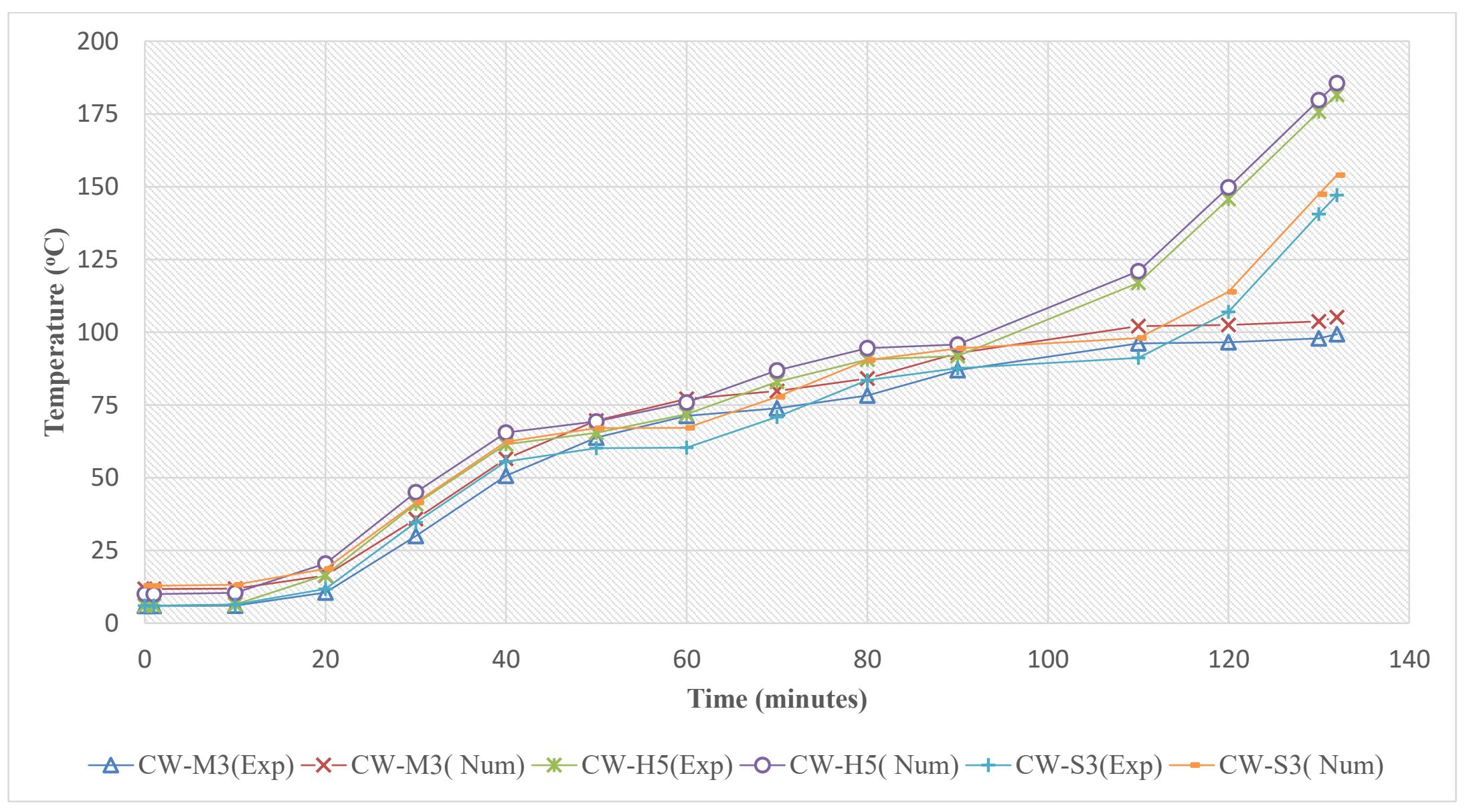

Figure 4-11: Temperature profile on control wall at solid, mortar and hollow sections (Exp. and Num.) 


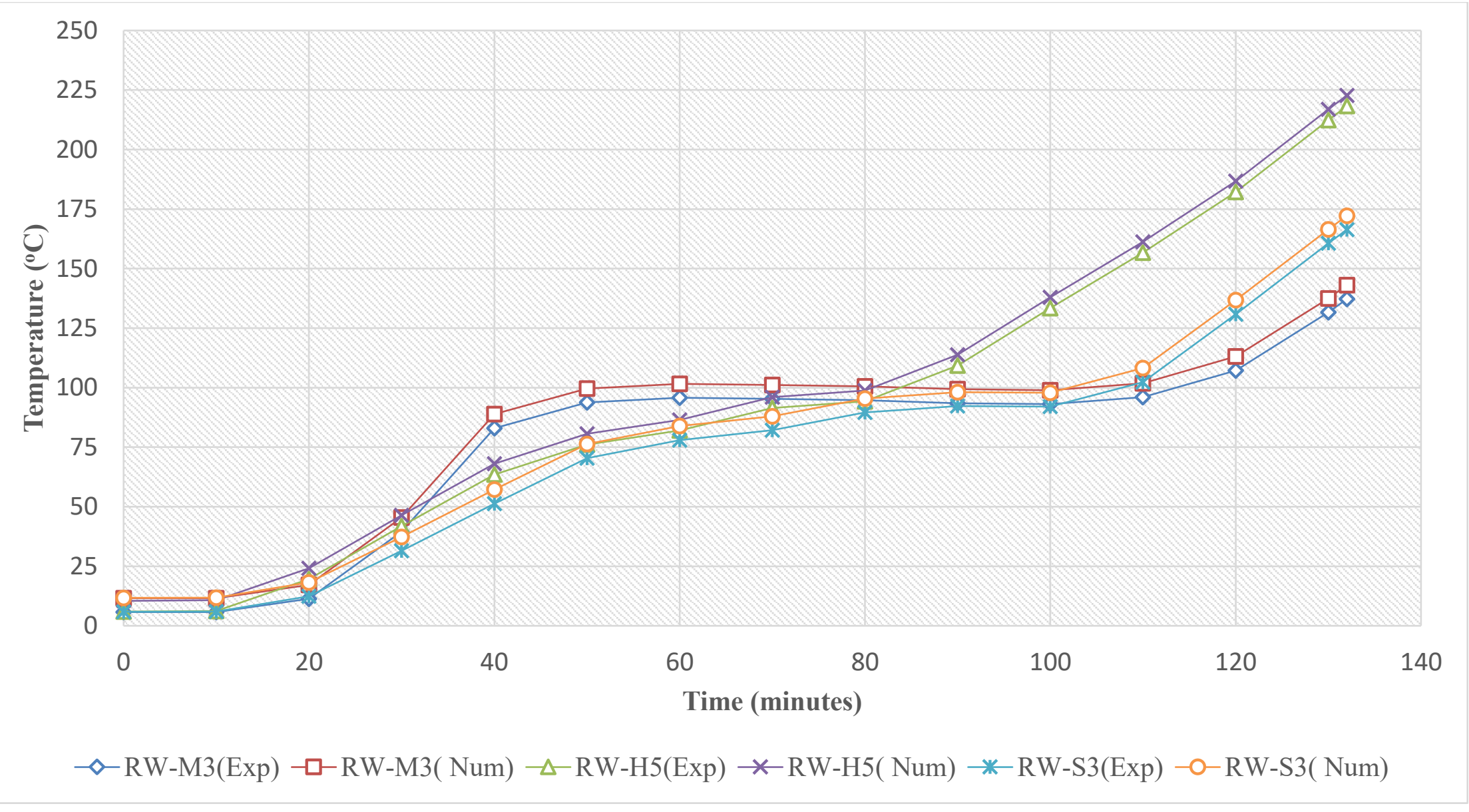

Figure 4-12: Temperature profile on control wall at solid, mortar and hollow sections (Exp. and Num) 


\subsubsection{The use of cavity radiation and surface radiation}

In ABAQUS, the heat transfer step in the interaction module provides an option for surface radiation or cavity radiation. The difference in these two forms of radiation is that surface radiation assumes the heat flux generated from the exposed sides and radiates within the surface(s) chosen. With cavity radiation, radiation is assumed to be taken within the full cavity chosen. While that of the cavity radiation presents the real experimental scenario as performed in the fire test, it comes with a few limitations and as such cannot be implemented when these limitations are hindered on.

These limitations include that there is a software limit of 16,000 nodes and facets in Abaqus/Standard. As such, if the nodes are more than 16,000, cavity radiation cannot be assumed. It also works with other complexities like a closed and open system, view factors and symmetry, which must be accordingly met. The surface radiation offers a more practical option in inputting radiation as a mode of heat transfer in the interaction module. In the end, the surface radiation proposes an option for a Cavity approximation and therefore this works just as applying cavity radiation without the limitations.

Two forms of radiation were implemented on a sample model, the difference in nodal temperatures were taken to evaluate the effect of both forms on the model.

From the results represented in Figure 4-13, the temperature profile was similar in both cases. However, the use of cavity radiation presented nodal temperatures, which were in close range with the experimental nodal temperatures as compared to surface radiation. The difference between the results generated from cavity radiation and that of surface radiation was an increase of $8-10^{\circ} \mathrm{C}$ of the experimental results. The model assumed surface radiation for all other tests as this did not significantly affect the results. 


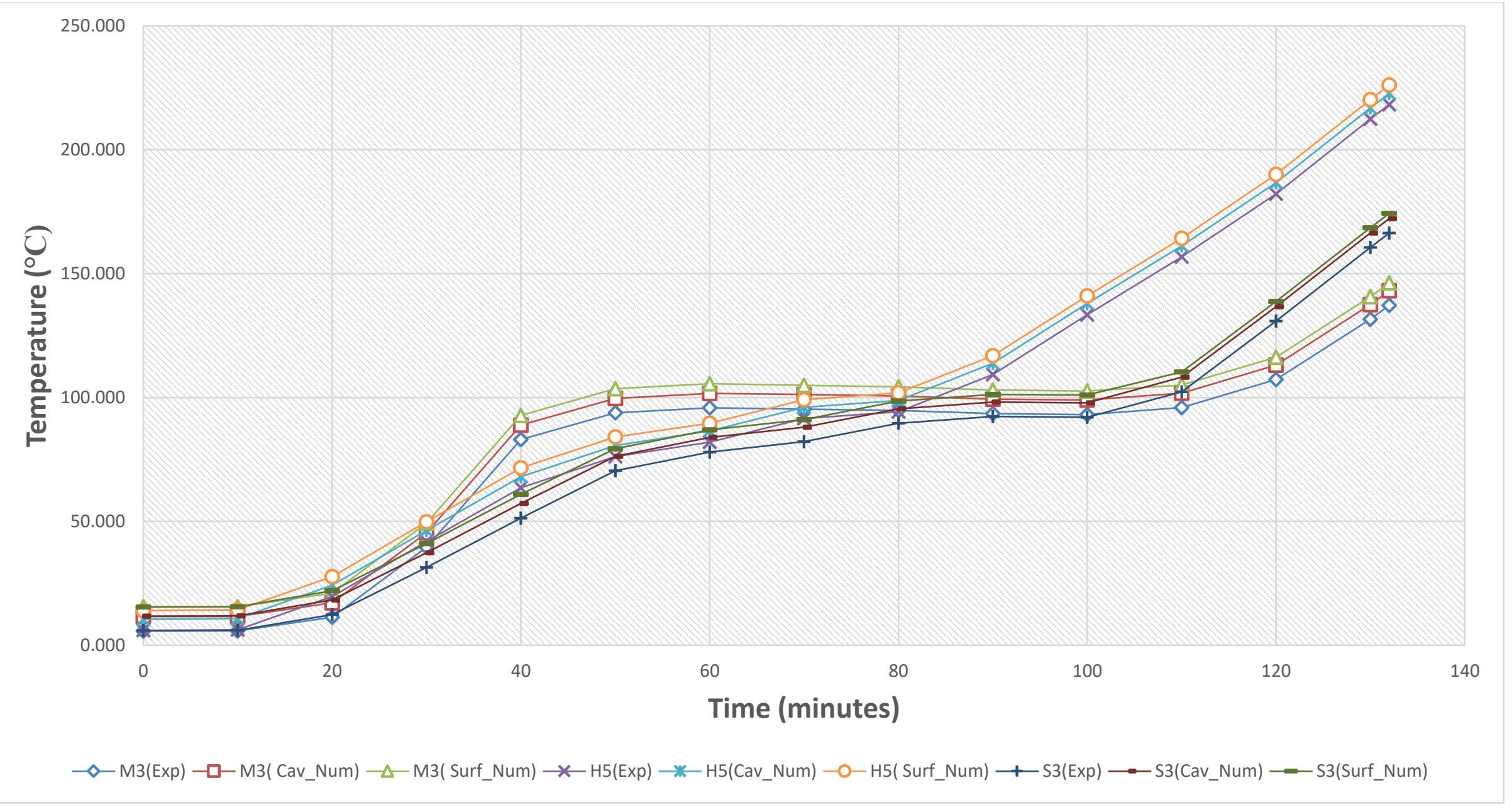

Figure 4-13: Nodal temperatures on sample model (cavity radiation and surface radiation) 


\subsection{Results - Types of Concrete Masonry}

From existing literature review, the thermal properties of various forms of concrete masonry when subjected to elevated temperatures were evaluated. (Appendix $A$ ). These thermal properties were simulated in the numerical study to evaluate the fire resistance of walls made from such concrete masonry types, Table 4-5 and Table 4-6.

Table 4-5: Wall description - Lightweight concrete masonry

\begin{tabular}{|c|l|c|}
\hline Wall Name & \multicolumn{1}{|c|}{ Description of masonry blocks } & Mortar Type \\
\hline LWC & Composed of lightweight aggregates & $\mathrm{S}$ \\
\hline NLWC & Composed of 45\% Metakaolin and 10\% Glass & $\mathrm{S}$ \\
\hline $\mathrm{LFC}_{1}$ & Composed of lightweight foam concrete at density & $\mathrm{S}$ \\
& $650 \mathrm{~kg} / \mathrm{m}^{3}$ & \\
\hline $\mathrm{LFC}_{2}$ & Composed of lightweight foam concrete at density & $\mathrm{S}$ \\
& $1000 \mathrm{~kg} / \mathrm{m}^{3}$ & \\
\hline
\end{tabular}

Table 4-6: Wall description - Normal weight concrete masonry

\begin{tabular}{|c|l|c|}
\hline Wall Name & \multicolumn{1}{|c|}{ Description of masonry blocks } & Mortar Type \\
\hline NWC & Composed of normal weight aggregates & $\mathrm{S}$ \\
\hline SCCA & Composed of silico-calcareous aggregates & $\mathrm{S}$ \\
\hline LRCA & Laboratory-sourced recycled normal weight aggregates & $\mathrm{S}$ \\
\hline IRCA & Industrially-sourced recycled normal weight aggregates & $\mathrm{S}$ \\
\hline
\end{tabular}




\subsubsection{Lightweight concrete masonry walls}

Lightweight concrete masonry walls showed similar temperature profile trend as observed in tests performed on normal weight concrete masonry walls. Comparison between these walls was necessary since no experimental work has been done on LWC walls yet. It was deemed necessary to compare if the temperature profile trends were similar, though there is a high possibility of recording different nodal temperatures in the model generated due to primarily different thermal properties. The model recorded nodal temperatures, which were then compared to both the experimental work and numerical simulation done on NWC walls. In this numerical simulation, TL of 1,5 and 9 were analyzed. From the model's prediction of nodal temperatures, TL9 recorded highest temperature as compared to all the locations throughout the entire numerical simulation. Just around 110 minutes into the numerical simulation, it can be observed that TL 5 and 9, almost record the same nodal temperatures. This could be attributed to several factors in the model's prediction. Notable factors include that the DFLUX subroutine file computed a heat flux at TL 5 which was similar to that been generated at TL 9 which in turn is associated to the interaction module that was inputted into the model.

However, the numerical simulation was made to run for a period of 180 minutes, based on the insulation criterion inputted as a boundary condition in the heat transfer step module, LWC walls failed at 145 minutes, Figure 4-14. At 145 minutes, TL 1, 5 and 9 recorded temperatures $140^{\circ} \mathrm{C}, 153^{\circ} \mathrm{C}$ and $179^{\circ} \mathrm{C}$ respectively. The average temperature on the wall was $155^{\circ} \mathrm{C}$. These results were then compared to the experimental work performed using NWC masonry blocks, Figure 4-15. The comparison focused on TL 1 and 9 since these were the extreme locations of the test, lowest and highest. It was observed that LWC 
masonry walls failed after 145 minutes while that of $\mathrm{NWC}$ failed at 122 minutes. At 145 minutes, TL 1 and 9 recorded temperatures $140^{\circ} \mathrm{C}$ and $179^{\circ} \mathrm{C}$ while NWC masonry walls recorded $140^{\circ} \mathrm{C}$ and $182^{\circ} \mathrm{C}$ after 122 minutes. Firstly, it is observed that LWC walls failed after an extra 23 minutes as compared to NWC walls. In addition, the temperatures recorded in LWC after failure are lower than that of NWC walls. This could be attributed to the low thermal conductivity of LWC masonry blocks; A.2 Low conductivity decreases the rate of heat penetration through the medium. Though NWC masonry blocks have a higher specific heat capacity as compared to LWC masonry blocks, it can be observed that this did not significantly affect the temperature profile, A.1. With a higher specific heat capacity, the concrete masonry blocks have the capacity to retain more energy, which is dissipated at a very low rate. However, the governing thermal property is the thermal conductivity, since it is effectively high in the NWC masonry blocks as compared to LWC masonry blocks; it in effect conducts this stored energy at a faster rate.

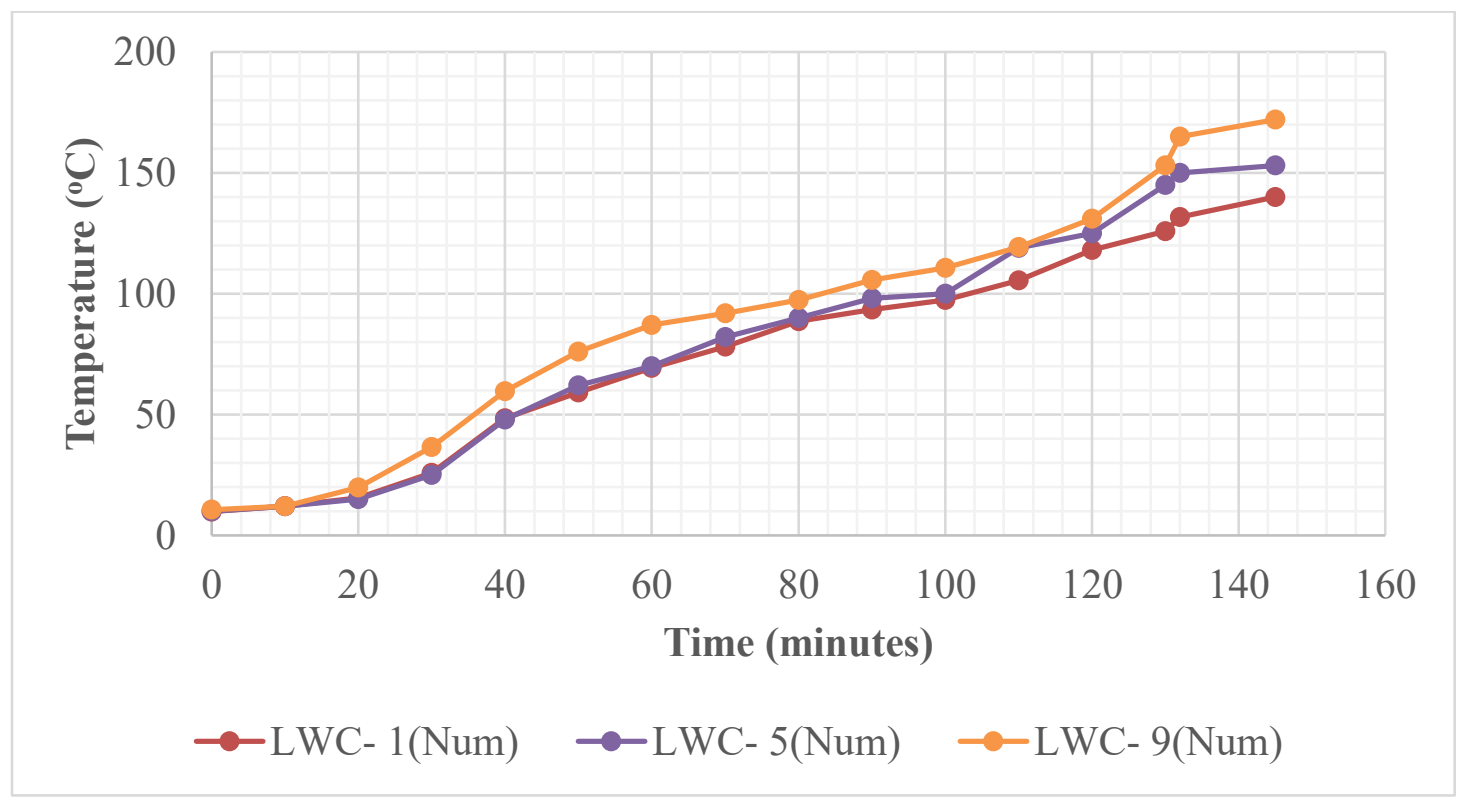

Figure 4-14: Temperature profile on masonry wall made from LWC (Num.) at locations 1, 5 and 9 


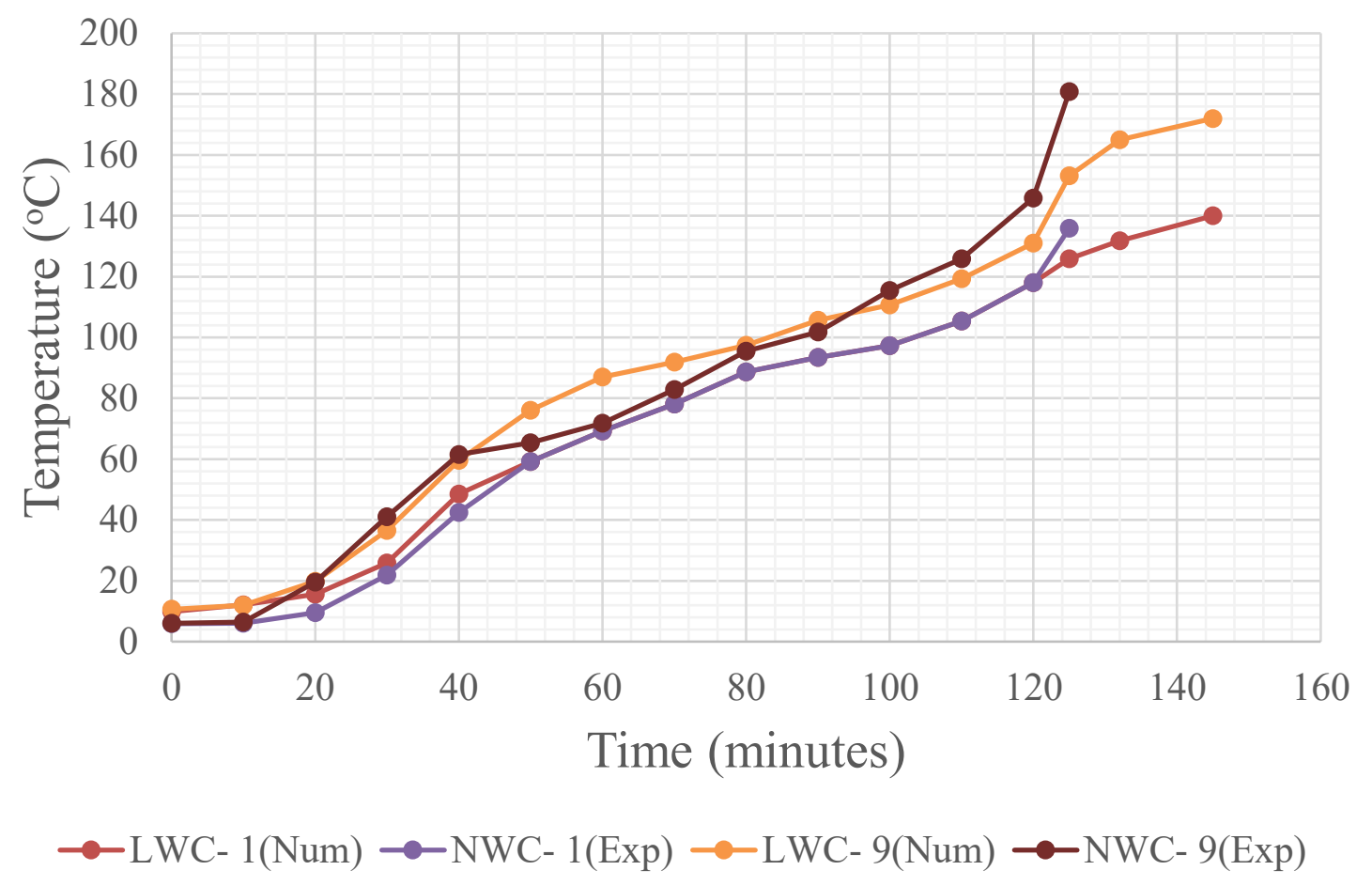

Figure 4-15: Temperature profile on masonry walls made from LWC (Num.) and NWC (Exp.) at locations 1 and 9

\subsubsection{Recycled aggregates - Normal weight aggregates}

SCCA, LRCA and IRCA walls were modelled and the fire resistance were evaluated. Thermal properties were obtained from existing literature and have been documented in A.4, A.5 and A.6 Temperature profiles for TL1, 5 and 9 for all types are illustrated in Figure 4-16, Figure 4-17, and Figure 4-18. SCCA, IRCA and LRCA masonry walls failed at 120 minutes, 135 minutes and 130 minutes respectively. Temperatures recorded at failure for TL 9 were $154^{\circ} \mathrm{C}, 167^{\circ} \mathrm{C}$ and $163^{\circ} \mathrm{C}$ respectively. In this category of recycled aggregates, it could be observed that IRCA masonry walls had the highest fire resistance as compared to the other two. This could be attributed to the thermal properties of the individual compositions of IRCA. IRCA is obtained from an industrial source where impurities such as wood, brick, plastic are found. These impurities have a very low thermal 
conductivity, which ultimately lowers the magnitude of the thermal conductivity of the entire block. The results obtained further affirms the effect of using materials with low thermal conductivity. For all tested walls, at about 110 minutes, TL 5 is observed to have a lower temperature as compared to TL 1 ; this could be possibly due to a change in thermal property during the numerical analysis. However, existing literature provided thermal properties from a range of $0^{\circ} \mathrm{C}$ to $300^{\circ} \mathrm{C}$ and therefore at elevated temperatures beyond $300^{\circ} \mathrm{C}$, the change in thermal properties of these aggregates were not considered in the model. This is also observed between thermocouple locations 5 and 9 at about 55 minutes for all tested walls, where TL 5 records a higher temperature than that of TL 9.

LRCA masonry walls fail 5 minutes before that of IRCA. This could be attributed to the similarity of thermal properties of both LRCA and IRCA. Both walls have relatively the same thermal conductivities. For all temperature ranges, the difference in their thermal conductivities is approximately an average of 0.03 . However, the major difference lies in the magnitude of the specific heat capacity where LRCA has a higher specific heat capacity and as such increases the amount of heat stored in the walls. The approximate difference in specific heat capacity is an average of $100 \mathrm{~J} / \mathrm{kgK}$. This is quite significant and therefore it is expected to record high nodal temperatures within this wall. This is not so since the thermal conductivity of LRCA is high as well and therefore dissipates the energy stored at a faster rate. This explains why it fails a bit before that of IRCA masonry walls, Figure 4-19. With that of SCCA masonry walls, both the thermal conductivity and specific heat capacity are relatively high and as such the temperature profile attained from the numerical simulation was predominantly steep which depicts the high rate of energy gained and dissipated in the wall. 


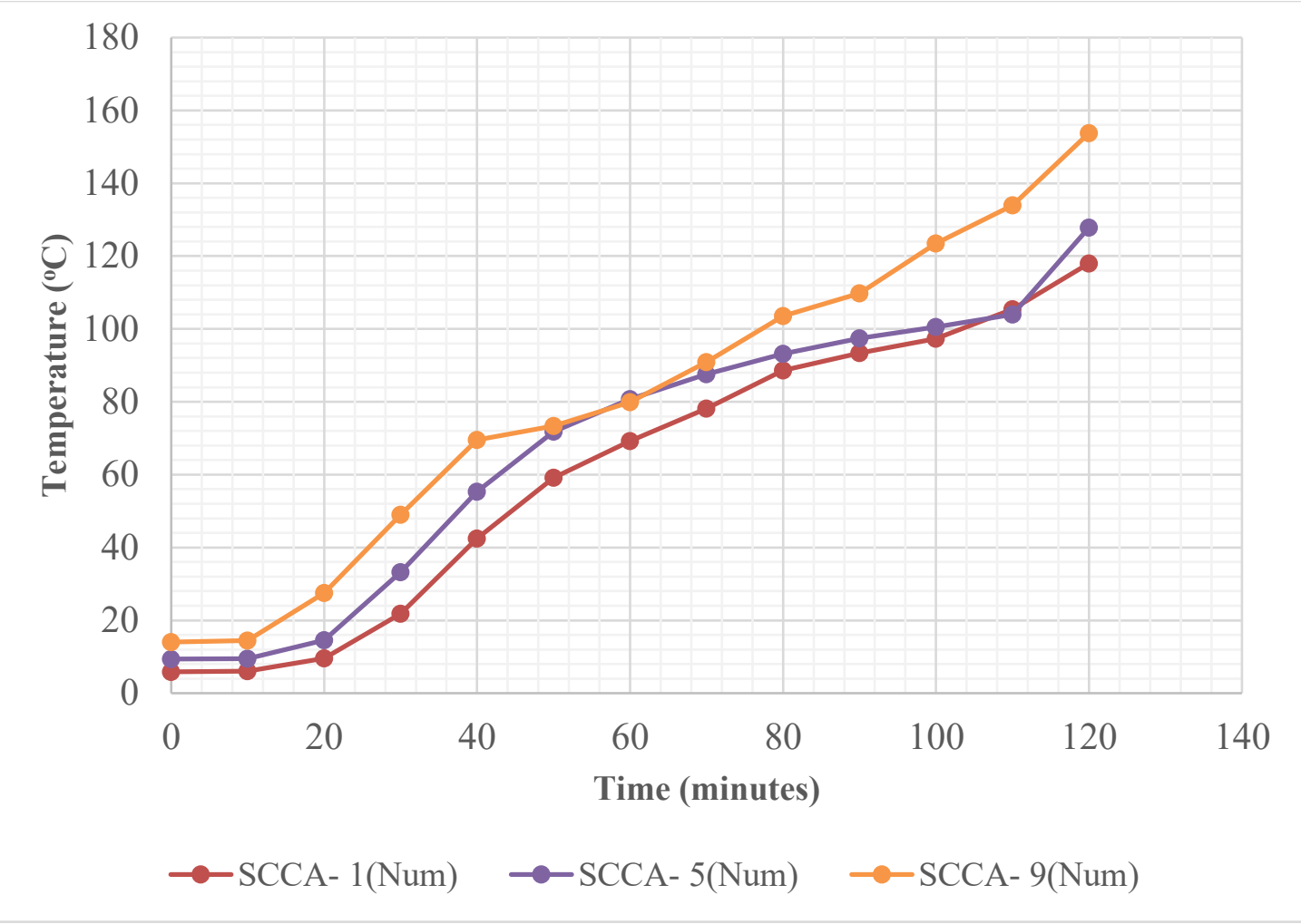

Figure 4-16: Temperature profile on masonry wall made from SCCA (Num.) at locations 1, 5 and 9

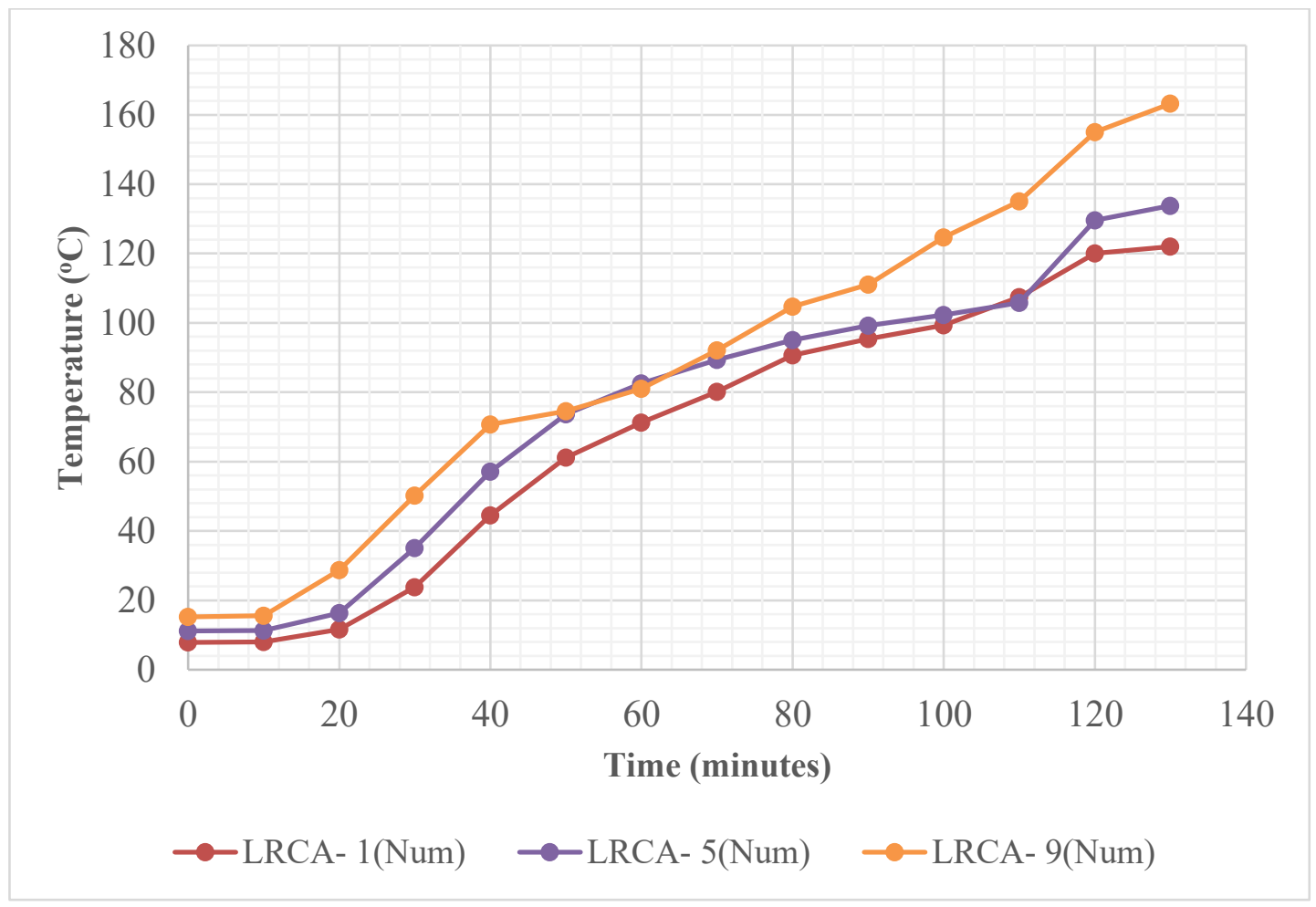

Figure 4-17: Temperature profile on masonry wall made from LRCA (Num.) at locations 1, 5 and 9 


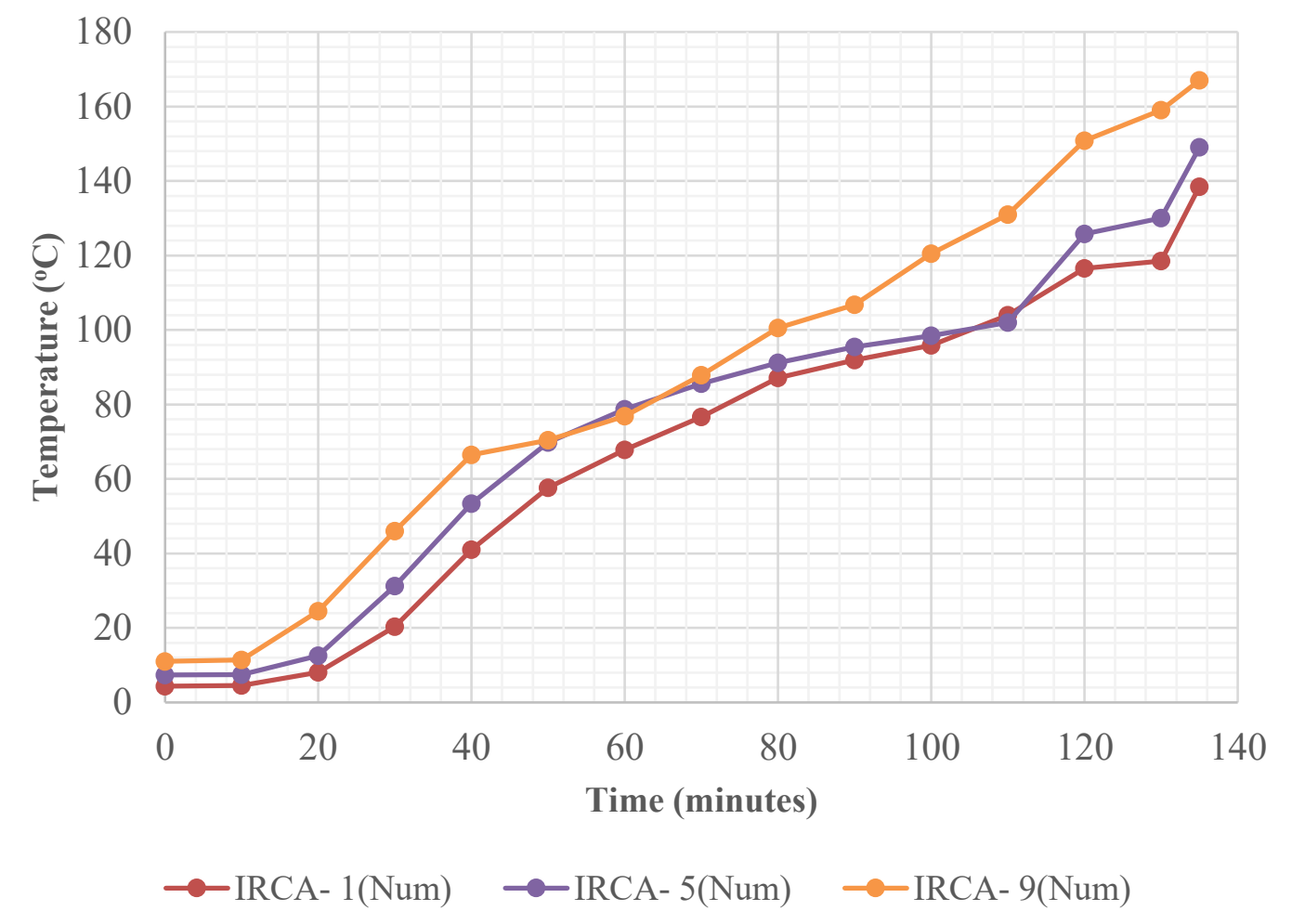

Figure 4-18: Temperature profile on masonry wall made from LRCA (Num.) at locations 1, 5 and 9

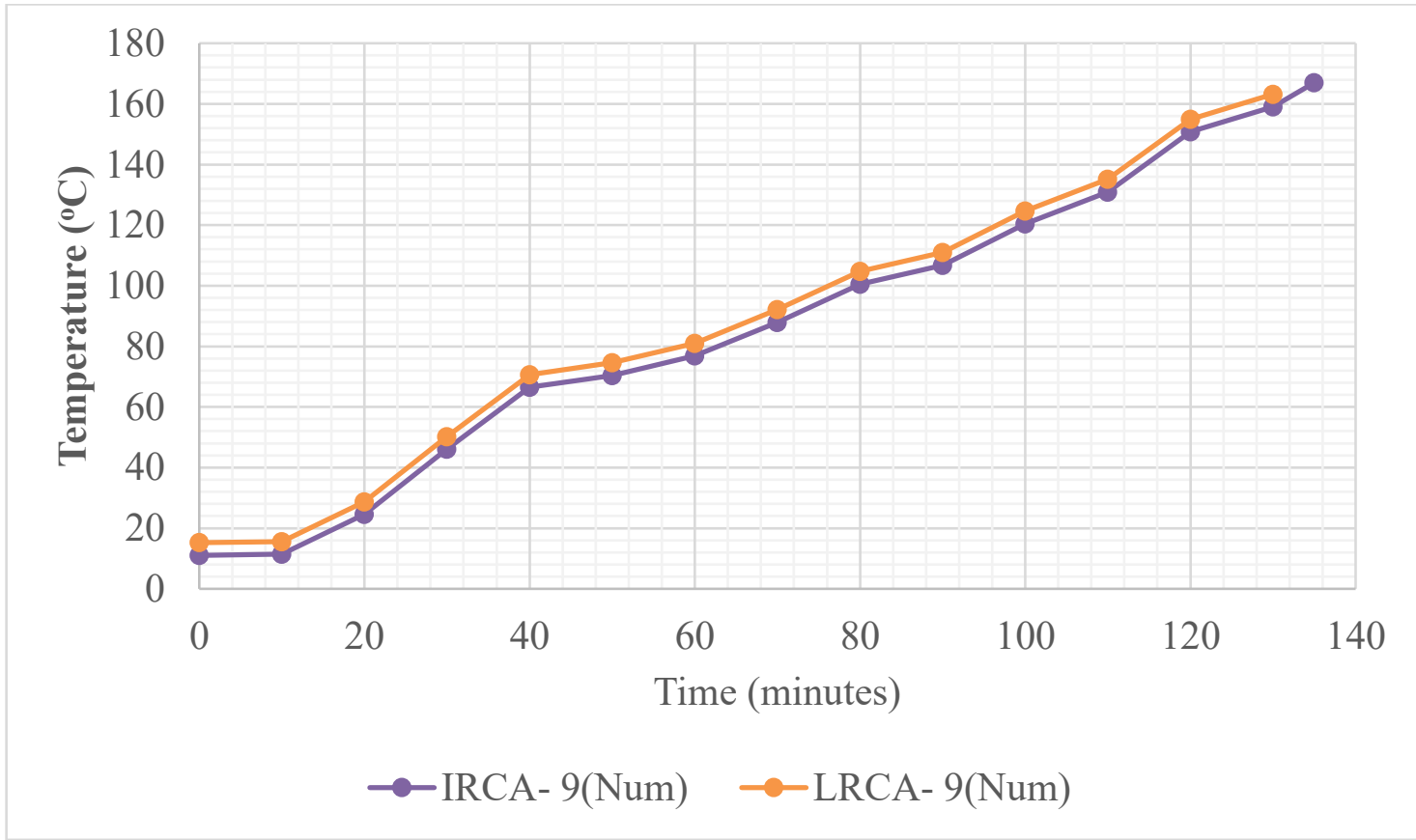

Figure 4-19: Temperature profile on masonry walls made from LRCA and IRCA (Num.) at location 9 


\subsubsection{Novel lightweight concrete (NLWC) masonry walls}

A numerical simulation was performed on a novel lightweight concrete masonry. This form of concrete masonry was composed of lightweight aggregates, $45 \%$ recycled glass and $10 \%$ metakaolin (Al-Sibahy \& Edwards, 2012) (See Section 2.13.2.3). Thermal properties are documented in $A .7$ Test results as obtained from the numerical simulation are illustrated in Figure 4-20. The temperature profile follows that of the experimental work done on NWC walls where TL 9 records the highest temperature throughout the numerical simulation. This is followed by thermocouple location 5 and 1. NLWC masonry walls failed at approximately 172 minutes, recording temperatures $153^{\circ} \mathrm{C}, 172^{\circ} \mathrm{C}$ and $179^{\circ} \mathrm{C}$ at locations 1,5 and 9 respectively. This was compared to LWC masonry walls, which failed at 145 minutes. This showed that NLWC masonry walls gained an extra 27 minutes before failing. NLWC walls had a better fire resistance as compared to LWC walls. This has been illustrated in Figure 4-21 which depicts the average temperatures (AT) recorded on these walls. NLWC recorded an AT of $158^{\circ} \mathrm{C}$ while $\mathrm{LWC}$ recorded $155^{\circ} \mathrm{C}$.

The model's prediction was also compared to the numerical simulation performed by AlSibahy and Edwards (Al-Sibahy \& Edwards, 2012) on the same type of NLWC. The temperature profile trends were similar in both simulations and this is due to having both models subjected to a unidirectional heat flow and approximately the same heat flux. However, the numerical simulation from (Al-Sibahy \& Edwards, 2012) shows that NLWC blocks had an insulation period reaching as long as 195 minutes and this was consistent with its superior thermal conductivity resulting from the combined effect of metakaolin and glass. The difference in the insulation period between the current research and work performed by Al-Sibahy and Edwards (Al-Sibahy \& Edwards, 2012) is approximately 23 
minutes. This could be attributed to the fact that the sample tested in (Al-Sibahy \& Edwards, 2012) was basically a concrete block composed of the NLWC material and therefore did not have any mortar to interact with. Whereas, this current research focuses on the combined effect of the NLWC masonry block and its interaction with a mortar joint. This difference proves that the combined effect of the thermal properties of both materials plays an essential role in obtaining the nodal temperatures during the numerical simulation. Another possible cause for the difference is in the magnitude of the coefficient of convection. In Al-Sibahy and Edward's numerical simulation, a lower coefficient of convection value of $15 \mathrm{~W} / \mathrm{m}^{2} \mathrm{~K}$ was used as compared $25 \mathrm{~W} / \mathrm{m}^{2} \mathrm{~K}$ adopted in this current research. The difference is significant as a lower value implies that the rate of heat transfer is lower between the exposed surface and unexposed surface as compared to a higher value, which transmits heat faster. Lastly, the insulation criterion used in (Al-Sibahy \& Edwards, 2012) indicates that the average temperature on the unexposed surface should not exceed $160^{\circ} \mathrm{C}$ while this current research is set at an increase of $140^{\circ} \mathrm{C}$. This implies that samples tested in (Al-Sibahy \& Edwards, 2012) have a longer lag period before attaining the failure temperature as compared to this research.

Generally, the nodal temperatures obtained from the model's prediction is in good agreement with the experimental work done. 


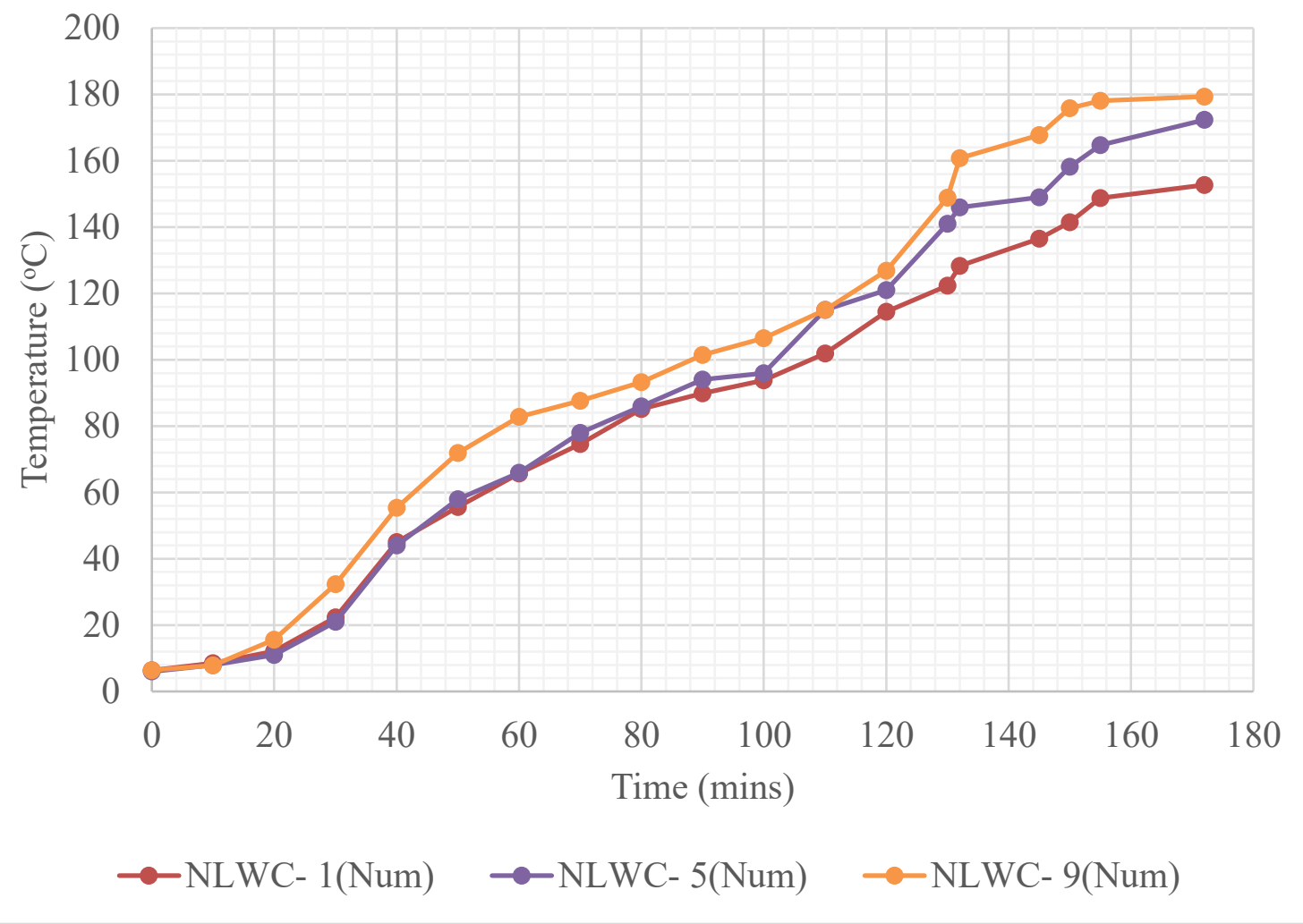

Figure 4-20: Temperature profile on masonry wall made from $N L W C$ (Num.) at locations 1, 5 and 9

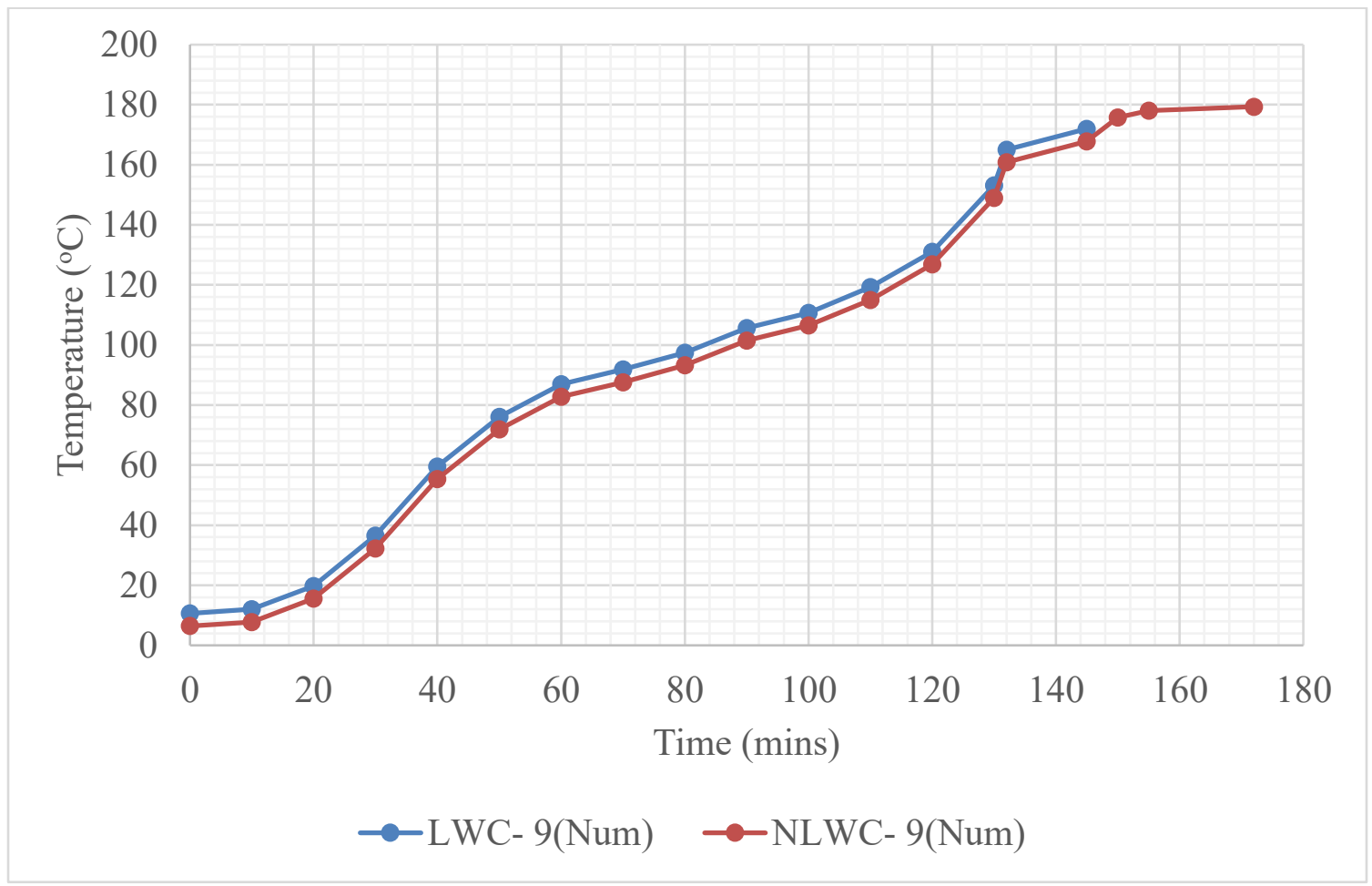

Figure 4-21: Average temperature profile on masonry walls made from $N L W C$ and LWC (Num.) 


\subsubsection{Lightweight foamed concrete masonry walls}

The lightweight-foamed concrete masonry walls consisted of masonry blocks made from lightweight-foamed concrete mortared with Type S mortar, (Othuman \& Wang, 2011). The two main densities were blocks made of $650 \mathrm{~kg} / \mathrm{m}^{3}\left(\mathrm{LFC}_{1}\right)$ and $1000 \mathrm{~kg} / \mathrm{m}^{3}\left(\mathrm{LFC}_{2}\right)$. The thermal properties for these two categories have been documented in Appendix A . The temperature profile for both densities were similar to that of the experimental test for NWC masonry walls. This followed a trend where the hottest part of the wall was located at the topmost part while the lowest part recorded low temperatures (Figure 4-22 and Figure 4-23). However, at the beginning of the simulation for both densities, it was observed that

TL 5 recorded a slightly higher temperature as compared to TL 1 and 9 for approximately 18 minutes before TL 9 gained a higher temperature. This behaviour could be attributed to the nature of TL 5; this was within the hollow section. The LFC masonry blocks are relatively made of a material, which is very porous and as such conducts more heat energy at a faster rate as compared to the other conventional materials. TL 5 is hollow and therefore since the LFC material is very porous, it would have gained much energy thereby transferring this gained energy to the hollow sections of the masonry block through convection, which occurs more rapidly in cavities. At the end of the numerical simulation, $\mathrm{LFC}_{1}$ walls fail after 147 minutes while $\mathrm{LFC}_{2}$ walls fail at 158 minutes. The difference in time is approximately 11 minutes. This could be attributed to the difference in densities and thermal properties. $\mathrm{LFC}_{2}$ blocks have relatively higher specific heat energy at a temperature of $120^{\circ} \mathrm{C}$, this coupled with the high specific heat capacity of mortar at this significant temperature, increases the amount of heat energy that could be stored within the masonry unit. With a combined high specific heat capacity, this would effectively decrease 
the rate at which this heat energy is dissipated. Since there is not much difference in the thermal conductivities of both block types, this would not significantly affect the rate of thermal conductance; it will almost be similar in both cases. Therefore, $\mathrm{LFC}_{2}$ walls with the higher specific heat capacity will have a higher fire resistance as compared to $\mathrm{LFC}_{1}$ walls as can be seen in Figure 4-22 and Figure 4-23.

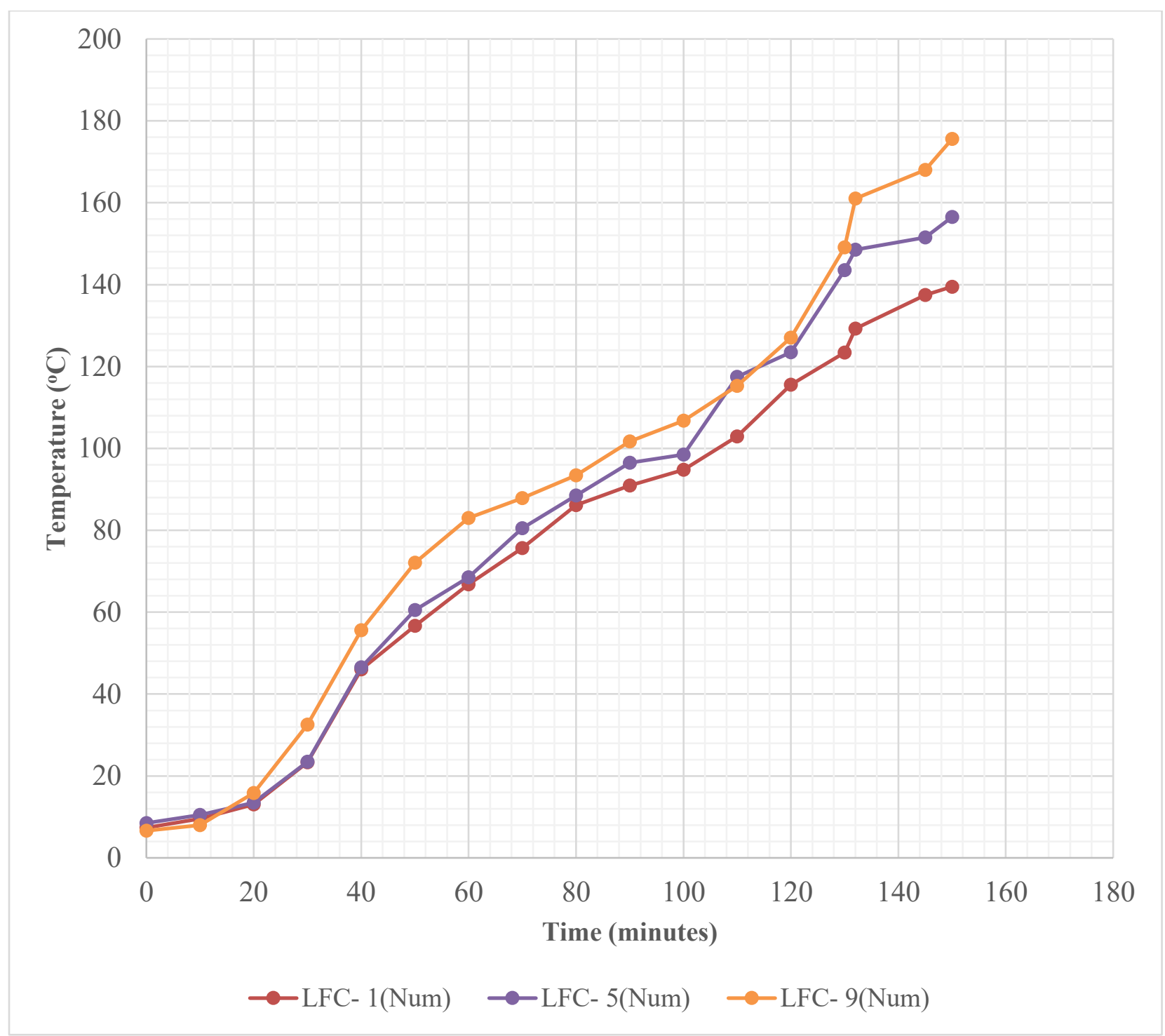

Figure 4-22: Temperature profile on masonry wall made from $L F C_{1}$ (Num.) at locations 1,5 and 9 


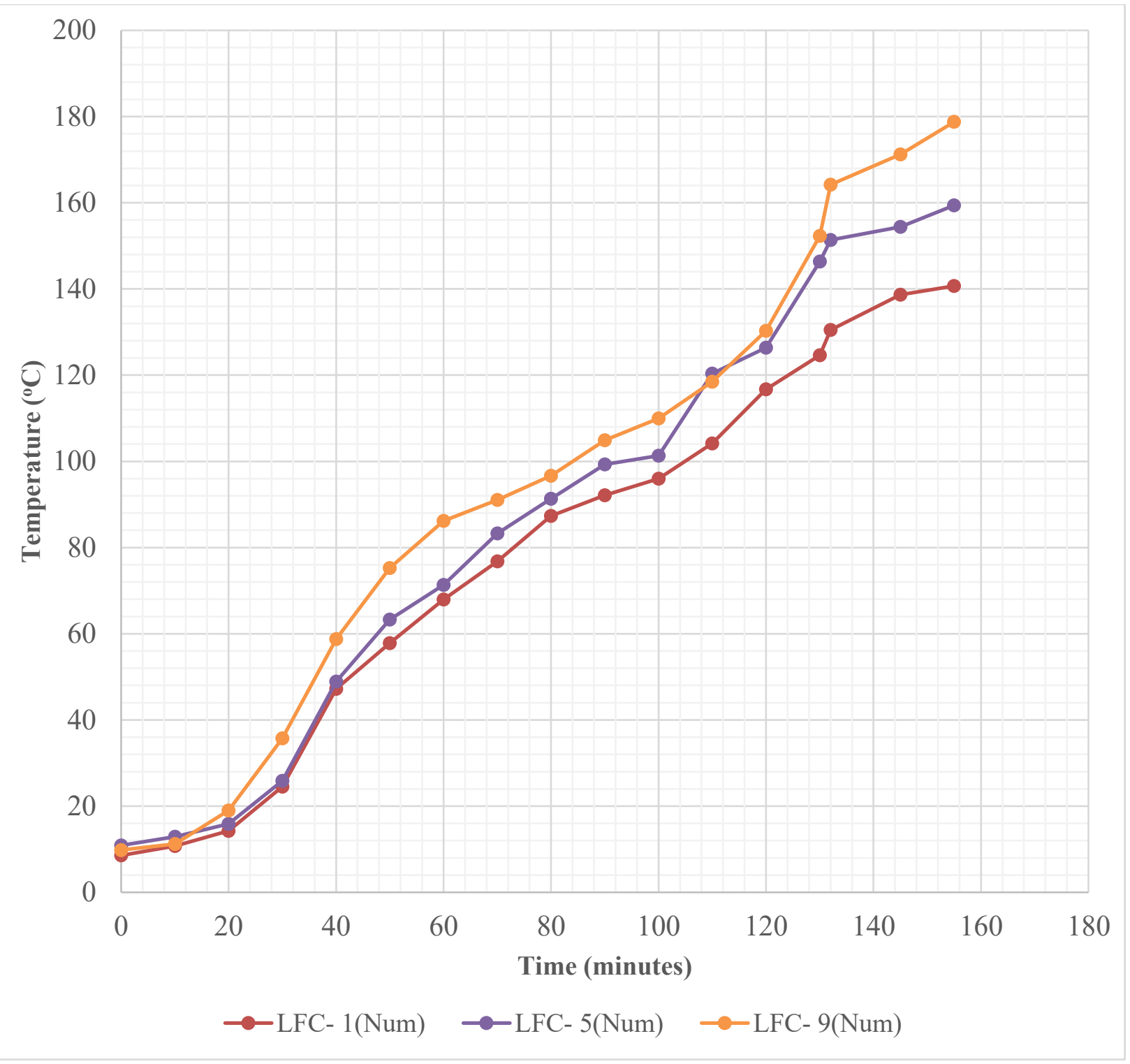

Figure 4-23: Temperature profile on masonry wall made from $\mathrm{LFC}_{2}$ (Num.) at locations 1,5 and 9

\subsection{Results - Insulating Materials}

The insulating materials were modelled as inserts in the cavities of the normal weight concrete masonry blocks. Inserts were rock wool, slag wool and glass wool. Thermal and mechanical properties as obtained from existing literature review was used as input into the material model, (See, A.10). Therefore, for each wall, a set of inserts were modelled 
into the cavities, Table 4-7 and Figure 4-24. A total of 3 walls were modelled and analyzed to evaluate the fire resistance. With the inclusion of the inserts in the model, the interaction module considered a surface-to-surface interaction between the surfaces of the hollow parts and that of the inserts. A surface radiation was then set on the exposed side of the wall to depict the modes of heat transfer occurring within the model. Walls were run through a couple of iterations and then compared to the experimental control wall without the use of inserts. TL 9 was used for all temperature analysis for the walls.

Table 4-7: Wall description - Inserts

\begin{tabular}{|c|c|c|c|}
\hline Wall Name & Insert type & Concrete Masonry Type & Mortar Type \\
\hline ROW & Rock wool & Normal weight concrete & S \\
\hline SW & Slag wool & Normal weight concrete & S \\
\hline GW & Glass wool & Normal weight concrete & S \\
\hline
\end{tabular}

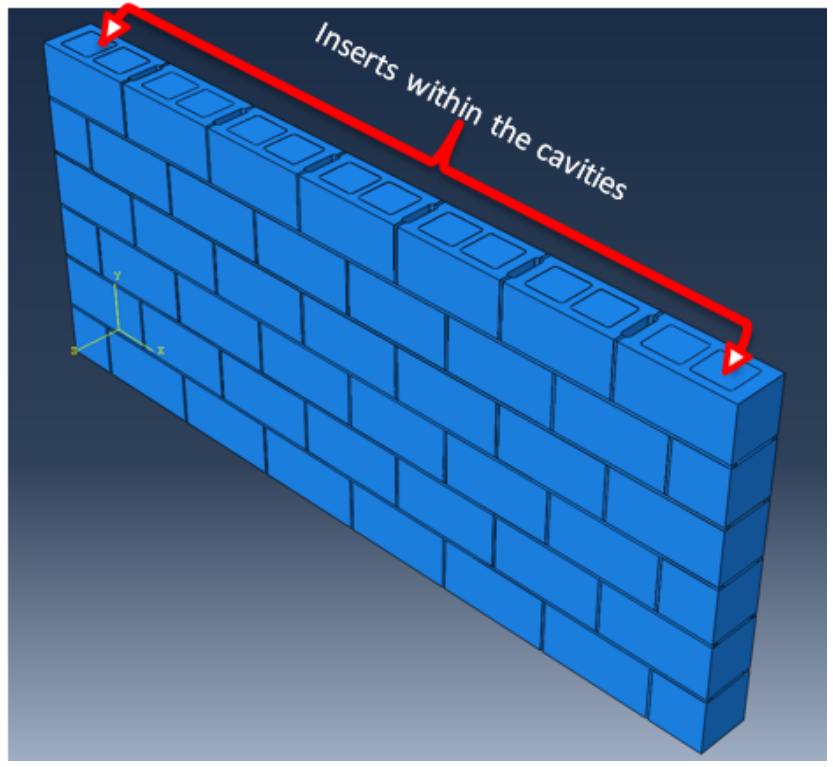

Figure 4-24: Section of modelled masonry wall with inserts

The temperature profile followed that of the experimental test wall. It was observed that 
inserts rock wool (ROW) and slag wool (SW) produced almost similar results since both materials had the same thermal properties. The only difference was in their densities, which did not show any significant influence in affecting the results. However, walls made of ROW recorded a failure temperature of $164^{\circ} \mathrm{C}$ while $\mathrm{SW}$ recorded a temperature of $169^{\circ} \mathrm{C}$ after 185 minutes of the numerical simulation. On the other hand, $\mathrm{GW}$ walls failed at $170^{\circ} \mathrm{C}$ after 178 minutes. This could be possibly due to its high thermal conductivity and specific heat. Another notable observation was found just around $45-80$ minutes into the numerical simulation for $\mathrm{GW}$, where higher temperatures were recorded as compared to the NWC without inserts and that of ROW and SW. A possible cause for this could be attributed to the material's ability to contain enough moisture content and considering that this occurred during the temperature phase of evaporation. Generally, walls without inserts failed at an earlier time as compared to walls composed of the inserts Figure 4-25. 


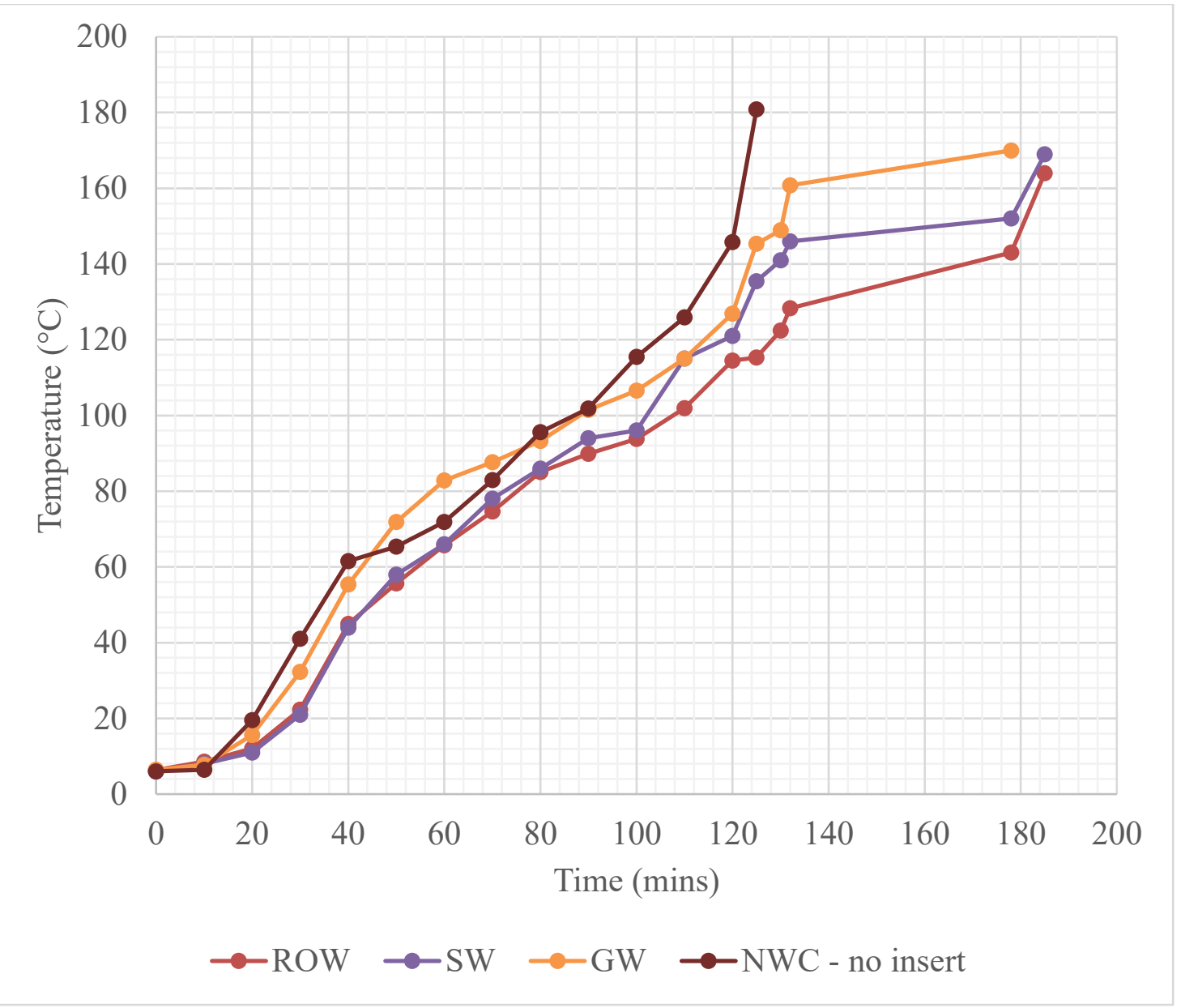

Figure 4-25: Comparison of temperature profile on masonry wall with inserts (Num.) and without inserts (Exp) at locations 9

\subsection{Fire Resistance - All Models}

Fire resistance is defined as the time it takes for the assembly to reach failure when subjected to the standard time-temperature curve. This failure is governed by the criterion selected for the analysis. In this research work, the insulation criterion was adapted as the governing failure criterion. Therefore, it was necessary to determine the onset of failure in the modelled assembly for a comparison with the experimental test results. In the simulation of the model, the assembly was subjected to the DFLUX subroutine (heat flux) 
which incorporated the CAN/ULC S-101 fire curve. This computes a heat flux which is equal to the fire temperature on the exposed side of the wall, which in turn sends the results to ABAQUS and using the required heat equations in ABAQUS computes a heat flux, which is subjected on the unexposed side. This in turn works on several steps and frames until the failure criterion, which has been specified within the simulation, is met. The DLUX subroutine file as well as the inputs made in the interaction module are the main parameters required for the computation of the heat flux and the mode of heat transfer within the model. The effectiveness of these two parameters coupled with a boundary condition, which is inputted in the step module, and an appropriate meshing technique is essential in obtaining results, which will converge to the experimental results.

From the numerical simulation, the time difference between the onsets of the test to the ultimate failure is defined as the approximate fire resistance of the assembly. This has been illustrated in

Figure 4-26 for all the models that were analyzed. It can be observed that the wall which recorded the highest fire resistance were walls made with inserts ROW and SW while the lowest was found in walls made of SCCA. This is mainly attributed to the magnitude of the thermal conductivity of the two materials. ROW and SW have the lowest thermal conductivity as compared to all the materials that were tested while SCCA had the highest thermal conductivity. This behaviour proves that thermal conductivity is the governing factor in determining the total fire resistance of an assembly or member under elevated temperatures. 


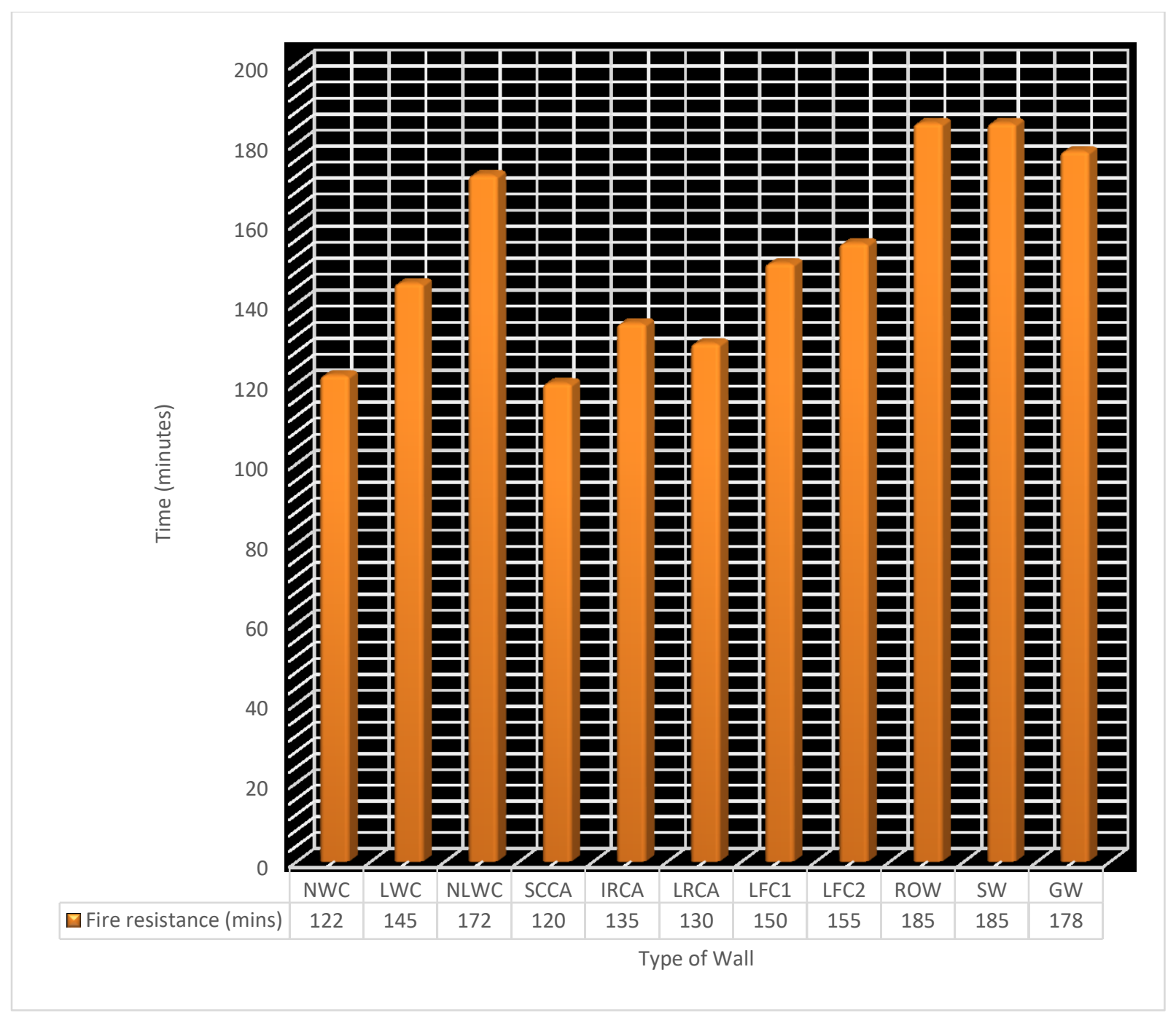

Figure 4-26: Fire resistance of all tested models 


\section{Chapter: Summary, Conclusions and Recommendations}

\subsection{Introduction}

This chapter includes the research summary, conclusions, limitations, recommendations for future studies and general observations from the experimental work and finite element models carried out for this thesis.

\subsection{Research Summary}

This study was undertaken to evaluate the thermal behaviour of masonry walls made from different joint profiles, material and geometric properties exposed to elevated temperatures. Following the objectives of this research, a reliable finite element model has been developed in ABAQUS/Standard V6.132, which can simulate the behaviour of these walls under fire conditions. Masonry walls made with different joint profiles included raked and concave joints. Different material properties included masonry walls made from normal weight, lightweight, modified normal weight, recycled aggregates and modified lightweight concrete masonry. Geometries were based on a $10 \mathrm{~cm}, 15 \mathrm{~cm}$ and $20 \mathrm{~cm}$ masonry block standard units while inserts were composed of rock wool, slag wool and glass wool. All these forms of masonry walls were modelled and were investigated in the numerical model to determine their correlation with full-scale fire resistance test results. This preliminary study focused on developing a reliable numerical model, the masonry wall type and configuration were the primary parameter, which were varied. The time to thermal failure based on the insulation criterion of the wall type and configuration in fire was the primary objective.

A three-dimensional thermal model was developed and accordingly used to simulate the 
different wall types and configurations in fire condition. A pure heat transfer analysis was used to model the solid body heat conduction with general, temperature dependent conductivity and the combined effect of convection and radiation. The heat transfer analysis was considered nonlinear because the material properties are temperature dependent and because the boundary conditions were nonlinear.

Based on the heat transfer model, the thermal behaviour of the assembly and its temperature profile with time obtained from the model generally correlates well with the test results from the experimental work and existing literature review. The model predictions of the fire resistance were generally within $\pm 9 \%$ variation of the recorded test results. Possible sources of error could be linked to the meshing technique used for some of the models and the inability to produce the same heating action on the modelled walls as performed in the experimental work. Another possible source of error could be linked to the type of radiation and convection used in the interaction module. Although, the model has the capability of generating an interaction module, which is close to the interactions as observed in the experimental work, this is not the same due to the natural occurrences, which may occur during the actual experimental work.

In terms of the different joint profiles, it can be noted that the use of raked joints in masonry walls, up until $0.5 \mathrm{~cm}$, does not affect the thermal behaviour of these walls as it has been thought of. Based on the numerical results, and as confirmed by experimental results as tested per the CAN/ULC S101 Standard, raked and full concave mortar joints produced similar fire resistance behaviour. Raked joints has no significant impact on the fire 
resistance of the masonry walls.

In terms of concrete masonry types, all forms of lightweight concrete masonry mixes produced high fire resistance as compared to the other normal weight concrete masonry mixes. This could be attributed to the generally low thermal conductivities of these mixes, which reduced the rate of transmitting heat directly into the assembly. Also, the high specific heat capacity of these lightweight mixes also created a high amount of heat energy to be stored and dissipated slowly thereby increasing the fire resistance. The lightweight concrete masonry mixes recorded a fire resistance level in the range of $15 \%-20 \%$ higher than that of the normal weight concrete masonry types; SCCA, LRCA and IRCA. Notable of the LWC group was NLWC; $45 \%$ recycled glass and $19 \%$ metakaolin recorded the highest fire resistance. This was also affirmed from existing literature as the thermal behaviour of NLWC subjected to elevated temperatures was compared to other forms of LWC masonry mixes.

Walls made from NLWC failed at 172 minutes, which was 27 and 50 minutes greater than conventional LWC and NWC masonry mixes. NLWC recorded an average temperature of $158^{\circ} \mathrm{C}$ as compared to $155^{\circ} \mathrm{C}$ in LWC. Although, there is a temperature rise of about $3^{\circ} \mathrm{C}$ in NLWC, it is observed that NLWC failed at a period, which was higher than that of LWC mixes. In comparing the average temperature of NLWC to NWC, it was found that NWC recorded an average temperature of $172^{\circ} \mathrm{C}$, which is approximately $14^{\circ} \mathrm{C}$ and $17^{\circ} \mathrm{C}$ higher in both NLWC and LWC respectively.

Rock wool and slag wool had similar fire resistance levels due to similar thermal properties. 
Glass wool recorded the lowest fire resistance in terms of the inserts. All NWC walls with inorganic inserts produced higher fire resistance levels as compared to walls modelled without the use of inserts. Of all the inserts, rock wool and slag wool measured a fire resistance of 185 minutes recording failure temperatures of $164^{\circ} \mathrm{C}$ and $169^{\circ} \mathrm{C}$ respectively. The fire resistance of these inserts is approximately 13 minutes, 40 minutes and 63 minutes higher when compared to NLWC, LWC and NWC masonry respectively. This proves that the combining effect of insulating materials used as inserts have a significant influence of increasing the fire resistance of any of the types of concrete masonry wall which were analyzed. This is conclusive because walls in this category were made from NWC, which recorded one of the lowest fire resistance after SCCA walls. The resulting fire resistance level of all the insulating materials was in a range of $15 \%-35 \%$ higher than all the types of concrete masonry walls.

\subsection{Conclusions}

The conclusions regarding the detailed objectives of this study were given at the end of their respective chapters. However, the main findings may be summarized as follows:

1. Numerical simulations can be used to assess the fire resistance of masonry walls, as an alternative to full-scale fire resistance tests, following a successful model validation. A pure heat transfer analysis procedure in FE model generally represents the thermal response of the masonry walls in fire conditions. The model's predictions for the fire resistance of both cases were closely within the temperatures recorded from the experimental study. 
2. The thermal properties of the material determine the level of fire safety, which can be achieved. Generally, materials with low thermal conductivity and relatively high specific heat has a good correlation to produce high fire resistance levels. This was evident in the use of modified lightweight concrete masonry mixes and subsequently the insulating materials; rock wool, glass wool and slag wool.

3. Density of insulating materials has no significant effect on the thermal behaviour of the masonry walls. This was observed in the use of rock wool and slag wool where they had different densities. The influencing characteristics were based on the thermal properties of the material.

4. Based on numerical results, and as confirmed by experimental results, raked and full mortar joints produced similar fire resistance behaviour. The use of raked mortar joints has no thermal effects on fire behaviour of masonry walls.

5. The material properties for normal weight and lightweight concrete produced in EN 1993 provided the temperature dependent properties of the concrete masonry material for the thermal analysis. The validation of the thermal model showed the reliability of these values in accounting for the thermal behaviour of concrete masonry.

6. The material properties for all other mix designs as obtained from existing literature review provided temperature dependent properties for the other forms of concrete masonry material for thermal analysis. The validation of the thermal model showed 
the reliability of these values in accounting for the thermal behaviour of concrete masonry.

\subsection{Relevance of Research Study}

Based on results from the experimental and numerical simulation, the following conclusions can be made:

1. In terms of joint profiles, it was observed that both raked and concave jointed walls have similar fire resistance behaviour. This therefore cancels the effects of thermal bridging known to be occurring in buildings with raked joints. This is a significant result because it suggests that the fire resistance of walls do not greatly depend on the thickness of the mortar. Since it has been observed that those two types of wall joints have similar fire resistance, this reduces the amount of work (labour) masons must do to make such walls perfectly jointed and as such save both labour time and cost.

2. Most experimental parametric studies are difficult to control in a laboratory setting, and are also expensive and time consuming. For instance, a single fire resistance test on a masonry wall could involve varying moisture contents of concrete masonry materials, type of concrete masonry materials and inclusions of different insulation materials as inserts or spray on materials. Therefore, having a reasonable accuracy of the validated finite element model, in reproducing the experimental fire behaviour of normal weight concrete masonry walls and walls modelled as concave and raked joints, makes it very useful for both numerical and analytical studies. These studies would involve all other parametric variations to be considered. 


\subsection{Limitations}

This study incorporated some limitations, which are either related to the sake of simplification considerations or to comply with the intended research objectives. These include:

1. The DFLUX subroutine file incorporated the CAN/ULC standard fire-curve. The coefficient of convection used was $25 \mathrm{~W} / \mathrm{m}^{2} \mathrm{~K}$.

2. The mechanical properties were not considered since this is a pure heat transfer analysis.

3. Mortar was modelled with a higher specific heat value, for a temperature range of $80^{\circ} \mathrm{C}$ to $100^{\circ} \mathrm{C}$, as compared to that of the concrete block to account for its higher moisture content based on studies from (Wang, 1995), (Ang \& Wang, 2004) and (Othuman \& Wang, 2011).

4. Raked joints modelled were $0.5 \mathrm{~cm}$ deep on both sides of the wall as per the experimental work. In addition, that is the standard to be considered as deeper joints would technically mean the absence of mortar in the joints.

5. For all tests on mix designs and insulating materials, the standard concave mortar joint was used.

6. The DFLUX subroutine file produced heat fluxes that were due to radiation and convectional effects.

\subsection{Recommendations for Future Studies}

Since this study was not previously conducted, it forms a constitutive subject for a wide scope of further research. Relevant topics that may be undertaken in the future are 
summarized as follows:

1. The thermo-mechanical behaviour of the different forms of masonry walls need to be determined. This study focused primarily on the thermal behaviour and as such did not incorporate the mechanical properties of the materials used for the walls. This thesis mainly focused on using the insulation criterion. However, future studies could incorporate the mechanical properties of the walls and perform either a fully coupled or a sequentially coupled thermal-stress procedure. This would incorporate the integrity criterion and aid in the complete thermal analysis of nonload bearing masonry walls. The fully coupled or sequentially coupled thermal stress procedures are suitable for systems where the thermal and mechanical solutions affect each other significantly. The fully coupled thermal stress procedure could be used for such analyses to obtain simultaneous stress/displacement and temperature field solutions of the system. However, using a sequentially coupled thermal-stress is a simplified procedure where the stress solution is dependent on the temperature solution or no inverse dependency. Therefore, the recommended suggestion is to model the concrete masonry material using the Concrete Damage Plasticity (CDP) model in ABAQUS. This would identify plastic deformations of the concrete masonry material and the extent of cracks and fissures propagation.

2. The difference in thermal behaviour was based on the thermal properties that were inputted in the material properties modules. Concrete masonry material properties were obtained from Standards, which were confirmed in the heat transfer model. 
However, mortar properties were obtained based on existing literature review and modified as such based on their thermal behaviour. To account for the reliability of the mortar properties, it is suggested that some specimens be tested for their thermal conductivity and specific heat capacities for all temperature ranges. This could also incorporate finding the mechanical properties such as the strength and elastic properties to be used in the thermo-mechanical analysis.

3. Numerical modelling on insulating materials used as inserts focused on only inorganic materials. A more in-depth numerical analysis on evaluating the thermal behaviour of inserts could be performed on all classes of insulating materials to draw a more conclusive work. These classes involve the organic materials, combined and other forms. Laboratory works should be first performed on all classes of insulating materials to obtain thermal characteristics of these for all temperature ranges and accordingly used for the numerical analysis. 


\section{References}

(CCMPA), C. C. M. P. A., 2004. Metric Techincal Manual, Toronto: s.n.

Abdel-Reheem, A., Imam, M. \& Shihata, A., 2003. Lightweight concrete; how and why. Abu Dhabi, United Arab Emirates, s.n.

Ablowitz, J. M. \& Clarkson, P. A., 1991. The finite difference method. In: Linear and Nonlinear Waves - Lecture Note Series. Cambridge: Cambridge University Press, pp. 7992.

ACI Committee 122, 2002. Guide to Thermal Properties of Conrete and Masonry Systems, s.1.: American Concrete Institute.

ACI/TMS, 2002. Standard Method for Determining Fire Resistance of Concrete and Masonry Construction Assemblies. Detroit: American Concrete Institute.

Adefemi, A., Muhammed, U., Kebbi, U. M. B. \& Olugbenga, S., 2013. Effect of Admixture on Fire Resistance of Ordinary Portland Cement Concrete. Civil and Environmental Research, Volume 3, pp. 105-114.

Ali, F., Nadjai, A., Silcock, G. \& Abu-Tahir, A., 2004. Outcomes of a Major Research on Fire Resistance of Concrete Columns. Fire Safety Journal, Volume 39, pp. 433-445.

Ali, J. H., 2014. Materials, Production, Properties and Application of Aerated Lightweight Concrete: Review. Internaional Journal of Materials Science and Engineering, Volume 2, pp. 152-157.

Al-Jabri, K., Hago, A., Al-Nuaimi, A. \& Al-Saidy, A., 2005. Concrete blocks for thermal insulation in hot climate. Cement and Concrete Research, Volume 35, pp. 1472-1479. Al-Sibahy, A. \& Edwards, R., 2012. Mechanical and thermal properties of novel lightweight concrete mixtures containing recycled glass and metakaolin. Construction 
and Building Materials, Volume 31, pp. 157-167.

Al-Sibahy, A. \& Edwards, R., 2012. Thermal behaviour of novel lightweight concrete at ambient and elevated temperatures: Experimental, modelling and parametric studies. Construction and Building Materials, Volume 31, pp. 174-187.

Andreini, M. \& Sassu, M., 2011. Mechanical behaviour of full unit masonry panels under fire action. Fire Safety Journal, Issue 46, pp. 440-450.

Ang, C. N. \& Wang, C. Y., 2004. The Effect of Water Movement on Specific Heat of Gypsum Plasterboard in Heat Transfer Analysis under natural Fire Exposure.

Construction and Building Materials, 18(7), pp. 505-515.

ANSYS Inc., 2013. ANSYS Installation and Licensing Documentation. USA: SAS IP, Inc..

Arioz, O., 2007. Effects of elevated temperatures on the properties of concrete. Fire Safety Journal, Volume 42, pp. 516-522.

Arthur H, N., Darwin, D. \& Charles W, D., 2010. Design of Concrete Structures. New York: McGraw-Hill Higher Education.

ASTM C113-90, 2013. Test method for thermal conductivty of refractories by hot wire (Platinum Resistance Thermometer Technique). s.1.:s.n.

ASTM C192 M-95 , 1998. Annual Book of ASTM Standards. s.l.:s.n. ASTM E119, 1988. Standard Tests and Methods for Fire Tests of Building Construction and Materials. s.1.:s.n.

ASTM, 1997. Standard test method for steady-state heat flux measurements and thermal transmissions properties by means of the guarded-hot-plate apparatus, ASTM C 177-97. s.1.:s.n. 
Aydin, S., 2008. Development of a high-temperature-resistant mortar by using slag and pumice. Fire Safety Journal, Volume 43, pp. 610-617.

Bahar, D. \& Oguzhan, K., 2010. Effect of elevated temperature on the mechanical properties of concrete produced with finely ground pumice and silica fume. Fire Safety Journal, Volume 45, pp. 385-391.

Bathe, K., 1996. Finite Element Procedures. New Jersey, USA: Prentice-Hall, Inc.. Bergman, T. L., Lavine, A. S., Incropera, F. P. \& Dewitt, D. P., 2011. Fundamentals of Heat and Mass Transfer. Jefferson City: John Wiley and Sons.

Bingol, A. F. \& Gul, R., 2004. Compressive strength of lightweight aggregate concrete exposed to high temperatures. Indian Journal of Engineering and Materials Sciences, Volume 11, pp. 68-72.

British Standards, 1987. Fire Tests on Building Materials and Structures. UK: s.n. BS EN 1996-1-2, 2005. Eurocode 6: Design of masonry structures: Part 1-2: General rules-structural fire design. s.1.:British Standards.

BS EN 993-15, 2005. Methods of test for densed shape refractory products. Part 15: Determination of thermal conductivty by the hot wire (parallel) method. s.1.:British Standards.

BS EN, 2002. Eurocode 1: Actions on structures : Part 1-2: General actions on structures exposed to ifre. s.1.:Bristish Standards.

Buchanan, A. H., 2006. Concrete Structures. In: Structural Design for Fire Safety. England: John Wiley and Sons Limited, pp. 225-259.

Buchanan, A. H., 2006. Structural Design for Fire Safety. England: John Wiley \& Sons, Ltd.. 
CAN/ULC-S101, 2007. Standard Methods of Fire Endurance Tests of Building Construction and Materials. Scaborough, Canada: s.n.

Casandijian, C., Challamel, N., Lanos, C. \& Hellesland, J., 2013. Reinforced Conrete Beams, Columns and Frames: Mechanics and Design. s.1.:John Wiley and Sons, Inc.. Cash, B., 1997. Thermal Bridging: An investigation of the heat loss effects of thermal bridges common in Irish Construction Pratcice. Dublin: Dublin City University. Cavaleri, L., Miraglia, N. \& Papia, M., 2003. Pumice concrete for structural wall panels. Engineering Structures, 25(1), pp. 115-125.

Cerny, R., 2008. Properties of cementitious composites at high temperatures, Czech Republic: Thermo Physics.

Cerny, R. et al., 2000. The effect of compressive stress on thermal and hygric properties of Portland cement mortar in wide temperature and moisture ranges. Cement and Concrete Research, Volume 30, pp. 1267-1276.

Cerny, R. et al., 2003. Thermal and hygric properties of portland cement mortar after high-temperatures exposure combined with compressive stress. Cement and Concrete Research, Volume 33, pp. 1347-1355.

Chen, C. H., 2006. Waste E-glass particles used in cementitious mixtures. Cement Concrete Research, 36(3), pp. 449-456.

Chen, X. et al., 2009. Experimental evidence of a moisture clog effect in cement-based materials under temperature. Cement and Materials, 39(12), pp. 1139-1148.

Chow, W. K. \& Y, C. Y., 1996. Computer simulation of the thermal fire resistance of building materials and structural elements. Construction and Building Materials, 10(2), pp. 131-140. 
Cioni, P., Croce, P. \& Salvatore, W., 2001. Assessing Fire Damage to Reinforced Concrete Elements. Fire Safety Journal, Volume 36, pp. 181-199.

Como, M., 2013. Masonry Strength and Deformability. In: Statics of Historic Constructions. Verlag Berlin Heidelberg: Springer, pp. 1-49.

Cooke, G. M. E., 1988. Thermal bowing in fire and how it affects building design, United Kingdom: Building Research Establishment.

Cooke, G. M. E., 1988. Thermal bowing in fire and how it affects building design, United Kingdom: Building Research Environment, Dept. of the Environment.

Cooper, M. G., Mikic, B. B. \& Yovanovich, M. M., 1969. Thermal Contact Conductance. International Journal Heat Mass transfer, Volume 12, pp. 279-300.

Corbitt-Dipierro, C. E., 2016. Inter Fire Online. [Online] Available at: http://www.interfire.org/features/spalling.asp [Accessed 15 June 2016].

Crane, A. E. \& McLaren, L., 2008. Insulation Materials: Rock and Slag Wool Insulation: A Sustainable Choice. Insulation Outlook, July.

CSA A165.1, 2004. Concrete Block Masonry Units. Mississauga, Ontario, Canada:

\section{CCMPA.}

Dassault Systemes Simulia Corp., 2013. ABAQUS/CAE Version 6.13 Standard Manual. Rhode Island, USA: s.n.

Demirboga, R. \& Gul, R., 2003. The effects of expanded perlite aggregate, silica fume and fly ash on the thermal conductivity of lightweight concrete. Cement and Concrete Research, Volume 33, pp. 723-727.

Demir, I. \& Serhat, B. M., 2008. Effect of silica fume and expanded perlite addition on the technical properties of the fly ash lime-gypsum mixture. Construction and Building 
Materials, Volume 26, pp. 1299-1304.

Drysdale, R. G. \& Hamid, A. A., 2005. Masonry Structures Behaviour and Design. Mississauga, Ontario: Canada Masonry Design Centre.

EN 1363-1, 2000. Fire resistance test-part 1: general requirements. s.1.:British Standards.

EN 1363-1, 2000. Fire resistance test-part 1: General requirements. s.1.:s.n. EURIMA, 2006. Types of Mineral Wool, s.1.: s.n.

Federation of Canadian Municipalities, 2009. Getting to 50\% and Beyond: Waste Diversion Success Stories from Canadian Municipalities, Ottawa: FCM Green Municpal Fund.

Gardner, J. D., Vijayaraghavan, A. \& Dornfeld, D. A., 2005. Comparative study of finite element simulation software, Berkeley: University of Carlifornia.

Georgali, B. \& Tsakiridis, P., 2005. Microstructure of Fire-Damaged Concrete. Cement and Concrete Composites, 27(2), pp. 255-259.

Gnankrishnan, N. \& Lawther, R., 1990. Performance of masonry walls exposed to fire. Ilinois, s.n.

Hamidah, M. S. et al., 2005. Optimization of foamed concrete mix of different sandcement ratio and curing conditions. Dundee Scotland, UK, s.n.

Harmathy, T. Z. \& Allen, L. W., 1972. Thermal performance of concrete masonry walls in fire, s.1.: Division of Building Research, National Research Council of Canada. Harper, C. A., 2004. Handbook of Building Materials for Fire Protection. s.1.:McGrawHill Handbooks.

Hendry, A. W., Sinha, B. P. \& Davies, S. R., 2004. Design of masonry structures. 
London: E \& FN SPON, an imprint of Chapman and Hall.

Hertz, K. D., 2005. Concrete Strength for Fire Safety Design. Magazine of Concrete Research, 57(8), pp. 445-453.

Hibbeler, 2010. Mechanics of Materials. s.1.:s.n.

Houben, H. \& Guillaud, G., 1994. Earth Construction : A Comprehensive Guide.

s.1.:Intermediate Technology Publication.

Information, G. N. a., 2005. Geology.com. [Online] Available at:

geology.com/rocks/amphibolite.shtml [Accessed 25 July 2016].

Ingham, J. P., 2009. Application of petrographic examination techniques to the assessment of fire-damaged concrete and masonry structures. Materials Characterizatiob, 60(7), pp. 700-709.

ISO 834-1, 1975. Fire Resistance Tests - Elements of Building Construction. s.1.:s.n. ISO 834-1, 1999. Fire resistance tests-element of building construction, part 1: general requirements. Geneva,Switzerland: s.n.

Janotka, I. \& Nurnbergerova, T., 2005. Effects of temperature on structural quality of the cement paste and high-strength concrete with silica fume. Nuclear Engineering and Design, Volume 235, pp. 2019-2032.

Karamanos, A., Hadiarakou, S. \& Papadopoulos, A., 2008. The Impact of Temperature and Moisture on the Thermal Performance of Stone Wool. Energy and Buildings, Issue 40, pp. 1402-1411.

Khoury, G. A., Majorana , C. E., Pesavento, F. \& Schrefler, B. A., 2002. Modelling of heated concrete. Magazine of Concrete Research, 54(2), pp. 77-101.

Khoury, A. \& Anderberg, Y., 2000. Concrete spalling review, s.1.: Swedish National 
Road Administration.

Kodur, V. \& Phan, L., 2007. Critical factors governing the fire performance of high strength concrete systems. Fire Safety Journal, 42(6), pp. 482-488.

Koksal, F., Gencel, O., Browston, W. \& Lobland, H. E. H., 2012. Effect of high temperature on mechanical and physcal properties of lightweight cement based refractory including expanded vermiculite. Materials Research innovations, Volume 6, pp. 7-13. Kompatscher, M., 2007. Efflorescence Control, Zurich: BASF Construction Chemicals Europe.

Kosmatka, S. H., Kerkhoff, B. \& Panarese, W. C., 2003. Aggregates for Concretes. In: Design and Control of Concrete Mixtures. Illinois: Portland Cement Association, pp. 79103.

Kothandaraman, P. \& Subramanyan, S., 2004. Property Values of insulating Building and Other Materials. In: Heat and Mass Transfer Data Book. s.1.:New Age International Ltd., pp. 8-9.

Laneyrie, C. et al., 2016. Influence of recycled coarse aggregates on normal and high performance concrete subjected to elevated temperatures. Construction and Building Materials, Volume 111, pp. 368-378.

Laurent, C., 2014. Investigating the fire resistance of ultra lightweight foam concrete. Revista Technica De La Facultad De Ingenieria, 37(1), pp. 11-18.

Lawrence, S. J. \& Gnankrishnan, N., n.d. The fire resistance of masonry walls. Melbourne, s.n.

Li, D. \& Lam, T. N. T., 2008. An analysis of building performances and benefits using solar facades. Journal of Power and Energy, 222(3), pp. 299-308. 
Livermore Software Technology Corporation, 2007. LS-DYNA Keyword user's Manual Volume I. Livermore, California: s.n.

Logan, D. L., 2007. A First Course in the Finite Element Method. Toronto, Canada: Nelson.

Lotfy, A., Hossain, K. M. \& Lachemi, M., 2016. Durability properties of lightweight selfconsolidating concrete developed with three types of aggregates. Construction and Building Materials, Volume 106, pp. 43-54.

Luccioni, B. M., Figueroa, M. I. \& Danesi, R. F., 2003. Thermo-Mechanic Model for Concrete Exposed to Elevated Temperatures. Engineering Structures, Volume 25, pp. $729-742$.

Malhotra, H., 1982. Design of masonry elements. In: Design of Fire-Resisting Structures. s.1.:Surrey University Press, pp. 170-178.

Malhotra, H., 1982. Properties of Materials. In: Design of Fire-Resisting Structures. London: Surrey University Press, pp. 48-77.

Mariyana, A. A. K., Awal Abdul, A. S. M. \& Tahir, M. M., 2015. Finite element modelling of compartment fire using ABAQUS. Jurnal Teknologi, 4(74), pp. 33-38. Mindeguia, J., Pimenta, P., Noumowe, A. \& Kanema, M., 2010. Temperature, pore pressure and mass variation of concrete subjected to high temperature - experimental and numerical discussion on spalling risk. Cement and Concrete Research, 46(1), pp. $217-$ 230.

Mueller, A., Leydolph, B. \& Stanelle, K., 2009. Recycling Mineral Wool Waste Technologies for the Conversion of the Fiber Structure, Part 1. InterCeram: International Ceramic Review, Volume 6, pp. 378-381. 
Neville, A., 2002. Properties of concrete. Edinburg; England: Pearson Education Limited.

Nguyen, T.-D. \& Meftah, F., 2012. Behaviour of clay hollow-brick masonry walls during fire. Part 1: Experimental analysis. Fire Safety Journal, Issue 52, pp. 55-64.

Nguyen, T.-D., Meftah, F., Chammas, R. \& Mebarki, A., 2009. The behaviour of masonry walls subjected to fire: Modelling and paramterical studies in the case o hollow burnt-clay bricks. Fire Safety Journal, Volume 44, pp. 629-641.

Noumowe, A., 1995. Effet des hautes temperatures $(20$ - 600 C) sur le beton; PhD Thesis, s.l.: Institute National des Sciences Appliquees.

Othuman, M. A. \& Wang, Y. C., 2011. Elevated-Temperature Thermal Properties of Lightweight Foamed Concrete. Construction and Building Materials, Volume 25, pp. 705-716.

Patnayaka, R., 2013. Mortar Building Materials, Visakhapatnam, India: Gitam School of Architecture.

Peng, H.-S., Chen, H.-J., Tang, C.-W. \& Chen, Y.-P., 2011. Fire performance and thermal insulation of reinforced lightweight aggreagte concrete. Advanced Materials Research, 287-290(1662-8985), pp. 1065-1069.

Peng, L., 2010. Performance of Heavy Timber Connections in Fire; Ph.D Thesis. s.l.:Carleton University, Ottawa, Canada.

Phan, L. T., 2008. Pore pressure and explosive spalling in concrete. Materials and Structures, Volume 41, pp. 1623-1632.

Piasta, J., Sawicz, Z. \& Rudzinski, L., 1984. Changes in the structure of hardened cement paste due to high temperature. Materials and Structures, 17(4), pp. 291-296. 
Podebradska, J., J, P., J, T. \& R, C., 2003. Specific heat capacity of cementitious composites in high-temperature range. Thermo Physics, pp. 18-23.

Poon, C.-S., Azhar, S., Anson, M. \& Wong, Y.-L., 2001. Comparison of the Strength and Durability Performance of Normal-and High-Strength Pozzolanic Concretes at Elevated Temperatures. Cement and Concrete Research, Volume 31, pp. 1291-1300.

Poon, C.-S., Azhar, S., Anson, M. \& Wong, Y.-L., 2003. Performance of metakaolin concrete at elevated tempertaures. Cement and Concrete Composites, Volume 25, pp. 8389.

Pope, H. \& Zalok, E., 2017. Issues with Masonry and Fire: Spalling and Thermal Blowing. Halifax, Canada, s.n.

Prior, A., 2012. SIMULIA: Past, Present and Future, United Kingdom: Dassault Systemes.

Rahmanian, I., 2008. Fire Resistance of Gypsum Board Based Systems, United Kingdom: School of Mechanical, Aerospace and Civil Engineering, University of Manchester. Reddy, J. N., 1993. An Introduction to the Finite Element Method. New York, USA: McGraw-Hill Inc..

Reinhardt, H. W. \& Stegmaier, M., 2006. Self-consolidating concrete in fire. $A C I$ Material Journal, 103(2), pp. 130-135.

Robert, F. \& Colina, H., 2009. The influence of aggregates on the mechanical characteristics of concrete exposed to fire. Magazine of Concrete Research, Volume 5, pp. 311-321.

Sarhat, S. R. \& Sherwood, E. G., 2013. Residual mechanical response of recycled aggregate concrete after exposure to elevated temperatures. Journal of Materials, 25(11), 
pp. 1721-1730.

Serdar Aydin, B. B., 2007. Effect of pumice and fly ash incorporation on high temperature resistance of cement based mortars. Cement and Concrete Research, Volume 37, pp. 988-995.

Seung, B., 2004. Studies on mechanical properties of concrete containing waste glass aggregate. Cement Concrete Research, 34(12), pp. 2181-2189.

Siddique, R. \& Klaus, J., 2009. Influence of metakaolin on the properties of mortar and concrete: A review. Applied Clay Science, Volume 43, pp. 392-400.

Sisson, J., 2017. Div 24: Recommendations for Mortar Joints. [Online] Available at: http://www.div2-4.com/mortar-joints.html [Accessed 29 June 2017].

Standards, B., 1987. Fire tests on building materials and structures, Part 20: Method for determination of the fire resistance of elements ofconstruction (general principles). s.l.:s.n.

Sturgeon, G., 2013. Fire Performance, s.1.: Canadian Concrete Masonry Producers Association.

Sturgeon, G., 2013. Physical Properties - Metric Technical Manual, s.l.: Canadian Concrete Masonry Producers Association.

Tatro, S. B., 2006. Thermal Properties. In: Significance of Tests and Properties of Concrete and Concrete-Making Materials. West Conshohocken, Pennsylvania: ASTM International, pp. 226-238.

Tavares, R. M., 2008. Prescriptive codes vs. Performance codes: Which one is the best fire safety code for the Brazilian context?. Safety Science Monitor, 12(1), pp. 1-10. Taylor, H. F. W., 1992. Cement Chemistry, London: Academic Press. 
Toman, J. \& Cerny, R., 1995. Calorimetry of building materials. Journal of Thermal Analysis, Volume 43, pp. 489-496.

Toman, J., Nemeckova, J. \& Cerny, R., 2007. Specific heat capacity of building materials at high temperatures, s.1.: Czech Technical University.

Topcu, I. \& Canbaz, M., 2004. Properties of concrete containing waste glass. Cement Concrete Research, 34(2), pp. 267-274.

Trisco Systems, 2016. The Different Types of Mortar Joints, Ohio: Masonry restoration. Turker, P., Erdogdu, K. \& Erdogdu, B., 2001. Investigation of fire-exposed mortars with different types of aggregates. Cement Concrete World, 6(31), pp. 445-453.

Vieira, J. P. B., Correia, J. R. \& Brito, J. d., 2011. Post-fire reisdual mechanical properties of concrete made with recycled rubber aggregate. Cement and Concrete Research, 41(5), pp. 533-541.

Wang, B. H., 1995. Heat Transfer Analysis of Components of Construction Exposed to Fire; PhD Thesis, University of Salford, Manchester: Department of Civil Engineering and Construction.

Won, J.-P.et al., 2010. Thermal characteristics of high-strength polymer-cement composites with lightweight aggregates and polypropylene fiber. Construction and Building Materials, Volume 25, pp. 3810-3819.

Xiao, J. Z. \& Zhang, C. Z., 2007. Fire damage and residual strengths of recycled aggregate concrete. Key Engineering Materials, pp. 937-940.

Xing, Z. et al., 2011. Influence of the nature of aggregates on the behaviour of concrete subjected to elevated tempertaure. Cemenet and Concrete Research, Volume 41, pp. 392402. 
Yoon, M. et al., 2015. Effect of coarse aggregate type and loading level on the high temperature properties of concrete. Construction and Building Materials, Volume 78, pp. $26-33$

Zega, C. J. \& Maio, A. A. D., 2009. Recycled concrete made with different natural coarse aggregates exposed to high temperature. Construction and Building Materials, 23(5), pp. 2047-2052.

Zega, C. \& Maio, A. A. D., 2006. Recycled concrete exposed to high temperatures. Magazine of Concrete Research, 58(10), pp. 675-682. 


\section{Appendices}

\section{Appendix A : Thermal Properties of Materials for Model Input}

\section{A.1 Normal weight Concrete Masonry}

\begin{tabular}{|c|c|c|c|}
\hline \multicolumn{4}{|c|}{ Masonry Block - Normal Weight Concrete (NWC) } \\
\hline $\begin{array}{c}\text { Temperature } \\
\left({ }^{\circ} \mathrm{C}\right)\end{array}$ & $\begin{array}{l}\text { Density } \\
\left(\mathrm{kg} / \mathrm{m}^{3}\right)\end{array}$ & $\begin{array}{c}\text { Specific } \\
\text { Heat }(J / k g K)\end{array}$ & $\begin{array}{c}\text { Thermal } \\
\text { Conductivity } \\
(\mathrm{W} / \mathrm{mK})\end{array}$ \\
\hline 20 & 2300 & 900 & 1.60 \\
\hline 50 & 2300 & 950 & 1.55 \\
\hline 100 & 2200 & 1000 & 1.50 \\
\hline 150 & 2200 & 1020 & 1.40 \\
\hline 200 & 2200 & 1050 & 1.35 \\
\hline 250 & 2200 & 1100 & 1.30 \\
\hline 300 & 2200 & 1100 & 1.25 \\
\hline 350 & 2200 & 1120 & 1.20 \\
\hline 400 & 2200 & 1150 & 1.15 \\
\hline 450 & 2200 & 1180 & 1.15 \\
\hline 500 & 2200 & 1190 & 1.10 \\
\hline 550 & 2200 & 1200 & 1.05 \\
\hline 600 & 2200 & 1220 & 1.00 \\
\hline 650 & 2200 & 1240 & 0.95 \\
\hline 700 & 2200 & 1260 & 0.90 \\
\hline 750 & 2200 & 1280 & 0.85 \\
\hline 800 & 2200 & 1300 & 0.85 \\
\hline
\end{tabular}




\section{A.2 Lightweight Concrete Masonry}

\begin{tabular}{|c|c|c|c|}
\hline \multicolumn{4}{|c|}{ Masonry Block - Lightweight Concrete (LWC) } \\
\hline $\begin{array}{c}\text { Temperature } \\
\left({ }^{\circ} \mathrm{C}\right)\end{array}$ & $\begin{array}{l}\text { Density } \\
\left(\mathrm{kg} / \mathrm{m}^{3}\right)\end{array}$ & $\begin{array}{l}\text { Specific Heat } \\
(\mathrm{J} / \mathrm{kgK})\end{array}$ & $\begin{array}{c}\text { Thermal } \\
\text { Conductivity } \\
(\mathrm{W} / \mathrm{mK})\end{array}$ \\
\hline 20 & 1800 & 840 & 1.00 \\
\hline 50 & 1800 & 840 & 0.98 \\
\hline 100 & 1700 & 840 & 0.97 \\
\hline 150 & 1700 & 840 & 0.95 \\
\hline 200 & 1700 & 840 & 0.92 \\
\hline 250 & 1700 & 840 & 0.90 \\
\hline 300 & 1700 & 840 & 0.87 \\
\hline 350 & 1700 & 840 & 0.84 \\
\hline 400 & 1700 & 840 & 0.81 \\
\hline 450 & 1700 & 840 & 0.78 \\
\hline 500 & 1700 & 840 & 0.73 \\
\hline 550 & 1700 & 840 & 0.70 \\
\hline 600 & 1700 & 840 & 0.63 \\
\hline 650 & 1700 & 840 & 0.61 \\
\hline 700 & 1700 & 840 & 0.59 \\
\hline 750 & 1700 & 840 & 0.52 \\
\hline 800 & 1700 & 840 & 0.51 \\
\hline
\end{tabular}




\section{A.3 Type S Mortar}

\begin{tabular}{|c|c|c|c|}
\hline \multicolumn{4}{|c|}{ Mortar Joint- (Type S Mortar) } \\
\hline $\begin{array}{c}\text { Temperature } \\
\left({ }^{\circ} \mathrm{C}\right)\end{array}$ & $\begin{array}{c}\text { Density } \\
\left(\mathrm{kg} / \mathrm{m}^{3}\right)\end{array}$ & $\begin{array}{c}\text { Specific Heat } \\
(\mathrm{J} / \mathrm{kgK})\end{array}$ & $\begin{array}{c}\text { Thermal } \\
\text { Conductivity } \\
(\mathrm{W} / \mathrm{mK})\end{array}$ \\
\hline 20 & 1850 & 750 & 1.60 \\
\hline 80 & 1850 & 27960 & 2.00 \\
\hline 100 & 1750 & 28960 & 2.00 \\
\hline 200 & 1750 & 850 & 1.40 \\
\hline 400 & 1750 & 1050 & 1.40 \\
\hline 600 & 1750 & 1150 & 1.40 \\
\hline 700 & 1750 & 1050 & 1.40 \\
\hline 800 & 1750 & 900 & 1.40 \\
\hline
\end{tabular}

\section{A.4 Silico-calcareous Concrete}

\begin{tabular}{|c|c|c|c|}
\hline \multicolumn{4}{|c|}{ Masonry Block - NA SCCA } \\
\hline $\begin{array}{c}\text { Temperature } \\
\left({ }^{\circ} \mathrm{C}\right)\end{array}$ & $\begin{array}{c}\text { Density } \\
\left(\mathrm{kg} / \mathrm{m}^{3}\right)\end{array}$ & $\begin{array}{c}\text { Specific } \\
\text { Heat }(\mathrm{J} / \mathrm{kgK})\end{array}$ & $\begin{array}{c}\text { Thermal } \\
\text { Conductivity } \\
(\mathrm{W} / \mathrm{mK})\end{array}$ \\
\hline 20 & 2354 & 950 & 1.87 \\
\hline 50 & 2354 & 1020 & 1.85 \\
\hline 100 & 2354 & 1110 & 1.80 \\
\hline 150 & 2354 & 1250 & 1.75 \\
\hline 200 & 2354 & 1290 & 1.68 \\
\hline 250 & 2354 & 1270 & 1.58 \\
\hline 300 & 2354 & 1180 & 1.50 \\
\hline
\end{tabular}




\section{A.5 Industrially-sourced Recycled Concrete}

\begin{tabular}{|c|c|c|c|}
\hline \multicolumn{4}{|c|}{ Masonry Block - IRCA } \\
\hline $\begin{array}{c}\text { Temperature } \\
\left({ }^{\circ} \mathrm{C}\right)\end{array}$ & $\begin{array}{c}\text { Density } \\
\left(\mathrm{kg} / \mathrm{m}^{3}\right)\end{array}$ & $\begin{array}{c}\text { Specific Heat } \\
(\mathrm{J} / \mathrm{kgK})\end{array}$ & $\begin{array}{c}\text { Thermal } \\
\text { Conductivity } \\
(\mathrm{W} / \mathrm{mK})\end{array}$ \\
\hline 20 & 2264 & 700 & 1.57 \\
\hline 50 & 2264 & 720 & 1.55 \\
\hline 100 & 2264 & 750 & 1.50 \\
\hline 150 & 2264 & 780 & 1.47 \\
\hline 200 & 2264 & 850 & 1.39 \\
\hline 250 & 2264 & 900 & 1.30 \\
\hline 300 & 2264 & 980 & 1.23 \\
\hline
\end{tabular}

\section{A.6 Laboratory-sourced Recycled Concrete}

\begin{tabular}{|c|c|c|c|}
\hline \multicolumn{4}{|c|}{ Masonry Block - LRCA } \\
\hline $\begin{array}{c}\text { Temperature } \\
\left({ }^{\circ} \mathrm{C}\right)\end{array}$ & $\begin{array}{c}\text { Density } \\
\left(\mathrm{kg} / \mathrm{m}^{3}\right)\end{array}$ & $\begin{array}{c}\text { Specific Heat } \\
(\mathrm{J} / \mathrm{kgK})\end{array}$ & $\begin{array}{c}\text { Thermal } \\
\text { Conductivity } \\
(\mathrm{W} / \mathrm{mK})\end{array}$ \\
\hline 20 & 2258 & 820 & 1.57 \\
\hline 50 & 2258 & 900 & 1.56 \\
\hline 100 & 2258 & 1010 & 1.52 \\
\hline 150 & 2258 & 1120 & 1.51 \\
\hline 200 & 2258 & 1170 & 1.41 \\
\hline 250 & 2258 & 1190 & 1.38 \\
\hline 300 & 2258 & 1200 & 1.37 \\
\hline
\end{tabular}




\section{A.7 Novel Lightweight Concrete (10\% MK and $45 \%$ G)}

\begin{tabular}{|c|c|c|c|}
\hline \multicolumn{4}{|c|}{ Masonry Block - LWC (10\% MK and 45\% G) } \\
\hline $\begin{array}{c}\text { Temperature } \\
\left({ }^{\circ} \mathrm{C}\right)\end{array}$ & $\begin{array}{c}\text { Density } \\
\left(\mathrm{kg} / \mathrm{m}^{3}\right)\end{array}$ & $\begin{array}{c}\text { Specific Heat } \\
(\mathrm{J} / \mathrm{kgK})\end{array}$ & $\begin{array}{c}\text { Thermal } \\
\text { Conductivity } \\
(\mathrm{W} / \mathrm{mK})\end{array}$ \\
\hline 20 & 1480 & 700 & 0.100 \\
\hline 80 & 1480 & 1100 & 0.160 \\
\hline 100 & 1480 & 1220 & 0.180 \\
\hline 140 & 1470 & 980 & 0.145 \\
\hline 160 & 1470 & 940 & 0.125 \\
\hline 200 & 1460 & 800 & 0.110 \\
\hline 300 & 1440 & 780 & 0.105 \\
\hline 400 & 1420 & 760 & 0.100 \\
\hline 500 & 1360 & 740 & 0.098 \\
\hline 600 & 1340 & 720 & 0.095 \\
\hline 700 & 1270 & 700 & 0.094 \\
\hline 800 & 1240 & 680 & 0.090 \\
\hline
\end{tabular}




\section{A.8 Lightweight Foamed Concrete $\left(650 \mathrm{~kg} / \mathrm{m}^{3}\right)$}

\begin{tabular}{|c|c|c|c|}
\hline \multicolumn{4}{|c|}{ Masonry Block - LFC } \\
\hline $\begin{array}{c}\text { Temperature } \\
\left({ }^{\circ} \mathrm{C}\right)\end{array}$ & $\begin{array}{c}\text { Density } \\
\left(\mathrm{kg} / \mathrm{m}^{3}\right)\end{array}$ & $\begin{array}{c}\text { Specific Heat } \\
(\mathrm{J} / \mathrm{kgK})\end{array}$ & $\begin{array}{c}\text { Thermal } \\
\text { Conductivity } \\
(\mathrm{W} / \mathrm{mK})\end{array}$ \\
\hline 0 & 650 & 1100 & 0.210 \\
\hline 100 & 650 & 1300 & 0.210 \\
\hline 120 & 650 & 2400 & 0.180 \\
\hline 150 & 650 & 1700 & 0.170 \\
\hline 180 & 650 & 1100 & 0.140 \\
\hline 200 & 650 & 1100 & 0.140 \\
\hline 300 & 650 & 1100 & 0.160 \\
\hline 400 & 650 & 1100 & 0.170 \\
\hline 500 & 650 & 1100 & 0.180 \\
\hline 600 & 650 & 1100 & 0.210 \\
\hline 700 & 650 & 1100 & 0.230 \\
\hline 800 & 650 & 1100 & 0.270 \\
\hline 900 & 650 & 1100 & 0.310 \\
\hline 1000 & 650 & 1100 & 0.340 \\
\hline & & & \\
\hline
\end{tabular}




\section{A.9 Lightweight Foamed Concrete $\left(1000 \mathrm{~kg} / \mathrm{m}^{3}\right)$}

\begin{tabular}{|c|c|c|c|}
\hline \multicolumn{4}{|c|}{ Masonry Block - LFC } \\
\hline $\begin{array}{c}\text { Temperature } \\
\left({ }^{\circ} \mathrm{C}\right)\end{array}$ & $\begin{array}{c}\text { Density } \\
\left(\mathrm{kg} / \mathrm{m}^{3}\right)\end{array}$ & $\begin{array}{c}\text { Specific Heat } \\
(\mathrm{J} / \mathrm{kgK})\end{array}$ & $\begin{array}{c}\text { Thermal } \\
\text { Conductivity } \\
(\mathrm{W} / \mathrm{mK})\end{array}$ \\
\hline 0 & 1000 & 1300 & 0.320 \\
\hline 100 & 1000 & 1500 & 0.320 \\
\hline 120 & 1000 & 3800 & 0.280 \\
\hline 150 & 1000 & 2000 & 0.250 \\
\hline 180 & 1000 & 1300 & 0.240 \\
\hline 200 & 1000 & 1300 & 0.240 \\
\hline 300 & 1000 & 1300 & 0.250 \\
\hline 400 & 1000 & 1300 & 0.260 \\
\hline 500 & 1000 & 1300 & 0.270 \\
\hline 600 & 1000 & 1300 & 0.280 \\
\hline 700 & 1000 & 1300 & 0.310 \\
\hline 800 & 1000 & 1300 & 0.320 \\
\hline 900 & 1000 & 1300 & 0.340 \\
\hline 1000 & 1000 & 1300 & 0.360 \\
\hline
\end{tabular}




\section{A.10 Insulating Materials - Inserts}

\begin{tabular}{|c|c|c|c|}
\hline $\begin{array}{c}\text { Mineral } \\
\text { Wool } \\
\text { Products }\end{array}$ & $\begin{array}{c}\text { Density } \\
\left(\mathrm{kg} / \mathrm{m}^{3}\right)\end{array}$ & $\begin{array}{c}\text { Specific Heat } \\
(\mathrm{J} / \mathrm{kgK})\end{array}$ & $\begin{array}{c}\text { Thermal } \\
\text { Conductivity } \\
(\mathrm{W} / \mathrm{mK})\end{array}$ \\
\hline Rock wool & 220 & 840 & 0.045 \\
\hline Slag wool & 250 & 840 & 0.045 \\
\hline Glass wool & 153 & 1000 & 0.065 \\
\hline
\end{tabular}




\section{Appendix B : Heat flux for Model Input}

\section{B.1 DFLUX User Subroutine file}

Subroutine_File_CAN_ULC Fire - Notepad

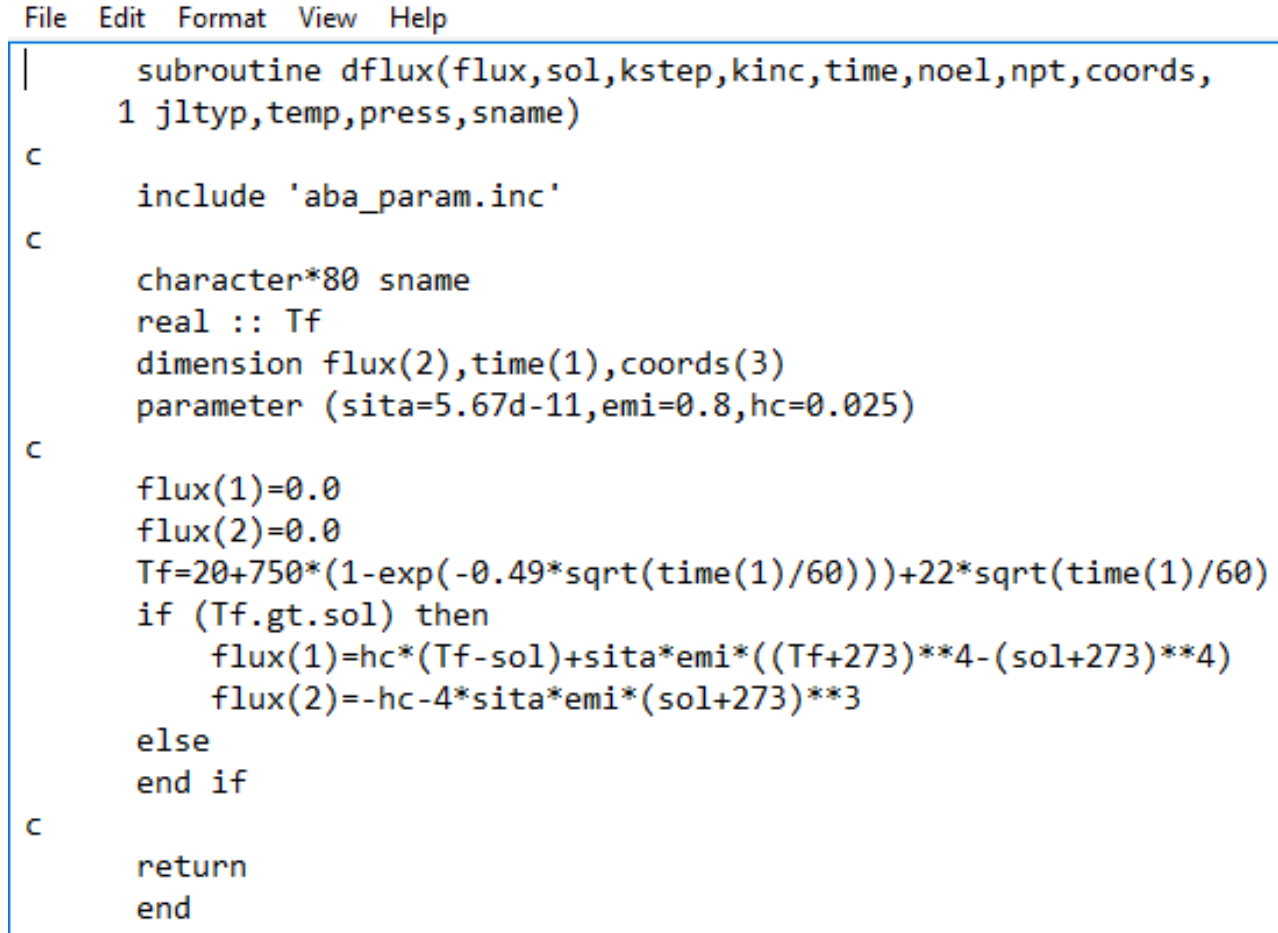




\section{Appendix C : ABAQUS Basics}

\section{C.1 How to Use ABAQUS on the Carleton Cygwin Terminal}

1. Select and install the Cygwin_x64 for Windows 10 and cyqwin7 for Windows 8 and lower

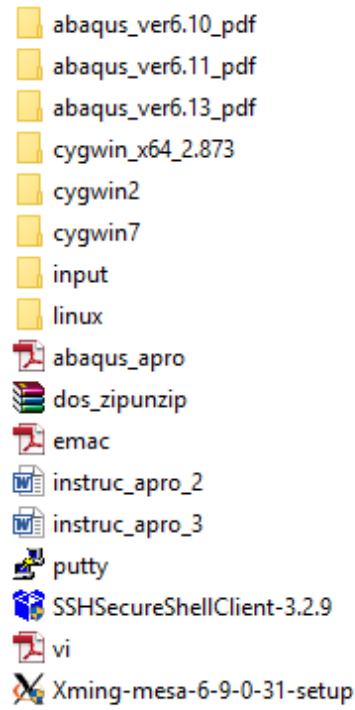

$\begin{array}{lll}2016-04-1011: 01 \ldots & \text { File folder } \\ 2016-04-1011: 03 \ldots & \text { File folder } \\ 2016-04-1011: 04 \ldots & \text { File folder } \\ 2016-04-1011: 04 \ldots & \text { File folder } \\ 2016-04-1011: 07 \ldots & \text { File folder } & \\ 2016-04-1011: 09 \ldots & \text { File folder } & \\ 2016-04-1011: 19 \ldots & \text { File folder } & \\ 2016-04-1011: 19 \ldots & \text { File folder } & \\ 2008-12-171: 08 \text { PM } & \text { Adobe Acrobat D... } & 211 \text { KB } \\ 2006-08-22 \text { 4:22 PM } & \text { WinRAR ZIP archive } & 130 \text { KB } \\ 2004-05-111: 50 \text { PM } & \text { Adobe Acrobat D... } & 628 \text { KB } \\ 2013-11-057: 00 \text { PM } & \text { Microsoft Word 9... } & 26 \text { KB } \\ 2016-03-24 \text { 9:58 AM } & \text { Microsoft Word 9... } & 40 \text { KB } \\ 2004-08-241: 28 \text { PM } & \text { Application } & 348 \text { KB } \\ 2005-10-04 \text { 7:11 PM } & \text { Application } & 5,388 \text { KB } \\ 2004-05-111: 53 \text { PM } & \text { Adobe Acrobat D... } & 447 \text { KB } \\ 2013-03-2011: 49 \ldots & \text { Application } & 2,569 \text { KB }\end{array}$

2. After installation, the icon (left-picture) shows on your desktop. Open this program (right-picture) pops up
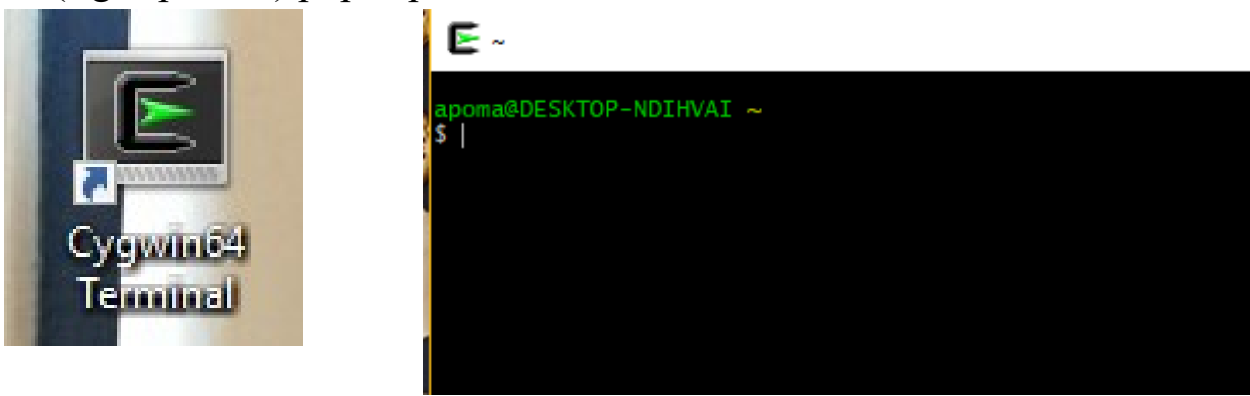

3. Login to server. Type "startx \&" (left-picture). XTerminal (XTerm) program pops up (right-picture)
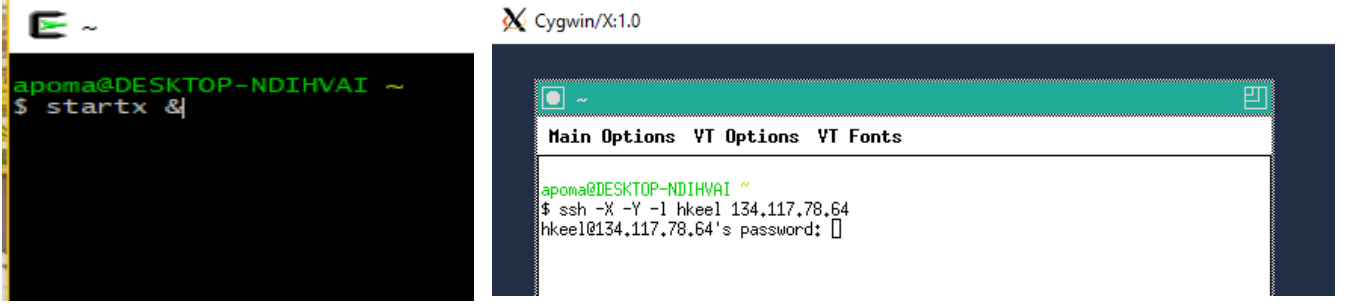

In the XTerm type the following in these steps. 
Type: ssh -X -Y -1 "insert your username" "insert the hostname"

After this line, you will be asked for your password (N.B. the password does not show as you type)

For example, in my case my username is hkeel and the hostname is 134.117 .78 .64 That is what you see typed in the picture above.

N.B. the hostnames change with time so you would have to ask Prof. Heng Khoo if you are experiencing challenges.

\section{Current hostnames:}

4. Once the password is accepted, the program directs you to a command line as seen below.

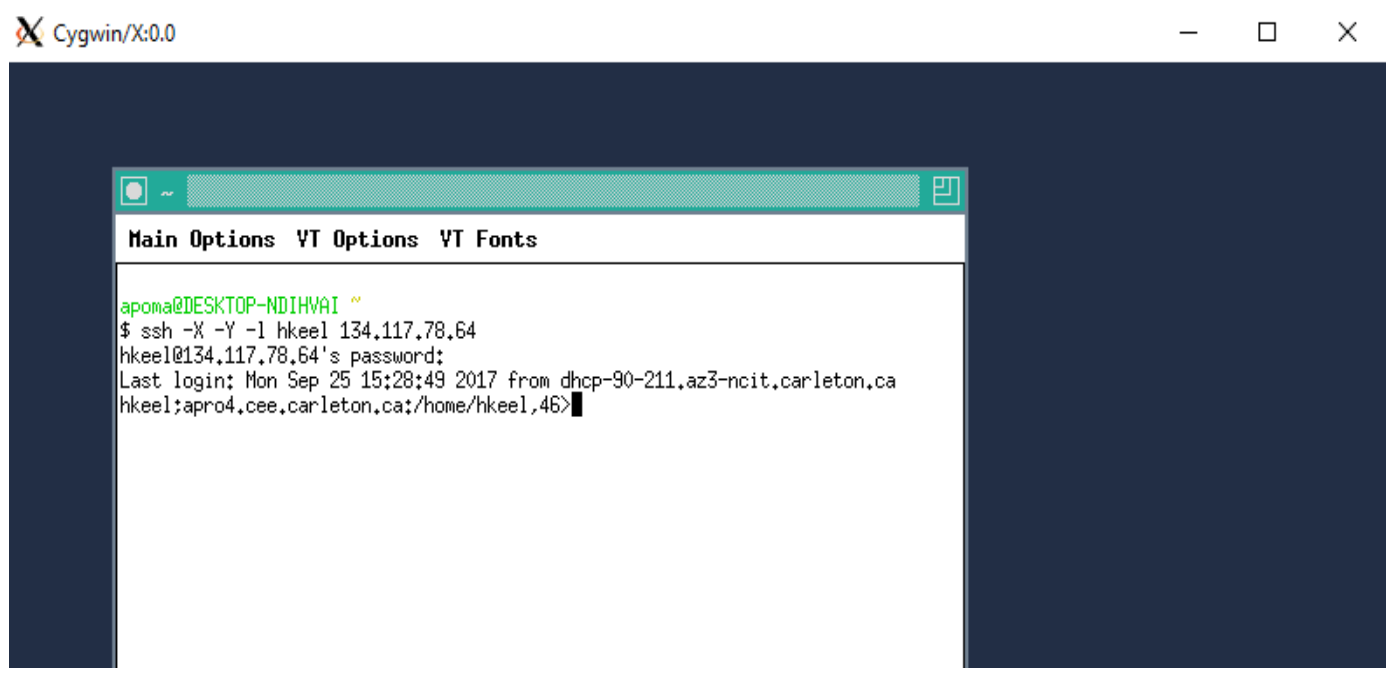

5. Two commands of interest are the "cd.." and "mkdir" Now, "cd.." means change directory while "mkdir" means make directory. The first is used to change directory as the name implies till the user is in the carleton.ca directory (figure below). This is important because the network is a large system and therefore creating your work in Carleton's system aids in easily finding your work. 


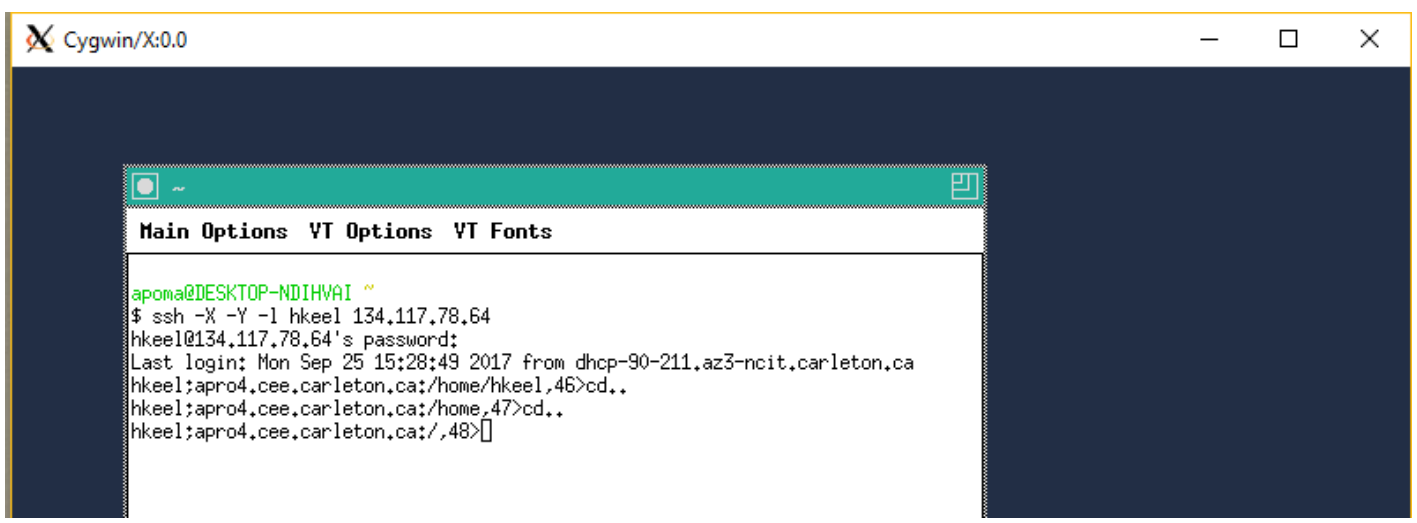

From this step, the user will need to create a directory (first time user) in the school's work directory. To accomplish this, first change directory to the work directory; type "cd work" this takes you to the work directory. Once you do this, type mkdir "insert a name here", so for instance if the user wanted to make a directory called Hannah. The user will type mkdir Hannah (as seen in figure below). (N.B. The directory created is case sensitive and therefore the user will have to bear that in mind)

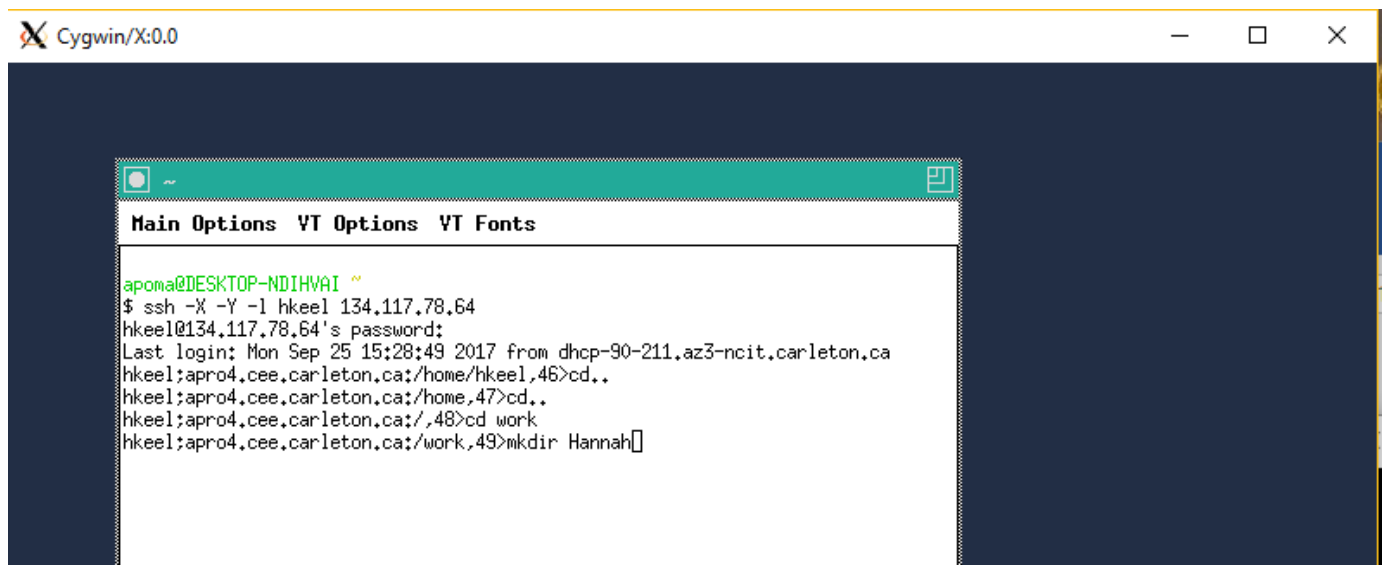

Now in the case where you have already created your personal directory (after your first login). All the user does after type cd work is cd "insert the name you used". In my case my personal work directory is Apomabea and therefore I type cd Apomabea after I have typed cd work. (Picture below) 


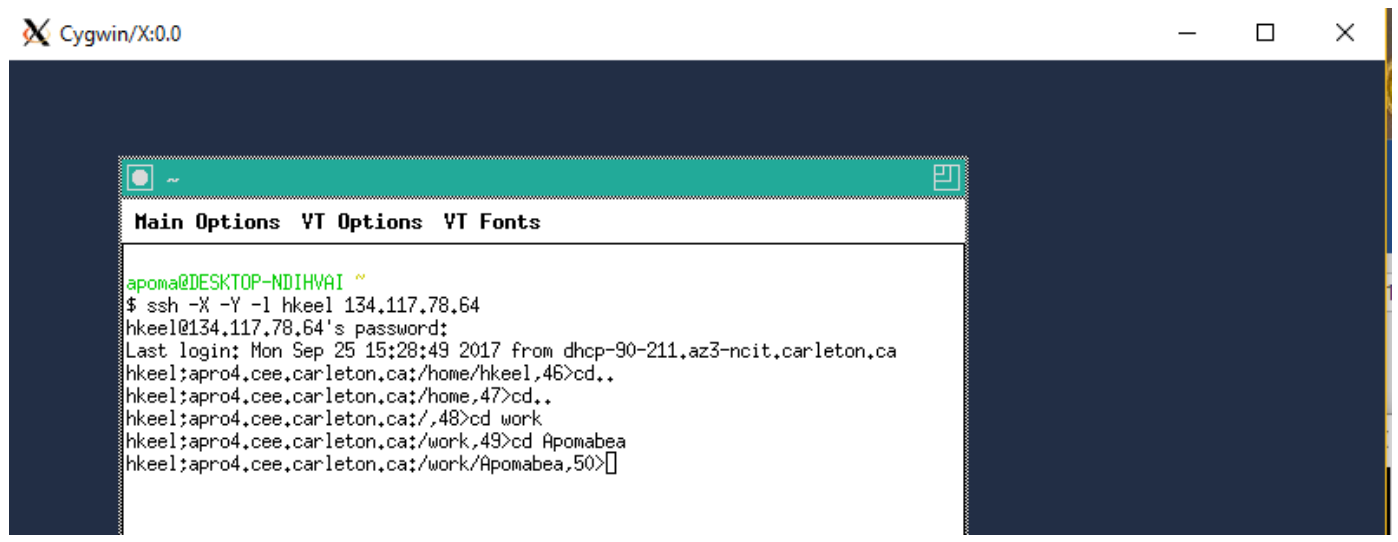

6. Using the ABAQUS Cae on the school's system: The school's system has the ABAQUS versions 11, 13 and 14 and therefore you can use any of them. Type the version you would like to use: "abq6112 cae \&" or "abq6132 cae \&" or "abq6142 cae \&" respectively for these versions. The "\&" sign is just so you still have the command line even after it pops up the ABAQUS Cae program.

\section{C.2 How to Transfer Files from the User's System to the School's System directly}

Now, there is a case where the user already has ABAQUS Cae installed on his/her personal computer and therefore would just transfer files from that personal computer. The user would still need to run all input files (jobs-models) on the school's system since the school's system has enough processors and solvers to run the models at a faster rate. The process of transferring such input files has been discussed below.

1. First Install the program below from the cd drive (SSHSecureShellClient-3.2.9) 


\begin{tabular}{|c|c|c|c|}
\hline Name & Date modified & Type & Size \\
\hline abaqus_ver6.10_pdf & 2016-04-10 11:01 ... & File folder & \\
\hline abaqus_ver6.11_pdf & 2016-04-10 11:03 ... & File folder & \\
\hline abaqus_ver6.13_pdf & 2016-04-10 11:04 ... & File folder & \\
\hline cygwin_x64_2.873 & 2016-04-10 11:04 ... & File folder & \\
\hline$\square$ cygwin2 & 2016-04-10 11:07 ... & File folder & \\
\hline cygwin 7 & 2016-04-10 11:09 ... & File folder & \\
\hline$\square$ input & 2016-04-10 11:19 ... & File folder & \\
\hline$\square$ linux & 2016-04-10 11:19 ... & File folder & \\
\hline 2] abaqus_apro & 2008-12-17 1:08 PM & Adobe Acrobat D... & $211 \mathrm{~KB}$ \\
\hline dos_zipunzip & 2006-08-22 4:22 PM & WinRAR ZIP archive & $130 \mathrm{~KB}$ \\
\hline [1] emac & 2004-05-11 1:50 PM & Adobe Acrobat D... & $628 \mathrm{~KB}$ \\
\hline Wi instruc_apro_2 & 2013-11-05 7:00 PM & Microsoft Word 9... & $26 \mathrm{~KB}$ \\
\hline Wी instruc_apro_3 & 2016-03-24 9:58 AM & Microsoft Word 9... & $40 \mathrm{~KB}$ \\
\hline putty & 2004-08-24 1:28 PM & Application & $348 \mathrm{~KB}$ \\
\hline SSHSecureShellClient-3.2.9 & 2005-10-04 7:11 PM & Application & $5,388 \mathrm{~KB}$ \\
\hline 2] vi & 2004-05-11 1:53 PM & Adobe Acrobat D... & $447 \mathrm{~KB}$ \\
\hline X Xming-mesa-6-9-0-31-setup & 2013-03-20 11:49 ... & Application & $2,569 \mathrm{~KB}$ \\
\hline
\end{tabular}

2. Open the SSH Secure File Transfer Program (Once you install this, both get installed)

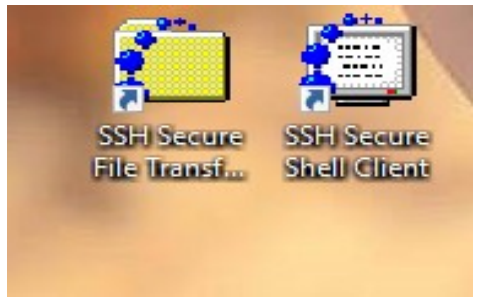

3. Connect to the School's system (highlighted)

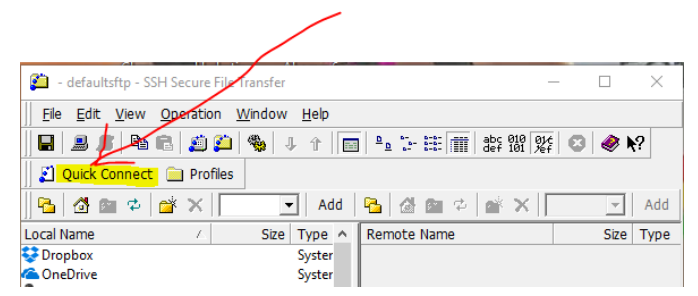

4. Type your username and password (hostname: either the 134.117.78.64 or 134.117.78.64 or whatever is available since it may change)

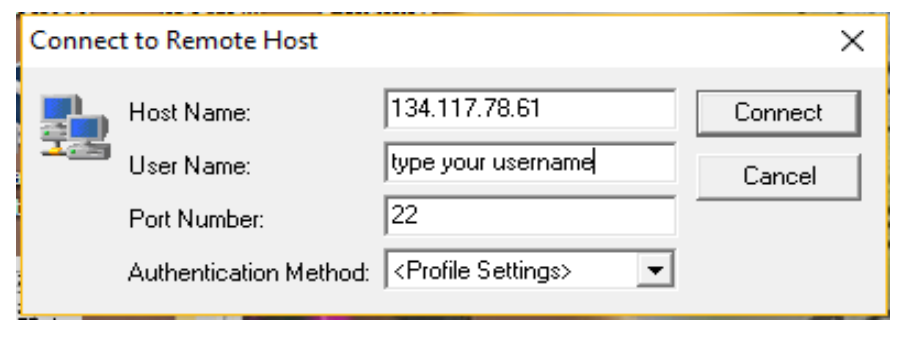




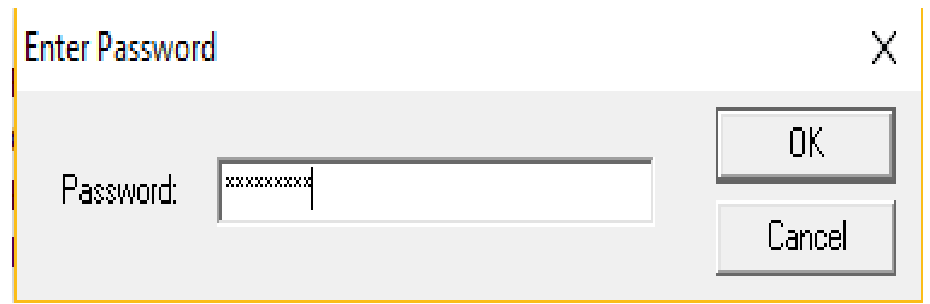

5. Change the directory to /work/"type your work folder here"

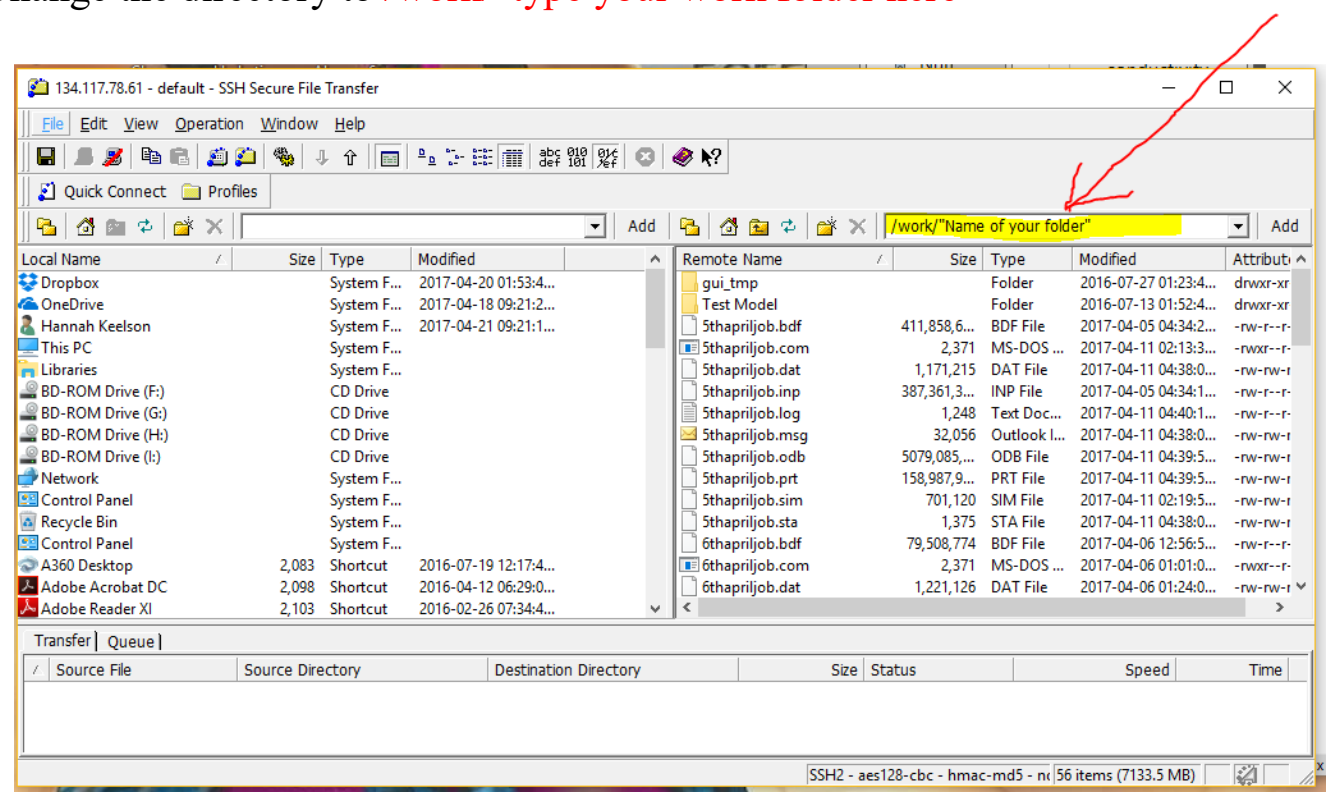

Now, you can transfer files using upload option from your computer to the school's system or download for vice versa. Right click for options (upload, download, etc.)

\section{C.3 How to Run an Input File (Job) on the Cygwin 64 Terminal}

To run a job on the Cygwin Terminal, the user will first need to create an input file from the job (model). This input file can easily be created from the ABAQUS interface job module. The job is first created and from there exported to a Nastran Input file (picture below) 


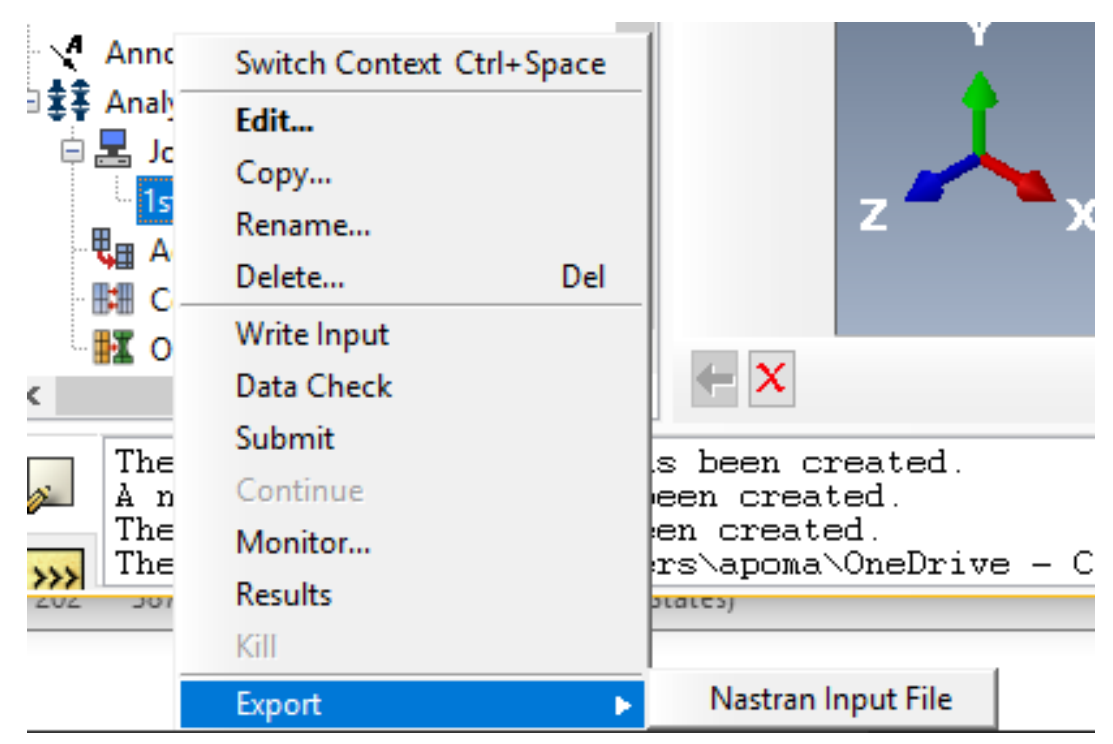

Once the input file is created and uploaded to the User's work folder on the School's system, the run can commence.

The run is initiated by typing the following line: abq6132 job = "input file name" cpus=2 Any available version on the School's system can be used to run the job therefore; abq6112 or abq6132 or abq6142 followed by job. cpus is the number of processors to run the job. Carleton University has 2 processors and this reduces the time by half the original time. In a case where there are Subroutine files to be attached, this is also added to the job command line. Subroutine is a sequence of program instructions that perform a specific task, packaged as a unit. This unit can then be used in programs wherever that particular task should be performed. All subroutine files should be saved in Fortran format (i.e. "name of file".f) In this thesis for instance, a DFLUX Subroutine file (dflux.f) was attached to the load module. The DFLUX incorporated the CAN/ULC S -101 standard fire curve and that served as the heating action on the exposed side of the wall. Therefore, in all the model runs the following command line was used. (N.B. the Subroutine file should also be located in the work directory)

$$
\text { abq6132 job }=\text { "input file name" user }=\text { dflux cpus }=2
$$




\section{C.4 Heat Transfer Problem - Heat flow through a concrete masonry wall}

Problem: Determine the nodal temperatures on the unexposed side of the wall after being subjected to the CAN/ULC S-101 Standard fire.

\section{Step 1: Creation of Parts}

Parts of the wall to be created are the masonry block and the mortar joints.

- Name: The parts created would first need to have a name so the user can easily identify it.

- Modelling space: 3D or 2D planar or Axisymmetric. 3D was used in this analysis since it is a three-dimensional problem. Therefore, it embeds the part in the $\mathrm{X}, \mathrm{Y}$ and $\mathrm{Z}$ coordinate system.

- Type: Deformable was adopted for use. This was chosen because it represents that the part created can deform any load. i.e. mechanical, thermal etc.

- Base Feature: this describes the first feature that is been created before the construction of the remainder of the part by adding more features that either modify or add detail to the base feature. In this analysis, a Solid shape was first chosen and from there the type under this was Extrusion.

- Approximate Size: This is used to describe the size and provide a worksheet for the part to be sketched. Since ABAQUS has no units, the user would need to be consistent in the application of units to ensure uniformity and to obtain accurate results. A pdf document on the consistency of units has been attached to this report.

Once these are done, a worksheet is provided for the base feature to be created, thereafter the Part Module provides other features, which can be used to modify and/or add to the base feature. This would include cut, extrude, fillet, and other features. 


\section{Step 2: Material Properties}

- Name: This is to help easily identify what material the user is working with

- Description: The user can input a description here to allow other users o to understand what type of material is been adopted for use

- Material Behaviours; The material properties have been grouped under General, Mechanical, Thermal, Electrical/Magnetic and Other. Depending on the type of analysis, the choice of properties is very important as the ABAQUS has equations within the program to analyze the problem. For instance, for a typical heat problem, the density, specific heat capacity and the thermal conductivity are paramount in obtaining the heat flow through the medium. As such, it would be necessary to input these properties in the Material Module. Consistency of units should be maintained in this section as well. In addition, the material properties could wither be temperature-dependent or not and as such there is an option to include temperaturedependent properties if need be.

\section{Step 3: Creation of Section}

A section contains information about the properties of a part or a region of a part. Sections are created so they can be assigned to the parts that have been created previously.

- Name: This is to help identify what section the user is working with

- Category: Solid, Shell, Beam and Other are the different options under this section. In this analysis, a solid section was chosen. A solid section defines the section properties of two-dimensional, three-dimensional and axisymmetric solid regions.

- Type: Under the Solid section, there are four types; Homogenous, Generalized plane strain, Eulerian and Composite. Homogenous solid section consists of a 
material name. This is for a section which has one material been assigned to the whole part.

- Material: This is to assign the material type to the section that is been created.

\section{Step 4: Section Assignment}

Once the section(s) has been created, the user must assign these sections to all the parts that were created previously. Without doing so, the part has no material properties assigned to them.

\section{Step 5: Assembly Module}

The Assembly module is used to create and modify the assembly. The model contains only one assembly, which is composed of instances of parts from the model. Parts when created exists in their own coordinate system, which is independent of other parts you have created in the model. In contrast, the Assembly module is used to create instances of your parts and to position these instances relative to each other in a global coordinate system, thereby creating the assembly. This gives a full representation of the physical problem. A model can contain many parts, and a part can be instanced many times in the assembly, however, a model contains only one assembly. An instance is that part created during the assembly formation. An instance maintains its association with the original part. In creating an instance, a part is selected and from that an instance type ic chosen; Dependent (mesh on part) or Independent (mesh on instance). A dependent instance is only a pointer to the part and therefore that instance cannot be meshed. However, meshing can be done on the original part from which the instance was derived, in which case ABAQUS/CAE applies the same mesh to each dependent instance of the part. Independent instance is a copy of the part and therefore can be meshed directly. 
In creating the assembly, the basic options available include features such as the linear pattern, radial pattern, translate instance, rotate instance, merge/cut instance, and translate to.

Linear pattern is used to create several patterns in the preferred linear coordinate system in a faster mode. This same applies to a radial pattern but then its purpose is achieved radially. Rotation of an instance to the global coordinate system is done by the use of the rotate feature. Other detailed options include creating constraints and then applying the feature of interest to the model. For instance, a constraint can be placed on the parallel face of a selected face of the movable part instance to become parallel with a selected face of the fixed part instance.

\section{Step 6: Step Module}

The step module defines the sequence of the analysis the user would run. It provides a convenient way to capture changes in the loading and boundary conditions of the model, other changes include the way parts of the model interact with each other, the removal or addition of parts, and other changes that may occur in the model during the analysis. For instance, in a heat transfer analysis, there is an initial step where the model is subjected to the ambient temperature and from thence a standard fire temperature. If there were any other boundary conditions, this would be included in the heat transfer analysis. It is therefore imperative that a heat transfer step is chosen to incorporate the analysis that would take place once the model is set to run. This is also necessary because in the Interaction Module, the interaction, which involves radiation and convection, occur during the heat transfer analysis. 


\section{Step 7: Interactions}

The interactions module account for the interconnections and modes of heat transfer within the model. The modes of heat transfer include Conduction, Convection and Radiation.

To account for Conduction, the model integrated a surface to surface mode interaction and defined an interaction property "Thermal Conductance" The thermal conductance property defines a conductance between the surfaces in contact. To define these contact interactions, surfaces in contact must be identified. Surfaces in contact are therefore referred to as "contact pairs"; these can be generated automatically or manually. Once the property has been defined and the surfaces in contact have been identified, a master and slave surface were defined for all surfaces in contact. For each contact pair, the thermal conductance property was defined. The meshing techniques are applied in this module to define which surface is master and that of the slave. Master and slave surfaces are roles, which are assigned to surfaces in the contact interaction formulation of a numerical simulation. The contact interaction formulation in ABAQUS requires that the specific slave surfaces are more finely meshed of the surfaces and it should be a softer underlying material surface (if the mesh sizes are similar). In the current developed model, the concrete masonry block was the master surface while that of the slave surface was assigned to the mortar joint. To account for Convection and radiation, this usually occurs during the heat transfer step and therefore the surface radiation and film coefficients are defined under this step. ABAQUS has an option for a form of a radiation known as cavity radiation but this has a limit of 16,000 nodes and has other requisition on closed and open systems. Therefore, surface radiation can easily be used since this is not limited to the total number of nodes and the other complexities that come with using the cavity radiation. With surface radiation, there 
is an option to account for it as a cavity radiation in 3D models and as such easier to use.

\section{Step 8: Mesh Module}

The Mesh module provides the following features:

- Tools for prescribing mesh density at local and global levels.

- Model coloring that indicates the meshing technique assigned to each region in the model.

- A variety of mesh controls, such as: element shape, meshing technique, meshing algorithm, adaptive remeshing rule

The meshing process includes:

1. Assign mesh attributes and set mesh controls: This option focuses on the mesh density, element shape and element type. Mesh density included meshing along global and local seeds. Critical areas were meshed along the edges while other parts were meshed as whole unit. In this thesis, the element shape is Hex and the technique adopted is structured, the element type is DC3D8, which is an 8-node linear heat transfer brick. This element type produces a scalar temperature NT11.

2. Generate mesh: Once the mesh is assigned, it can be generated in different meshing techniques so that the user has different levels of control over the mesh.

3. Refine mesh: Mesh could be refined through seeding, partitioning and/or virtual topology. This thesis adopted the use of seeding meshing to adjust the mesh density in a few selected regions since parts were not complex in nature.

4. Optimize the mesh: Remeshing can be assigned on certain regions within the model. This was done during the mesh sensitivity analysis to calibrate and validate the model. 
5. Verify the mesh: This provided the quality of the elements used in the mesh. If meshes were not accurate, the ABAQUS program would signify a warning before analysis would take place.

\section{Step 9: Load Module}

In the load module, the heat transfer step is used. In this thesis, a DFLUX subroutine file was used to account for the heating action on the exposed side of the wall. Therefore, the exposed side of the wall was selected and the User-defined option was assigned with a magnitude of 0 . This DFLUX subroutine file calculates the heat flux required in a set of iterative procedures while using the CAN/ULC S-101 Standard fire. This was saved in a Fortran format and uploaded in the work directory.

\section{Step 10: Analysis- Cygwin Interface}

Before the analysis can commence, a predefined field temperature is applied on the whole model (initial step) this is the ambient temperature at which the model was exposed to before subjection to elevated temperatures. To run the analysis (See C.3) 